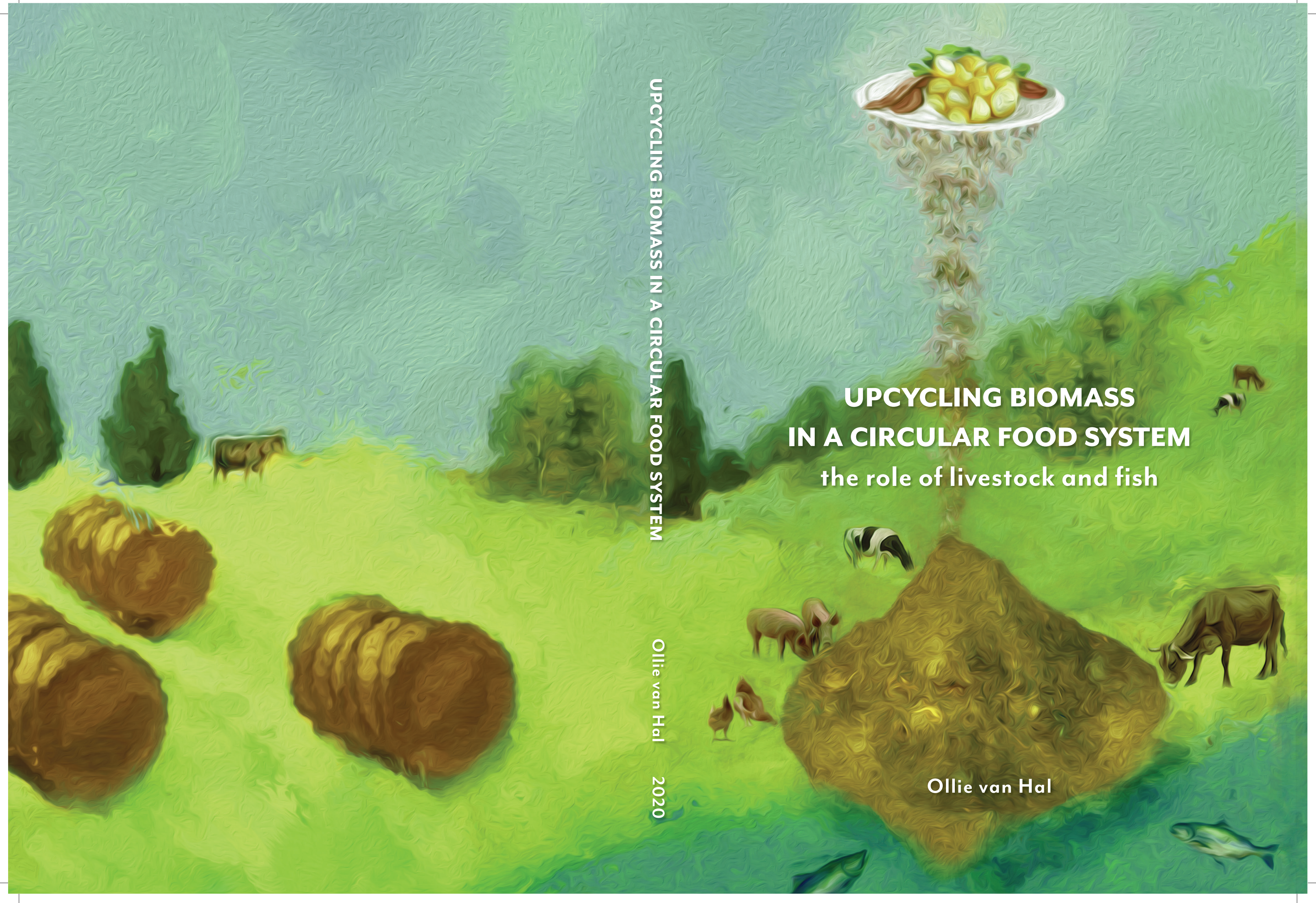




\section{Propositions}

1. Each farm animal has a unique role in a healthy and resource-efficient food system. (this thesis)

2. Metrics used in practice to reduce environmental impacts of animal-source food counteract resource use efficiency of the food system.

(this thesis)

3. Our current economic systems exploit our planet.

4. Solutions proposed by research for development are often ineffective as they are based on limited understanding of those affected.

5. We should not hold on to traditions that harm others.

6. There is no such thing as positive discrimination.

Propositions belonging to the thesis, entitled

'Upcycling biomass in a circular food system - the role of livestock and fish'

Ollie van Hal

Wageningen, 30 October 2020 


\title{
Upcycling biomass in a circular food system \\ - the role of livestock and fish -
}

\author{
Ollie van Hal
}




\section{Thesis committee}

\section{Promotor}

Prof. Dr I.J.M. de Boer

Professor of Animal Production Systems

Wageningen University \& Research

\section{Co-Promotor}

Dr H.H.E. van Zanten

Assistant professor, Animal Production Systems group

Wageningen University \& Research

\section{Other members}

Prof. Dr G.F. Wiegertjes, Wageningen University \& Research

Dr M.H. Kuiper, Wageningen University \& Research

Dr P. Bikker, Wageningen University \& Research

Dr. E. Röös, Swedish University of Agricultural Sciences, Sweden

This research was conducted under the auspices of the Graduate School of Wageningen Institute of Animal Sciences (WIAS) 


\title{
Upcycling biomass in a circular food system - the role of livestock and fish -
}

\author{
Ollie van Hal
}

\section{Thesis}

submitted in fulfilment of the requirements for the degree of doctor at Wageningen University

by the authority of the Rector Magnificus,

Prof. Dr A.J.P. Mol,

in the presence of the

Thesis Committee appointed by the Academic Board

to be defended in public

on Friday 30 October 2020

at 1.30 p.m. in the Aula. 
van Hal, Ollie

Upcycling biomass in a circular food system - the role of livestock and fish, 216 pages.

PhD thesis, Wageningen University, Wageningen, the Netherlands (2020)

With references, with summaries in English and Dutch

DOI: https://doi.org/10.18174/524412

ISBN: 978-94-6395-431-O 


\section{Abstract}

A more circular food system is increasingly proposed to address the challenge of feeding a growing world population while limiting environmental impacts and resource use. A circular food system prioritises resources for direct food supply to avoid feed-food competition. The role of animals is to upcycle resources unsuitable or undesired for human consumption, so called low-opportunity-cost feeds (LCF) into animal-source food. This thesis evaluates the potential of various animals in upcycling LCF in a circular food system by applying an optimisation model that allocates available LCF to that combination of animals that maximise the supply of human digestible protein (HDP) to a EU-28 case study. We first explored the potential of common livestock species in the EU (e.g. pigs, laying hens, broilers, dairy cattle and beef cattle) under various productivity levels. Optimal use of LCF required livestock systems that had a high conversion efficiency (laying hens, dairy cattle), were best able to valorise specific LCF (dairy cattle for grass; pigs for food waste) and could valorise low quality LCF due to their low productivity. When, in addition, considering fish currently the only natural source of the essential eicosapentaenoic (EPA) and docosahexaenoic (DHA) $\omega-3$ fatty acids - while demanding EPA/DHA requirements are met, fish provide nutritious food via both capture fisheries and fish farming. Even if capture fisheries rebuilds stocks and prioritises edible fish for human consumption, it can only fulfil $40 \%$ of EPA/DHA requirements. The farmed fatty fish needed to meet these requirements depend on fisheries by-products to meet their EPA/DHA requirements and livestock slaughter by-products to meet their high fat and protein requirements. A circular food system thus requires a combination of co-dependent animal production systems, tailored to the available LCF and the desired nutrient output. As the availability of food leftovers as LCF is currently restricted by legislation and other barriers, we explored the potential of food leftovers currently not used as LCF. Potential to increase animal protein intake was highest for, currently banned, household waste $(+12 \%)$ and livestock byproducts $(+18 \%)$ that are allowed in fish feed but currently not used and appear essential to meet human requirements of EPA/DHA $\omega-3$ fatty acids in a circular food system. Improved use and legalisation of inevitable food leftovers can improve the resource use efficiency of both current and future circular food systems. When allowing all LCF in a circular food system, livestock and fish provide an HDP intake up to $39 \mathrm{~g}$ per capita per day, less than current animal protein supply but meeting $65 \%$ of total protein requirements. A circular food system, thus, requires a reduction in ASF consumption, and a change in the type of ASF we consume, where fish and milk become more prominent. While the used food systems approach illustrates the potential of animal production in a circular food system, it provides little direction to farmers in achieving sustainability objectives. 
Currently, they base their sustainability strategies on supply chain life cycle assessments (LCA) that does not account for feed-food competition. In a case study of a novel egg production system, such LCA underestimated the environmental benefit of feeding only LCF with $57 \%$ for global warming potential and $96 \%$ for land use. The proposed food-based allocation, better captures the complexity of the food system, a first step towards metrics that stimulate circularity. Besides improved understanding of our food system, such novel metrics and changed consumption patterns, the paradigm shift needed to move towards a circular food system requires that policy makers value social and economic aspects within the ecological boundaries of our planet. This way, farm animals can contribute to the resource use efficiency of the entire food system. 


\section{Contents}

$\begin{array}{llr}\text { Chapter } 1 \quad \text { General introduction } & 1\end{array}$

Chapter 2 Upcycling food leftovers and grass resources through livestock: 13

Impact of livestock system and productivity

Chapter 3 The role of fisheries and fish farming in a circular food system

Chapter 4 Feeding food leftovers to farm animals:

the potential of improved use and legalisation

Chapter 5 Accounting for feed-food competition in environmental impact assessment: towards a resource efficient food system

Chapter 6 General discussion

Appendix A Supplement to Chapter 2

Appendix B Supplement to Chapter 3

Appendix C Supplement to Chapter 4

Appendix D Supplement to Chapter 5

References

Summary 195

Samenvatting 198

Acknowledgements / Dankwoord 202

About the author 204

Publications 205

Education Certificate 207

Colophon 208 



\section{Chapter 1}

General introduction 


\section{Background}

The food system faces the continuous challenge of feeding the ever growing world population that is expected to reach 9.7 billion people in 2050 (United Nations, 2015). Since the industrial revolution, and more so, after the second world war, we addressed this challenge in Europe by intensifying agricultural production, through increased use of farm inputs such as mineral fertilizers, pesticides, imported feed, improved plant and animal genetics, advanced machinery and new technology. (Giampietro, 2019; Warde, 2009). Where pre-industrial agriculture was dictated by nature and characterised by scarcities, intensification helped overcome natures limitations and increased yields exponentially (Crone, 2015; Giampietro, 2019). Grain yields, for example, increased from 1 tonne per hectare in pre-industrial agriculture to 1000 tonne per hectare in industrial agriculture (Giampietro, 2019). Mechanisation and specialisation, furthermore, reduced the labour required to produce these yields. Above described developments also disconnected crop and animal production and thereby, reduced the extent to which resources such as manure are shared (de Boer \& van Ittersum, 2018). Our agricultural system, therefore, currently operates on a linear system.

While these advances enabled Europe, and many other regions, to feed our growing population with more luxurious diets, we are currently faced with the environmental consequences of this system (Jurgilevich et al., 2016). As agriculture currently globally extracts, uses and disposes resources at a high pace, it is no longer aligned with the rate at which nature generates resources and neutralises wastes (Giampietro, 2019; Haberl et al., 2011; Korhonen et al., 2018). After years of picking the fruits of this system, we run into the limits of available resources and the hazards of undesired emissions and accumulated waste (Jurgilevich et al., 2016; O’Neill et al., 2018). Scarcity of agricultural land, for example, drives destruction of our most valuable forests in terms of biodiversity and carbon storage (Foley et al., 2011). Agriculture, furthermore, has depleted phosphate mines to such extent that their continued availability for agriculture is under threat (Cordell \& White, 2015). Imports that feed the European livestock sector, mine soils of nutrients in areas where food security is already threatened (Patnaik, 1996; Smil, 2014). These nutrients accumulate in the European Union (EU) and, combined with mineral fertiliser application, result in eutrophication and acidification of local ecosystems (Oenema et al., 2005; Sims et al., 2005). Finally, our food system contributes $25 \%$ to human induced global warming (Bajželj et al., 2014; Tilman et al., 2011). 
Together these impacts have reduced earths potential to provide life-sustaining functions, such as food, fibre and fuel (Korhonen et al., 2018). This problem will become worse if we maintain current production and consumption standards to feed the growing population, as we will exceed the ecological boundaries of our planet (Haberl et al., 2011; Steffen et al., 2015; Tilman et al., 2011). To preserve life-sustaining functions for future generations we must, therefore, reconsider our food production and consumption practices (Giampietro, 2019; Springmann et al., 2018; Willett et al., 2019). Our food system is, thus, not only faced with the challenge of feeding a growing population, but must simultaneously increase its resource use efficiency and mitigate environmental impacts. In this light, consumption of animal-source food (ASF) is criticised due to its relatively inefficient use of resources and high environmental impact (Aleksandrowicz et al., 2016; Hallström et al., 2015). In the following sections we discuss the controversy regarding the production and consumption of ASF (1.1), and the role of animals in a circular food system (1.2).

\subsection{The animal controversy}

Scientifically, production and consumption of ASF is controversial in many ways, but its high environmental impact is a prominent concern. While studies agree that the high environmental impact of ASF should be addressed, controversy is found in the proposed mitigation strategies. Recent reviews illustrate that these studies can be classified based on the core assumptions that shape the mitigation strategies they propose (Frehner et al., 2020; van Zanten et al., 2018). Three distinct paradigms result from this classification; the production paradigm, the consumption paradigm, and the circularity or consistency paradigm. The circularity paradigm is relatively young, as it was introduced in response to limitations of the production and consumption paradigm which will be described in detail first.

The production and consumption paradigms both rely on data and methods of the life cycle assessment (LCA), a standardised method to evaluate the environmental impact of a product or production system (ISO14044, 2016). The production paradigm assumes that the increasing human demand for ASF must be met and, therefore, aims to reduce the impact per kg ASF through changes in the production system (van Zanten et al., 2018). They typically propose to increase the efficiency with which animals convert their feed into ASF, through breeding, feeding and housing strategies (de Vries \& de Boer, 2010; Herrero et al., 2016). The consumption paradigm, in contrast, assumes consumption of ASF should be reduced to mitigate the environmental impacts of human diets (Frehner et al., 2020). They typically recommend a vegan or vegetarian diet, or a shift from high impact ASF, such as beef, to low impact ASF, such as milk or chicken (Aleksandrowicz et al., 2016; Hallström et al., 2015). These studies often highlight the health benefits of such dietary 
change as high consumption of ASF in high-income countries increases the risk of noncommunicable diseases (Aleksandrowicz et al., 2016; Willett et al., 2019).

While both production and consumption paradigms provide valuable insights, the LCA methodology used undermines the complexity of our food system (Gamboa et al., 2016; van Kernebeek et al., 2016; van Zanten et al., 2018). While considered a holistic method, LCA takes a supply chain approach, including only those processes that contribute directly to the final product, in this case food (de Vries \& de Boer, 2010). LCA, thereby, does not consider that the numerous supply chains that form our food system are interconnected, and that changes in one chain likely triggers changes in others. Due to their supply chain approach, studies under both the production and consumption paradigm, often promote mitigation strategies that counteract the resource use efficiency of the food system as a whole, as will be demonstrated in Section 2.2 (Frehner et al., 2020; van Zanten et al., 2016b). In response, researchers increasingly proposed a shift to the circularity paradigm that uses a food systems approach to account for the consequences of changes in our food system (Garnett, 2011; Schader et al., 2015; van Zanten et al., 2018). Studies under this paradigm indicate that efficient use of resources requires changes in both production and consumption, and highlight that animals have a valuable role in upcycling biomass unsuitable for human consumption into food and other ecosystem services (Frehner et al., 2020; van Zanten et al., 2018). Typically, such studies encourage a more circular food system - as aspired by the EU (EuropeanCommission, 2015) - where the resource use efficiency of the food system as a whole is central (Ghisellini et al., 2016; Jurgilevich et al., 2016).

\subsection{A circular food system}

A circular food system aims to minimise resource use and environmental impacts by closing the loop of materials and substances (Ghisellini et al., 2016; Jurgilevich et al., 2016). To this aim, the use of finite resources (e.g. phosphate rock and land) should be minimised, while use of regenerative resources (e.g. wind and solar energy) is stimulated (de Boer \& van Ittersum, 2018; van Zanten et al., 2019). A system based on renewable resources, however, has to adhere to natures pace and requires moderated consumption (Haberl et al., 2011; O’Neill et al., 2018; Vivien et al., 2019). A circular food system, therefore, requires that we adapt both production and consumption practices (de Boer \& van Ittersum, 2018; van Zanten et al., 2019). It, furthermore, requires that resource losses are reduced, while inevitable losses are reused or recycled in a way that adds the highest value to the food system (Ghisellini et al., 2016; Jurgilevich et al., 2016). To move to a (more) circular food system, we must thus focus on the resource use efficiency of the entire food system, rather than of individual subsystems as currently applied in research that advices policy 
makers (Korhonen et al., 2018). Assuming the food system aims to provide adequate nutrition to all humans, we should value resources based on their potential to provide humans with the nutrients they require. This can be achieved by exploring the opportunity costs of various applications of biomass in the food system, for example as feed or food (Palmer \& Raftery, 1999).

\section{Opportunity costs and feed-food competition}

Opportunity costs refer to the benefits missed out on when choosing one alternative over another (Palmer \& Raftery, 1999). Garnett (2009) illustrated the relevance of opportunity costs in the food system, where they refer to the nutritional costs of choosing to use resources in a specific food production system. She proposed that, given the global constraint on agricultural land, we should consider the opportunity costs of using such land to feed animals rather than produce food for direct consumption. When feeding grains to animals, for example, we lose the nutritional benefits of eating these grains ourselves. This specific application of opportunity cost in the food system, that implies that products consumed by animals may compete for resources with human food supply, is referred to as feed-food competition (van Zanten, 2016). Direct feed-food competition refers to the opportunity costs of feeding animals with products suitable for human consumption. Indirect feed-food competition refers to the opportunity costs of producing feed on arable land suitable for food crop production (van Zanten, 2016).

Feed-food competition counteracts efficient use of resources due to the nutrients lost via emissions and heat when animals convert feed into ASF (Goodland, 1997). Nutrients that do end up in ASF, however, often have a high bioavailability compared to plant based alternatives, such as protein and iron, or are currently only obtained from ASF such as vitamin B12 and EPA/DHA fatty acids (Godfray et al., 2018; Smith et al., 2013; West et al., 2014). Regardless of these nutritional benefits, the environmental and resource costs of the food system are lowest if arable land is used to grow crops for human consumption (Bowles et al., 2019; Foley et al., 2011; Godfray et al., 2010). For land use, this was illustrated with the land use ratio (LUR), which reflects the human digestible protein (HDP) cost of using land to feed animals rather than to produce the most suitable food crop (van Zanten et al., 2016b). Of the livestock systems evaluated by van Zanten et al. (2016b) only dairy cattle grazing on land unsuitable for food crop production provided more HDP than food crops could provide using the same land.

As in high income countries diets contain relatively large amounts of ASF, their environmental impact and resource use is much higher than needed to meet nutrient requirements (Bowles et al., 2019). The opportunity cost of this high ASF consumption even exceeds that of all food waste 
(Shepon et al., 2018). High income countries should, thus, reconsider their excessive consumption of ASF, as this results in feed-food competition and inefficient use of resources (Springmann et al., 2018).

\section{Circularity framework}

To avoid feed-food competition, a circular food system prioritises the use of resources, especially spatial ones like land and waterbodies, for direct food supply (de Boer \& van Ittersum, 2018). This implies arable land should be used for food crop cultivation and waterbodies for sustainable fisheries of which edible fish is used as food (Figure 1). Processing and consumption of this food, however, result in by-products and wastes, unsuitable or undesirable for human consumption. Feeding animals with such food leftovers, and grass resources, especially from land unsuitable for food crop cultivation, has a low opportunity cost as they otherwise find no use in the food system (Bowles et al., 2019; Garnett, 2009). By upcycling these low-opportunity-cost feeds (LCF), animals may contribute to the resource use efficiency of the food system van Zanten et al. (2018). The role of animals in a circular food system is, thus, to upcycle LCF into ASF, to provide protein and other valuable nutrients (van Zanten et al., 2019).

\section{Knowledge gaps}

\subsection{Animals in a circular food system}

A recent review of van Zanten et al. (2018) illustrates that the land use of a diet containing a small amount of ASF, produced by feeding only LCF, is lower than that of a vegan diet. They, thereby, show that animals fed solely on LCF indeed increase the resource use efficiency of the food system. The reviewed studies, furthermore, show that farm animals fed only with LCF can provide 7-30 g HDP per capita per day. Variation between studies was largely due to differences in the assumed availability of LCF, and the animal species assumed to upcycle them. While these initial studies are a valuable prove of concept, their case-study approach provides limited insights in how different animals may contribute to a circular food system. To better understand the role of different animals, we must explore the conditions in which these animals should function. These conditions relate to the properties of the LCF they are expected to upcycle and what nutrients the should provide the human population in doing so. Based on these conditions, we can explore which animals are most suitable to a circular food system. 


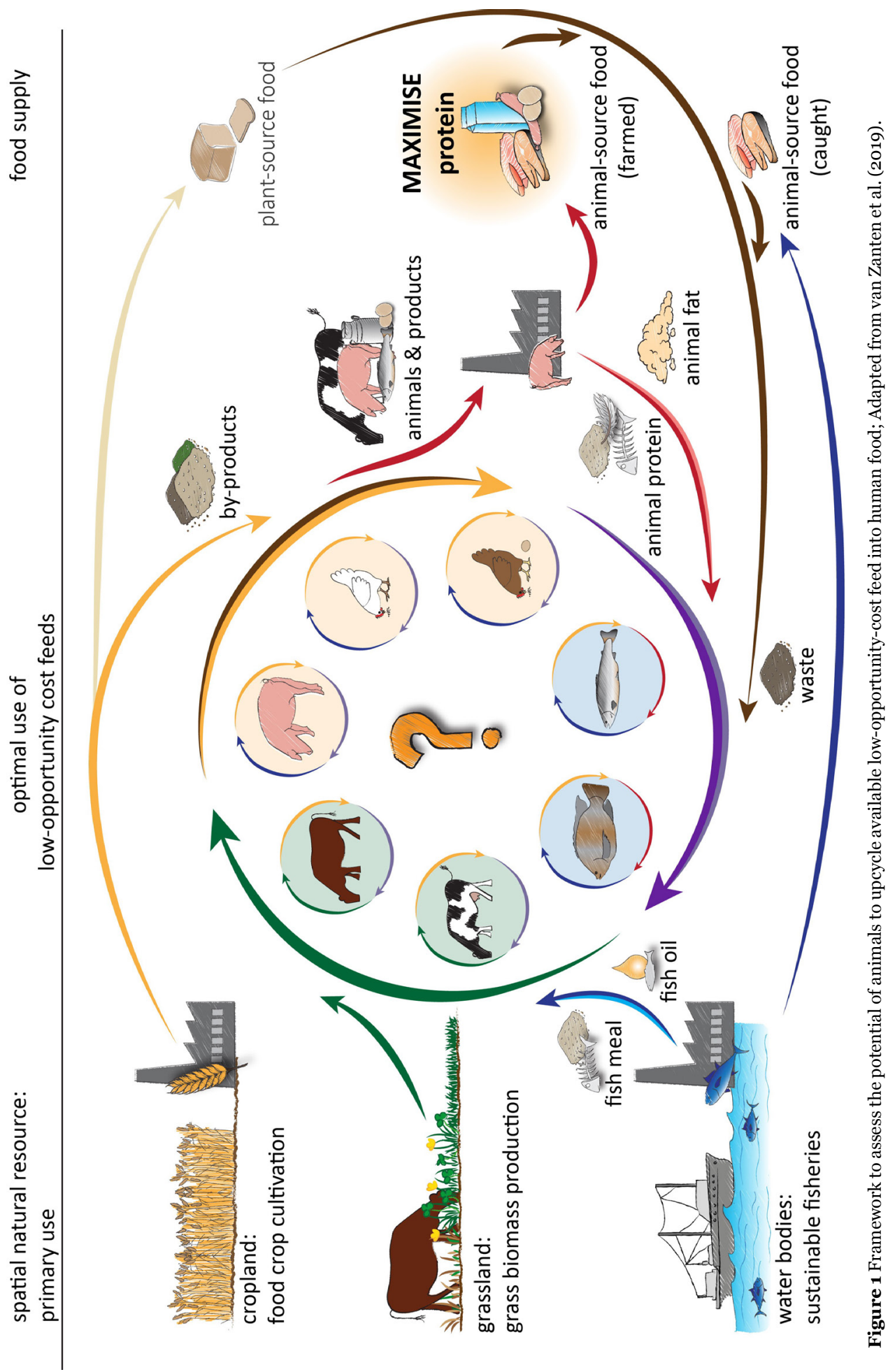


Regarding LCF, it is debated which agricultural products unsuitable or undesirable for human consumption should be used as feed (van Zanten et al., 2018). While most grass resources and food leftovers (losses and wastes from the food system) qualify, it remains uncertain to what extent they should be used. For grass resources there is an ongoing debate about the inclusion of grass produced on land suitable for food crop cultivation, as conversion of such grassland results in release of stored carbon and loss of biodiversity (Foley et al., 2005, 2011; Garnett, 2011; Gerber et al., 2013). Same holds for the inclusion of crop residues, as leaving (some of) these on the field is essential to ensure soil health, the fundament of a circular food system (de Boer \& van Ittersum, 2018). Some other food leftovers (e.g. crop by-products) are already fully used as feed, while the use of others (e.g. animal by-products and food waste) is limited by legislation and other barriers (Vernier et al., 2016). Exploring the potential of currently unused food leftovers can increase the potential of animals in a circular food system and the resource use efficiency in our current food system.

Regarding supply of animal-based nutrients, most studies that assessed the potential of animals fed only with LCF focused on the supply of human-edible protein (HDP). ASFs are, however, also known to contain a range of valuable micronutrients (Mertens et al., 2017), such as iron, zinc, vitamin D and selenium. Like protein - iron, zinc, vitamin D and selenium in ASF have a higher bioavailability than their plant-based equivalents (Smith et al., 2013). Moreover, vitamin B12 and eicosapentaenoic (EPA) and docosahexaenoic (DHA) $\omega-3$ fatty acids are currently only obtained from ASF (de Smet, 2012; Duru, 2019). As these nutrients are currently under consumed by much of the EU population, their supply is the most valuable property of animals, especially as proteins are currently over-consumed (de Smet, 2012; Givens \& Gibbs, 2008; Oh \& Brown, 2003). While vitamin B12 occurs in virtually all ASF, EPA/DHA are mainly found in fatty fish, which are, therefore, essential to derive balanced diets. Due to this variation in nutrient content, a circular food system requires a variation of animal production systems to provide balanced diets.

Regarding animal production systems, previous studies considered only few species, and assumed a high productivity common in industrial agriculture (van Zanten et al., 2018). They, furthermore, manually assigned which animal would value which LCF (van Zanten et al., 2016a). While this served well to prove that animals contribute to a resource efficient food system, to make the most of available LCF their use should be optimised (van Kernebeek et al., 2016). As LCF vary in their nutritional properties, we hypothesise that the optimal use of LCF requires a combination of animal production systems, as animals vary in their ability to value specific LCF. Ruminants, for example, are well adapted to value grass, while the high feed intake capacity of pigs enables them to value 
bulky LCF such as pulp. Optimal use of LCF may, furthermore, require animals with a lower productivity than common in animal farming in developed countries. The lower nutrient requirement related to such reduced productivity is likely easier to achieve within the feed intake capacity with LCF that often have a relatively low nutritional value.

The few regional studies that optimised the use of LCF by animals aimed to illustrate the potential of a resource efficient food system as a whole (Karlsson \& Röös, 2019; van Kernebeek et al., 2016). They, therefore, included only few animal production systems, or provided limited insights into their functioning. To our knowledge, no study has applied such optimisation to explore which animals can value available LCF best. Answering this question requires an optimisation model with a variety of detailed animal production systems (Figure 1) and improved understanding on the availability and nutritional properties of LCF. This model, furthermore, should account for the nutritional value of different types of ASF have for humans.

\subsection{Feed-food competition in supply chain environmental impact assessment}

The above described food systems approach provides valuable insights into the role of different animals in a circular food system, but it provides little direction to farmers in achieving sustainability and circularity objectives. At present governments, farmers, and consumers base their sustainability strategies on farm or product-level LCAs. As explained in Section 1.1, an LCA typically takes a supply chain approach which does not account for interlinkages between the numerous supply chains the food system entails, and thereby overlooks consequences of their applied mitigation strategies on the food system as a whole.

Food system interlinkages relate to processes with multiple outputs for which environmental impacts have to be divided over the resulting products. Producing oil from sunflower seed, for example, also yields meal and hulls. While guidelines propose to consider interlinkages by using labour intensive system expansion methods, LCAs of ASF typically use economic allocation (de Vries et al., 2015; ISO14044, 2016; Zehetmeier et al., 2014). Under economic allocation, the impact of a multifunctional process is allocated to its multiple outputs based on their relative economic value (Guinée, 2002). The economic value of a product, however, does not reflect their (un)suitability for direct human consumption, while feeding humans is the assumed aim of a circular food system (van Zanten et al., 2016b). This results in mitigation strategies that counteract the resource use efficiency of the food system (Frehner et al., 2020; van Zanten et al., 2018; van Zanten et al., 2016b). 
This paradox is well illustrated by the contradiction between the principles of a circular food system and mitigation strategies proposed by studies under the production and consumption paradigm (van Zanten et al., 2018). Increased animal productivity, as proposed by the production paradigm, for example, requires additional high quality feed that is produced on arable land suitable for food crop production. Similarly, a shift from beef to chicken, as proposed by the consumption paradigm, increases the demand for high quality chicken feed, while leaving grassland, unsuitable to produce such feeds, unused. Both of these mitigation strategies thus enhance feed-food competition and reduce the efficiency with which arable land is used, effectively moving us away from a resource efficient food system. The proposed transition towards vegetarianism, furthermore, overlooks that meat associated to egg and diary production no longer finds a use in the food system. Under the consumption paradigm, the environmental impact of vegetarian diet is underestimated as part of the environmental impact of milk and egg production is allocated to the inevitable meat production that no longer finds a use in the food system. With a broad application of a vegan diet, environmental impacts could even increase because LCF no longer find a use in our food system. In the absence of nutrients provided by animals upcycling these LCF, the nutrient demand from food crops increases. To promote environmental mitigation strategies that improve the resource use efficiency of the food system, environmental impact assessment requires novel allocation methods that account for feed-food competition and, thus, suit the circular paradigm.

\section{Aim}

This thesis aims to evaluate the potential of various farmed animals in upcycling LCF in a circular food system, using the EU-28 as a case study, and addresses two main objectives.

The first objective is to explore what combination of animals is needed to optimally use available LCF, considering a variety of production animals and productivity levels. This requires understanding of the conditions under which these animals should function that relate to:

a. the availability and nutritional properties of LCF including food leftovers and grass resources

b. the nutritional purposes ASF should contribute to, and the value of different animals production systems in doing so.

The second objective is to explore how to account for feed-food competition in chain level environmental impact assessment in practice.

Objective one was evaluated for the case study of EU-28, while objective two uses a novel egg production system as a case study. 


\section{Outline of this thesis}

The structure of the research included in this thesis is illustrated in Figure 1. Chapter 2, 3 and 4 each address objective 1, using the optimisation model illustrated in Figure 2 that allocates available LCF to that combination of animals that best fulfils relevant nutritional purposes. The model is extended in each chapter to consider more LCF, animal production systems and nutritional purposes as illustrated in Figure 1. In chapter 5 I develop and implement a novel allocation method to a case study LCA to addresses objective 2.

\begin{tabular}{|c|c|c|c|c|}
\hline Develop model that: & Allocates (LCF) & to a combination of (APS) & with the objective to & \multirow{6}{*}{ 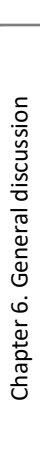 } \\
\hline \multirow[t]{2}{*}{$\begin{array}{l}\text { Chapter } 2 . \\
\text { Role of livestock \& productivity }\end{array}$} & $\begin{array}{l}\text { Grass } \\
\text { Crop by-products } \\
\text { Food waste }\end{array}$ & $\begin{array}{l}\text { Pig } \\
\text { Poultry (egg \& broiler) } \\
\text { Cattle (dairy \& beef) }\end{array}$ & Maximise protein & \\
\hline & + & + & + & \\
\hline $\begin{array}{l}\text { Chapter } 3 . \\
\text { Role of fisheries and farmed fish }\end{array}$ & $\begin{array}{l}\text { Livestock by-products } \\
\text { Fish by-products }\end{array}$ & $\begin{array}{l}\text { High trophic fish (salmon) } \\
\text { Low tropic fish (tilapia) }\end{array}$ & $\begin{array}{l}\text { Meet vitamin B12 } \\
\text { Meet EPA/DHA }\end{array}$ & \\
\hline $\begin{array}{l}\text { Chapter } 4 . \\
\text { Potential of food leftovers }\end{array}$ & $\underset{\text { Food waste }}{+}$ & & & \\
\hline Chapter 5. Accounting for feed-fo & competition in enviro & ental impact assessment & & \\
\hline
\end{tabular}

Figure 2 structure and outline of the chapters in this thesis

Chapter 2 identifies the combination of livestock systems, differing in productivity level that optimally converts the LCF available in the EU into HDP. To this aim, we developed a model that allocates available plant based LCF to that combination of animals that maximises HDP supply.

Chapter 3 explores the contribution of capture fisheries and farmed fish to a circular food system. To assess the contribution of farmed fish we extend the model of Chapter 2 with two fish species. This model was used to allocate available animal and plant based LCF to that combination of animals which maximises HDP supply while meeting population requirements for nutrients currently only obtained from ASF.

Chapter 4 explores the ASF and nutrient supply potential of improved collection and legalisation of food leftovers as LCF. To this aim we extend the model of Chapter 3 to include wastage along the food supply chain. We then apply this model to the currently used LCF, which we compare to scenarios of cumulative inclusion of additional LCF moving along the supply chain.

Chapter 5 evaluates the impact of explicitly accounting for feed-food competition on LCA results. A conventional LCA with economic allocation was compared with an alternative LCA with "food- 
12 | Ch a p ter 1

based" allocation that explicitly accounts for feed-food competition. The limitations of economic allocation, illustrated by the impact of accounting for feed-food competition in LCA, were assessed in a case study of an innovative egg production system that avoids feed-food competition.

Chapter 6 brings the findings of all previous chapters together, places them in a wider perspective and gives a final conclusion. 


\section{Chapter 2}

\section{Upcycling food leftovers and grass resources through livestock: impact of livestock system and productivity}

O. van Hal'1, I.J.M. de Boer ${ }^{1}$, A. Muller ${ }^{2}$, S. de Vries'3, K.-H. Erb' ${ }^{4}$ C. Schader ${ }^{2}$, W.J.J. Gerrits ${ }^{3}$ and H.H.E. van Zanten ${ }^{1}$

${ }^{1}$ Animal Production Systems group, Wageningen University \& Research, PO Box 338, 6700 AH Wageningen, the Netherlands ${ }^{2}$ Research Institute of Organic Agriculture (FiBL), Ackerstrasse 113, 5070 Frick, Switzerland

${ }^{3}$ Animal Nutrition group, Wageningen University \& Research, PO Box 338, 6700 AH Wageningen, the Netherlands

${ }^{4}$ Insitute of Social Ecology, University of Natural Resources and Life Sciences, Schottenfeldgasse 29, 1070 Vienna, Austria 


\begin{abstract}
Consumption of animal-source food is criticised, among other reasons, for its relatively high environmental impact. It is, however, increasingly acknowledged that livestock can contribute to nutrition security if they upcycle low-opportunity-cost feed (LCF) - food waste, food processing by-products and grass resources - into nutritious animal-source food. So far, however, no study explored the allocation question "to which livestock should we feed what LCF to maximise livestock's contribution to human nutrition". Here we optimise the use of the LCF available in the $\mathrm{EU}$, using a model that assigns LCF to those livestock systems that maximise animal protein production. We included the five most common livestock systems in the EU - pigs, laying hens, broilers, dairy cattle and beef cattle - considering their nutrient requirements under three productivity levels (low, mid and high). LCF availability is based on current food supply combined with food wastage and food processing data, and current grassland productivity. Our results showed that optimal conversion of LCF available in the EU, could supply $31 \mathrm{~g}$ animal protein per EU capita per day. We confirmed that this optimal conversion requires a variety of both livestock systems and productivity levels. Dominant livestock systems were those that have a high conversion efficiency (laying hens, dairy cattle), were best able to valorise specific LCF (dairy cattle for grass; pigs for food waste), and could valorise low quality LCF because of their low productivity. Limiting the model to use only conventional, high productive, livestock reduced animal protein supply by

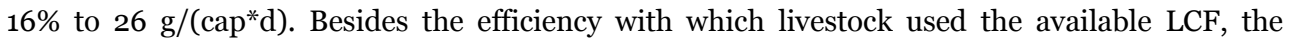
estimated protein supply from livestock fed solely on LCF, was sensitive to assumptions regarding the availability and quality of LCF, especially grass resources. Our model provides valuable insights into how livestock can efficiently use LCF, which is essential for a transition towards a circular food system.
\end{abstract}




\section{Introduction}

The food system faces the challenge of feeding a population growing in size and prosperity, while simultaneously reducing its environmental impact (FAO, 2009; Foley et al., 2011; Tilman et al., 2011). The production of animal-source food (ASF) has a high environmental impact relative to other food items, as much energy and protein is lost when converting plant biomass into ASF. No matter how efficiently e.g. cereals are produced, direct consumption of these cereals by humans is ecologically more efficient than consumption of ASF produced by animals fed with these cereals (Garnett, 2009; Goodland, 1997). Many studies, therefore, conclude that reducing or even avoiding the consumption of ASF reduces the environmental impact of the food system most (Aleksandrowicz et al., 2016; Hallström et al., 2015). Moderating the consumption of ASF is especially relevant in regions with an affluent diet and a high ASF consumption (Fairlie, 2010), such as the European Union (EU), the focus area of the current study.

Completely avoiding consumption of ASF, however, has a major drawback; feed resources unsuitable or undesired for human consumption can no longer be converted by livestock into nutritious food (Garnett, 2011). Such low-opportunity-cost feedstuff (LCF), for example food leftovers (i.e. processing by-products and waste) and grass resources (van Zanten et al., 2018), do typically not compete for land with food production. Consuming a limited amount of ASF, from animals fed solely with LCF, appears most land efficient, as such animals provide nutrient-dense food to humans without requiring additional cropland (van Zanten et al., 2018). With land availability being a major limitation to sustainably feeding the future population (Lambin \& Meyfroidt, 2011), livestock's role in valuing this LCF is of utmost importance.

Previous studies estimate that feeding livestock solely on LCF provides 7 to $30 \mathrm{~g}$ animal protein per capita per day (Appendix A1, Table A1; van Zanten et al. (2018)). The variation between studies in available animal protein per capita per day has two main causes. First, the types of LCF included and their assumed availability as feed differed largely across studies (Table A1). Per capita availability of food leftovers related to current European (Röös et al., 2016, 2017b) or Dutch consumption (Elferink et al., 2008) is, for example, much higher than those related to average global consumption (Schader et al., 2015; Smil, 2014). Inclusion of food waste (Röös et al., 2017a, 2017b; van Zanten et al., 2016a) and assuming soybean oil for all human food oil consumption (Elferink et al., 2008; van Zanten et al., 2016a), furthermore, result in higher animal protein supply estimates. Second, the considered livestock systems and productivity levels differed largely between studies. van Kernebeek et al. (2016), for example, included only high productive pigs and dairy 
cattle, while van Zanten et al. (2016a) considered low productive, tropical dairy cattle, and estimated pig productivity based on the provided diet.

Although the above mentioned studies underpin that livestock can contribute to global food security, no study so far explored the allocation question "to which livestock should we feed what LCF to maximise livestock's contribution to human nutrition". Such optimal use of available LCF may require various livestock systems, as animals differ in their ability to digest available feeds (Preston, 1986). Ruminants, for example, are better adapted to feed on grass. Additionally, optimal use of available LCF may require reduced livestock productivity (i.e. growth or yield/day) compared to conventional farming systems (i.e. common farming practice). While conventional livestock are generally provided a nutrient dense diet to maximise their productivity, LCF often have a low nutrient density. When using only LFC, the lower nutrient requirement related to reduced animal productivity may be easier to satisfy within the feed intake capacity (FIC) (Zijlstra \& Beltranena, 2013). Finally, the contribution of such livestock to food supply was, so far, only measured by their protein provision, undermining their supply of valuable micronutrients valuable such as vitaminD, vitamin B12, calcium, iron, zinc, and selenium (Macdiarmid et al., 2012; Mertens et al., 2017)

We here aim to identify which combination of livestock systems, differing in productivity level, can optimally convert LCF into animal protein, and how much the resulting ASF contributes to the required intake of nutrients for which ASF is specifically valued. Our approach estimates the potential contribution of livestock fed on currently available LCF to food security and, more importantly, provides insight into how animals can efficiently use such LCF. Adapting current practice considering these insights may improve the efficiency of the entire food system. We use the EU-28 food system as a case study; LCF include by-products and waste related to current EU food supply and grass resources from current grassland in the EU.

\section{Methods}

To assess the optimal use of LCF, an optimisation model was developed in General Algebraic Modelling System (GAMS) version 24.2., based on the system illustrated in Figure 1. This model maximises the output of animal protein by converting available LCF in Europe (input to the model) into valuable ASF (output of the model) using (a combination of) livestock systems with different productivity levels. We first describe the general structure of the model and subsequently present the model components displayed in Figure 1 in more detail. This description starts with three types of LCF included (model inputs): food by-products, food waste, and grass resources. Subsequently, we describe the five livestock systems included: pigs, laying hens, broilers, dairy cattle, and beef 
cattle, and their three productivity levels: high, mid, and low. Finally, we describe the computation of the model output, in terms of human digestible animal protein, vitamin D, vitamin B12, calcium, iron, zinc, and selenium.

\subsection{Model structure}

The basic structure of the optimisation model has the standard form of a linear programming model:

$\begin{array}{ll}\text { Maximise } & Z=\boldsymbol{c}^{\prime} \boldsymbol{x} \\ \text { Subject to } & \boldsymbol{A x} \geq \boldsymbol{b} \\ \text { and } & \boldsymbol{x} \geq O\end{array}$

where $\boldsymbol{x}$ is a vector of animal production activities; $\boldsymbol{c}$ is a vector of human-digestible protein produced per unit of activity; $\boldsymbol{A}$ is a matrix of technical coefficients; and $\boldsymbol{b}$ is a vector of quantitative constraints. The objective function of the model is to maximise human-digestible animal protein (HDP) output ( $Z$ ). Animal protein production is restricted by: the amount of each LCF available, the nutritional value of each LCF for each livestock system, and the nutritional requirements and limitations of the animals in each livestock system. Livestock nutritional requirements are met using only LCF, without use of additives such as synthetic amino acids. The nutritional value of each LCF and the nutrient requirements of various animals were based on the nutritional system of the Dutch animal feed board; referred to as the CVB system (CVB, 2012; van Vliet et al., 1994). This nutritional system provides animal specific net nutrient contents for a wide range of feed products $(\mathrm{CVB}, 2016)$ and methods to calculate productivity dependent nutrient requirements for a wide range of livestock systems.

\subsection{Computation of available LCF in Europe}

We included three types of LCF: by-products and food waste related to current plant-source food supply in the EU-28, and currently available grass resources in the EU-28. While food waste and grazing resources were assumed local resources to be consumed in the country of origin, byproducts resulting from food processing (e.g. wheat bran from wheat milling) could be traded between EU countries. Feeding losses (Vermeij, 2017) and grazing losses (van den Pol- van Dasselaar et al., 2002) were assumed unavailable for livestock production. Crop residues, such as straw, were assumed to be left on the field to maintain soil fertility or used for non-feed/food purposes and are thus not considered as an LCF available for livestock production (Reicosky \& Wilts, 2005). Also processing losses and food waste related to the ASF production and consumption proposed by the model were assumed unavailable for livestock production as most of them are considered a food safety hazard (Salemdeeb et al., 2017). 


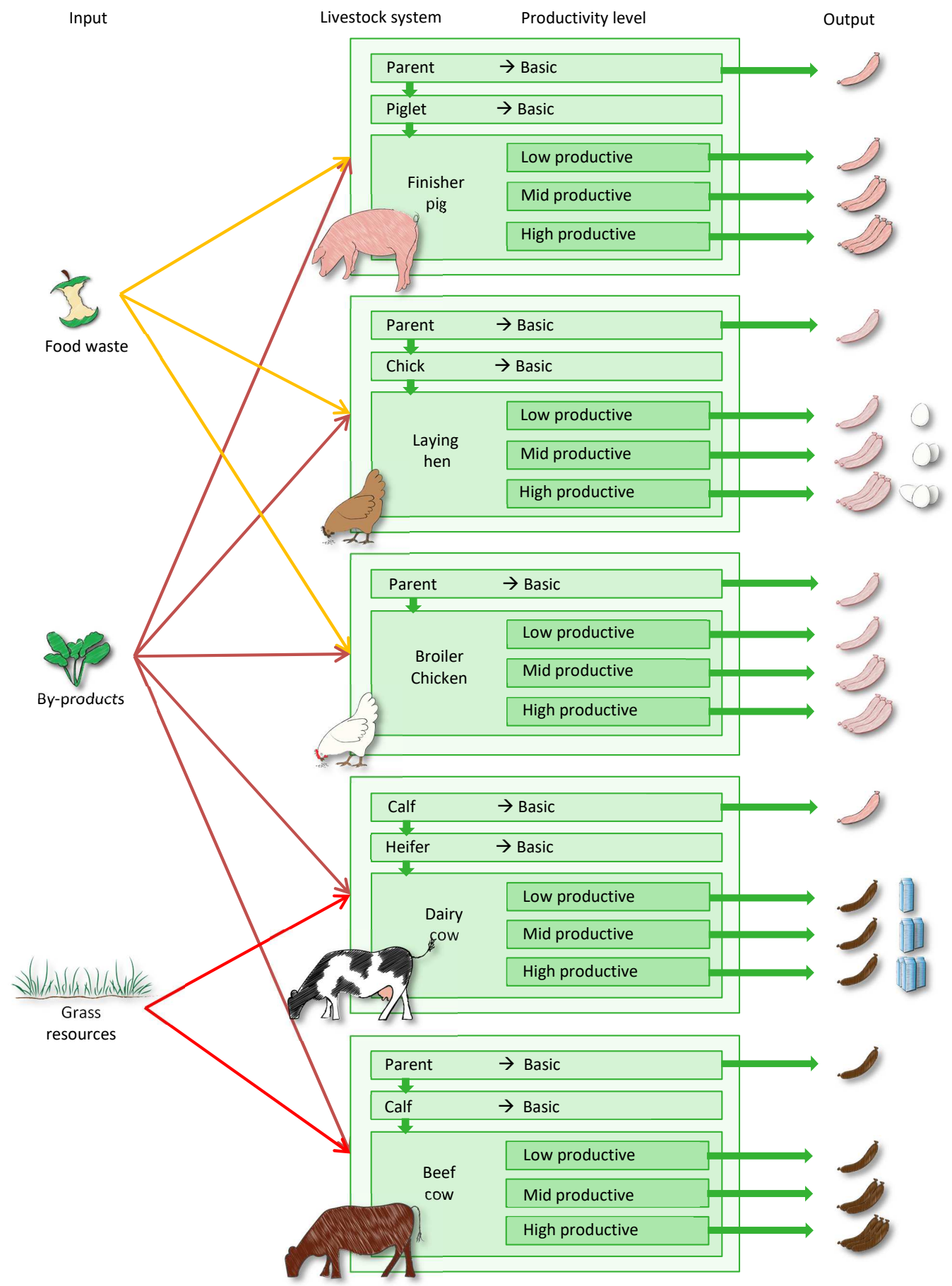

Figure 1. Definition of the livestock systems (pig, laying hen, broiler, dairy cattle \& beef cattle) varying in productivity (low, mid, and high), including their inputs (low-opportunity-cost feeds; food waste, food by-products \& grass resources) and outputs (animal products; milk, meat \& eggs). 
between EU countries. Feeding losses (Vermeij, 2017) and grazing losses (van den Pol- van Dasselaar et al., 2002) were assumed unavailable for livestock production. Crop residues, such as straw, were assumed to be left on the field to maintain soil fertility or used for non-feed/food purposes and are thus not considered as an LCF available for livestock production (Reicosky \& Wilts, 2005). Also processing losses and food waste related to the ASF production and consumption proposed by the model were assumed unavailable for livestock production as most of them are considered a food safety hazard (Salemdeeb et al., 2017).

The amount of food leftovers related to plant-source food consumed in each EU country was calculated using data on the primary products (e.g. wheat grain) annually used as food according to FAO's food balance sheets FAO (2017c) of 2009 to 2013 (Appendix A2). Available by-products were calculated using so-called technical conversion factors (FAO, 1996; Vellinga et al., 2013), which represent the fraction of main product (e.g. wheat flour) and by-product (e.g. wheat bran) resulting from each process (e.g. wheat milling). For presentation purposes the resulting byproducts are classified based on their nutritional properties into cereal by-products, oil seed byproducts, roughage like products (i.e. products with a high fibre content), tuber peels, molasses and pulps (Table A2). Each of the considered by-products can be fed to each of the included livestock systems.

Food waste considers products intended for human consumption, wasted in the retailing or consumption phase. Available food waste was calculated by applying waste fractions of Gustavsson et al. (2011), specific to Europe, to the available main products after processing. All food waste was combined into one waste stream, of which the dry matter and nutrient content equals the weighted average of the included products. Thirty five percent of this produced food waste was assumed available as animal feed (in undried form), which is achievable when legalising and stimulating the use of food waste as animal feed (zu Ermgassen et al., 2016). As legalisation of feeding food waste to ruminants is unlikely due to associated health risks (Salemdeeb et al., 2017), only pigs and poultry were allowed to consume food waste, which was provided in undried form.

The amount of grass resources available in the EU was derived from (Plutzar et al., 2016) and classified into three vegetation types - managed grassland, natural grassland and rangeland based on Haberl et al. (2007) and Plutzar et al. (2016) (Appendix A2). Considering grass from managed grassland as LCF is arguable, as such land could provide food more efficiently under food crop production (Garnett, 2011). We included this grass, however, to avoid negative environmental consequences of converting grassland to cropland, such as the release of soil carbon stocks or the 
loss of biodiversity (Foley et al., 2005; Foley et al., 2011; Gerber et al., 2013). A range of nutritional values for each vegetation type, collected from field study literature, was converted into three grazing quality classes, over which the available biomass of each vegetation type was assumed to be normally distributed (16\% low, 68\% mid \& 16\% high quality; Appendix A2).

\subsection{Description of livestock systems}

We included the five most prevailing livestock systems in Europe: pig, laying hen, broiler, dairy, and beef production (FAO, 2017d), considering the entire life cycle including food-producing animals (e.g. fattening pig) and non-food-producing animals (e.g. sow, gilt, boar and piglet see Figure 1). The number of non-producing animals relative to a producing animal (Appendix A3) was calculated from the European herd composition (FAO, 2016a, 2016c), supplemented with Dutch averages for pig litter size (AgroVision, 2016) and dairy calving interval (CRV, 2017). As feed requirements of livestock systems are largely determined by the requirements of producing animals (Reckmann et al., 2012), productivity and nutrient requirements of non-producing animals (Appendix A4) were fixed and based on Dutch production averages (CVB, 2012). Such Dutch production averages served as a proxy for conventional livestock production in the EU throughout this study as this sector is highly industrialised and focussed on production efficiency resulting in little variation between countries (Bos et al., 2013).

Regarding the productivity of producing animals, we distinguished three productivity levels: low, mid, and high (Figure 1). For each productivity level, we computed specific nutrient requirements using the CVB system (CVB, 2012; van Vliet et al., 1994). Productivity was expressed in annual-fatand-protein corrected milk (FPCM) production for dairy cattle, annual egg production for laying hens and average daily gain (ADG) - determining the growing period required to achieve a target slaughter weight - for pigs, broilers, and beef cattle. For each livestock system, performance of the Dutch livestock sector served as a proxy for high-productive animals (Bos et al., 2013). Low productivity of dairy cattle was approximated by the performance of Irish extensive dairy farming (Läpple et al., 2012), while mid productivity was the average of high and low. The same method was used for broilers and beef, for which low productivity was based on Dutch slow growing broilers (Vermeij, 2017), and extensive beef farming in the French Charolaise region (IDELE, 2014). Pig performance under reduced feed quality was simulated using the growth model underlying the CVB system (CVB, 2012), for both low and mid productivity. For laying hens, the CVB system provided nutrient requirements for the average Dutch laying percentage ( $85 \%$ of days an egg is laid), assumed for high productivity, as well as for the lower laying percentages, assumed for mid (75\%) and low (65\%) productivity. Protein requirements for the considered monogastrics (i.e. pigs and 
poultry) considered the most limiting essential amino acids lysine and methionine, assuming these requirements will also ensure sufficient intake of other amino acids if the diet contains a variety of products. While maximum feed intake capacity (FIC) of pigs and poultry is expressed in kg fresh matter, for cattle the satiety effect of different feed components was considered in saturation units (SU) (CVB, 2012). The assumed performance and related nutrient requirements for each livestock system under each productivity level are displayed in Table 1; underlying data and calculations are provided in Appendix A4.

\subsection{Computation of nutrient output of livestock systems}

As the produced ASF is assumed tradable between countries, the output of human digestible nutrients is expressed as an average per EU capita. To compute this output of human digestible nutrients, we converted the ASF output (kg product) of each livestock system and productivity level into nutrient output (Appendix A5), using product-specific human digestible nutrient content data of USDA (2018a). For milk and eggs these nutrient contents were directly available, whereas for meat products, average nutrient contents per kg carcass weight (Figure A7) were calculated, based on relative cut weights and cut specific human digestible nutrient contents including cutting (CBB \& NCBA, 2014) and cooking losses (USDA, 2012). The growth development (high versus low productivity) could however effect the nutrient content of each cut. The growth models for pig (van Milgen et al., 2008) and beef (van Vliet et al., 1994) and, for example, predicted an increase in meat protein content under reduced growth. We, therefore, adjusted the weighted HDP content per $\mathrm{kg}$ meat accordingly. Due to a lack of data, other nutrients could not be corrected.

\subsection{Sensitivity analysis}

A sensitivity analysis was conducted to evaluate model responses to changes in key model parameters. We compared results of our baseline optimisation with alternative optimisations, including additional restrictions or alternative data for those parameters we expect most influential and/or uncertain, namely: animal productivity, the inclusion of food waste used as animal feed, the quantity and quality of grazing resources available, and the diversity of produced ASF.

\section{Animal productivity}

Besides assessing whether low-productive animals are needed to optimally convert LCF into animal protein, we wanted to quantify the impact of allowing for such reduced productivity on protein supply. This impact was calculated as the difference in animal protein supply from livestock optimally using LCF when allowing for a range of productivity levels, and when only using highproductive animals. 
Table 1. Performance and related nutrient requirements (CVB, 2012) for each livestock system (pig, laying hen, broiler, dairy cattle, and beef cattle) under different productivity levels (low, mid, and high) ${ }^{1}$

\begin{tabular}{|c|c|c|c|c|c|c|}
\hline \multirow{2}{*}{$\begin{array}{l}\text { Livestock } \\
\text { system }\end{array}$} & & & \multirow[b]{2}{*}{ Units } & \multicolumn{3}{|c|}{ Productivity level } \\
\hline & & & & High & Mid & Low \\
\hline \multirow[t]{6}{*}{ Pig } & Performance & Growth & $\mathrm{ADG}^{2}(\mathrm{~kg} / \mathrm{d})$ & 0.80 & 0.76 & 0.71 \\
\hline & & & Period $^{3 a}(d)$ & 112 & 119 & 128 \\
\hline & Daily nutrient requirements & Energy $^{4}$ & NE (MJ) & 20 & 18 & 17 \\
\hline & & Protein 5 & Dlys (g) & 15 & 14 & 13 \\
\hline & & & Dmeth (g) & 9 & 9 & 8 \\
\hline & & $\mathrm{FIC}^{6}$ & $\mathrm{DM}(\mathrm{kg})$ & 3 & 3 & 3 \\
\hline \multirow[t]{6}{*}{ Laying hen } & Performance & Yield & Laying $\%^{7}$ & 85 & 75 & 60 \\
\hline & & & Period (d) & 392 & 392 & 392 \\
\hline & Daily nutrient requirements & Energy $^{3}$ & ME (MJ) & 1.36 & 1.29 & 1.19 \\
\hline & & Protein $^{5}$ & Dlys (g) & 0.74 & 0.70 & 0.65 \\
\hline & & & Dmeth (g) & 0.36 & 0.34 & 0.32 \\
\hline & & $\mathrm{FIC}^{6}$ & $\mathrm{DM}(\mathrm{g})$ & 151 & 151 & 151 \\
\hline \multirow[t]{6}{*}{ Broiler } & Performance & Growth & $\mathrm{ADG}^{2}(\mathrm{~g} / \mathrm{d})$ & 56 & 49 & 42 \\
\hline & & & Period $^{3 b}(d)$ & 40 & 48 & 56 \\
\hline & Daily nutrient requirements & Energy ${ }^{4}$ & $\mathrm{ME}(\mathrm{MJ})$ & 1.18 & 1.15 & 1.12 \\
\hline & & Protein $^{5}$ & Dlys (g) & 0.92 & 0.89 & 0.87 \\
\hline & & & Dmeth (g) & 0.36 & 0.35 & 0.34 \\
\hline & & $\mathrm{FIC}^{6}$ & $\mathrm{DM}(\mathrm{g})$ & 111 & 133 & 148 \\
\hline \multirow[t]{6}{*}{ Dairy cattle } & Performance & Milk & $\mathrm{FPCM}(\mathrm{kg} / \mathrm{y})$ & 8862 & 6807 & 4751 \\
\hline & Daily nutrient requirements & Energy $^{4}$ & FUM & 17617 & 14963 & 12355 \\
\hline & & Protein $^{5}$ & $\operatorname{IDP}(\mathrm{g})$ & 1536 & 1198 & 876 \\
\hline & & & RDPB (g) & $>0$ & $>0$ & $>0$ \\
\hline & & Structure $^{8}$ & SV & 0.99 & 0.95 & 0.90 \\
\hline & & $\mathrm{FIC}^{6}$ & SU & 14.5 & 14.5 & 14.5 \\
\hline \multirow[t]{7}{*}{ Beef } & Performance & Growth & $\mathrm{ADG}^{2}(\mathrm{~kg} / \mathrm{d})$ & 1.22 & 1.07 & 0.93 \\
\hline & & & Period $^{3 c}$ (d) & 329 & 374 & 432 \\
\hline & Daily nutrient requirements & Energy ${ }^{4}$ & FUB & 7143 & 6848 & 6496 \\
\hline & & Protein $^{5}$ & $\operatorname{IDP}(\mathrm{g})$ & 484 & 450 & 400 \\
\hline & & & $\operatorname{RDPB}(\mathrm{g})$ & $>0$ & $>0$ & $>0$ \\
\hline & & Structure $^{8}$ & SV & 0.75 & 0.75 & 0.75 \\
\hline & & $\mathrm{FIC}^{6}$ & SU & 9.6 & 9.6 & 9.6 \\
\hline
\end{tabular}

${ }^{1}$ Underlying data and calculations are presented in Appendix A4

${ }^{2} \mathrm{ADG}=$ average daily gain, growth per day averaged over the growth period

${ }^{3}$ Period required to grow from:

${ }^{a}$ weaning $(25 \mathrm{~kg})$ to slaughter (115 kg live weight)

${ }^{b}$ hatch to slaughter (+/-2.3 kg live weight)

${ }^{c}$ weaning (350 kg) to slaughter (650 kg live weight)

${ }^{4}$ Daily energy requirements expressed in:

$\mathrm{NE}=$ net energy (pigs)

$\mathrm{ME}=$ apparent metabolisable energy (poultry)

FUM = feed units milk (dairy cattle)

FUB $=$ feed units beef (beef cattle)

${ }^{4}$ Daily protein requirements expressed in:

Dlys \& Dmeth = intestinal/faecal (pig/poultry) digestible lysine \& methionine

IDB = intestinal digestible protein \& RDPB = rumen degraded protein balance (ruminants)

${ }^{5}$ Maximum daily FIC = feed intake capacity averaged over days of production period in:

DM (monogastrics); due to maturation near slaughter age, broiler FIC varied between productivity levels.

$\mathrm{SU}=$ satiety units (ruminants)

${ }^{6}$ Laying \%: number of days in laying period on which an egg is laid

${ }^{7}$ Structure requirement of ruminants expressed in the average SV = structure value of the feed 
Inclusion of food waste used as animal feed

The amount of protein that can be produced from LCF is highly dependent on the quantity of LCF available. Regarding the inclusion of food waste, we assumed $35 \%$ of the food wasted after the processing stage can be used as feed. In the EU, however, the use of such consumer, catering, and retailing food waste as animal feed is not allowed due to presumed food safety hazards. While our assumption suits the hypothetical future food system, the future availability of food waste as livestock feed remains uncertain as it requires legislative changes (Salemdeeb et al., 2017). Running the model while excluding all food waste does not only indicate the sensitivity of the model to this assumption, but also quantifies the benefits of allowing the use food waste (partly, i.e. 35\%) as animal feed.

\section{Quantity and quality of grazing resources}

Inclusion of grass biomass from managed grassland as an LCF is debatable as this arable land can be used more efficiently, in terms of food production, under food crop production. We, therefore, explored the consequences of excluding grass resources from managed grassland on our results. While uncertainty regarding the quantity of grazing resources available in Europe is already considerable (Fetzel et al., 2017), uncertainty regarding their nutrient contents is even higher. We addressed this uncertainty in the baseline model by converting the whole range of vegetation specific nutritional values obtained from field study literature into three grass quality classes, over which the available biomass of the corresponding vegetation type was assumed normally distributed (16\% low, 68\% mid, and 16\% high quality). To explore the sensitivity to this assumption, we also tested a uniform distribution of biomass over each quality class (33\% for each low, mid, and high quality) (Appendix A2; Figure A5).

\section{Diversity in animal-source foods}

Optimal conversion of LCF into ASF, likely favours certain production systems that are most efficient in protein production. Such optimal conversion, then requires an extreme change in the types and amounts of ASF consumed, which is likely difficult to achieve (de Bakker \& Dagevos, 2012). To assess sensitivity regarding the assumption that conversion efficiency should drive the selection of ASF in the human diet, we ran the model while requiring that the animal protein in the human originates from a diversity of ASF. To reflect consumer preference, this required ASF diversity reflected the origin (milk, meat, and eggs) of HDP the average European diet; a milk:meat:egg (M:M:E) ratio of 28:65:7 (FAO, 2017a). 


\section{Results}

The proposed optimal conversion of available LCF in the EU requires 56 million low-productive pigs, 9.5 million high-productive laying hens, and 30 million low-productive dairy cows, across all EU countries (Appendix A6; Figure A8). Compared to current EU livestock numbers, an optimal LCF conversion would, therefore, require $78 \%$ less pigs and $98 \%$ less laying hens, but $9 \%$ more dairy cattle besides a complete abolishment of beef cattle and broilers. Almost all food waste was fed to pigs as well as the majority of oil-seed by-products (Figure 2). Laying hen diets also consisted mainly of these products (Figure $3 \mathrm{~b}$ ) - but were produced only in countries where food waste quality was highest (Bulgaria and Czech Republic, Appendix A2; Table A3). Although the majority of by-products was fed to dairy cows (Figure 2), their diet mainly consisted of grass resources (Figure 3c). Grazing resources of the highest quality were fed to dairy cows, while lower quality grass resources were fed to the associated non-producing animals, such as heifers, with lower nutritional requirements (results not shown). Although diet composition varied somewhat between countries (Appendix A6; Figures A9 \& A10), especially for dairy, only the EU average feed composition used per producing animal is discussed and displayed in Figure 3.

This optimal use of LCF resulted in an ASF supply of $27 \mathrm{~g}$ pork, $610 \mathrm{~g}$ dairy (fresh milk equivalents), $33 \mathrm{~g}$ beef related to dairy production and one $\mathrm{g} \mathrm{egg} /\left(\mathrm{cap}^{*} \mathrm{~d}\right)$. Relative to current ASF supply in the $\mathrm{EU}$ (FAO, 2017a) this is a reduction of $40 \mathrm{~g}$ dairy, $160 \mathrm{~g}$ meat and $31 \mathrm{~g}$ eggs. Collectively this ASF provides $31 \mathrm{~g}$ animal HDP/(cap*d), (5 g from pork, $20 \mathrm{~g}$ from dairy, $6 \mathrm{~g}$ from dairy cattle meat), 19 $\mathrm{g}$ less than current average protein consumption in the EU (Figure 4). Besides protein, this ASF also provides a range of valuable micro-nutrients (Figure 5). This ASF consumption also provides $93 \%$ of our daily calcium requirements, because of the large role of dairy, and $80 \%$ of our vitamin B12 requirements, which we currently mainly obtain via animal-source food. Compared with the current ASF consumption, however, the intake of all nutrients is reduced.

\subsection{Animal productivity}

When considering only high-productive animals, pigs could no longer use food waste to meet their (high) nutrient requirements within their feed intake capacity, mainly due to the low dry matter content of food waste (Appendix A2; Table A3). The majority of available food waste, therefore, remained unused (Figure 2) and pig numbers reduced with $98 \%$ compared to the baseline optimisation to 0.9 million. To achieve their higher nutrient requirements the few remaining pigs were fed only high quality food waste and an increased share of cereal by-products (Figure 3a). The oil seed by-products no longer used by pigs, became available for dairy production (Figure 2). Dairy 
cattle were fed these oil seed co-products to meet increased nutrient requirements, which also required an increase in grass resource quality and feed intake (Figure $3 c$ ). As availability of high quality resources is limited, dairy cattle numbers - the main protein providers in the baseline optimisation - reduced with $49 \%$ to 15 million. Additionally, 6.3 million beef cattle were kept, who valued the lower quality grass resources unsuitable for high-productive dairy cattle (Figure $3 \mathrm{~d}$ ). Despite the large reduction in animal numbers, animal protein supply reduced only by $16 \%$ to 26 $\mathrm{g} /\left(\right.$ cap* $^{*}$ ) (Figure 4) due to the higher animal protein output per animal.

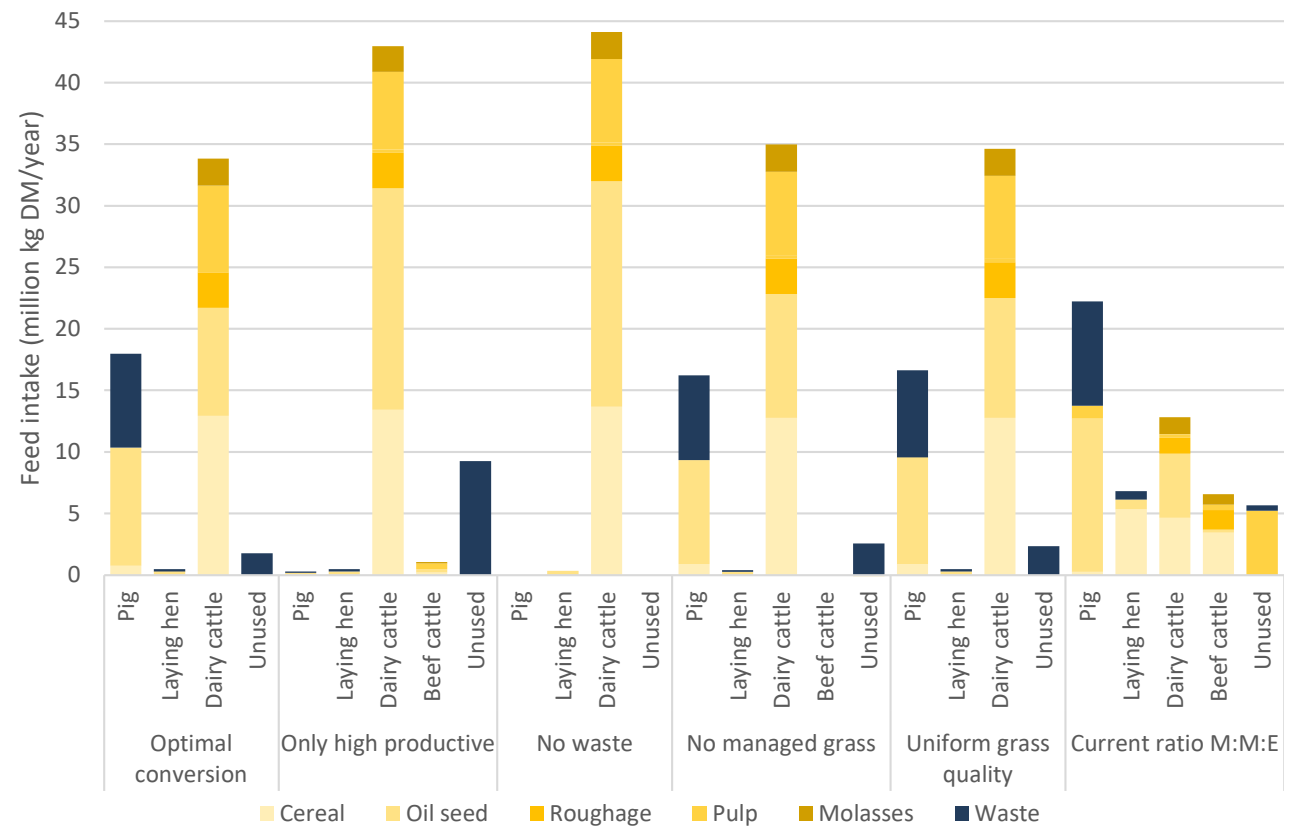

Figure 2 Proposed allocation of available food leftovers (by-products and waste; classification Appendix A2; Table A3) in the EU over the selected livestock systems (pig, laying hen, broiler, dairy, beef) under optimal use of available non-food-competing feed (LCF) and alternative optimisations of the sensitivity analysis (M:M:E is Milk:Meat:Eggs)

\subsection{Quantity of food waste used as feed}

When excluding all food waste, optimal conversion of LCF no longer requires pigs, which were the main consumers of food waste in the baseline optimisation, whereas the number of laying hens decreased with $55 \%$ to 5.3 million. Waste in the laying hen diet was replaced by both cereal and oilseed by-products (Figure 3a). By-products that in the baseline optimisation were fed to pigs (mainly oil-seed), were now allocated to dairy cattle (Figure 2), sustaining the larger cattle population $(+13 \%$ to 34 million). With the inclusion of the nutritious oilseed by-products in the cattle diet, a larger share of the grazing resources in the dairy cattle diet was of lower quality (Figure $3 \mathrm{c}$ ). Supply of animal HDP was reduced by $3 \%$ to $30 \mathrm{~g} /\left(\mathrm{cap}^{*} \mathrm{~d}\right.$ ) (Figure 4 ). 
a. Pig

Optimal conversion

Only high productive

No managed grass

Uniform grass quality

Current ratio M:M:E

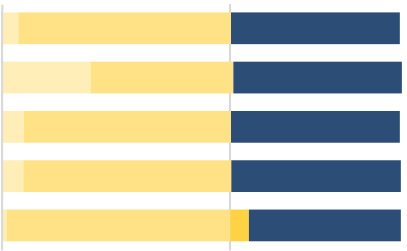

0,00

$$
\text { 0,50 } \stackrel{1,00}{\text { Feed intake (kg DM/day) }}
$$

b. Laying hen

Optimal conversion

Only high productive

No waste

No managed grass

Uniform grass quality

Current ratio M:M:E

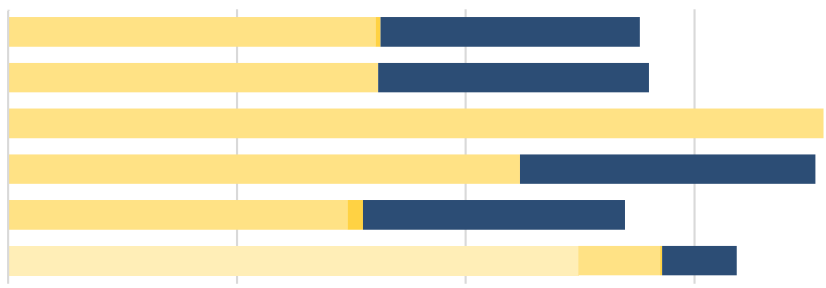

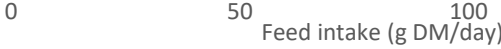

c. Dairy cattle

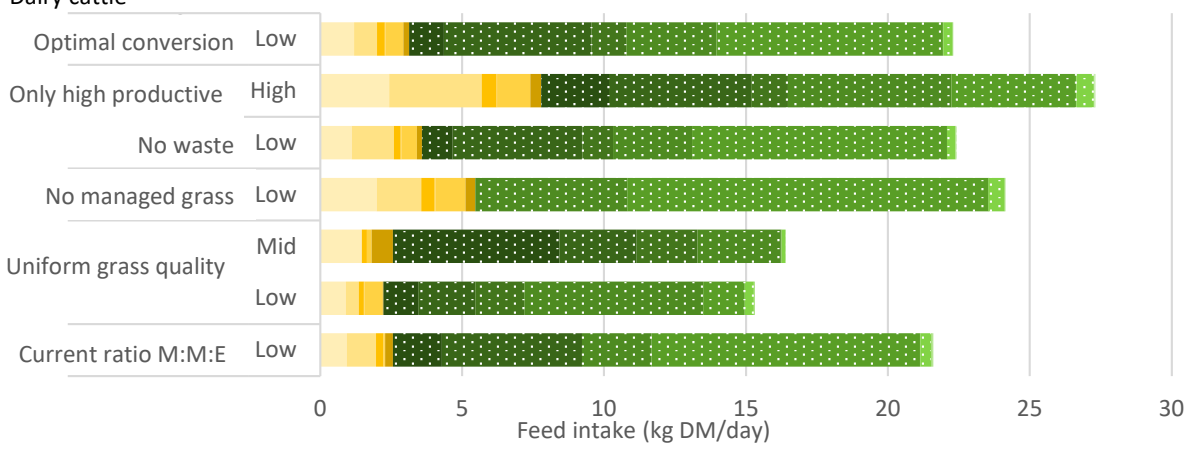

d. Beef cattle

Only high productive High
Current ratio M:M:E Low

0

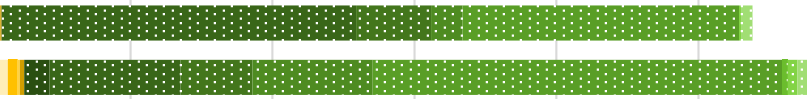

$5 \quad 10 \quad 15$

20

25

30

Feed intake (kg DM/day)

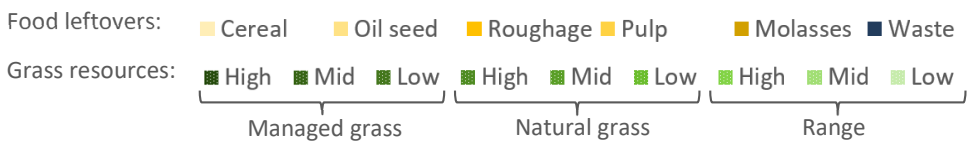

Figure 3 Proposed averaged (EU) diet for each livestock system (a. pig, b. laying hen, c. dairy cattle, d. beef cattle) under the optimal use of food leftovers (classification Appendix A2; Table A2) and grass resources; and alternative optimisation scenarios of the sensitivity analysis. Expressed per production animal per day including related requirement of non-producing animals. 


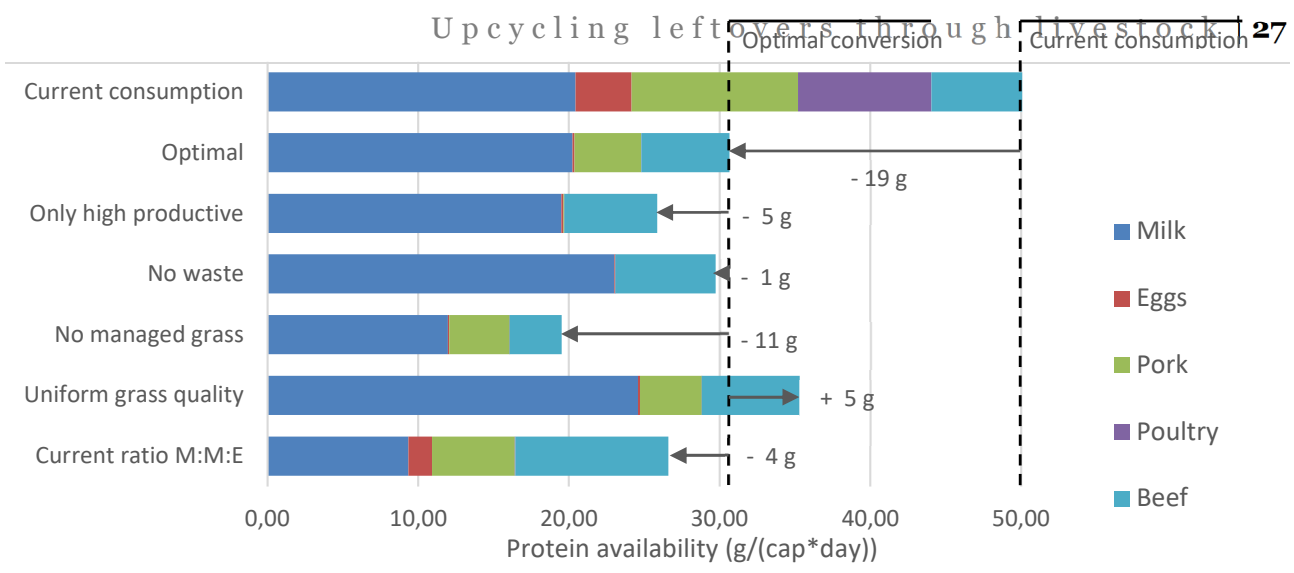

Figure 4. Animal human digestible protein (HDP) supply, per EU capita per day, under optimal conversion of LCF compared with current animal HDP consumption, and alternative optimisation scenarios of the sensitivity analysis

\subsection{Quantity and quality of grazing resources}

Excluding managed grasslands, the most nutritious grass resource, reduced the number of dairy cows with $40 \%$ to 18 million. The dairy cattle compensated the lower availability of grass resources and its lower nutritional value by consuming relatively more by-products (Figure $3 \mathrm{c}$ ). These byproducts were, therefore, to a lesser extend available for pigs and laying hens (Figure 2) resulting in reduced animal numbers (pigs $-10 \%$ to 50 million; laying hens $-35 \%$ to 6 million) but similar diets compared to the baseline optimisation (Figure $3 \mathrm{a} \& \mathrm{~b})$. Per capita supply of animal HDP decreased by $36 \%$ to $20 \mathrm{~g} / \mathrm{d}$ (Figure 4 ).

Assuming the available grass biomass of each vegetation type was uniformly distributed over the grass quality classes, increased the dairy cow numbers with $11 \%$ to 33 million compared with the baseline optimisation. Of these dairy cows, 20\% (7 million) was mid-productive. Under a uniform distribution more of the available grass biomass is of high quality, with which mid-productive cows met their higher nutritional requirement. Both mid and low-productive dairy cattle reduce feed intake compared to the baseline optimisation by consuming grass of a higher quality (Figure $3 \mathrm{c}$ ). Pig numbers reduced with $8 \%$ to 52 million, while laying hen numbers remained the same. Due to the higher dairy cow productivity, an increased (11\%) animal HDP supply of $34 \mathrm{~g} /\left(\right.$ cap $^{*} \mathrm{~d}$ ) was achieved with less animals (Figure 4).

\subsection{Diversity of animal-source foods}

When demanding a diverse output of ASF, the optimal conversion of LCF logically requires a wider range of animal production systems. With 70 million low-productive pigs, 117 million highproductive laying hens, 14 million low-productive dairy cows, and 14 million low-productive beef cows, various livestock systems and productivity levels were needed. Beef production was mainly grass based (98\%), using grass of a lower quality and less food by-products than dairy production 
(80\% grazing) (Figure 3c\&d). In total, however, beef cattle consumed a considerable amount of food by-products, mainly cereal by-products and roughage like products (Figure 2). The remaining food leftovers available from the reduced dairy cattle production (-54\%) were fed to monogastrics (Figure 2), where poultry were fed mainly cereal by-products and pigs consumed most of the oil byproducts and waste (Figure $3 \mathrm{a} \& \mathrm{~b}$ ). Collectively these livestock systems provide $280 \mathrm{~g}$ milk, $13 \mathrm{~g}$ egg, and $90 \mathrm{~g}$ meat / (cap*d) (33g pork, $1 \mathrm{~g}$ poultry, $56 \mathrm{~g}$ beef). Compared with the baseline optimisation, this reduces protein availability by $13 \%$ to $27 \mathrm{~g} /\left(\mathrm{cap}^{*} \mathrm{~d}\right.$ ) (Figure 4 ), due to the use of relatively inefficient livestock systems that are unable to valorise grass. This lower but more diverse supply of animal products does, however, provide more zinc and iron (Figure 5).

\section{Discussion}

When feeding livestock only with LCF, they provide some nutritious ASF without competing for land with food-crop production. Here we estimate that if we would use LCF available in the EU optimally, we can produce $31 \mathrm{~g}$ of animal protein/(cap*d) (Figure 4); just above the range of 9-30 $\mathrm{g} /\left(\right.$ cap $^{*} \mathrm{~d}$ ) (Supplement 1 , Table A1) found in previous studies. As previously described, availability of ASF from LCF is mainly influenced by the quantity and quality of LCF available, and the efficiency with which animals utilise these feeds. The following paragraphs present the influence of these factors on our estimate.

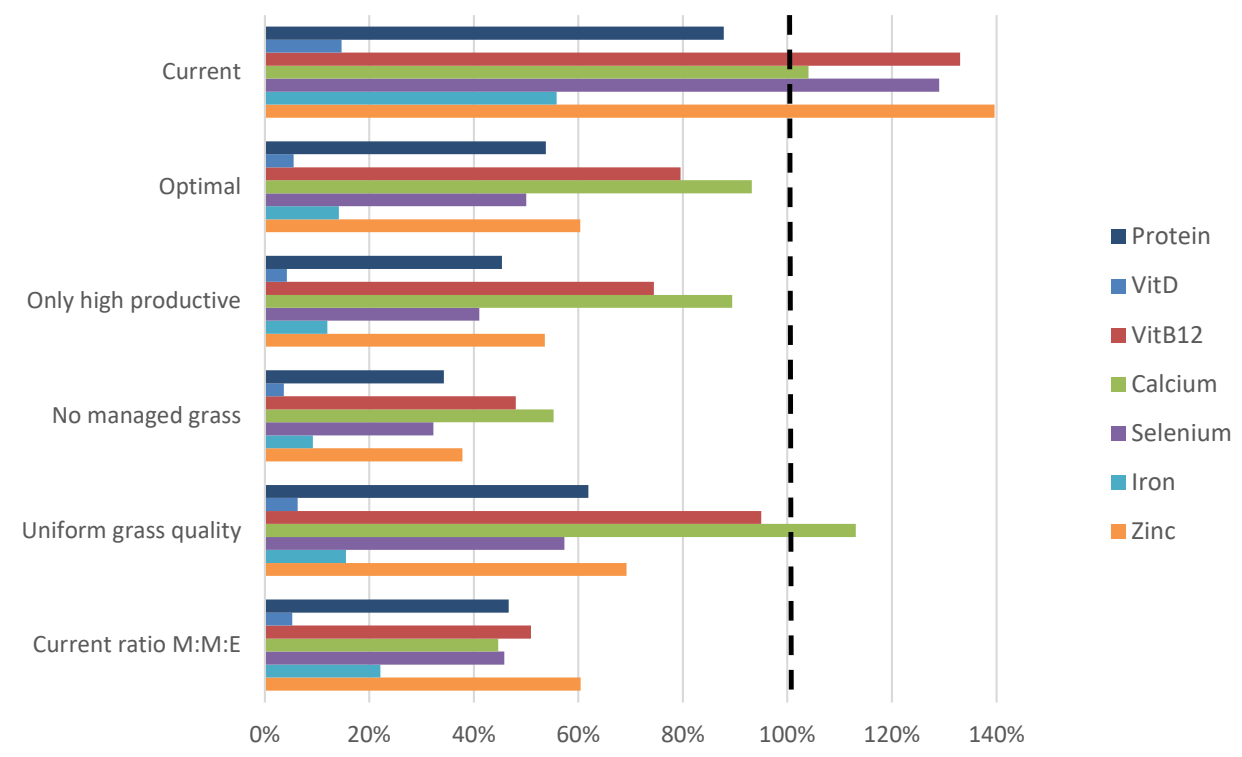

Figure 5 Nutrient supply by ASF, per EU capita per day, relative to daily intake requirements (USDA) under optimal conversion of LCF compared with the current average European diet and alternative optimisation scenarios of the sensitivity analysis 
The availability of food leftovers depends on the amount and type of plant-source foods in the human diet. We based this plant-source food consumption on food supply statistics that reflect our current, superfluous, diet likely resulting in a higher leftover availability than, for example, van Zanten et al. (2016a), who based this consumption on a 'healthy vegan diet'. Food leftover availability based on our current diet, served fine to illustrate the need for diverse livestock systems in a circular food system. Striving to use plant resources more efficiently for food production - as a circular food system should - will, however, change the availability of LCF, illustrated by the following three examples. First, numerous food by-products, currently used as feed, could be used as food (e.g. by consuming whole grain instead of plain flour). Second, avoiding overconsumption by restricting our food consumption based on dietary guidelines and consumption of plant based foods that do not provide nutritional benefits (e.g. coffee, sugar) (Alcott, 2008) reduces the availability of related by-products. Third, in terms of food supply, avoiding food waste is more efficient than reusing it as livestock feed (Mourad, 2016). Food waste reductions should therefore be atop of the political agenda, and only unavoidable food waste should be reused as feed, to the second most efficient use in terms of food production (Papargyropoulou et al., 2014).

Besides the availability of food leftovers also their inclusion as an LCF varied among studies. Only few previous studies considered food waste as an LCF (Table A1), as EU law forbids its use as livestock feed (zu Ermgassen et al., 2016). As relegalisation of feeding food waste is currently under debate (EuropeanCommission, 2015), we assumed 35\% of the produced food waste can be fed to monogastric livestock, as achieved in Japan where safe feeding of food waste is stimulated (zu Ermgassen et al., 2016). Excluding this food waste reduced the protein supply with $3 \%$ (30 $\mathrm{g} /\left(\right.$ cap $\left.^{*} \mathrm{~d}\right)$ ) compared with the baseline scenario (Figure 4 - No waste). This surprisingly low reduction in protein supply compared to previous studies which nominate food waste as a potent LCF (Röös et al., 2017a, 2017b; van Zanten et al., 2016a; zu Ermgassen et al., 2016) has multiple causes. As our food waste had a relatively low DM content (35-55\%), intake thereof by pigs required considerable supplementation of food by-products (Figure 2a). In the absence of food waste, these by-products were reallocated to dairy cattle, which convert them into protein more efficiently. Thus, our reallocation of by-products to dairy cattle limits the impact of excluding food waste, but by providing food waste only in wet form we likely underestimated its potential in the first place. To better understand the potential of relegalising food waste as livestock feed, optimal use of LCF should be assessed under likely future policy scenarios (e.g. feeding retailing waste or slaughter waste to pigs) and provision forms of food waste (e.g. dried vs wet) as well as potential food waste reduction. 
Regarding the availability of grass resources, considering grass grown on arable land as an LCF is debatable as it competes with direct plant-based food production (Garnett, 2011). Conversion of such grassland into cropland, however, is associated with a release of stored carbon and often also the loss of biodiversity (Foley et al., 2011; Gerber et al., 2013). We, therefore, included the managed grassland, situated on arable land, as an LCF. Excluding this managed grassland (23\% of total grass biomass) reduced the availability of animal protein by $35 \%$ to $20 \mathrm{~g} /\left(\mathrm{cap}^{*} \mathrm{~d}\right.$ ) (Figure 4 - No managed grass). In contrast to managed grasslands, natural grasslands and rangelands are generally not suitable for crop production and can only contribute to food production through grazing. One could, however, question whether we should use this land for food production at all, rather than spare this land to bind carbon through afforestation, where such is possible (Balmford et al., 2018). Grazed lands, however, contain specific flora and fauna, which may contribute to biodiversity, and hinder the spread of forest fires (Fuhlendorf et al., 2006).

The quality (nutritional value) of grazing resources varies considerably within the EU (Appendix A2), and the distribution of the quality over the available grass biomass of each vegetation type is largely uncertain. Changing the grass quality distribution considerably alters the livestock systems selected and the animal protein supply, as grass resources form the bulk of the available LCF in the EU. Compared to a normal distribution, assuming a uniform distribution, for example, increases the availability of high quality grass (Appendix A2; Figure A5), resulting in an increase in dairy cattle numbers and their productivity level, and hence in animal protein supply ( $34 \mathrm{~g} /\left(\mathrm{cap}^{*} \mathrm{~d}\right)$; Figure 4 - Uniform grass quality). A more robust assessment of animal protein supply using only available LCF in the EU, requires a concise overview of nutritional value of natural grasslands and rangelands, but was beyond the scope of this study.

The efficiency with which livestock utilise available LCF depends on the considered livestock systems (van Zanten et al., 2018). Where previous studies assumed fixed LCF rations to achieve a fixed (often high) productivity, our model uses LCF more efficiently by formulating nutritionally adequate rations for those animal production systems that maximised protein output. Our results, thus, give insights into what livestock should be used, and which LCF we should feed to what animals to maximise their contribution to nutrition security. The developed model is, furthermore, suitable to explore resource use efficiency of the livestock sector under any given feed availability. Our results confirm that optimal conversion of LCF requires a variety of both livestock systems and productivity levels. Regarding variation in livestock systems, the optimal conversion of LCF into protein required dairy cattle, pigs, and few laying hens. Selection of these livestock systems logically follows from high conversion efficiencies of laying hens and dairy cattle (de Vries \& de Boer, 2010), 
ruminants ability to valorise grass, and pigs ability to consume a wide range of low quality feeds (Preston, 1986), such as food waste. Forcing the model to use less efficient livestock systems by requiring a diverse ASF output, reduced animal protein supply by $13 \%$ (to $27 \mathrm{~g} /\left(\right.$ cap $^{*} \mathrm{~d}$ ); Figure 4 Diverse ASF). Forcing the model to use all considered livestock system including additional requirements on the origin of the produced meat (Pork:Poultry:Beef) will likely reduce this even further.

Regarding livestock productivity, optimal conversion of LCF required low productive pigs and dairy cattle to valorise LCF with a low nutrient density. The proposed low density LCF diets satisfy the relatively low nutrient requirements within the feed intake capacity. Data on both nutrient contents of LCF and the nutrient requirements of each livestock system contains relatively little uncertainty as they are well validated. This validation, however, holds best under high productivity, and breeding livestock that is suited to feed on LCF may increase efficiency. Data on FIC is less validated, as this knowledge is less valuable for conventional livestock production that strives for high productivity. Results are logically sensitive to assumptions on FIC, as they influence the required nutrient density of the proposed feed. Besides FIC also the applicability of LCF based feed in practice should be tested to consider palatability and voluntary intake. When allowing only for high-productive animals, pigs were no longer able to value food waste within their feed intake capacity, leaving this LCF largely unused while by-products were reallocated to dairy production

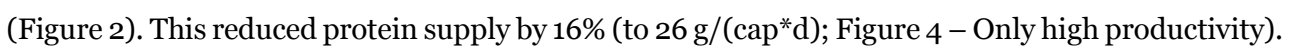

It has to be noted that optimal conversion of LCF under the above described assumptions, resulting in a $31 \mathrm{~g} /\left(\mathrm{cap}^{*} \mathrm{~d}\right)$ protein supply, would require reformation of the entire food system. This reformation includes fundamental changes related farming practices, food distribution and consumption patterns, resulting in far reaching consequences on, for example, the environmental impact. Regarding farming practices, breeding should focus on livestock well adapted to the available feed quality. Livestock housing should be adapted to lower intensity farming, which provides opportunities to simultaneously address other challenges the sector faces, for example, animal welfare requirements. Regarding consumption patterns, we should consider the impact of the reduced animal product supply (compared to our current consumption) on nutrient intake. While such reduced supply may not be critical regarding protein - protein requirements are still met when halving our animal protein supply to $31 \mathrm{~g} /\left(\mathrm{cap}^{*} \mathrm{~d}\right)$ - it is relevant for nutrients for which sufficient intake is currently already uncertain. The intake of vitamin B12 and iron by women, for example, is mostly obtained from ASF and does often not meet intake requirements (Biesalski, 2005). As a diverse ASF intake increased supply of iron and zinc at the cost of protein (Figure 5 - 
Current ratio M:M:E), combined livestock systems might be most suitable to fulfil our complete nutrient requirement. Furthermore, the reduced ASF consumption could be compensated by artificial supplements or food crops. The cropland area demand for this compensation can be assumed to be much smaller than the set free area on former fodder crop production areas, due to the large conversion losses in livestock systems.

Alternatively, ASF supply from LCF can likely be increased by considering alternative animal production systems with a high conversion efficiency, or the ability to valorise alternative LCF, which should be considered in future research. Small ruminants, for example, are well adapted to graze on low quality grazing an browsing resources, while insects may value manure and aquaculture can legally feed on animal and fish by-products (Parodi et al., 2018), Furthermore, supplementation with a small amount of concentrates (high quality feed), or synthetic amino acids likely increases productivity and ASF supply (van Zanten, 2016), especially when applied in the most critical growth stages (very young animals). In addition to animal protein sourced from LCF, fisheries, if limited to sustainable catch (Froese et al., 2018), can provide animal protein without competing with food crop production.

While this study indicates how livestock fed on LCF can optimally contribute to nutrition security, it does not consider direct environmental impacts of the food system. Indirectly, however, avoiding feed production reduces land use related to food production. Furthermore, previous studies showed that a diet including ASF produced with LCF, reduces land use of the food system by $25 \%$ compared to a vegan diet (van Zanten et al., 2018). Compared to current consumption patterns, limiting livestock production to available LCF, reduces greenhouse gas (GHG) emissions by 19-50\% (Röös et al., 2017a, 2017b; Schader et al., 2015). Maximising the output of animal protein when limiting livestock production to available LCF, however, likely comes with a trade-off regarding GHG emission, compared to these estimations. Optimal use of leftovers may, for example, require feed and animal protein transport in smaller quantities on a higher frequency and additional processing of food waste, causing additional GHG emission. Furthermore, while reducing productivity enables livestock to consume low quality by-products, it also increases the manure output and methane emissions relative to their production. When considering only high productive livestock, furthermore, a slightly reduced protein supply (-16\%) was achieved with considerably less animals (21 million vs 33 million cattle), which is possibly more desirable from an environmental perspective. Future studies, therefore, should consider both environmental impact and food security. 


\section{Conclusions}

By optimally converting low-opportunity-cost feedstuff (LCF) available in the EU, livestock can supply $31 \mathrm{~g}$ animal protein per capita per day (i.e. 40\% less than today), covering about half of our daily protein requirements. Our modelling results show that this optimal conversion requires a variation of livestock systems, mostly of lower productivity than conventional systems, confirming our hypothesis. The model selected those livestock systems that have a high conversion efficiency (laying hens, dairy cattle), or are best able to valorise specific LCF (dairy cattle for grass; pigs for food waste). Their reduced productivity enables them to use low quality LCF to meet their nutrient requirements, within their feed intake capacity. If we continue to use mainly high productive livestock, animal protein supply from LCF reduces with $16 \%$. The estimated supply of animal protein $(31 \mathrm{~g})$ is sensitive to uncertainties regarding the availability of LCF especially grass. To conclude, this paper provides valuable insights into how livestock can efficiently use LCF, using a model that can be applied to any assumed availability of feed resources.

\section{Acknowledgments}

This project received funding from the European Union's Horizon 2020 research and innovation program under grant agreement No 633692. The views expressed in this publication are the sole responsibility of the authors and do not necessarily reflect the views of the European Commission. 


\section{Chapter 3}

\section{The role of fisheries and fish farming in a circular food system}

Ollie van Hal ${ }^{1}$, Imke J.M. de Boer ${ }^{1}$, Friederike Ziegler², Johan W. Schama ${ }^{3}$, Kiki Kuiper ${ }^{1,3}$ and Hannah H.E. van Zanten ${ }^{1}$

${ }^{1}$ Animal Production Systems group, Wageningen University \& Research, PO Box 338, 6700 AH Wageningen, the Netherlands

${ }^{2}$ Food and Agriculture, RISE Research Institutes of Sweden, PO Box 5401, 402 29, Göteborg, Sweden 3Aquaculture and Fisheries group, Wageningen University \& Research, PO Box 338, 6700 AH Wageningen, the Netherlands 


\begin{abstract}
Recent studies show that livestock reared under the circular paradigm can contribute significantly to human food supply. By converting biomass unsuitable for human consumption into valuable animal-source food, such livestock upcycle nutrients that would otherwise be lost for food production. These studies, however, focussed solely on livestock, while aquatic animals can also make a valuable contribution to food supply. Fish, for example, is currently our main source of eicosapentaenoic (EPA) and docosahexaenoic (DHA) $\omega-3$ fatty acids. Here we explore the contribution of capture fisheries and fish farming (salmon and tilapia), relative to common farm animals, to a circular food system in an EU-28 case study. We demonstrate that, under the circular paradigm, fish provide nutritious food via both capture fisheries and fish farming. Capture fisheries should increase their food supply by rebuilding fish stocks and prioritising edible fish for human consumption. Such sustainable fisheries, however, can fulfil only about $40 \%$ of our daily per capita EPA/DHA requirements. To meet these requirements, we need to additionally farm fatty fish (salmon). These fatty fish, however, depend on by-products from fisheries to meet their own EPA/DHA requirements and on livestock slaughter by-products to meet their high nutrient requirements. Feeding livestock by-products to farmed fish, however, is not common practice due to concerns about consumer acceptance. Fish farming, moreover, competes with livestock production for upcycling of biomass unsuitable for human consumption. We conclude that a circular food system requires a combination of animal production systems, tailored to the available human inedible feed and desired nutrient supply to the human population. Such co-dependent animal production systems are essential to achieve balanced healthy diets with respect for our planet.
\end{abstract}




\section{Introduction}

A circular food system is increasingly seen as a promising way to feed our growing population within the carrying capacity of the planet, both by scientists and politicians (European Commission, 2015; Ghisellini et al., 2016; Jurgilevich et al., 2016; Springmann et al., 2018). Central to a circular food system is the efficient use of natural resources, especially spatial resources like arable land, grassland and waterbodies (van Zanten et al., 2019). Efficient use of arable land, for example, prioritises plant biomass for human consumption, as the alternative - using arable land to cultivate animal feed - is less efficient due to metabolic losses when converting feed to food (Foley et al., 2011; Godfray et al., 2010). Animal production should, therefore, focus on upcycling so called lowopportunity-cost feed (LCF) into animal-source food (ASF) and other ecosystem services (Garnett, 2011; van Zanten et al., 2016a). Such LCF, unsuitable or currently undesired for human consumption, include crop residues, by-products from food processing (e.g. beet pulp or rapeseed meal), food waste and grass biomass. Feeding animals solely with LCF is most land use efficient as competition between feed and food production is minimised (van Kernebeek et al., 2016). The availability of LCF is, however, limited and poses a boundary to the production and consumption of ASF in a circular food system (van Zanten et al., 2018).

Recent studies show that livestock fed solely with available LCF can contribute significantly to the supply of nutrients that are highly bio-available, such as protein and iron, or absent in plant-source food, such as vitamin B12 (Godfray et al., 2018; Smith et al., 2013; van Hal et al., 2019; van Zanten et al., 2018). So far, however, studies on the role of animals in a circular food systems focussed solely on livestock, while also aquatic animals can make a valuable contribution to global nutrition security (Béné et al., 2015). Besides providing valuable micro-nutrients, such as vitamin D and selenium, fish are currently our main source of eicosapentaenoic (EPA) and docosahexaenoic (DHA) $\omega-3$ fatty acids, essential e.g. for brain development and functioning, and immune regulation (Kris-Etherton et al., 2009; Racine \& Deckelbaum, 2007; Simopoulos, 2009). Humans can desaturate alpha-linolenic acid (ALA) into EPA/DHA, but both ALA intake and desaturation potential are limited (Calder \& Yaqoob, 2009). Guidelines for healthy diets (Willett et al., 2019), therefore, include a significant share of fish to fulfil the daily recommended intake of $250 \mathrm{mg}$ EPA+DHA (EFSA, 2017).

Fish are either harvested from the wild (capture fisheries) or farmed (aquaculture) (FAO, 1988). Capture fisheries require no input of feed, and, therefore do not directly compete for resources with food crop cultivation. The current use of human edible parts of captured fish to feed farm animals, however, does cause feed-food competition (Cashion et al., 2017), although at present, there is no 
food demand for these species. Furthermore, food supply by capture fisheries is ultimately limited by the production capacity of the fish stocks in our water bodies (Hamilton et al., 2020). To avoid overexploitation and to rebuild impaired fish stocks, fish stocks in shared seas are managed through international agreements (ICES, 2016). The impact of these international agreements on rebuilding fish stocks, and the potential of marine ecosystems too supply food, is uncertain, and while progress has been made, it is slower than desired (Froese et al., 2018; Rindorf et al., 2017).

Unlike fisheries, farmed fish generally require a nutrient-dense feed comprised of plant, livestock and/or fish-based ingredients (Tacon, 1997). As part of these feed ingredients are suitable for human consumption (Cashion et al., 2017) or grown on land suitable for food crop production (Fry et al., 2016). Fish farming, therefore, currently results in feed-food competition. For example, only $30 \%$ of globally produced fishmeal consists of human inedible fish by-products, while the remainder consists of rendered whole, often food-grade, fish (Cashion et al., 2017; Jackson \& Newton, 2016). Nevertheless, farmed fish may play an important role in a circular food system, as they can contribute to the efficient use of LCF for the following reasons. First, fish have relatively high feed efficiencies (Tacon \& Metian, 2008). Second, they can feed on animal proteins currently prohibited as livestock feed (EU, 2013a); and third, they can efficiently upcycle EPA/DHA from marine sources into nutritious ASF (Tocher, 2015).

To our knowledge, the contribution of capture fisheries and fish farming to a circular food system is unknown. Understanding the relevance of fish in a circular food system - in terms of nutrient supply and efficient use of resources - can provide direction to strategic development of both capture fisheries and fish farming. This study, therefore, explores the potential role of capture fisheries and fish farming, relative to common farm animals, to a circular food system, using the EU-28 as a case study.

\section{Methods}

The contribution of capture fisheries and farmed fish to a circular food system was assessed using the methodological framework depicted in Figure 1. Efficient use of spatial natural resources implies arable land and waterbodies primarily produce biomass for direct human consumption through food crop cultivation and capture fisheries. LCF associated with this food production (e.g. processing by-products and manufacturing wastes) can be fed to animals, resulting in additional, indirect food supply. While grassland does not supply food directly, ruminants can upcycle grass into an indirect supply of meat and milk. Besides ASF, animals that upcycle LCF provide associated by-products that can be used as feed under strict regulations to avoid transfer of diseases. 


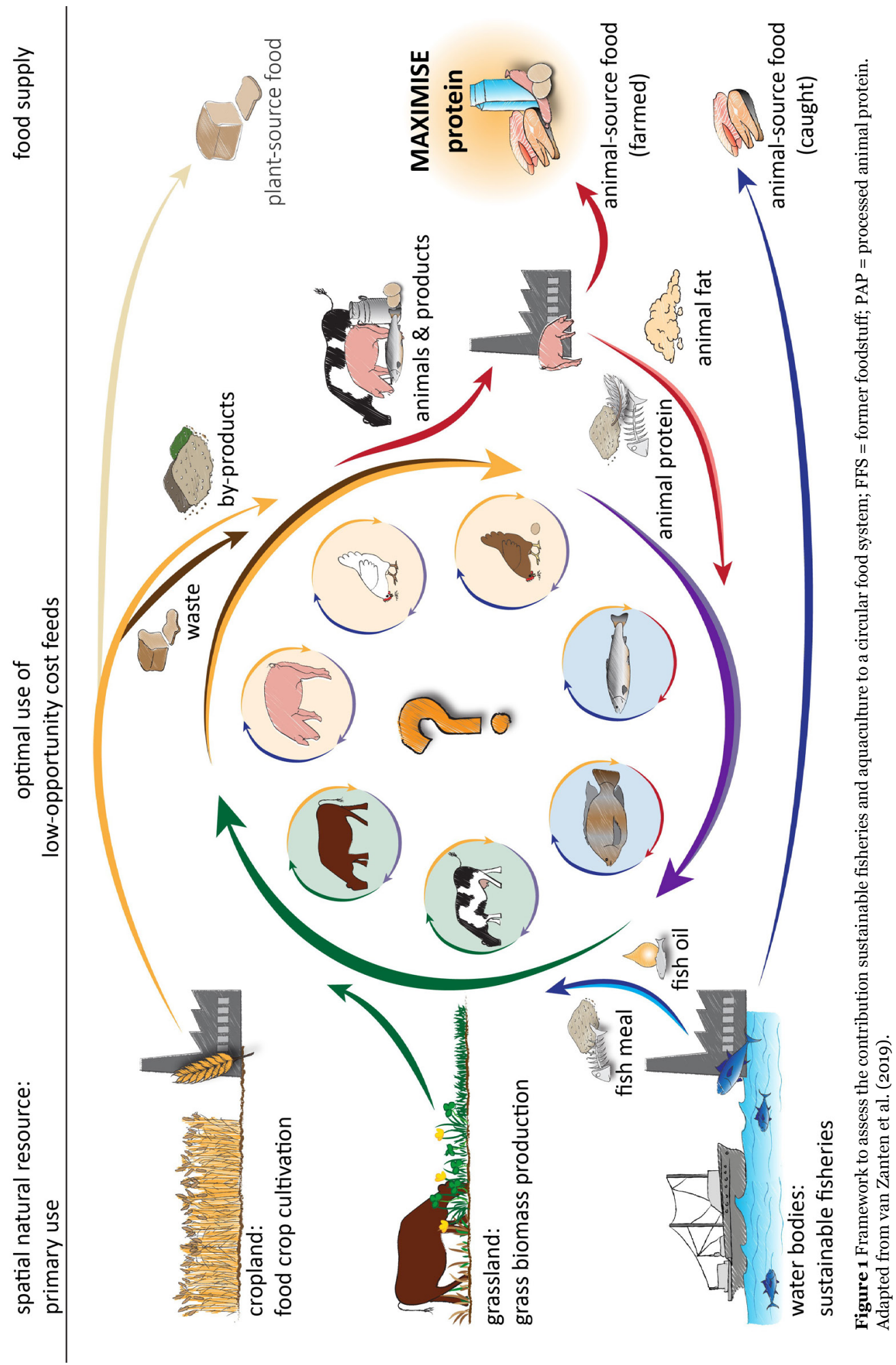


To assess the contribution of capture fisheries, we define EU fisheries that align with the principles of a circular food system (Section 2.1). To assess the contribution of farmed fish to the optimal conversion of LCF - where they compete with livestock - we extended the livestock optimisation model of van Hal et al. (2019) with two farmed fish species (Figure 1). This extended model allocates the LCF available in the EU to that combination of fish and livestock that maximises human digestible protein (HDP) supply, while meeting human requirements of vitamin B12 and EPA/DHA. We prioritised meeting the requirements of these nutrients for two reasons. First, they are currently only provided by ASF (Béné et al., 2015; Smith et al., 2013). Second, both vitamin B12 and EPA/DHA are currently under-consumed by a significant part of the EU population while protein is abundantly available (de Smet, 2012; Duru, 2019; Givens \& Gibbs, 2008; Oh \& Brown, 2003). We, furthermore, illustrate the supply of calcium, selenium, vitamin A, vitamin D, iron and zinc, as their adequate intake might be threatened under changed ASF supply, and ASF vary in contents of these nutrients (Godfray et al., 2018; Mertens et al., 2017).

The model, described in Section 2.2, predicts which animals we should keep and which of the available LCF we should feed them to produce as much HDP as possible, while meeting daily requirements of vitamin B12 and EPA+DHA. In Section 2.3 we quantify available LCF from food crops, grass production and capture fisheries in the EU. Thereafter, we define the included livestock and fish farming systems (i.e. pig, laying hen, broiler, dairy, beef, salmon and tilapia; Section 2.4), and quantify the LCF associated with processing their outputs into food (Section 2.5). In Section 2.6, we explain how we quantified ASF and nutrient supply from fisheries (direct) and animal production systems (indirect) to humans. Finally we performed a sensitivity analysis by comparing our reference scenario (Section 2.1 to 2.5) to scenarios with alternative assumptions (Section 2.7).

\subsection{Sustainable fisheries and fish use}

Food supply by fisheries is limited by the amount of harvestable fish in waterbodies and how we choose to use these fish. The amount of fish that can be harvested from a waterbody depends on the production capacity of its fish stocks, which in most EUs shared waters is impaired due to overexploitation (Costello et al., 2016; Froese et al., 2018). As the production capacity of a waterbody should be sustained or even restored in a circular food system, we assumed landings (i.e. harvested fish in tonnes of fresh fish) to be limited to the maximum sustainable yield (MSY) implemented in EU legislation (EU, 2013b; ICES, 2016). This MSY represents the highest achievable landings without long-term negative impacts on the population, considering both harvested biomass and fish mortality (EU, 2013b). To avoid feed-food competition we also assumed 
that the edible yield fraction of all landed food-grade fish is used as food, while only their byproducts are rendered into feed.

To estimate EU MSY landings (Appendix B1, Table B1), we first quantified MSY landings of 100 stocks of 16 species in the Northeast Atlantic (ICES, 2016). Subsequently, we quantified the share of these landings available to EU member states based on the current quota distribution (EU council, not publicly available). The selected 16 species were most relevant in terms of biomass landed in 2016, for which coherent data on MSY landings and quota distributions was available (Appendix B1). In 2016, the considered 100 stocks provided 75\% of total EU landings (ICES, 2018), the remainder originated mainly from the Mediterranean and Black Seas. Of the 16 species, two were classified as non-food-grade, namely Sandeels (Ammodytus) and Norway pout (Trisopterus esmarki) (Cashion et al., 2017). For five of the 14 food-grade species, part of the landed whole fish is currently rendered into feed (e.g. European Sprat (Sprattus sprattus)(EUROSTAT, 2016)), while landings of one food-grade species (blue whiting (Micromesistius poutassou)), was fully rendered into feed (Appendix B1). Here we assumed that all food-graded fish is used as human food instead of as animal feed.

\subsection{Optimising low-opportunity-cost feed (LCF) conversion}

To assess the optimal conversion of LCF by livestock and fish we extended the optimisation model of van Hal et al. (2019). This extended model has the standard form of a linear programming model:

$\begin{array}{ll}\text { Maximise } & Z=\boldsymbol{c} \boldsymbol{x} \\ \text { Subject to } & \boldsymbol{A x} \geq \boldsymbol{b} \\ \text { and } & \boldsymbol{x} \geq O\end{array}$

Where, $\boldsymbol{x}$ is a vector of animal production activities; $\boldsymbol{c}$ is a vector of HDP produced per unit of activity; $\boldsymbol{A}$ is a matrix of technical coefficients; and $\boldsymbol{b}$ is a vector with quantitative constraints. The objective function to maximise HDP output $(Z)$ is restricted by the availability of each LCF, the nutritional value of each LCF for each animal system, and the nutritional requirements of the animals in each production system. Additional "nutrient constraints" ensure that daily human requirements of vitamin B12 (4 $\mu \mathrm{g})$ and EPA+DHA (250 mg) are fulfilled (EFSA, 2017). We, furthermore, restrict the allocation of available LCF to animal production systems to follow current EU feed legislation. Current EU feed legislation allows feeding of grass resources, crop residues and processing by-products, and animal fats, such as tallow and fish oil, to all farm animals. To avoid transfer of diseases to animals or humans, feeding of animal proteins is strictly regulated (Table B6) and feeding of food waste from households and catering is prohibited (EU, 2009, 2013a, 2017, 2018). 


\subsection{Low-opportunity-cost feeds (LCF)}

We included the following LCF as model input: crop processing by-products, plant-based formerfoodstuffs, grass resources, and by-products of sustainable fisheries. Former-foodstuffs (FFS) are products intended for human consumption but wasted during manufacturing or retailing. Only plant-based FFS are currently allowed as animal feed (EU, 2017, 2018). Crop residues were assumed to be left on the field to maintain soil fertility (van Zanten et al., 2019) and, like feeding losses, were considered unavailable as animal feed (Vermeij, 2017). We assumed that grass resources can be valued only by ruminants in the country of origin, whereas other LCF can be traded freely between EU countries.

The availability of by-products from the processing of EU plant-source food was derived from van Hal et al. (2019) (Appendix A2). The availability of plant-based FFS was based on estimations of their current use in the EU and amounted $5 \mathrm{Mt}$ fresh matter per year (EFFPA, 2019). The composition of these FFS equalled the average composition in the UK (UKFFPA, 2019), the Netherlands (VIDO, 2019) and France (Vernier et al., 2016) (Figures B1 \& B2). For reporting purposes, available by-products and FFS were classified based on their nutritional properties (Table A2 \& Figure B3). The availability of grass resources derived from van Hal et al. (2019) distinguishes three vegetation types: managed grassland, natural grassland and rangeland (Appendix A2). Managed grassland, while suitable for food crop production, was included to avoid release of carbon and loss of biodiversity and cultural value when converting grassland into cropland (Foley et al., 2011; Gerber et al., 2013). The availability of LCF from fisheries was calculated by applying species specific rendering fractions (output of fish oil and meal) to the inedible part of the landings, which were quantified using the species specific slaughter yield (Table B2). Underlying data, assumptions and calculations are provided in Appendix B2.

\subsection{Animal production systems}

We included the five most prevailing livestock production systems in Europe (i.e. pig, laying hen, broiler, dairy and beef production (FAO, 2017d)), and two fish farming systems (i.e. salmon and tilapia). We modelled the entire life cycle of these animal systems, including food producing as well as non-food producing animals, such as parent and young stock.

\section{Livestock production systems}

The number of non-food producing livestock (e.g. sows, gilts and piglets) relative to a producing animal (e.g. fattening pig) (Appendix A3; Table A6) was based on European herd compositions (FAO, 2016a, 2016c). We distinguished three productivity levels in livestock systems: low, mid and high. Productivity was expressed in annual milk/egg production or average daily gain, where high 
productivity reflects intensive production using Dutch production averages as a proxy (Bos et al., 2013), and low productivity reflects extensive systems throughout Europe. Production performances, related nutrient requirements (Tables B8 \& B9) and net nutrient contents of LCF (CVB, 2016) for each livestock system were adopted from van Hal et al. (2019) as described in Appendix B3.

\section{Fish farming systems}

We included two types of farmed fish with contrasting ability to utilise feed. Atlantic salmon (Salmo salar), the most prevailing farmed fish species in the EU (EUROSTAT, 2019). Salmon represents a high-trophic carnivore species that requires animal protein in their feed. Nile tilapia (Oreochromis niloticus) represents a lower trophic omnivorous species. Tilapia is the most consumed low trophic, farmed fish in EU (FAO, 2018b) and was selected in the absence of commercial farming of such species in the EU due to low profitability (Sprague et al., 2016). As an oily fish, salmon is a rich source of EPA+DHA while these contents are much lower in Tilapia (Sprague et al., 2016).

The number of non-producing animals (e.g. alevin, fry, smolt and brood stock) needed to harvest one producing animal (i.e. salmon or tilapia grower) (Appendix B3; Table B5) was based on species specific mortality (Bhujel, 2014; EY, 2017; McGeachy et al., 1995) and fertility data (Eskelinen, 1989; FAO, 2018a; TIL-AQUA, 2016), assuming mortality occurs evenly over each life phase. We distinguished only one productivity level for fish farming that reflects the high productivity common in the EU, as a lack of data limited us to simulate reduced productivity levels. To define the performance of these high productive fish (Table 1), we first simulated their optimal growth and associated feed and nutrient intake during the entire production cycle using Skretting's AquaSim model. Subsequently, we calibrated simulated growth and feed intake values with values of common practice, using literature. Details on the below described data, assumptions and calculations of fish farming systems are provided in Appendix B3.

Fish growth

As fish are poikilothermic, their growth, metabolism and feed intake depend on water temperatures. For Atlantic salmon, we simulated optimal growth and feed intake assuming the sea water temperature pattern in the Atlantic ocean around Great Britain (SeaTemperatures, 2019), where the majority of EU28 salmon is produced (EUROSTAT, 2019). Simulated growth and feed intake (Figure B3) were calibrated with average feed conversion ratios (FCR: kg feed needed per kg growth) of 1.2 to 1.3 observed in Europe (Tacon \& Metian, 2008). The assumed cumulative FCR of 1.22 is attained through a yearlong fresh water phase before transfer to sea cages where fish grow from $77 \mathrm{~g}$ to a slaughter weight of $5500 \mathrm{~g}$ in 520 days (Table 1 ). 
Table 1 Assumed performance and related nutrient requirements of Atlantic salmon and Nile tilapia

\begin{tabular}{|c|c|c|c|c|c|c|c|c|c|c|c|}
\hline & \multicolumn{7}{|c|}{ Performance } & \multicolumn{4}{|c|}{ Nutrient requirement ${ }^{3}$} \\
\hline & \multirow{2}{*}{$\begin{array}{l}\text { Period } \\
\text { days } \\
\end{array}$} & \multicolumn{2}{|c|}{ Growth (g) } & \multicolumn{2}{|c|}{ Feed intake (g) } & \multicolumn{2}{|c|}{$\mathrm{FCR}^{1}$} & \multicolumn{2}{|c|}{$\mathrm{DE}(\mathrm{MJ})$} & \multicolumn{2}{|c|}{$\mathrm{DP}(\mathrm{g})^{4}$} \\
\hline & & $/ \mathrm{d}$ & Total & $/ \mathrm{d}$ & Total & Phase & Cum $^{2}$ & $/ \mathrm{d}$ & Total & $/ \mathrm{d}$ & Total \\
\hline \multicolumn{12}{|l|}{ Salmon } \\
\hline Alevin & 85 & 0.00 & 0.31 & 0.00 & 0.19 & 1.08 & 1.08 & 0.000 & 0.003 & 0.001 & 0.093 \\
\hline Fry & 25 & 0.03 & 0.70 & 0.02 & 0.49 & 0.98 & 1.01 & 0.000 & 0.009 & 0.009 & 0.237 \\
\hline Parr & 111 & 0.13 & 29.01 & 0.23 & 25.51 & 1.14 & 1.14 & 0.004 & 0.48 & 0.11 & 11.92 \\
\hline Smolt & 143 & 0.33 & 47 & 0.32 & 45.87 & 1.20 & 1.18 & 0.006 & 0.84 & 0.13 & 18.93 \\
\hline Grower & 519 & 10.47 & 5433 & 11.66 & 6049 & 1.22 & 1.22 & 0.235 & 122 & 3.69 & 1917 \\
\hline Brood stock & 32 & 15.32 & 490 & 17.90 & 573 & 1.17 & 1.22 & 0.315 & 10 & 7.39 & 236 \\
\hline \multicolumn{12}{|l|}{ Tilapia } \\
\hline Swim up fry & 21 & 0.02 & 0.35 & 0.01 & 0.30 & 3.29 & 3.29 & 0.000 & 0.005 & 0.006 & 0.134 \\
\hline Fry & 21 & 0.10 & 2.15 & 0.06 & 1.16 & 0.82 & 1.16 & 0.001 & 0.017 & 0.022 & 0.471 \\
\hline Fingerling & 18 & 0.41 & 7.46 & 0.40 & 7.17 & 1.29 & 1.18 & 0.006 & 0.10 & 0.15 & 2.65 \\
\hline Juvenile & 29 & 1.72 & 50 & 1.77 & 51 & 1.14 & 1.15 & 0.022 & 0.62 & 0.54 & 15.76 \\
\hline Grower & 107 & 6.50 & 695 & 9.33 & 999 & 1.48 & 1.45 & 0.109 & 12 & 2.62 & 280 \\
\hline Brood stock & 270 & 1.02 & 275 & 7.90 & 2134 & 7.76 & 1.45 & 0.095 & 26 & 2.92 & 788 \\
\hline \multicolumn{12}{|c|}{$\begin{array}{l}\text { 1: Feed conversion ratio including feed consumed by non-surviving fish, brood stock and their replacement } \\
\text { 2: Cumulative FCR summed over all preceding phases; bold value at broodstock represents FCR of entire life cycle } \\
\text { 3: Assuming phase specific Skretting feeds nutrient content in Table B6 }\end{array}$} \\
\hline \multicolumn{12}{|c|}{ 4: Protein digestibility of conventional feeds assumed: } \\
\hline \multicolumn{12}{|c|}{ * Salmon: 87\% \% (Aas et al., 2015; Dessen et al., 2017; Weihe et al., 2018) } \\
\hline \multicolumn{12}{|c|}{ * Tilapia: 92\% (Tran-Ngoc et al., 2016) } \\
\hline
\end{tabular}

\section{Nutrient requirement}

For Nile tilapia, optimal growth and feed intake (Table 1) were simulated for a tank system with a constant water temperature of $28^{\circ} \mathrm{C}$ and controlled high oxygen levels. The cumulative FCR of the simulated growth (1.45) falls in the range of values observed in practice (i.e. 1.0-2.6 (Tacon \& Metian, 2008)), which include pond systems, in which feed obtained from the pond ecosystem is excluded (Kabir et al., 2019), as well as tank systems with suboptimal oxygen or temperature management (El-Sayed, 2019). This FCR is attained by growing to a slaughter weight of $750 \mathrm{~g}$ in 200 days, which is typical for the European market, (Rutten et al., 2004; TIL-AQUA, 2016).

Digestible energy (DE) and protein (DP) requirements to achieve the assumed growth (Table 1) were calculated by multiplying the required feed intake with DE and DP contents in Skrettings' commercial feeds, tailored for each species and life phase. We assumed a protein digestibility of $87 \%$ in salmon feed and of $92 \%$ in tilapia feed (Aas et al., 2015; Dessen et al., 2017; Tran-Ngoc et al., 2016; Weihe et al., 2018). To ensure fish health as well as appropriate EPA+DHA levels in edible fish tissue (Sprague et al., 2016), we assumed the EPA+DHA content in salmon feed to be larger than 2.5\% of DM (Bou et al., 2017). Furthermore, we assumed that the maximum feed intake capacity (FIC) of farmed fish was equal to the simulated feed intake (Table 1). Commercially farmed 
fish, typically consume feed to their maximum capacity which can be limited by oxygen availability or other physiological constrains (Saravanan et al., 2012, 2013).

DE contents and protein digestibility (PD\%) of the considered LCF were obtained from the IAFFD database (IAFFD, 2018). To calculate the DP content of each LCF, its PD\% was multiplied with its crude protein content (van Hal et al., 2019). While the IAFFD database gives nutrient content values for a broad range ingredients - including most considered LCF - they do not differentiate between fish species, even though omnivorous fish like tilapia are known to better digest plantbased proteins than carnivorous fish like salmon (Magalhães et al., 2018). To account for this difference, we adjusted PD values of IAFFD based on literature data (Table B7).

\subsection{Low-opportunity-cost feed (LCF) from animal production systems}

The LCF from ASF production included animal fat, fish oil, meal from blood, plasma, feathers, meat and bones, and fish and bones, which result from slaughtering and meat processing of animals selected for the optimal use of LCF into raw meat or fish. The availability of LCF from livestock production was calculated by multiplying the predicted live weight (LW) output of each livestock system with slaughter and processing yields per kg LW (Appendix B2; Table B3). For pigs and cattle, these fractions were derived from slaughter reports (USDA, 2018b, 2018c), whereas for poultry they were derived from literature (Haslinger et al., 2007; Sams, 2010). The availability of LCF from farmed fish was calculated by multiplying the inedible fraction of the predicted LW with rendering fractions for oil and meal (Table B2). The above described calculations show that the availability of animal-based LCF depends on the animal production systems selected to upcycle available LCF, creating a model loop as shown in Figure 1, that forms no issue in solving optimisation models.

As indicated, we adhere to current legislation regarding use of animal-based LCF as animal feed (Table B4). Amongst others, this EU legislation forbids feeding farmed animals with proteins originating from farmed animals of the same species (EU, 2013a). The farmed fish species in our model, however, are a proxy for a range of species with similar characteristics (e.g. rainbow trout for salmon), that are allowed to feed on each other's by-products. To reflect this we allow for intraspecies recycling of fish farming by-products, meaning farmed fish can consume by-products of farmed fish of the same species.

\subsection{Animal source food and nutrient supply}

Supply of ASF, expressed per EU capita per day (/cap/d), includes the direct supply from capture fisheries and indirect supply from the farmed livestock and fish selected to upcycle available LCF. 
Direct ASF supply from fisheries (kg cooked fish) was calculated by multiplying fisheries landings (Table B1) with species specific slaughter yields (Table B2) and cooking retentions (USDA, 2012). Similarly, supply of edible meat, offal and fish by farmed livestock and fish was calculated by multiplying their predicted LW output with species specific slaughter yields (Tables B2 \& B3) and cooking retentions (USDA, 2012). Supply of milk and eggs (kg fresh product), was equal to the predicted output of the production systems. Nutrient supply was calculated by multiplying supply of each ASF with its product specific nutrient content (Appendix B4; Table B8). We consider the nutrients most affected by reducing ASF consumption, namely HDP, vitamins A, D and B12, calcium, iron, zinc, selenium and EPA+DHA (Macdiarmid et al., 2012; Mertens et al., 2017). Nutrient content of cooked meat reflects the weighted average nutrient content of all cuts, and variation in protein content related to productivity (Figure B4) was based on literature (van Hal et al., 2019). Finally, we compare the resulting daily per capita nutrient supply with the nutrient specific daily recommended intake (DRI) (EFSA, 2017).

\subsection{Sensitivity analysis}

To evaluate model responses to changes in key model parameters, we conducted a sensitivity analysis in which results of the reference scenario (Sections 2.1-2.6) were compared with alternative optimisation scenarios. First, we explored the impact of the "nutrient constraints" implemented in the reference scenario to prioritise meeting the human demand for vitamin B12 and EPA+DHA when optimising the use of LCF. We assess the consequences including these nutrient constraints, by comparing the reference scenario with a scenario in which no nutrients constraints were included (No NC Scenario).

Second, we explored the implications of our assumptions regarding capture fisheries in the reference scenario, where landings were limited to MSY and all edible fish was assumed to be used as food (Section 2.1.). While such fisheries are suited to a circular food system, they do not reflect current practice, where $64 \%$ of EU fish stocks are subject to ongoing overexploitation (Froese et al., 2018) and whole food-grade fish are rendered into feed (Cashion et al., 2017). We assessed the impact on ASF supply of shifting from current to sustainable fisheries practices, by comparing the reference scenario with a Current fisheries scenario, that assumed current landings and current fish use (Table B1; Current).

The MSY yields assumed in the reference scenario are, however, only a first step to rebuild overexploited commercially used fish stocks in the EU (EU, 2013b). In the long run, rebuilding stocks to recover their production potential, which may increase food supply, implies a further 
reduction of fishing pressure that is not yet quantified by legislation (Costello et al., 2016; Froese et al., 2018; Rindorf et al., 2017). Froese et al. (2018) indicated that to effectively rebuild stocks by 2030, fishing pressure should be limited to $80 \%$ of levels yielding MSY. We estimated the impact of such stock rebuilding on ASF supply with a Stock rebuilding scenario, where landings reflect predicted MSY landings in 2030 under proposed reduced fishing pressure (Table B1; MSY o.8) while maintaining the improved fish use of the reference scenario.

\section{Results}

In our reference scenario that mimics an optimal circular food system, animals supply $620 \mathrm{~g}$ fresh milk, $12 \mathrm{~g}$ fish, $37 \mathrm{~g}$ meat and $4 \mathrm{~g}$ offal (edible organ meat) per capita per day (cap/d). Putting this in perspective, this is $28 \mathrm{~g}$ more milk, $4 \mathrm{~g}$ more fish, 180 less meat and $33 \mathrm{~g}$ less egg than currently supplied in the EU (FAO, 2017a). In total, this ASF provides $35 \mathrm{~g} \mathrm{HDP/cap/d,} \mathrm{fulfils} \mathrm{the} \mathrm{DRI} \mathrm{of}$ vitamin B12 (131\%) and EPA/DHA (100\%), and contributes significantly to the DRI of other essential nutrients (Figure 2). Fish provide 8.3\% of total HDP supply (2.9 g/cap/d)), $98 \%$ of the DRI of EPA/DHA, and 14\% of the DRI of vitamin B12 (o.7 $\mu \mathrm{g} / \mathrm{cap} / \mathrm{d})$. Fish, furthermore, contribute significantly to the DRI of fat-soluble vitamin D, but this DRI is uncertain as synthesis of vitamin D from sunlight is highly variable in humans (EFSA, 2017). The contribution of fish to most other considered nutrients is relatively small, while livestock play a more essential role. Milk supply, for example, nearly fulfils the DRI of calcium, while meat significantly contributes to both iron and zinc supply. Due to its high vitamin A and B12 content, offal has a relatively large contribution to the DRI of these nutrients (Figure 2).

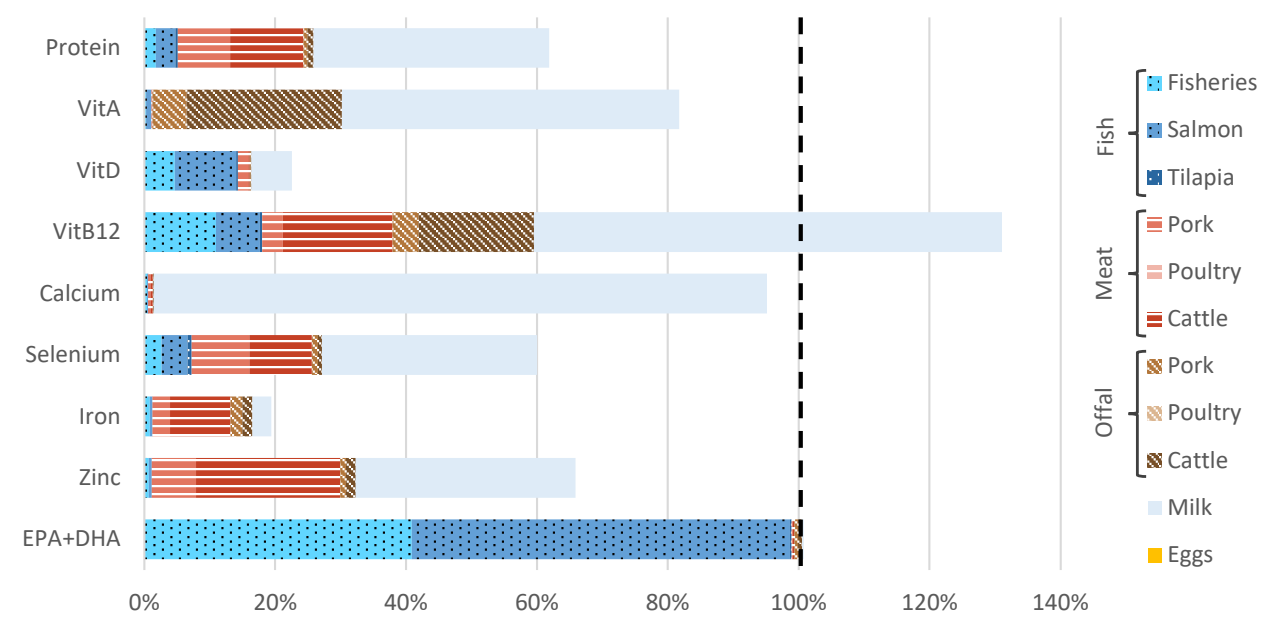

Figure 2 Contribution of animal source food supplied by fisheries and animal production systems to the daily recommended intake (DRI) of protein and relevant nutrients in the reference scenario for a circular food system. 


\section{Fisheries}

About $38 \%$ of the daily supply of edible fish ( 4.5 out of $12 \mathrm{~g} / \mathrm{cap} / \mathrm{d}$ ) originates directly from capture fisheries (Figure $3 \mathrm{a}$; Reference). The various species from capture fisheries fulfil $2 \%$ of daily DRI of HDP (1 g/cap/d), 11\% for vitamin B12 (0.45 $\mu \mathrm{g} / \mathrm{cap} / \mathrm{d})$ and 40\% for of EPA+DHA (100 mg/cap/d)

(Figure 3). The contribution of each species to HDP supply follows that of their product supply (Figure 3a,b), indicating a similar protein content among fish species. In contrast, herring, mackerel and sprat have a relatively high contribution to the intake of vitamin B12 and EPA+DHA, because their flesh contains relatively high amounts of these nutrients (Figure $3 \mathrm{c}, \mathrm{d}$ ).

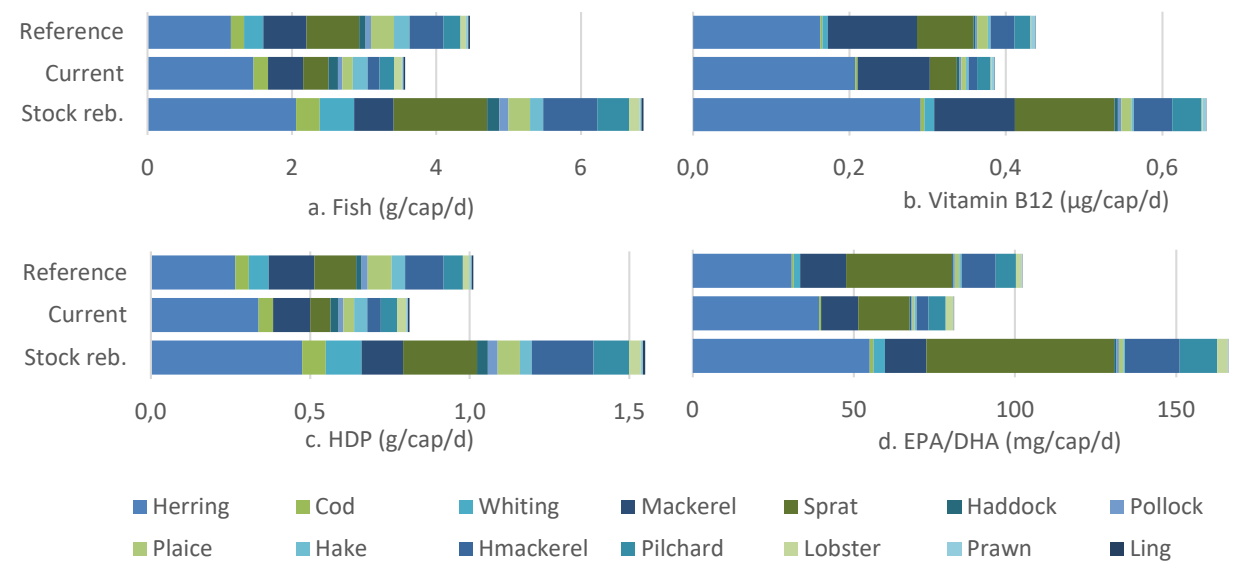

Figure 3 Contribution of food-grade fisheries species to the supply of (a) fish, (b) human digestible protein (HDP), (c) vitamin B12 and (d) EPA+DHA in the reference, current fisheries and stock rebuilding scenarios.

\section{$\underline{\text { Farmed fish }}$}

Salmon farming, the only included production system with a high EPA/DHA output, was selected to fulfil the majority (58\%) of the DRI for EPA/DHA. As salmon require a protein dense, EPA/DHA containing feed, they received all available high protein animal by-products (Figure 4) and their diets comprised mainly of fish based ingredients (Appendix B5; Figure B5). Contrastingly, tilapia received all available bone meal, which has a lower protein quality (Figure 4), and their diets consisted mainly of cereal and oilseed products (Figure B5$_{5}$ ).

\section{Optimal use of LCF}

Optimal conversion of LCF requires 442 million farmed salmon (2.2 Mt harvested fish), 1 billion b.

tilapia (0.4 Mt harvested fish), 52 million low-productive pigs and 30 million low-productive dairy cows, but no poultry or beef cattle. The selected animal production systems used all available food leftovers (by-products and FFS), while leaving part of the natural grassland (47\%) and shrubland (82\%) unused (Figure 4). Fish diets contained the majority of the animal-based LCF, whereas 
livestock diets contained the majority of the plant-based LCF. Pig diets consisted mainly of cereal and oilseed by-products (Figure B5), but their low productivity and intake of some animal fat enabled them to upcycle some bulky LCF, such as pulp and roughage (Figure 4). The diet of dairy cattle included as much grass as possible and was supplemented with plant-based food leftovers (Figure 4). High quality grass resources were fed to dairy cows and young stock, while bulls only grazed natural grass and shrubs, to maximum the intake of this low quality feed (Figure $\mathrm{B}_{5}$ ). These roles of livestock are in line with findings of van Hal et al. (2019)

\subsection{Excluding nutrient constraints}

Results were hardly affected when excluding the constraint to meet human vitamin B12 and EPA+DHA requirements. The No NC scenario resulted in a protein supply of $36 \mathrm{~g} / \mathrm{cap} / \mathrm{d}$ (0.5 g higher than in reference), and fulfilled 99\% of DRI of EPA+DHA and 136\% of DRI of vitamin B12. These results indicate that only EPA/DHA requirements constrained protein supply in the reference scenario, and that this restriction had only limited effect on protein supply. The effect on the number of farm animals selected to produce this protein, however, was larger. Compared to the reference scenario, the number of salmon reduced with $4 \%$, tilapia with $19 \%$, pigs with $21 \%$, whereas cattle numbers increased with $4 \%$ (Figure B8 - No NC).

\subsection{Alternative fisheries scenarios}

On the one hand, current fisheries practice resulted in lower direct protein supply than the reference scenario (-0.2 g/cap/d), as their higher landings (+o.1 g/cap/d) did not compensate for the loss in food supply due to the current use of edible fish as animal feed (-o.3 g/cap/d; Figure 3 current fisheries). On the other hand, the use of edible fish as feed under current fisheries practices, enabled higher salmon production(+16\% 511 million, 2.6 Mt of harvested live fish) and tilapia production ( $+48 \% 0.5$ billion, $0.2 \mathrm{Mt}$ harvested live fish) compared to the reference scenario (Figures B7b \& B8). Besides the extra fisheries by-products, this farmed fish required high quality protein, which was attained from pig by-products. The increased demand for these pig by-products drove the selection of pigs (+2\%) over dairy cattle (-1\%) who's by-products are banned as feed for all production animals in the EU (Figure B8). Total animal protein supply was $0.1 \mathrm{~g} / \mathrm{cap} / \mathrm{d}$ lower for current fisheries than in our reference scenario (Figures B7a). 


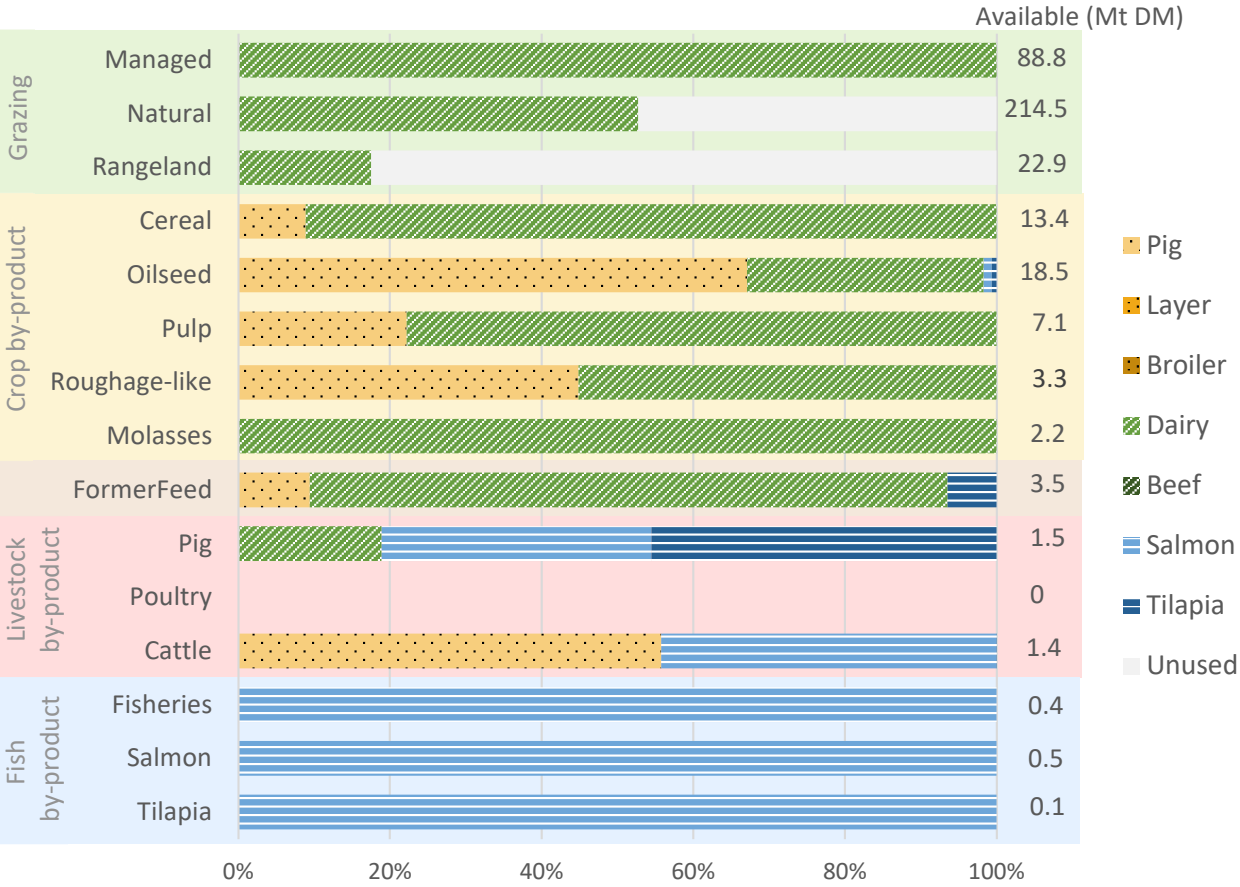

Figure 4 Allocation of available LCF (classified based on their origin) over the included animal production systems as \% of available LCF. Absolute mass allocation is provided in Figure B6 to whom we refer for a thorough discussion of the role of livestock species and productivity.

Stock rebuilding (MSY 0.8; Froese et al. (2018)) increased direct ASF supply with about 50\% to 6.9 g/cap/d (Figure 3 - Stock rebuilding). We observed a similar increase in protein and vitamin B12 supply, while the increase in EPA/DHA supply was larger ( $65 \%)$, because landings of species rich in these fatty acids (i.e. herring and sprat) increased most. Stock rebuilding not only increased the direct supply of EPA/DHA from fisheries, but also increased the availability of EPA/DHA containing fish by-products. These high quality fish by-products were allocated to farmed salmon, enabling them to value more oilseed meal and increase their production with $21 \%$ to 536 million animals and 2.7 Mt harvested fish (Figures B8 \& B9b). Pig and tilapia production both reduced with 9\% (Figure B8) which freed up food leftovers for dairy production, enabling them to value more natural grass biomass (Figure B9b) and increase cattle numbers with 1\% (Figure B8). All in all, reducing the fishing pressure increased the total supply of animal protein with $2 \%$ to $36 \mathrm{~g} / \mathrm{cap} / \mathrm{d}$, while the supply of EPA/DHA increased beyond DRI to $350 \mathrm{mg} / \mathrm{cap} / \mathrm{d}$ (Figure B7). When excluding fisheries, no feasible solutions were found as human EPA/DHA requirement could not be met. 


\section{Discussion}

We demonstrate that under the circular paradigm, fish provide nutritious ASF through sustainable capture fisheries and farmed fish fed with LCF. The assumed sustainable fisheries provide about $25 \%$ more HDP than current fisheries do. To achieve this increase in protein supply, we should prioritise using edible fish for human consumption, which also compensates for the temporary reduction in landings needed to adhere to MSY. To prioritise edible fish for human consumption, we should overcome practical limitations that currently cause rendering of whole food-grade fish into feed. We might want to stimulate seasonal consumption and preservation of, for example, sardines and herring, to overcome the seasonality and perishability of their landings (Ganias, 2014). Similarly, we could stimulate the consumption of low value food-grade fish like blue whiting (Cashion et al., 2017).

Besides avoiding feed-food competition, capture fisheries should rebuild impaired fish stocks (Froese et al., 2018). Fisheries landings were therefore reduced to MSY, which reflects the production capacity of the fish stocks in our waterbodies. We however underestimated food supply by EU capture fisheries by only considering MSY landings of the most relevant stocks and species in the Northeast Atlantic, which currently provide $75 \%$ of EU fisheries landings. This underestimation, however, is limited as the majority of stocks in the excluded Black and Mediterranean seas are severely impaired and require severe yield reductions to adhere to MSY (Froese et al., 2018). The MSY assumed in EU legislation and our reference scenario, however, are only a first step to rebuilding impaired fish stocks, and fishing pressure should be further reduced (EU, 2013b; Froese et al., 2018; Thorpe et al., 2017). In our Stock rebuilding scenario, we found that, in the long run, such reduced pressure can increase direct fish supply with 53\% (Figure 3). Part of this observed increase may, however, be due to methodological differences underlying the MSY estimations in our reference (ICES, 2016) and Stock rebuilding (Froese et al., 2018) scenario. Nevertheless, reducing fisheries pressure appears essential to rebuild impaired fish stocks and, therefore, for feeding our growing population in the future.

To maximise food supply from natural waterbodies, we should also explore consumption of alternative aquatic foods not yet included in our analysis (SAPEA, 2017). Consuming food from lower trophic levels, such as seaweed, filter feeders and herbivorous finfish, is always beneficial as nutrients are lost between trophic levels. Globally, current captured seafood, for example, only contains about $0.04 \%$ of the EPA/DHA produced by primary aquatic producers (zooplankton and phytoplankton) (Hamilton et al., 2020). The potential of tapping into low trophic levels in natural 
aquatic ecosystems by balanced harvesting, however, is uncertain (Duarte et al., 2009; Zhou et al., 2019).

In line with previous indications, we found that sustainable fisheries alone cannot fulfil our human demands for EPA/DHA (Hamilton et al., 2020; Sprague et al., 2016). To meet these requirements, we additionally need to farm fatty fish. In our analysis, for example, about $60 \%$ of the daily recommended intake of EPA/DHA was provided by farmed salmon (Figure 2). To produce EPA/DHA rich ASF, however, farmed salmon requires EPA/DHA containing feed commonly achieved by including fish by-products (Hamilton et al., 2020; Sprague et al., 2016). Of the fish byproducts allocated to salmon farming, $40 \%$ originated from fisheries, $9 \%$ from tilapia and $51 \%$ from salmon farming (Figure 4). While current legislation bans feeding farmed salmon with meal of other farmed salmon (EU, 2013a), we allowed this in our model as our salmon farming system represents a wide range of fish species with similar properties, such as rainbow trout and seabass. Given the large share of salmon by-products in the salmon diet, we conclude that such a diversity of species, able to recycle each other's by-products, is essential for efficient use of EPA/DHA in a circular food system.

Our results also confirm that fish farming, and thereby the supply of EPA/DHA to humans, depend on capture fisheries (Hamilton et al., 2020; Sprague et al., 2016). This dependency is illustrated by the fact that salmon could not be produced if fisheries were excluded from the model (model infeasible), and their increased production with increasing availability of fisheries by-products (Figures B7b \& B8). To fulfil the growing demand for EPA/DHA by our future population, four main solution pathways have been suggested (Hamilton et al., 2020; SAPEA, 2017; Sprague et al., 2016). First, precision feeding, which implies feeding relatively much ALA to young fish that are best adapted to elongate ALA into EPA/DHA (Bell \& Koppe, 2010), while keeping EPA/DHA rich ingredients to feed fish at harvesting stages where they are upcycled into the ASF most efficiently (Bell et al., 2003; Codabaccus et al., 2013). Second, farming fish species that are better able to convert ALA into EPA/DHA, such as rainbow trout (Oncorhynchus mykiss) (Mente et al., 2019) and other freshwater species (Rodrigues et al., 2017). Third, in-vitro production of EPA/DHA by micro algae for both feed and food, an industry that is still in its infancy (Peltomaa et al., 2018; Vigani et al., 2015). Fourth, reconsidering human consumption of fish oil from industrial grade fish or fish by-products, which is far more efficient than feeding it to salmon, but hampered by food quality issues (Hamilton et al., 2020; Jackson \& Newton, 2016). 
Besides EPA/DHA rich ingredients, farmed fish, especially salmon, require high quality protein to meet requirement within their feed intake capacity. When limited to LCF, fish feeds can only reach such high protein content by including a large share of processed animal proteins (PAPs, e.g. fish, blood, bone and meat and bone meal; Figure 4). The farmed fish in our model require such highquality proteins because they are highly productive. Like low-productive livestock (Figure B5; pigs and dairy), fish with a lower productivity might be better able to value lower quality LCF. Unlike livestock, however, fish are generally forced to reduce their feed intake when provided with low quality feeds as their digestion requires additional oxygen, which is often limitedly available in aquatic environments (Saravanan et al., 2013). This reduced feed intake, in combination with lower nutrient contents in LCF reduces growth rate, which increases the relative share of feed required for maintenance. This relative increase is however lower for poikilothermic fish than homothermic livestock (Fry et al., 2018). While such low productive fish can value more LCF, their increased excretion of non-digestible nutrients can cause practical problems. For salmon in sea cages increased excretion of non-digestible nutrients might cause addition eutrophication and environmental degradation of their surroundings (Nordvarg \& Johansson, 2002; Qi et al., 2019). For Tilapia housed in tanks an increased excretion of non-digestible nutrients might cause adverse health effects (Austin, 1998), where for tilapia in pond ecosystems such non-digestible nutrients can feed the pond ecosystem thereby increasing the amount of natural food for fish (Kabir et al., 2019). In its current form tilapia pond systems are, however, unsuitable for Europe's temperate climate.

In summary, high-productive fish that require animal-based LCF are likely most suitable to a circular EU food system. These farmed fish have a valuable role in upcycling livestock PAPs, as they are the only farm animals allowed to eat them currently (EU, 2013a). Livestock, however, appears more suitable to upcycle most plant-based LCF, especially those of low nutritional quality, but full understanding of the potential of farmed fish requires that we consider a broader range of fish species. Here we found that livestock provide the majority of all considered essential nutrients, except vitamin D and EPA/DHA, as dairy upcycled grass resources and pigs plant-based food leftovers. Low productivity enabled this livestock to consume low quality LCF, but supplementation with high quality LCF was needed to upcycle as much low quality LCF as possible. Livestock thus competes for such high quality LCF with the farmed fish needed to meet EPA/DHA requirement. Animal-based LCF, however, were consistently allocated to farmed fish, even when relaxing the EPA/DHA requirement constraint (Figure B9; Excl. NRC). 
In practice, use of livestock PAPs as aquafeed is limited in the EU due to country level legislation and industry concerns about consumer acceptance (IUCN, 2017). Using livestock PAPS in fish feeds, increases overall resource efficiency, as this frees high quality plant-based LCF for livestock. This strategy is also highly relevant in our current food system where much more animals and thus by-products are produced. The EU relegalised feeding of livestock PAPs as aquaculture feed in 2013, to enable efficient use of these nutritious by-products within the food system (EU, 2013a). Currently, the EU is exploring further amendments to the food safety legislations implemented to avoid future outbreaks of transmittable diseases (EU, 2009, 2018). While these legislations specifically target avoiding transmission of diseases between animals and to humans, they also hinder the efficient use of LCF that are potentially contaminated with such PAPs considering most food waste (EU, 2009, 2018). To stimulate legalisation of PAPs and food waste as animal feed, future research should clearly demonstrate their potential as well as the risks of feeding them to livestock and farmed fish.

Our findings show that a circular food system requires a combination of co-dependent animal production systems (e.g. fish farming requires capture fisheries and livestock by-products) to achieve balanced healthy diets with respect for our planet. Efficient use of available LCF requires a combination of animals that collectively have a high production efficiency, and are best able to upcycle specific feeds and/or supply essential nutrients. Selected animals are, thus, tailored to the available LCF and the desired nutrient supply to the human population, to which we made assumptions in the current study that should be considered when interpreting our findings. Here, we based availability of plant-based LCF on current consumption and focused only on nutrients typically obtained from ASF, while in a circular food system integrated crop and animal production should optimise the use available land to meet all population nutrient requirements within our environmental ceilings. Finally, to explore the full potential of fish in a circular food system, we considered only its biophysical components. Considering also societal and or economic aspects is relevant to design of a realistic future circular food system and stimulate the transition towards it. While predicted nutrient supply and animal numbers are only indicative of their potential, we are convinced that we deduced valuable principles for the use of fish in a circular food system. Given these principles, farmed fish have a large potential to upcycle LCF, as they appear relatively efficient, are essential in utilizing livestock PAPs and have the ability to upcycle EPA+DHA into their food outputs. 


\section{Conclusion}

Our findings clearly show that capture fisheries as well as fish farming play an important role in a circular food system. Capture fisheries should increase their contribution to the food supply by prioritizing edible fish for human consumption and by rebuilding fish stocks. EU fisheries alone, however, are not enough to meet population requirements for the essential $\omega-3$ fatty acids EPA and DHA. To meet these requirements, we need to additionally farm a variety of fatty fish species rich. These fish currently depend on fisheries to fulfil their EPA/DHA demand. Furthermore, when fed only with LCF these fish can only meet their high protein requirements by feeding on livestock byproducts, uncommon in EU fish farming, but essential to the efficient use of resources. We conclude that a circular food system requires a combination of animal production systems tailored to the available LCF and desired nutrient supply to the human population and fish is essential in a healthy and environmentally-friendly diet.

\section{Data availability}

The authors declare that the data supporting the findings of this study are either provided in within the article and its supplementary material, or come from public databases traceable with the references provided.

\section{Acknowledgments}

The authors thank Arjen Roem, Trygve Berg Lea and Liv Håland (Skretting), Neil Auchterlonie (IFFO), Karel van der Velden (Nijssen Granico), Kees van Gorp (VIDO), Anton van den Brink (EFFPA), Karen Luyckx (FeedBack), Louisa Borthwick (RISE) for valuable contributions to this research. This project received funding from the European Union's Horizon 2020 research and innovation program under grant agreement No 633692. The views expressed in this publication are the sole responsibility of the authors and do not necessarily reflect the views of the European Commission. 


\section{Chapter 4}

\section{Feeding food leftovers to farm animals:}

\section{the potential of improved use and legalisation}

Ollie van Hal, Hannah H.E. van Zanten and Imke J.M. de Boer

Animal Production Systems group, Wageningen University \& Research, PO Box 338, 6700 AH Wageningen, the Netherlands 


\begin{abstract}
Recent studies show that animals can contribute to a circular food system by upcycling lowopportunity-cost feeds (LCF) - products unsuitable for human consumption such as grass and food leftovers - into valuable animal-source food (ASF). Variation in the estimated amount of ASF such animals provide is to a large extent due to differences in the assumed availability and quality of LCF. The availability of food leftovers as LCF is currently restricted by legislation and other barriers. So far, no study has comprehensively analysed the ASF supply potential of enhancing the availability of food leftovers as LCF. Here we use a circular food system approach to model ASF supply potential of improved use and/or legalisation of food leftovers as LCF, when feeding animals only with LCF in an EU-28 case study. Our results showed that, of the considered food leftovers, household waste and livestock by-products have most potential to increase animal protein supply. Optimal use of currently used LCF (given their assumed availability) provides an intake of $27 \mathrm{~g}$ animal protein per capita per day. Reintroducing household swill can increase this intake with $12 \%$, while using livestock by-products is fish feeds increases protein intake with $18 \%$, and is essential to meet human requirements of EPA/DHA $\omega-3$ fatty acids. Feeding swill, however, requires legislative change, and feed quality and safety remain difficult to safeguard even with the development of a collection and processing system. In contrast, livestock by-products are allowed in fish feed, but currently not used indicating other barriers to the transition towards a circular food system. We conclude that improved use and legalisation of inevitable food leftover can improve the resource use efficiency of both current and future circular food systems. Efficient use of available LCF requires a combination of animals tailored to the available LCF and the desired nutrients for human consumption.
\end{abstract}




\section{Introduction}

To feed our growing world population with limited natural resources, scientists and politicians recommend a transition to a more circular food system (EuropeanCommission, 2015; Jurgilevich et al., 2016; Springmann et al., 2018). A circular food system prioritises efficient use of natural resources to provide nutrition security for all humans (van Zanten et al., 2019). This implies that the limited land and water surfaces available for food production should, where possible, be used to provide food directly through food crop cultivation and sustainable fisheries (van Hal et al., 2020). Currently, however, a large share of these resources is used to produce animal feed which is less efficient due to animal metabolic losses (Foley et al., 2011; Godfray et al., 2010). While current animal production systems are major pollutants to the environment, animals fed only with biomass unsuitable or undesired for human consumption can contribute to food security while lowering the pressure on nature resources use (van Zanten et al., 2019). The role of farm animals in a circular food system, therefore, is to upcycle such biomass, referred to as low-opportunity-cost feeds (LCF), into valuable animal-source food (ASF) (de Boer \& van Ittersum, 2018). LCF include grass resources and biomass lost along the food supply chain, so called food leftovers (Foley et al., 2011; Garnett, 2011; van Zanten et al., 2018). Food leftovers include crop residues (unharvested crop biomass), by-products (unintended outputs of crop processing) and food waste (products intended for human consumption but wasted along the supply chain) (FAO, 2011). As a circular food system assumes that the majority of the crop residue is left on the field to maintain soil fertility, "food leftovers" from now on refer to by-products and waste only (de Boer \& van Ittersum, 2018).

A recent review of van Zanten et al. (2018) indicated that livestock fed only LCF can provide 7-30 g human digestible protein (HDP) per capita per day. Variation in HDP between these studies mainly results from difference in assumed LCF availability and which animals upcycle them. Most of the reviewed studies used a scenario approach and assigned available LCF to specific animal production systems (APS), while to make most of available LCF their use should be optimised. Using an optimisation model (van Hal et al., 2019, 2020) illustrated that optimal use of LCF requires various livestock and farmed fish species, each especially adapted to upcycle specific LCF (i.e. cattle valuing grass) and/or supply specific nutrients to humans (i.e. EPA/DHA fatty acid supply by fish). This model, that considers nutritional quality of LCF, can also be used to explore the potential of food leftovers that are currently not used as animal feed, to facilitate the debate on what food leftovers should be considered LCF.

While feeding animals is the most efficient use of food leftovers from a food systems perspective, this use is often limited by legal or practical restrictions (Papargyropoulou et al., 2014). Current 
legislation allows feeding plant-based leftovers such as by-products and industrial waste as well as animal fats, such as tallow and fish oil (EU, 2017). Feeding animal proteins, however, is strictly regulated to avoid spread of transmittable diseases, such as bovine spongiform encephalopathy (BSE), through contaminated feed (EU, 2009, 2013a). While this legislation primarily limits feeding processed animal protein (PAPs) - the main transmitter of these diseases - it also applies to food wastes potentially contaminated with animal protein (EU, 2017, 2018). Due to its rigidity, this legislation is criticised for hindering resource use efficiency (zu Ermgassen et al., 2016). In response, the EU is exploring legislative change to facilitate a safe use of PAPs and food waste as animal feed, starting with the legalisation of livestock PAPs in fish feeds (EU, 2013a). Regardless of this legalisation in 2013, livestock PAPs are still barely used in fish feeds, indicating that not only legal but other barriers related to society, politics, economy and technology, may restrict the use of food leftovers as LCF (BioMar, 2018; IUCN, 2017). This is also the case for retailing waste for which the use as LCF appears limited due to a lack of economic incentive to collect these wastes (Truong et al., 2019).

To stimulate a transition towards a circular food system as aimed by the EU it is essential to assess the potential of feeding unused LCF streams to farm animals in terms of protein supply (Priefer et al., 2016). To our knowledge, no study has coherently assessed the potential of enhancing the availability of food leftovers as LCF. Here we assess the ASF supply potential of improved use and/or relegalisation of food leftovers as LCF in a circular food system (i.e. animals are fed only with LCF) using the EU-28 as a case study. To this aim we compared the optimal use of currently used LCF with various scenarios that add food leftovers currently banned or not fully recovered as feed. Exploring which food leftovers can be used as LCF not only extends potential animal production in circular food system but is also relevant in our current food system to reduce dependency on externally sourced feeds, as is needed to develop appropriate policies.

\section{Methods}

We assessed how much additional ASF could be supplied by improved use and/or legalisation of food leftovers as LCF in a circular food system, using an optimisation model developed by van Hal et al. (2019, 2020). This model allocates available LCF to that combination of farmed animals that maximise human digestible protein (HDP) supply, while meeting human requirements of nutrients currently only obtained from ASF. The model, thereby, predicts which animals we should keep and which of the available LCF we should feed them to produce as much HDP as possible, while also meeting daily requirements of vitamin B12 and of the essential $\Omega 3$ fatty acids EPA and DHA. We 
prioritised meeting requirements of these nutrients - currently under consumed by much of the EU population - as their supply is the most valuable food function of animals (van Hal et al., 2020) especially under the current abundance of protein (de Smet, 2012; Duru, 2019; FAO, 2017c; Givens \& Gibbs, 2008; Oh \& Brown, 2003).

We first describe the general structure of the model (Section 2.1) and the included animal production systems (Section 2.2). To assess their ASF supply potential we applied this model to various scenarios of improved use and/or legalisation. Section 2.3 describes these scenarios and their assumed availability of LCF. While this study focusses on the ASF supply potential of increasing the availability of LCF for farmed animals, ASF can also be obtained from nature (hunting/ranging/fisheries). To provide a complete picture on ASF supply in an EU circular food system, we included edible fish obtained though sustainable fisheries (Appendix B1; Table B1), but excluded ASF supply from terrestrial wild animals which is currently negligible in the EU (FAO, 2017a). For sustainable fisheries we assumed landings to be limited to the Maximum Sustainable Yield (MSY) and all edible fish to be used for human consumption (van Hal et al, 2020).

\subsection{General model structure}

The used optimisation model (van Hal et al., 2019) has the standard form of a linear programming model:

$\begin{array}{ll}\text { Maximise } & Z=\boldsymbol{c} \boldsymbol{x} \\ \text { Subject to } & \boldsymbol{A x} \geq \boldsymbol{b} \\ \text { and } & \boldsymbol{x} \geq O\end{array}$

where $\boldsymbol{x}$ is a vector of animal production activities; $\boldsymbol{c}$ is a vector of HDP produced per unit of activity; $\boldsymbol{A}$ is a matrix of technical coefficients; and $\boldsymbol{b}$ is a vector with quantitative constraints. The objective function to maximise HDP output ( $Z$ ) is restricted by the availability of each LCF, their nutritional value for each animal production system, and the nutritional requirements and limitations of the animals in each production system. Additional "nutrient constraints" ensure that daily human requirement of vitamin B12 (4 $\mu \mathrm{g}$ ) and EPA/DHA (250 mg)(EFSA, 2017), currently only obtained from ASF are fulfilled (de Smet, 2012). When unable to meet one of these nutrient constraints (model infeasible), we lower it to the maximum attainable supply of that nutrient, given the available LCF.

\subsection{Animal production systems}

The model includes the five most prevailing livestock production systems the EU, i.e. pig, laying hen, broiler, dairy and beef production (FAO, 2017d), and two fish farming systems with contrasting feeding habits. Atlantic salmon (Salmo salar), the most prevailing farmed fish in the 
EU (EUROSTAT, 2019), represents high-trophic carnivorous species that require animal protein in their feed. Nile tilapia (Oreochromis niloticus), the most consumed low trophic farmed fish in EU (FAO, 2018b) was selected in the absence of commercial farming of such species in the EU (Sprague et al., 2016). Fatty fish like salmon are rich in EPA/DHA while contents in Tilapia are much lower (Sprague et al., 2016).

The model includes the entire life cycle of these animal systems. For livestock, young and parent stock (e.g. sows, gilts and piglets) needed relative to a producing animal (e.g. fattening pig) (Appendix A3, Table A6) was based on European herd compositions (FAO, 2016a, 2016c). For farmed fish this was based on species specific mortality (Bhujel, 2014; EY, 2017; McGeachy et al., 1995) and fertility data (Eskelinen, 1989; FAO, 2018a; TIL-AQUA, 2016), assuming mortality occurs evenly across life phases (Appendix B3; Table B5). For livestock the model included three productivity levels (low, mid and high), where productivity was expressed in annual milk/egg production or average daily gain. High productivity reflects intensive production using Dutch production averages as a proxy (Bos et al., 2013), low productivity reflects extensive systems throughout Europe, and mid productivity is situated in between. Fish farming included only high productivity which reflects common practice in the EU. Fish performance was defined by first simulating optimal growth and feed intake using Skrettings AquaSim model, which was then calibrated to values commonly found in practice using literature. Production performances and related nutrient requirement for each animal production system were adopted from van Hal et al. (2019) for livestock (Table 1 of Chapter 2) and van Hal et al. (2020) for farmed fish (Table 1 of Chapter 3).

Supply of ASF and nutrients by the animal production systems selected for optimal use of LCF is expressed per EU capita per day (cap/d). Supply of edible meat/fish (kg cooked product) and offal by farmed livestock and fish was calculated by multiplying their predicted live weight (LW) output with species specific slaughter yields (Appendix B2; Tables B2 \& B3) and cooking retentions (USDA, 2012). Supply of milk and eggs (kg fresh product) was equal to the predicted output of the production systems. To provide a complete picture on ASF supply in an EU circular food system, we included fish supply from sustainable captured fisheries. This direct fish supply (kg cooked fish) was calculated by multiplying sustainable fisheries landings (Appendix B1; Table B1) with species specific slaughter yields (Appendix B2; Table B2) and cooking retentions (USDA, 2012).

Total ASF supply was translated into ASF intake by multiplying it with product specific waste coefficients for processing, retail and consumption in the EU (Caldeira et al., 2019). Depending on 
the scenario, the wasted animal product may be provided as LCF as described in Section 2.3. Nutrient intake (HDP, vitamin B12 and EPA/DHA) was calculated by multiplying the intake of each ASF with product specific nutrient contents (Appendix B4; Table B8). Nutrient content of cooked meat reflects the weighted average nutrient content of all cuts, and variation in protein content related to productivity (Figure B4) was based on literature (van Hal et al., 2019). Finally, to compare nutrient intake from ASF (/cap/day) with the nutrient specific daily recommended intake (DRI) (EFSA, 2017).

\subsection{Availability of LCF}

Here we included grass resources and food leftovers as LCF. Availability of grass resources was derived from van Hal et al. (2019), and included three vegetation types: managed grassland, natural grassland and rangeland (Appendix A2, Figure A2). Managed grassland, while suitable for food crop production, was included to avoid release of carbon and loss of biodiversity and cultural value when converting grassland into cropland (Foley et al., 2011; Gerber et al., 2013). We assumed grass resources can only be valued by ruminants in the country of origin.

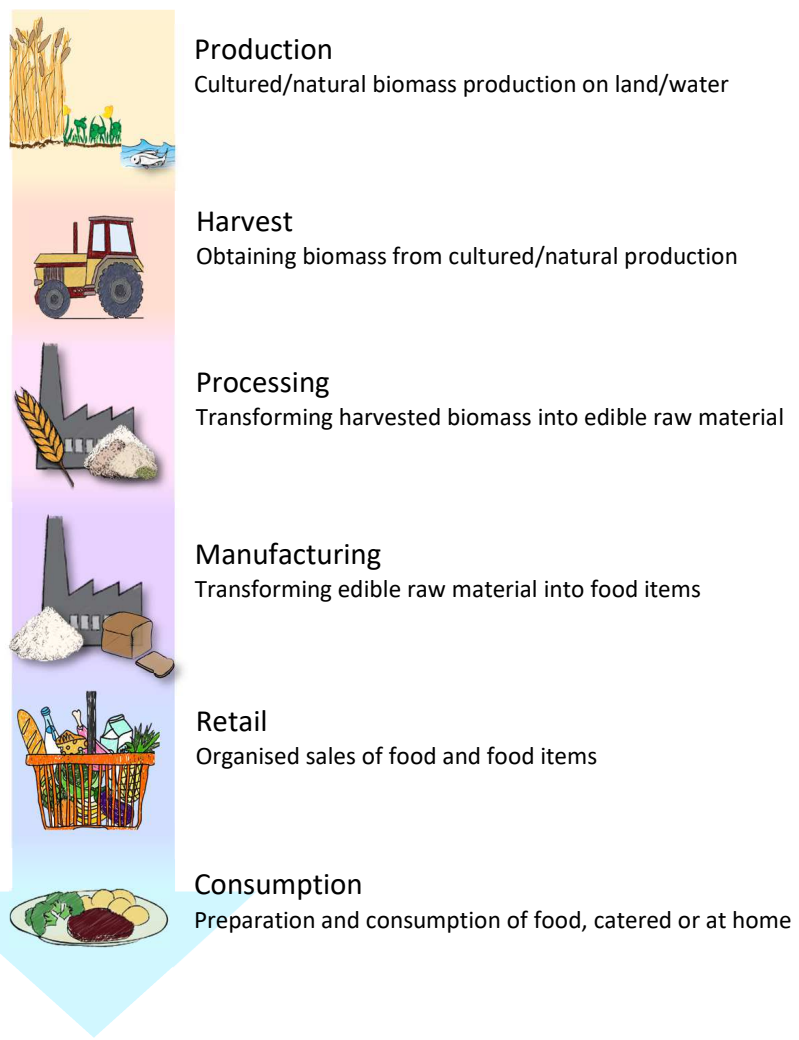

Figure 1 the food supply chain, its stages and their definitions 
To assess the availability of food leftovers as LCF, we used the food supply chain as illustrated in Figure 1. This chain ranges from the production of biomass in cultured systems (e.g. crop cultivation or animal farming) or natural systems (e.g. fish in nature), to human consumption, via harvesting, processing, manufacturing and retail. In this section we move along the chain to explore where biomass is lost and which of these leftovers are already used as feed, or could be made available as LCF through improved use (biomass allowed as feed but not fed in practice) and legalisation (biomass banned as feed) (Table 1). Based on this exploration we defined our reference scenario (o), which reflects the current use of food leftovers as LCF. Additionally we developed 7 scenarios that, moving along the supply chain, additively include first food leftovers that can be used as LCF under current legislation, followed by those that require legislative change. This implies we add the LCF made available in each scenario, to those available in the reference scenario, and the previous scenarios (Table 2). To assess the ASF supply potential of the LCF added in each scenario, we compared its results to those of the previous scenario. We chose this approach for two reasons. First it enables us to clearly illustrate the potential of using a certain food leftover stream as LCF. Second, the order of inclusion reflects the common view that feed safety is easiest to guarantee in the early industrial stages of the supply chain (Luyckx et al., 2019). Even though losses occur in each stage of the supply chain, we excluded the production and harvesting stages, as much of the biomass lost in these stages should be returned to the soil in circular food system to maintain/improve soil health which is the fundament of our food system (de Boer \& van Ittersum, 2018; van Hal et al., 2019). Furthermore, we differentiate between food processing and food manufacturing, as they are separated in practice and result in different leftovers.

\section{Processing leftovers}

Food leftovers from processing - transforming harvested crude material (e.g. wheat grain) into edible raw material or food (e.g. wheat flour) - consider by-products (e.g. wheat bran) and waste (e.g. spilled grain or flour). By-products from crop and fish processing are already fully used as animal feed (Vernier et al., 2016) and were, therefore, all assumed available in the reference scenario (o). The availability of crop by-products as LCF (Appendix A2; Figure A2) was derived from van Hal et al. (2019). The availability of fisheries by-products was derived from (van Hal et al., 2020) that applied species specific rendering fractions (output of fish oil and meal) to the inedible part of the landings, quantified using the species specific slaughter yield (Appendix B1; Tables B1 \& B2). Similarly, the availability of LCF from farmed fish was calculated by multiplying the inedible fraction of the predicted LW output of each species, with rendering fractions for oil and meal (Table B2). Note that fish meal may not be fed to ruminants due to below described legislation. 
Feeding of livestock processing by-products is restricted by EU legislation (Appendix C1) as well as other barriers. The relevant EU legislation restricts the use of PAPs as feed for food producing animals. This legislation (Table $\mathrm{C} 1$ ) focuses on PAPs from bodily tissues that are the main transmitter of diseases like BSE and foot and mouth disease (EU, 2009, 2013a). Animal fats, egg and dairy products are, thereby, excluded from this legislation and can be used as animal feed under feed-safety regulations. PAPs cannot be fed to ruminants as this practice is the suspected origin of BSE. Monogastric livestock, in contrast, are allowed to consume fish meal, hydrolysed feather meal and hydrolysed blood components, as long as they do not originate from ruminants or their own species (EU, 2009). Since a 2013 amendment, farmed fish are allowed to feed on all PAPs of nonruminant origin (EU, 2013a).

Table 1 Extent to which food leftovers from each stage of the supply chain are used as LCF currently (reference scenario o), or coould be made available under improved use and/or legalisation (scenario 1-7), and an overview of the added LCF per scenario.

\begin{tabular}{|c|c|c|c|c|c|}
\hline Stage & Food losses & 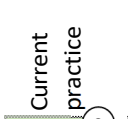 & 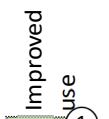 & 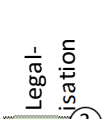 & Scenario overview \\
\hline \multirow[t]{4}{*}{ Processing } & Crop by-product & Fully (0) & Fully & Fully & Currently used LCF \\
\hline & Fish by-product & Fully & Fully & Fully & \multirow{2}{*}{ + lives tock PAPS to fish } \\
\hline & Livestock fat & Fully & Fully & Fully & \\
\hline & Livestock protein & Poorly & Partly* & Mostly* & + livestock PAPS to livestock \\
\hline \multirow[t]{2}{*}{ Manufacturing } & Plant-based waste & Partly & Fully & Fully & + additional plant-based waste \\
\hline & Contaminated ${ }^{a}$ waste & Not & Not & Fully & + potentially contaminated ${ }^{a}$ waste 4 \\
\hline \multirow[t]{2}{*}{ Retail } & \multirow{2}{*}{$\begin{array}{l}\text { Plant-based waste } \\
\text { Animal-based waste }\end{array}$} & Partly & Fully & \multirow{2}{*}{$\begin{array}{l}\text { Fully } \\
\text { Fully }\end{array}$} & + plant-based waste \\
\hline & & Not & Not & & + animal-based waste \\
\hline Consumption & Mixed household waste & Not & Not & Fully*7) & + all mixed household waste \\
\hline \multicolumn{6}{|c|}{$\overline{{ }^{(0)} \text { Reference scenario with currently recovered foodlosses }}$} \\
\hline \multicolumn{6}{|c|}{${ }^{(1-7)}$ Scenarios of improved recovery and legalization following their inclusion order } \\
\hline \multicolumn{6}{|c|}{ * Based on current and improved legislation for different production animals (Table C1) } \\
\hline \multicolumn{6}{|c|}{ ** Processed mixed household waste (swill) can be provided as wet or dry feed } \\
\hline \multicolumn{6}{|c|}{ a contaminated with animal proteins } \\
\hline
\end{tabular}

Currently, all animal by-products allowed by these legislations are used as feed (FEFAC, 2019), with the exception that the fish farming industry avoids using livestock PAPs (IUCN, 2017), as reflected in the reference scenario (o; Table 1). The use of livestock PAPs in fish farming is avoided due to social and technical barriers, such as concerns regarding consumer acceptance, especially of pescatarians, that might not want their fish to be fed with the livestock they avoid eating. We assess the potential of overcoming these barriers in the improved use of processing LCF scenario (1) that reflects what is achievable within current legislation if all LCF were used in the most efficient way. 
With the 2013 amendment, the EU showed a willingness to explore legislative change to aid and stimulate efficient use of resources in the food system (EU, 2013a). In the legalisation of processing LCF scenario (2) we assess the ASF supply potential of possible future legislation amendments (Table $\mathrm{C} 1$ ). We based the assumed amendments on the ongoing debate, where feeding of PAPs to ruminants and feeding organs of the nerve system to any food producing animal are argued to pose too much risk to public health and thus shall remain prohibited (EU, 2009). Feeding PAPs, including those of ruminants, to monogastric livestock and farmed fish, are considered more likely to be legalised and, therefore, assumed available as LCF in this scenario. The availability of livestock by-products in each scenario was calculated by multiplying the predicted LW output of each livestock system, with slaughter and cutting fractions per kg LW (Table C8). For pigs and cattle, these fractions were derived from slaughter reports (USDA, 2018b, 2018c), whereas for poultry they were derived from literature (Haslinger et al., 2007; Sams, 2010).

\section{Manufacturing leftovers}

Food leftovers from manufacturing - transforming edible raw material (e.g. wheat flour) into (combined) food items (e.g. bread) - consider wasted ingredients, food items and intermediaries (e.g. dough). Legislation specifies these wastes may be used as feed as long as they fulfil food quality standards and are not contaminated with animal proteins besides dairy or egg (EU, 2018). In Europe, much of the waste produced in industrial manufacturing is collected by specified companies, so called former foodstuff (FFS) processors (EFFPA, 2019). These companies facilitate separated collection by food manufacturers, were safe crop, egg and dairy wastes are processed into feed ingredients and spoiled or contaminated wastes are digested anaerobically to produce energy (VIDO, 2019). Currently, as reflected in the reference scenario (o), about $5 \mathrm{Mt}$ of FFS are recovered as LCF per year. We based the composition of these plant-based FFS on the average of composition in the United Kingdom (UKFFPA, 2019), the Netherlands (VIDO, 2019) and France (Vernier et al., 2016) (Figure C1). Processing of these FFS results in the availability of feed ingredients, as illustrated in Table C2.

Processors of FFS have joined forces in an association to improve the use of FFS as feed, and estimate that they could each year recover an additional 2 Mt (EFFPA, 2019). We assumed these additional FFS had a similar composition as those currently fed in the improved use of manufacturing LCF scenario (3). In the legalisation of manufacturing LCF scenario (4) we added available plant-based FFS that are possibly contaminated with PAPs. We assumed these additional FFS consisted of cereal-based FFS only, of which in total 7.4 Mt fresh matter is wasted per year (Caldeira et al., 2019). The composition of these additional cereal-based FFS was assumed to be 
similar to those of cereal-based FFS in previous scenarios. Safe use of these possibly contaminated FFS as feed requires standardised treatment even if they are still of food quality (Luyckx et al., 2019).

\section{$\underline{\text { Retail and consumption leftovers }}$}

At retail, food is mainly wasted for economic or commercial reasons. To provide consumers with choice and a high availability of products, both wholesalers and supermarkets overstock, resulting in wastage of mainly fresh cereal, meat, fruit and vegetable products (Cicatiello et al., 2017; Teller et al., 2018). Technically, products wasted at retail are FFS, and can be used as feed under the same regulations as manufacturing waste (EU, 2018). This implies that plant, egg and dairy-based products that are still fit for human consumption can be transformed into feed. Currently, as reflected in the reference scenario (o), virtually no food wasted at retail is used as animal feed, likely due to lack of economic incentive for the retailing industry to develop the infrastructure to safely recover their waste (Truong et al., 2019). The costs of oversupplying and wasting food are covered by high margins on products that do get sold (Teller et al., 2018). Furthermore, the industry is not transparent on how much food is wasted as this may threaten their revenue model in the current climate of reducing food waste (Cicatiello et al., 2017; Teller et al., 2018).

Optimally, retailing waste is collected in separate product streams, and processed into feed ingredients, requiring similar facilities as for manufacturing waste. The already developed FFS processing industry is willing to take up this task, which requires improved collaboration with the retailing industry (EFFPA, 2019). In the improved use of retail LCF scenario (5) we assumed that only plant-based retailing waste, derived through such collection, was available as LCF. In the legalisation of retail LCF scenario (6) we assumed that also animal-based retailing waste, currently banned as feed (EU, 2018), was available as LCF through legislative change. Besides separate collection, these animal-based wastes should be stored cold and treated into PAPs to ensure feed safety.

The availability of retailing and consumption wastes, was based on a recent study of Caldeira et al. (2019), that used a mass balance approach to quantify wastage for various product classes in each stage of the EU food supply chain. For plant-based products, we assumed the absolute amount of waste reported by Caldeira et al. (2019). For product classes that contain nutritionally differing products, we based the composition of the reported waste on underlying data provided by (Caldeira et al., 2019) for cereals and EU consumption for fruits and vegetables (FAO, 2017c). The resulting availability of plant-based feed ingredients from retail and available household waste is provided 
in Table $\mathrm{C}_{3}$. For animal-based products, we multiplied the waste coefficients for each phase, provided by (Caldeira et al., 2019), to the ASF supplied by sustainable fisheries and the animals selected for the optimal use of LCF.

Unlike retailing wastes, all food wasted at consumption, either at home or in food service facilities is banned as feed for food producing animals (EU, 2009, 2018), which is reflected in the reference scenario (o). This ban) result in high chances of contamination with inedible material, such as plastics (Truong et al., 2019). Furthermore, in most EU member states, food waste is collected mixed with other organic wastes results from the difficulty to guarantee safe collection of this waste, as handling by many actors (consumers every fortnight to be composted in regional facilities (WRAP, 2016). Using consumer food waste, thus requires a combination of improved use and legislative change. Such improved use should be facilitated by governments with a combination of clear instructions and new infrastructures (WRAP, 2016). As household food waste is sensitive to spoiling, it should be collected regularly. To ensure feed safety, the collected waste may not contain any inedible material and biohazardous contaminants should be inactivated with heat treatment and/or fermentation (Luyckx et al., 2019). Such processing, commonly applied in Japan, results in a wet feed called swill that can be fed as it is (with 20-30\% DM) or dried to a concentrate feed (with $>80 \% \mathrm{DM}$ ). This drying requires a high amount of energy which can be partly obtained from the heat produced in other processes. Here we assess the potential of providing household swill wet (7a) and dried (7b).

\section{Nutrient content of LCF}

To clearly illustrate the allocation of LCF in our results, crop by-products were classified based on their nutritional properties (Table $\mathrm{C} 4$ ), while other LCF were classified based on their origin. To assess ration composition, all LCF were classified based on nutritional properties. The nutrient content of each LCF and their availability to livestock (CVB, 2016) were adopted from (van Hal et al., 2019). The availability of nutrients in LCF for farmed fish (IAFFD, 2018) were adopted from (van $\mathrm{Hal}$ et al., 2020) that differentiate protein digestibility between farmed fish species based on literature (Appendix B; Table B8). Nutrient content of swill is calculated as the weighted average nutrient content of the included products. For wet swill we assume water is added during processing resulting in a DM content of $25 \%$, while dried swill is afterwards dried to a DM content of $80 \%$. 


\section{Results}

To illustrate the potential of improved use and legalisation of food leftovers as LCF in a circular food system, we first describe the optimal use LCF that currently already used as LCF (reference scenario). Thereafter, we illustrate the cumulative effect of making more LCF available in each step of the supply chain, in terms of nutrient supply and number of farm animals produced. To this end, we compared the nutrient supply from ASF and animal numbers from each scenario to that of the previous scenario. As population requirements for vitamin B12 were met for each scenario and its intake follows the pattern of HDP intake (correlated) we show only HDP and EPA/DHA intake.

\subsection{Reference scenario}

The optimal use of the currently used LCF provides a daily per capita intake of $470 \mathrm{~g}$ milk, $25 \mathrm{~g}$ fish (captured and farmed), $16 \mathrm{~g}$ meat, $2 \mathrm{~g}$ edible organ (offal) and $1 \mathrm{~g}$ egg. Putting this in perspective, this is $180 \mathrm{~g}$ less milk (-27\%), $17 \mathrm{~g}$ more fish (+200\%), $32 \mathrm{~g}$ less egg (-96\%) and $200 \mathrm{~g}$ less fish (92\%) than current daily per capita supply in the EU (FAO, 2017a). In total this ASF supply provides $27 \mathrm{~g} \mathrm{HDP}$ (cap/d) (Figure 2a), 47\% of DRI (Appendix C; Figure C2), fulfils vitamin B12 requirement, but was not able to meet recommended EPA/DHA intake. The maximum achievable EPA/DHA intake of $219 \mathrm{mg} / \mathrm{cap} /$ day fulfils $88 \%$ of DRI. The optimal use of currently used LCF requires 25 million low productive dairy cows, 12 million low productive laying hens, 368 million salmon and 26 billion tilapia (Figure 3d-h). Together these animals use all available plant and fish-based food leftovers (by-products and FFS), while leaving part of the natural grassland (62\%) and rangeland (82\%) unused (Figures $3 \mathrm{~h} \& \mathrm{C}_{3}$ ).

Dairy cattle valued as much grass as possible, supplemented with the majority of plant-based food leftovers (Figure 3g). High quality grass resources were fed to the dairy cows and young stock, while bulls only grazed natural grass and shrubs, resulting in high intake of low quality feed (Figure $\mathrm{C}_{3}$ ). Although laying hens valued all feather meal, the majority of their diet consisted of cereal and oilseed by-products (Figures $\mathrm{C}_{2} \& \mathrm{C}_{3}$ ). All fish by-products were fed to farmed fish (Figure $\mathrm{C}_{3}$ ). Salmon diets were, furthermore, supplemented with enriched cereals wasted at processing (biscuit meal), whereas tilapia diets consisted mainly of oilseed meal and cereal by-products and wastes (Figure 44 ). Despite salmon being the only model animal can effectively upcycle EPA/DHA from marine ingredients into EPA/DHA, a large share (30\%) of these ingredients were fed to tilapia with lower EPA/DHA contents, even though population requirement for these fatty acids is not met. This indicated that salmon production was limited by either energy or protein requirements or the ratio between the two. 


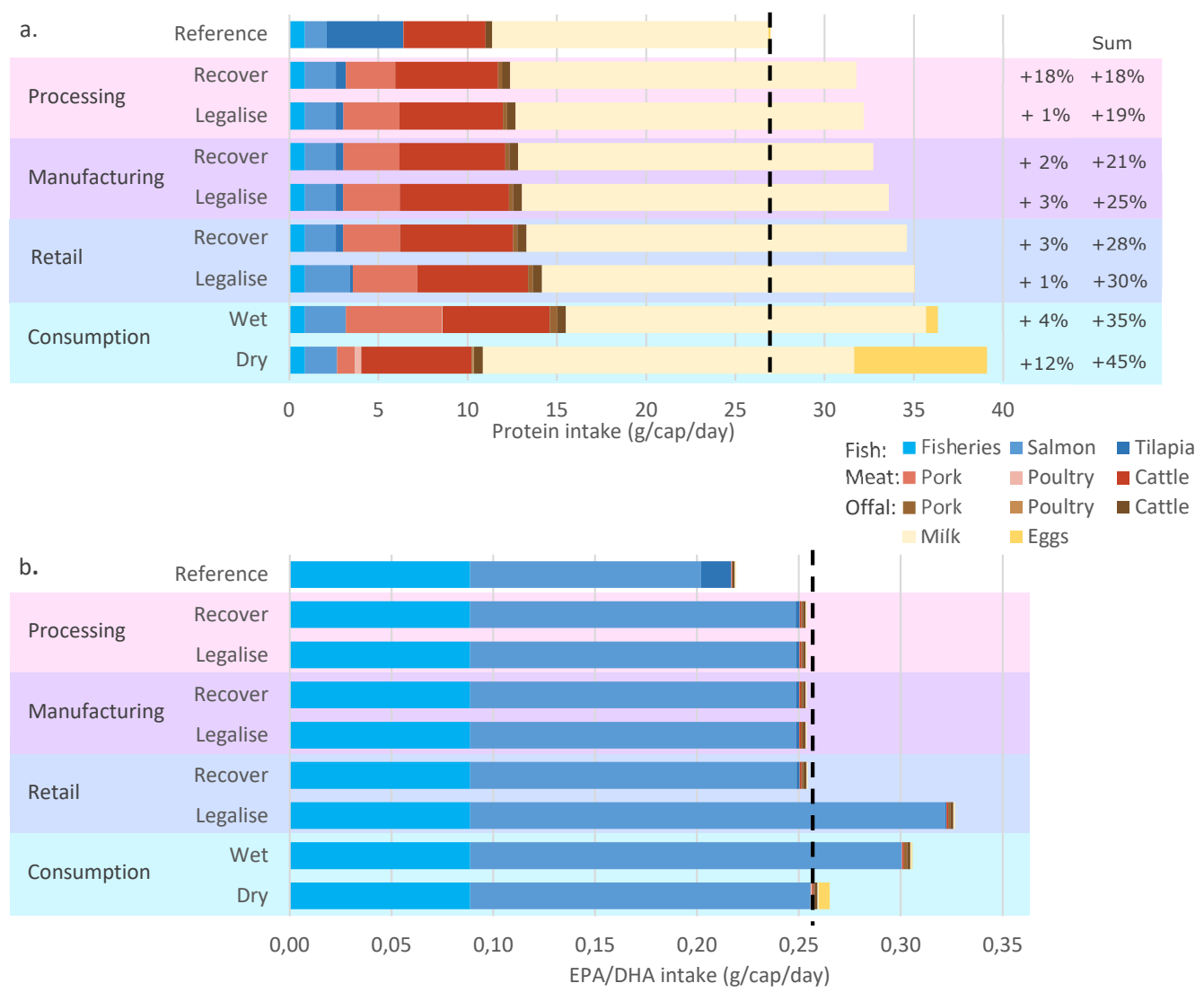

Figure 2 Cumulative impact of improved use and legalisation of food leftovers in each stage of the food supply chain on a. animal protein supply and b. EPA/DHA omega 3 fatty acid supply.

Partially legalising livestock proteins for as feed for livestock (Table C1) further increased HDP intake, but only with $1 \%$ (Scenario 2; Figure 2a). This increase was mainly due to the use of processed ruminant protein now available for fish, pigs and poultry (Figure $3 \mathrm{~b}$ ). Using these animal proteins, increased salmon production to 520 million harvested fish while requiring less cereal byproducts (Figure $3 \mathrm{~g}$ ). With this increase in salmon production, fewer tilapia were needed (-25\%) to meet EPA/DHA, freeing up cereal by-products (Figure $3 \mathrm{~h}$ ). These cereal by-products were reallocated to pig production, whose numbers increased to 43 million ( $+13 \%$; Figure $3 \mathrm{~d})$. In short, the additional LCF obtained from food processing increased HDP intake to $32.2 \mathrm{~g}$ HDP, i.e. an increase of $19 \%$ compared to the reference scenario (Figure 2a). 


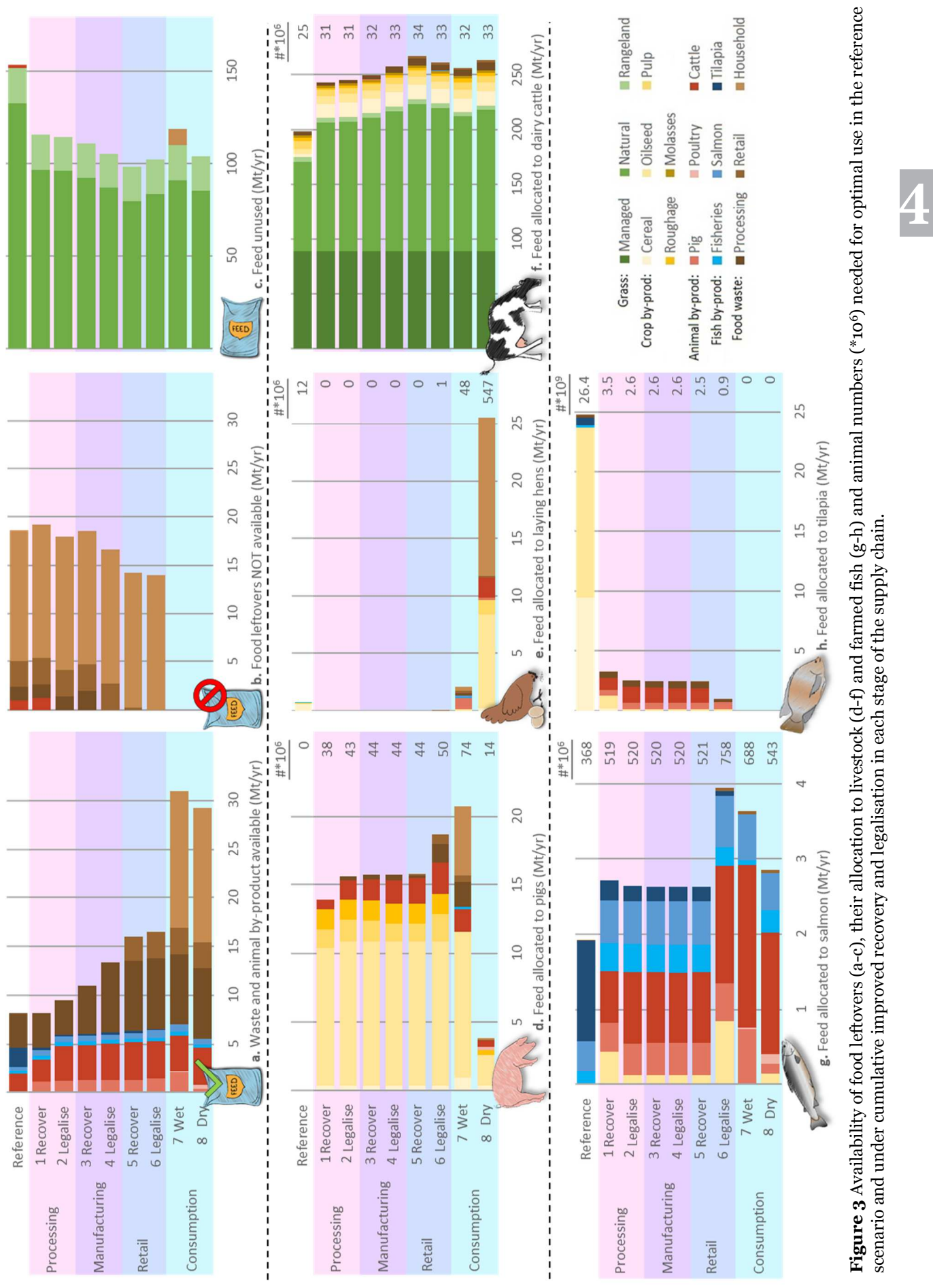




\section{Potential of manufacturing and retail waste}

The potential of manufacturing and retail wastes as LCF was limited (Scenario 3-6). Each improved use or legalisation scenario in these stages showed a similar response, except for legalising animal products wasted at retail (Scenario 6; Figure 2a). The common response was a small increase in HDP intake (2-3\%; Figure 2a), achieved by a continued increase in dairy production to 34 million (+ 9\%; Figure 3f). This dairy cattle were either fed directly with the newly available food waste or with the products displaced from pig diets by this waste, enabling them to value more nature grass (Figure $3 \mathrm{~d} \& \mathrm{f}$ ).

While legalising animal products wasted at retail (Scenario 6) did not have a big effect on animal protein supply (+1\%; Figure 2a), it had a large effect on which animals were selected to produce this protein. All of the animal products made available were allocated to salmon farming, increasing their production to 758 million harvested live fish (3.8 Mt; Figure 3g). Due to this increase in salmon production, human EPA/DHA intake increased to $325 \mathrm{mg} / \mathrm{cap} / \mathrm{d}$, far above the recommended intake (Figure $2 \mathrm{~b}$ ). This indicates that high-trophic farmed fish, such as salmon, are most efficient at upcycling animal by-products and wastes, and require such products to meet their high nutrient requirement. Despite no longer needed to meet human EPA/DHA requirement, 954 million tilapia were produced to upcycle pig bone meal, which was of too low protein quality to feed salmon or laying hens (Figure $3 \mathrm{~h}$ ). Adding the additional LCF obtained from manufacturing and retail increased HDP intake to $35 \mathrm{~g}$ HDP, an increase of $30 \%$ compared to the reference scenario (Figure 2a).

\section{Potential of consumption waste}

Legalising household waste as livestock feed had a relatively large impact (Scenario 7). When provided as wet swill, HDP intake increased with $4 \%$ (Figure 2a; Scenario 7a). Of this newly available wet swill , 36\% was allocated to pigs (Figure $3 \mathrm{~d}$ ), increasing pig production to 74 million pigs ( $+49 \%)$, as pigs are well adapted to value waste and wet feeds due to their relatively high feed intake capacity (Zijlstra \& Beltranena, 2013; zu Ermgassen et al., 2016). When upcycling 5 Mt of wet swill, however, pigs were no longer able to value the $2 \mathrm{Mt}$ of pulp and 1.5 Mt of roughage-like by-products they previously consumed (Figure $3 \mathrm{~d}$ ). Instead, these bulky crop leftovers were fed to dairy cattle, displacing 7.6 Mt of natural grass from their diets to be left unused (Figure $3 \mathrm{c}, \mathrm{f}$ ). Furthermore, $3 \%$ of wet swill with the highest quality was allocated to laying hens and $61 \%(8.6 \mathrm{Mt})$ was left unused (Figure 3c,e). For laying hens to be able to value swill, they were supplemented with highly nutritious fisheries and pig by-products, and cereal manufacturing waste (Figure 3e), making these less available for tilapia, salmon and dairy production. As a result salmon production 
reduced to 688 million harvested fish (-10\%), dairy to 32 million cows $(-3 \%)$, and no tilapia was farmed (Figure $3 \mathrm{~d}, \mathrm{~g}, \mathrm{~h})$. In short, adding wet swill from household waste increased HDP intake to $36.3 \mathrm{~g} / \mathrm{cap} / \mathrm{d}$, i.e. an increase of $35 \%$ compared to the reference scenario (Figure 2a).

Providing swill as a dry feed instead increased HDP intake with 10\% (Figure 2a; Scenario 7b), by feeding $99 \%$ of this dried swill to 547 million laying hens and leaving only $1 \%$ for pig production (Figure $3 \mathrm{~b}, \mathrm{~d}$ and e). To value dried swill, the laying hens required much of the available animal byproducts and high quality oil seed meal previously fed to salmon, reducing their numbers to 543 million harvested fish (-22\%)(Figure 3e,g) still enough to meet EPA/DHA requirement (Figure 2b). Pigs went back to valuing some pulp and roughage-like by-products, but their numbers reduced to 14 million (-88\%). Most crop by-products, retailing and manufacturing waste, and some fish oil was, therefore, left available for cattle to increase their numbers to $33 \mathrm{mln}(+3 \%)$ and value more natural grass (Figure $3 \mathrm{~d}$, f). In short, adding dried swill from household waste increased HDP intake to $39.1 \mathrm{~g} / \mathrm{cap} / \mathrm{d}$, i.e. an increase of $45 \%$ compared to the reference scenario (Figure $2 \mathrm{a}$ ).

\section{Discussion}

We found that, in the proposed circular food system ASF intake can fulfil between 50 and $69 \%$ of HDP requirement. We, thereby, demonstrated that improved use and legalisation of food leftovers as LCF can increase HDP intake up to $45 \%$ (Figure 2). While human vitamin B12 requirements were met in each scenario, the intake of EPA/DHA appeared critical, as these requirements could not be met in the reference scenario. We first discuss the optimal use of currently used LCF (reference scenario), and then discuss the potential of currently unused food leftovers as LCF (Scenario 1-7).

Optimal use of LCF currently used in the EU, requires a smart combination of dairy cows, laying hens, farmed salmon and tilapia (Figure $3 \mathrm{~d}-\mathrm{h}$ ), which all have a relatively high production efficiency. Dairy cattle and laying hens achieve this high efficiency by providing a daily product, while fish, being poikilothermic and unaffected by gravity, have low maintenance requirements (de Vries \& de Boer, 2010; Fry et al., 2018). In line with previous studies, dairy cattle were fed a large share of the available crop by-products to enable them to value as much of the low quality grass as possible (Figure 3f; (van Hal et al., 2019). Laying hens were selected to value feather meal as they are the most efficient species allowed to value these PAPs (Figure 3e). They were kept at low productivity to limit their use of high quality LCF that were needed for dairy and fish farming. Farmed fish were, namely, needed to provide humans with EPA/DHA. As the population requirements for EPA/DHA could not be met, their supply was maximised and highly influential in the selection of animals. Surprisingly, much of the EPA/DHA containing fish by-products were fed 
to tilapia that are inefficient at upcycling EPA/DHA, indicating salmon production was limited by other nutrient requirements (Figure 3g,h).

Our results show that, of the considered currently unused food leftover streams, livestock PAPs and dried household swill have the highest ASF supply potential. Livestock PAPs, when fed to farmed fish (Scenario 1) increased HDP supply with 18\% (Figure 2a), whereas using dried household waste as feed (Scenario 7b) increased HDP supply with 12\% (Figure 2a). To make more food leftovers available as LCF we must overcome legal and other barriers, which interestingly appear easiest for PAP s than for livestock by-products and hardest for household wastes as discussed below.

Livestock PAPs have a high potential as LCF due to their high quality. We found that if livestock PAPs are available as LCF, high-trophic fish are most efficient in upcycling them (Figures $2 \mathrm{~b} \& 3 \mathrm{~g}$ ). The inclusion of high quality livestock protein and fats enabled farmed salmon to upcycle more EPA/DHA containing feed ingredients and meet human EPA/DHA requirement (Figure 2b, 3g). Allowing livestock PAPs as fish feed increased the upcycling efficiency of EPA/DHA and was needed to meet human EPA/DHA requirement in circular food system (Figure 2b; shift from tilapia to salmon), which is in line with EFPRA (2016) and van Hal et al. (2020). Salmon production was selected to value livestock PAPs also when they were allowed as livestock feed (Scenario 3) and when human EPA/DHA requirements were already met (Scenario 6) (Figure 2b, 3g).

Livestock PAPs are currently allowed to be used to feed fish farmed for human consumption (EU, 2013a). Their safe collection and processing is, furthermore, relatively easy to organise as they are produced in slaughter facilities that operate under HACCP standards (EFPRA, 2016). While use of livestock PAPs in fish feed appears easy to achieve, their application has remained limited since their legalisation in 2013 (BioMar, 2018; IUCN, 2017). To stimulate the efficient use of such food leftovers, research into the technical or social barriers that limit their application is needed. Such research is especially relevant for livestock PAPs, due to their ASF supply potential, and their role in upcycling EPA/DHA as discussed above. Preliminary research shows that constraints partly relate to concerns about consumer acceptance (Krogdahl, 2016). Pescatarians, for example, may not want their fish to be fed with the livestock they avoid eating (IUCN, 2017). Pescatarians, however, are a minority of fish eaters, and consumption of imported seafood that was fed with livestock PAPs is plentiful (Tacon, 2012). To our knowledge, potential technical (feed formulation, farming) and environmental (local ecosystem) barriers to using PAPs as fish feed have not been studied. The benefit of feeding farmed fish with livestock PAPs is likely even higher in our current food system, due to higher availability of PAPS than in the circular food system illustrated here. 
Also for the fish farming industry the use of livestock PAPs is of interest as limits to the availability of fisheries by-products - historically their main feed ingredient - has driven them to explore and use alternative high quality feed ingredients (Tacon \& Metian, 2015). So far they explored mainly plant-based ingredients, where soy is preferred due to its high protein quality, but unlike PAPS additional soy production causes environmental impacts (EFPRA, 2016).

Household swill has high potential as LCF due to both its abundance and high feed quality when dried. Potential is highest when household swill is dried, as almost all can be fed to highly efficient laying hens (Figure 3e). While feeding food waste to laying hens is uncommon, a Japanese study has illustrated its feasibility, and a Dutch company proclaimed its interest in doing so (Kipster, 2017; Ruttanavut et al., 2011). Drying of feed ingredients, however, requires large amount of energy, which increases its environmental impact (Vellinga et al., 2013). This impact can be limited by the use of renewable energy or heat generated, as is often used when drying manure and compost fertiliser (Kipster, 2017; Loizia et al., 2019; van Zanten et al., 2015b). When provided wet, only pigs were able to value this bulky swill (Figure 3d), in line with previous study that single pigs out as best up-cycler of swill due to their relatively high feed intake capacity (van Hal et al., 2019; zu Ermgassen et al., 2016). Compared to dried swill, wet swill has less potential in terms of ASF supply (Figure 2a). Pigs have lower production efficiency and were not able to value all swill (Figure 3c).

Despite the high ASF supply potential dried household swill, (Figure 2a, Scenario 7), legalising household waste as LCF is hard to realise. EU guidelines indicate that safe feeding of household swill requires legislative changes and development of collection and treatment infrastructures (Luyckx et al., 2019). While we can inactive pathogens by heat and fermentation treatments, we depend on numerous households to ensure that food waste is not contaminated with inedible material (Luyckx et al., 2019). The collection potential of household food waste and the amount that can be used as feed is, therefore, limited (Levis et al., 2010). In Japan, where feeding of swill is legal and centrally organised, about $40 \%$ of all food wasted at the household is fed to livestock after 15 years of effort (zu Ermgassen et al., 2016). While the full potential of feeding household waste (+ $4 \mathrm{~g} \mathrm{HDP} /$ cap/d; Figure 2a) is, therefore hard to achieve, we likely underestimates generation of food waste in the consumption stage. For simplicity reasons we assumed all consumption takes place in the household, while in reality, consumption partly takes place in food service facilities where wastage is higher (Caldeira et al., 2019). Furthermore, there are recent indications that food wastage in households is underestimated systematically (van den Bos Verma et al., 2020). 
Using food wasted during manufacturing and retail (Scenario 3-6) as LCF also has potential to increase HDP intake, albeit lower for than at processing or consumption (+2-3\%; Figure 2a). This potential is limited by the low availability of these wastes, though their high quality enables the use of more low quality grass (Figure 3c). The FFS industry strives to make more manufacturing and retailing waste available as feed, which requires improved collection from manufacturers in eastern Europe, and improved collaboration with wholesalers and supermarkets (Priefer et al., 2016; Truong et al., 2019). Proposed obligatory waste reporting may motivate retailers to reduce or recycle them to maintain their image (Priefer et al., 2016). This may stimulate initiatives currently limited to pioneers such as Lidl Nederland (van Woensel Kooy, 2020), who use empty delivery trucks to return expired bread back to the manufacturer that already collaborates with FFS processers. With packaging being a major constraint to the use of retailing waste (Levis et al., 2010), highly sophisticated unpacking methods used already by FFS processors makes them a valuable partner for retailers.

While using food leftovers as LCF increases the resource use efficiency of the food system, we acknowledge that prevention of leftovers is even more efficient and that leftovers may have other valuable uses in the food system. While prevention of food waste is prioritised in EU policy, not all waste and by-products can be avoided (EU, 2008). Unavoidable leftovers, are most efficiently used as feed, but must refrain from using recycling as justification to continue wasting (Caldeira et al., 2019). Prominent other uses of LCF are as organic fertiliser or to produce bio-energy (Muscat et al., 2019). While there are many alternatives for renewable energy production, organic fertilizers are essential for soil health and crop production (Hijbeek et al., 2017; Sharma et al., 2019). As a healthy soil is the fundament of a circular food system (de Boer \& van Ittersum, 2018), future research should explore which leftovers have most value for feeding the soil or the animal. Such research requires an integrated soil-crop-animal model that optimises the use of natural resources to feed humans efficiently while minimising environmental impacts.

We simulated animal production in a circular food system, given a predefined availability of LCF. We, however, acknowledge that in a circular food system crop production should be optimised which affects the availability of plant-based LCF. While this affects the predicted ASF supply, we are confident that the illustrated principles for improved use of food leftovers as LCF hold regardless. We summarised these principles into the following three recommendations. First, when feeding only LCF, human EPA/DHA requirements can only be met when farmed fish are fed livestock by-products, which would also improve the resource use efficiency of our current food system. We, therefore, recommend research into the technical, social and/or economic restrictions 
that currently limit the use of livestock by-products in fish feeds in the EU. Second, we find that for efficient use of LCF, high quality LCF should be combined with low quality LCF to achieve an average nutrient content that enables animals to meet their nutrient requirement while upcycling low quality LCF. We, therefore, recommend to use highly nutritious manufacturing and retailing waste to enable the use of more low quality LCF. Third, low quality LCF are must most efficiently if they are fed to those animals that are best adapted to upcycle them. As pigs are best adapted to eat wet feeds, they were fed most pulp, and when available, wet household swill, which required supplementation with high quality LCF. When dried, however, household swill has a relatively high nutritional quality, and is most efficiently upcycled by laying hens without demanding a lot of other high-quality LCF. As other high quality LCF could then be used to value grass, we recommend that, if taking the effort to develop an infrastructure to collect and processing household waste, generated heat should be reused produce a dried swill.

\section{Conclusions}

Our findings show that improved use and legalising food leftovers as LCF improves the resource use efficiency of the food system and can increase HDP from ASF up to $45 \%$. Use of livestock PAPs in fish feed has most potential in terms of HDP supply (+18\%) and is essential to meet human EPA/DHA requirements in a circular food system. While seemingly easy to achieve, better understanding of why livestock by-products are currently not used in fish feed is needed, also to enhance resource use efficiency in our current food system. Besides PAPs, feeding dried household swill also has a high ASF supply potential (+12\%), but safe feeding of this waste is reported to require considerable effort. Due to low quantities, food leftovers from manufacturing and retail have limited potential in terms of protein supply (each $+5 \%$ ), but their use enables especially ruminants to value more low quality grazing resources. We conclude that improved use and legalisation of inevitable food leftover can improve the resource use efficiency of both current and future circular food systems. Efficient use of available LCF requires a combination of animals tailored to the available LCF and the desired nutrients for human consumption.

\section{Acknowledgments}

The authors thank Karel van der Velden (Nijssen Granico), Carla Caldeira and Valeria de Laurentiis (Joint Research Centre, Ispra) for valuable contributions to this research. This project received funding from the European Union's Horizon 2020 research and innovation program under grant agreement No 633692. The views expressed in this publication are the sole responsibility of the authors and do not necessarily reflect the views of the European Commission. 


\section{Chapter 5}

\section{Accounting for feed-food competition in environmental impact assessment: towards a resource efficient food-system}

O. van Hal, A.A.A. Weijenberg, I.J.M. de Boer and H.H.E van Zanten Animal Production Systems group, Wageningen University \& Research, PO Box 338, 6700 AH Wageningen, the Netherlands 


\begin{abstract}
This study demonstrates the effect of better accounting for feed-food competition in life cycle assessment (LCA) to derive mitigation strategies that contribute to efficiently feeding the growing world population. Economic allocation, commonly used in LCA, falls short in accounting for feedfood competition as it does not consider interlinkages in the food system. The authors hypothesise that an alternative "food-based" allocation better accounts for food-feed competition by assigning no environmental impact to feed products unfit for human consumption. To evaluate the impact of accounting for feed-food competition on LCA results, economic and food-based allocation were compared in an LCA of a novel egg production system that feeds only products unsuitable or undesired for human consumption. Using economic allocation, the global warming potential (GWP) of $1.13 \mathrm{~kg} \mathrm{CO}_{2}$-eq, energy use (EU) of $11.86 \mathrm{MJ}$, land use (LU) of $2.99 \mathrm{~m}^{2}$, and land use ratio (LUR) of 1.70 per kg egg of the case study farm were all lower than that of free range or organic eggs. Avoiding feed-food competition on this farm reduced the environmental impact per kg egg by 48-58\% for GWP, $21-37 \%$ for EU, 34-47\% for LU and 32\% for LUR, compared to free-range laying hens fed a conventional diet. Accounting for feed-food competition with food-based allocation further reduced impacts per $\mathrm{kg}$ egg by $57 \%$ for GWP to $0.49 \mathrm{~kg} \mathrm{CO}_{2}$-eq, $40 \%$ for EU to $7.19 \mathrm{MJ}, 96 \%$ for LU to $0.11 \mathrm{~m}^{2}$, and $88 \%$ for LUR to 0.30 . This improved LCA better captures the complexity of the food system.
\end{abstract}




\section{Introduction}

Animal-source food (ASF) supplies humans with high quality protein and essential micro-nutrients (Craig \& Mangels, 2009), but it's production has significant negative environmental impacts (Steinfeld et al., 2006). These impacts include climate change (Vermeulen et al., 2012), ecosystem pollution (Gerber et al., 2013), biodiversity loss (Newbold et al., 2016) and use of scarce resources such as land, water, and fossil-energy (Steinfeld et al., 2006). Globally, the livestock sector is responsible for $\sim 15 \%$ of anthropogenic greenhouse gas (GHG) emissions (Gerber et al., 2013), and uses $\sim 80 \%$ of farmed land (Poore \& Nemecek, 2018).

Feed cultivation is responsible for the majority of greenhouse gas (GHG) emissions and almost all land use (LU) of livestock production (de Vries \& de Boer, 2010). Globally, it occupies $\sim 40 \%$ of all arable land (Mottet et al., 2017) on which food crop cultivation is more efficient (Garnett, 2011) as nutrients are lost when converting plant into animal biomass (Godfray et al., 2010). To address arable land availability, a major limitation to sustainably feeding the world's future population (Lambin and Meyfroidt, 2011), recent studies propose to avoid this inefficiency by feeding livestock only with products that humans cannot or do not want to eat (van Zanten et al., 2018). These 'lowopportunity-cost feedstuffs' (LCF) include crop residues, e.g. wheat straw or beet tails, and byproducts, e.g. wheat middlings or sugar beet pulp, of food crops grown on arable land, food waste, and grazing resources from non-arable land (Schader et al., 2015). Livestock fed with only LCF upcycle nutrients that would otherwise be lost to the food system into ASF (Bowles et al., 2019), without using additional arable land (Garnett et al., 2015). By avoiding competition between feed and food crop production (Röös et al., 2017a), they contribute to a more efficient food supply (van Kernebeek et al., 2016).

Despite this scientific acknowledgement of the relevance of avoiding feed-food competition, the state of the art life cycle assessment (LCA) used to assess environmental impacts of ASF production falls short in addressing this issue as it is not designed to include interlinkages in the food system (van Zanten et al., 2018). Producing oil from sunflower seed, for example, also yields meal and hulls (see Figure 1). In an LCA of ASF, the environmental impact of this multifunctional process is allocated to its multiple outputs (e.g. oil, meal and hulls) based on their relative economic value (De Vries and de Boer, 2010), a method defined as economic allocation (Guinée, 2002). Of the impact of cultivating and processing one $\mathrm{kg}$ of sunflower seed, $80 \%$ is allocated to the resulting $285 \mathrm{~g}$ sunflower oil as this oil represents $80 \%$ (€0.25/€o.32) of the economic value of the process outputs (Figure 1). The economic value of a product, however, does not reflect their (un)suitability for direct human consumption (van Zanten et al., 2016b). 


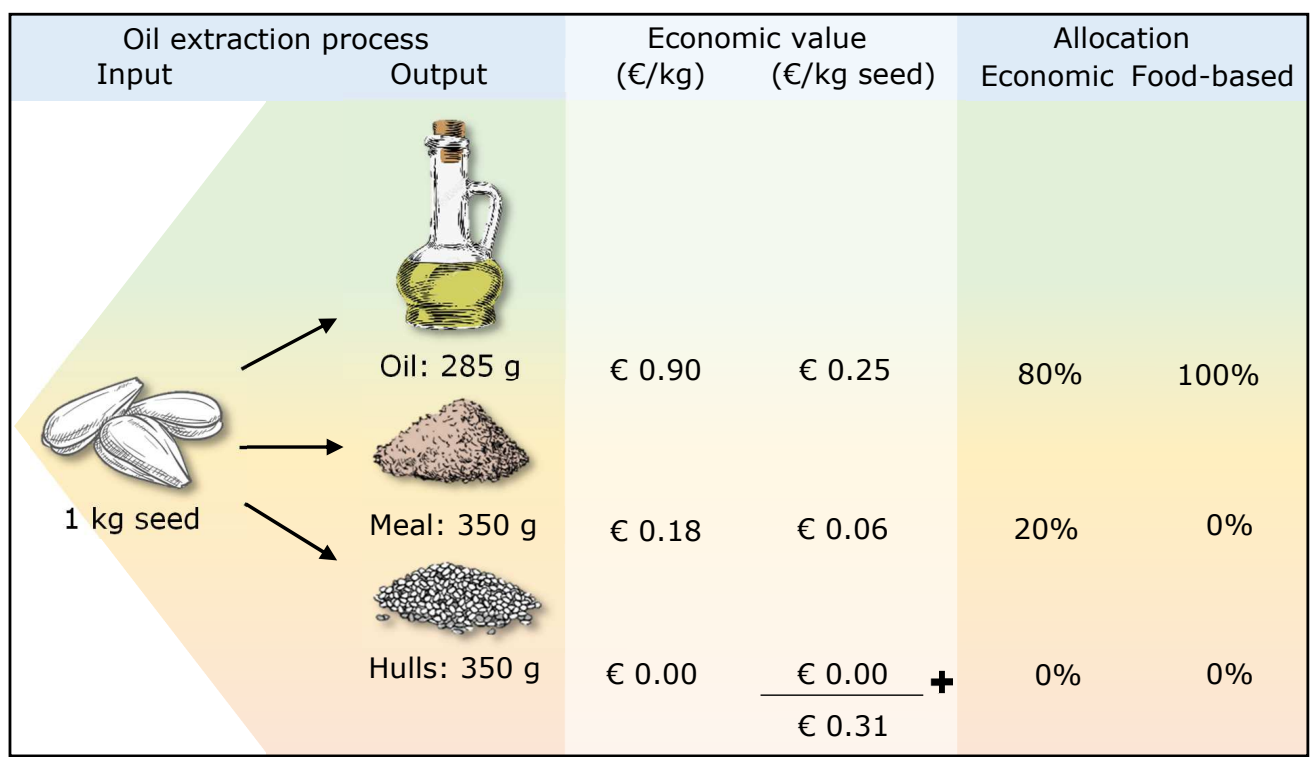

Figure 1 Environmental impact allocation over the co-products resulting from the multifunctional process sunflower seed crushing under traditional economic and food-based allocation as introduced in this paper (mass distribution of outputs \& price of outputs (Vellinga et al., 2013).

By not considering whether used feeds are fit for human consumption or compete for land with food crop production, mitigation strategies proposed by LCA studies may increase the resource use of the entire food system (van Zanten et al., 2018). LCA studies by Herrero et al. (2016), for example, propose to reduce the environmental impact per kg ASF by increasing animal productivity, defined as animal output over feed input (Balmford et al., 2018). This productivity increase requires high quality feeds (de Vries et al., 2015), typically including food crops or feed crops grown on arable land, thereby increasing competition with food production (Wilkinson \& Lee, 2018). Negative implications of such strategies, i.e. increased pressure on arable land, are overlooked as the state of the art LCA ignores their consequences on interlinked production systems (van Zanten et al., 2018).

To move towards a resource efficient food system, LCA's shortcoming in considering food system interactions such as feed-food competition should be addressed. This study presents a first step towards achieving this by introducing a novel allocation method that reflects the (un)suitability of feed products for human consumption. This food-based allocation assigns zero environmental impact to by-products unsuitable or undesired for human consumption whereas the determining (food) product is given full allocation. Of the environmental impact of cultivating and processing one $\mathrm{kg}$ of sunflower seed, $100 \%$ is now allocated to the resulting $285 \mathrm{~g}$ sunflower oil as this is the only edible end-product which drives sunflower seeds production (Figure 1). 
This study evaluates the impact of explicitly accounting for feed-food competition on LCA results. A conventional LCA with economic allocation was compared with an alternative LCA with "foodbased" allocation that explicitly accounts for feed-food competition (Figure 1). Both LCAs were extended with the land-use ratio (LUR) indicator which provides insights into the land use efficiency of the entire food system (van Zanten et al., 2016b). The limitations of economic allocation, illustrated by the impact of accounting for feed-food competition in LCA, were assessed in a case study of an innovative egg production system that avoids feed-food competition.

\section{Material and Methods}

The impact of explicitly accounting for feed-food competition in LCA was explored. LCA is a holistic approach to evaluate the environmental impact throughout a product's entire life cycle (Baumann \& Tillman, 2004). Following the LCA protocol (Guinée, 2002), the goal and scope definition and inventory analysis are described in the material and methods, the impact assessment in the results and interpretation of the results in the discussion.

\subsection{Goal and scope definition}

LCA was applied to a case study of 'Kipster', an innovative egg production system designed to produce eggs with respect for animals, farmer, and planet. The system avoids feed-food competition, produces and uses solar energy, and rears the male chicks associated with egg production for meat (Kipster, 2017). First, the environmental impacts of this system were benchmarked against free range and organic egg production, using traditional LCA with economic allocation. Subsequently, the impact of accounting for feed-food competition in LCA was illustrated by comparing economic with food-based allocation (Figure 1). How each allocation method applies to the feed used by Kipster is described in section 2.2.4, i.e. the inventory assessment of feed production.

The indicators $\mathrm{LU}\left(\mathrm{m}^{2}\right)$ and GWP $\left(\mathrm{CO}_{2}\right.$-eq) were selected as livestock production contributes significantly to land use and climate change (Steinfeld et al., 2006), and EU (MJ) for its inherent relation with GWP. To calculate GWP, the three main GHGs related to agriculture, $\mathrm{CO}_{2}, \mathrm{CH}_{4}$ and $\mathrm{N}_{2} \mathrm{O}$, were summed using their $\mathrm{CO}_{2}$-eq weighting factors for 100-year time horizon: 1 for $\mathrm{CO}_{2}, 28$ for biogenic $\mathrm{CH}_{4}, 30$ for fossil $\mathrm{CH}_{4}$ and 265 for $\mathrm{N}_{2} \mathrm{O}$ (Myhre, 2013). Where LU quantifies the amount of land needed to produce one kg egg, the land use ratio (LUR) was included to indicate whether this land could have been used more efficiently to produce plant-source food (van Zanten et al., 2016b), for more detail see section 2.3 . 


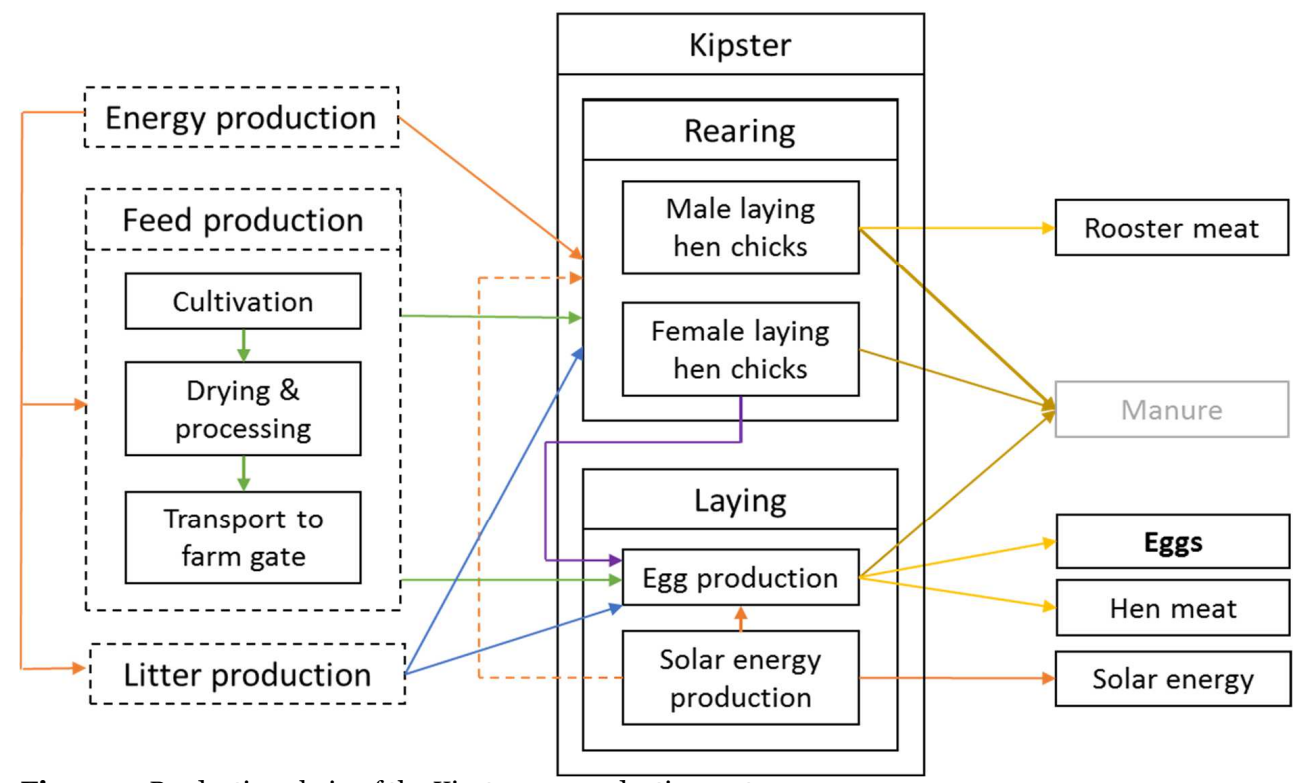

Figure 2. Production chain of the Kipster egg production system.

The LCA, performed from cradle-to-farm-gate, included the following processes: rearing female and male chicks, egg production, solar energy production, manure management, feed production, and other off farm processes such as bedding material and energy production (Figure 2). The hatching phase and parent stock were excluded.

\subsection{Inventory analysis.}

The following section quantifies the inputs and outputs related to each farm process (Table 1): chick rearing (2.2.1), egg production (2.2.2), and solar energy production (2.2.3). The environmental impacts per unit of these inputs and outputs are then quantified for the off-farm processes: feed production (2.2.4), bedding material and energy production (2.2.5), and manure management (2.2.6).

$\underline{\text { Rearing female and male chicks }}$

Female chicks were reared from hatch to the egg productive stage, whereas male chicks were reared as slow-growing broilers. Kipster rears male chicks in response to societal concerns about the conventional culling of day-old male chicks. In the European union only $16 \%$ of these chicks is used as feed for zoo animals or reptiles while the rest is wasted (Bokma \& Leenstra, 2010). Production data and inputs and outputs related to female chicks reared for Kipster (Table 1) are in line with the Dutch average production (Vermeij, 2017). Male chicks are reared under similar circumstances (Table 1) and reach a slaughter weight of $1.5 \mathrm{~kg}$ in 119 days (Zanders \& Claessens, 2018), resulting 
in a meat yield of $580 \mathrm{~g}$ per chick (Loetscher et al., 2015; USDA, 2018a). Based on the principles of system expansion, this valuable meat output, is expected to replace free range broiler meat with an average GWP of $7.01 \mathrm{~kg} \mathrm{CO}_{2}$-eq, EU of 41.2 $\mathrm{MJ}$ and LU of $9.96 \mathrm{~m}^{2}$ per $\mathrm{kg}$ (Appendix D1).

\section{Egg production}

Inputs and outputs related to the egg production phase (Table 1) were based on technical results of Kipster. The DeKalb white laying hens produce eggs for 64 weeks after a 3 week adaptation period, and are kept at a density of 6.7 animals per $\mathrm{m}^{2}$ (Zanders \& Claessens, 2018). At the end of the egg production phase, hens of $1.5 \mathrm{~kg}$ are slaughtered. The resulting $580 \mathrm{~g}$ meat per hen (Loetscher et al., 2015) was accounted for using similar system expansion assumptions as reported for rooster meat.

Table 1 Production data, inputs and outputs of rearing male and female laying hen chicks and the laying phase

\begin{tabular}{|c|c|c|c|c|}
\hline \multirow{2}{*}{ Production data } & & \multirow[t]{2}{*}{ Female chicks } & \multirow[t]{2}{*}{ Male chicks } & \multirow[t]{2}{*}{ Laying hens } \\
\hline & & & & \\
\hline Round size & \# animals & 24,840 & 24,930 & 24,000 \\
\hline Round duration & days & 119 & 119 & 470 \\
\hline Mortality & $\%$ & 3.5 & 4.75 & 7.81 \\
\hline Housing density & animals $/ \mathrm{m}^{2}$ & 10.50 & 10.50 & 6.70 \\
\hline Farm input & (/animal/round) & & & \\
\hline Feed & $\mathrm{kg}$ & 5.6 & $7 \cdot 3$ & $55 \cdot 33$ \\
\hline Bedding material & $\mathrm{kg}$ & 0.015 & 0.015 & 0.088 \\
\hline Diesel & 1 & 30 & - & - \\
\hline Gas & $\mathrm{m}^{3}$ & 0.15 & 0.15 & - \\
\hline Electricity & $\mathrm{kWh}$ & 2.35 & 2.35 & 8.36 \\
\hline Farm output & (/animal/round) & & & \\
\hline Eggs & $\mathrm{kg}$ & - & - & 23.17 \\
\hline Meat & $\mathrm{kg}$ & - & 0.58 & 0.58 \\
\hline Manure & $\mathrm{kg}$ & 2.48 & 3.14 & 13.12 \\
\hline Solar energy & $\mathrm{kWh}$ & - & - & 16.71 \\
\hline
\end{tabular}

\section{$\underline{\text { Solar energy production }}$}

The Kipster laying hen barn is covered with 1,097 solar panels, producing $\sim 385,479 \mathrm{kWh}$ solar energy per laying round, covering the energy requirement of both the rearing and the laying phases (Appendix D5; Table D10). The surplus solar energy sold to the grid is assumed to replace average Dutch grid electricity which has a higher environmental impact (Table 3). 


\section{Feed production}

In the rearing phase, both female and male chicks were fed a conventional diet (Appendix D2). Laying hens were fed a diet consisting of LCF specifically designed for Kipster to avoid feed-food competition. Energy providing LCF included bakery rest streams (e.g. bread crumbs, biscuit sand, crispbread, dough melange, rice waffle, rusk) and candy rest streams (e.g. candy syrup, waffle syrup), while European sunflower and rapeseed meal provided protein (Appendix D2; S1). The environmental benefits of two potential future protein-rich LCF were explored in two diet scenarios (Appendix D2; S2-S3) with the same nutritional value of $11.8 \mathrm{MJ}$ metabolisable energy, $6 \mathrm{~g}$ digestible lysine and $3 \mathrm{~g}$ digestible methionine per $\mathrm{kg}$. The alternative protein source in the oilseed scenario (S2) was soybean meal. As the demand for soybean meal drives soybean production, it's considered a feed crop that competes for arable land with food crop production (van der Werf et al., 2005). In a future circular food system where soybean cultivation is limited to the demand for soybean oil, soybean meal is a by-product unsuitable for human consumption. In the insect scenario (S3), the alternative protein source was meal from larvae fed on food waste and manure, both being unsuitable as livestock feed (van Zanten et al., 2015b). Feeding insects to livestock is not permitted in the EU (Veldkamp et al., 2012), but has the potential to reduce the environmental impact of livestock production (Sánchez-Muros et al., 2014).

The impact of each feed ingredient (Appendix D2) was derived from Feedprint (Vellinga et al., 2013), supplemented for larvae meal (van Zanten et al., 2015b), additives (Garcia-Launay et al., 2014), soybean oil and lecithin (Ecoinvent, 2013), and fish oil (AgriBalyse, 2017). Feed production impacts include those related to feed cultivation, drying/processing and transport to the farm but exclude those related to land use change. The environmental impact per $\mathrm{kg}$ feed, for each allocation method (Table 2), was calculated by multiplying the impact per $\mathrm{kg}$ feed ingredient with its relative use in the diet.

Table 2 Global warming potential (GWP), energy use (EU) and land use (LU) per $\mathrm{kg}$ feed for each phase/scenario, under economic and food-based allocation.

\begin{tabular}{|c|c|c|c|c|c|c|}
\hline \multirow[b]{2}{*}{ Feed } & \multicolumn{3}{|c|}{ Economic allocation } & \multicolumn{3}{|c|}{ Food-based allocation } \\
\hline & $\begin{array}{l}\mathrm{GWP} \\
(\mathrm{kg} \mathrm{CO}-\mathrm{eq})\end{array}$ & $\begin{array}{l}\text { EU } \\
(\mathrm{MJ})\end{array}$ & $\begin{array}{l}\mathrm{LU} \\
\left(\mathrm{m}^{2}\right)\end{array}$ & $\begin{array}{l}\text { GWP } \\
\left(\mathrm{kg} \mathrm{CO}_{2} \text {-eq) }\right.\end{array}$ & $\begin{array}{l}\text { EU } \\
(\mathrm{MJ})\end{array}$ & $\begin{array}{l}\mathrm{LU} \\
\left(\mathrm{m}^{2}\right)\end{array}$ \\
\hline Rearing female & 0.65 & 5.84 & 1.96 & 0.54 & 6.16 & 1.34 \\
\hline Rearing male & 0.65 & 6.53 & 1.65 & 0.46 & 4.95 & 0.91 \\
\hline Laying hen $\mathrm{S} 1$ & 0.37 & 3.44 & 1.02 & 0.13 & 1.75 & 0.01 \\
\hline Laying hen S2 & 0.30 & 3.75 & 0.85 & 0.20 & 2.79 & 0.27 \\
\hline Laying hen $\mathrm{S}_{3}$ & 0.40 & $4 \cdot 39$ & 0.09 & 0.30 & 3.66 & 0.02 \\
\hline
\end{tabular}


Using economic allocation, impacts related to cultivation and processing were allocated to the resulting co-products based on their relative economic value (Figure 1). This implies that of the impact of cultivating and processing $1 \mathrm{~kg}$ sunflower seed, $80 \%$ was allocated to the resulting sunflower oil, and 20\% to sunflower meal (Vellinga et al., 2013). Food industry wastes such as dough melange were assumed to have no economic value according to LCA regulations (FEFAC, 2018). Using food-based allocation, all cultivation and processing impacts were allocated to the determining (food) product (Figure 1). This implies that the impact of cultivating and processing 1 $\mathrm{kg}$ sunflower seed was fully allocated to the sunflower oil driving these processes, and none to the associated sunflower meal, as it is unfit for human consumption. Environmental impacts related to the processing of a by-product, for example, drying sunflower meal, were allocated to this byproduct. Although soybean meal drives soybean production, under food-based allocation no impact related to cultivation or processing of soybeans was allocated to it, assuming that in a future circular food system soybean production will be limited to oil demand.

\section{Bedding material and energy production}

Other off-farm processes include the production of animal bedding material and energy sources used on the farm and for transport. The environmental impact of each of these inputs (Table 3) was derived from Ecoinvent (2013).

\section{Manure management}

$\mathrm{CH}_{4}$ and $\mathrm{N}_{2} \mathrm{O}$ emissions from manure handling and storage were computed using a tier 2 approach (IPCC, 2006), country specific data from van Bruggen et al. (2014), and IPCC default values (IPCC, 2006), (Appendix D3). Laying hen manure was dried before storage and no leaching or volatilisation was assumed to occur (Oenema et al., 2000).

Table 3 Global warming potential (GWP), energy use (EU) and land use (LU) related to the production of farm inputs (Ecoinvent, 2013)

\begin{tabular}{|c|c|c|c|}
\hline Farm input & $\begin{array}{l}\mathrm{GWP}^{1} \\
\left(\mathrm{~kg} \mathrm{CO} \mathrm{CO}_{2}-\mathrm{eq}\right)\end{array}$ & $\begin{array}{l}\mathrm{EU} \\
(\mathrm{MJ})\end{array}$ & $\begin{array}{l}\mathrm{LU} \\
\left(\mathrm{m}^{2}\right)\end{array}$ \\
\hline Diesel (l) & 0.22 & $3 \cdot 39$ & 0.004 \\
\hline Gas $\left(\mathrm{m}^{3}\right)$ & 2.10 & 38.95 & 0.002 \\
\hline Electricity $^{2}$ (kWh) & 0.74 & 2.98 & 0.014 \\
\hline Solar power (kWh) & 0.11 & 1.31 & 0.010 \\
\hline Bedding material 3 (kg) & 0.07 & 0.76 & 0.005 \\
\hline
\end{tabular}

${ }^{1}$ : GWP includes production and combustion of energy sources

2: Dutch average grid electricity

3: Wood chips 


\subsection{Land use ratio}

The LUR, an indicator of land use efficiency, is defined as the maximum amount of plant-based human digestible protein (HDP) that can be derived from the land used to cultivate the feed to produce one kilogram HDP from ASF (van Zanten et al., 2016b). A LUR below one implies that livestock produce more HDP per $\mathrm{m}^{2}$ than food crops could on the same land. As described in detail in Appendix D4, the

$$
L U R=\frac{\sum_{i=1}^{n} \sum_{j=1}^{m}\left(L O_{i j} \times H D P_{j}\right)}{\text { HDP of one } \mathrm{kg} A S F}
$$

where $L O_{i j}$ is the land area $\left(\mathrm{m}^{2}\right)$ occupied for a year to cultivate the amount of feed ingredient $i$ $(i=1, n)$ in country $j(j=1, m)$ needed to produce $1 \mathrm{~kg}$ ASF, in this case eggs and chicken meat, including rearing young stock. $H D P_{j}$ is the maximum amount of $H D P$ that can be produced per $\mathrm{m}^{2} /$ year by direct cultivation of food-crops in country $j$. The denominator contains the amount of HDP of one $\mathrm{kg} A S F$ (van Zanten et al., 2016b).

\section{Results}

Using economic allocation, the GWP per kg Kipster egg was $1.13 \mathrm{~kg} \mathrm{CO}_{2}$-eq, the $\mathrm{EU}$ was $11.86 \mathrm{MJ}$, and the LU was $2.99 \mathrm{~m}^{2}$ of which $61-73 \%$ resulted from the laying phase (Figure 3). These results consider the impacts avoided by replacing grid energy with surplus solar energy, and replacing broiler meat with rooster and laying hen meat (Appendix D5; Table D6). The solar energy surplus of $80,476 \mathrm{kWh}$ reduced egg production phase GWP by $0.095 \mathrm{~kg} \mathrm{CO}_{2}$-eq, EU by $1.42 \mathrm{MJ}$, and LU by $0.002 \mathrm{~m}^{2}$ per kg eggs (Appendix D5, Table D10). The 12,900 kg meat produced from culled laying hens further reduced GWP by $0.17 \mathrm{~kg} \mathrm{CO}_{2}$-eq, EU by $0.99 \mathrm{MJ}$ and LU by $0.24 \mathrm{~m}^{2}$ per $\mathrm{kg}$ egg. The $13,750 \mathrm{~kg}$ meat produced from male chicks reduced GWP of rearing male chicks by $0.18 \mathrm{~kg} \mathrm{CO}_{2}$-eq, EU by $1.06 \mathrm{MJ}$, and LU by $0.26 \mathrm{~m}^{2}$ per $\mathrm{kg}$ egg.

\subsection{Food-based versus economic allocation}

Food-based allocation reduced the GWP per kg Kipster egg to $0.49 \mathrm{~kg} \mathrm{CO2-eq,} \mathrm{EU} \mathrm{to} \mathrm{7.19} \mathrm{MJ,} \mathrm{and}$ LU to $0.11 \mathrm{~m} 2$ (Figure 3). The majority of this reduction occurred in the laying phase, as only laying hens were fed an LCF-based diet. The contribution of the laying phase to the total impact per $\mathrm{kg}$ egg was reduced to $55 \%$ for GWP, $44 \%$ for EU, and $-206 \%$ for LU. The negative LU of the laying phase, the hatched area in Figure 3, resulted from the LU avoided by replacing broiler meat with laying hen meat (0.24 m2/ kg egg), being higher than the LU in the laying hen phase $(0.02 \mathrm{~m} 2 / \mathrm{kg}$ egg). The reduction in GWP (26\%) and EU (13\%) in the rearing phase was relatively small, while the reduction of LU was $59 \%$. 


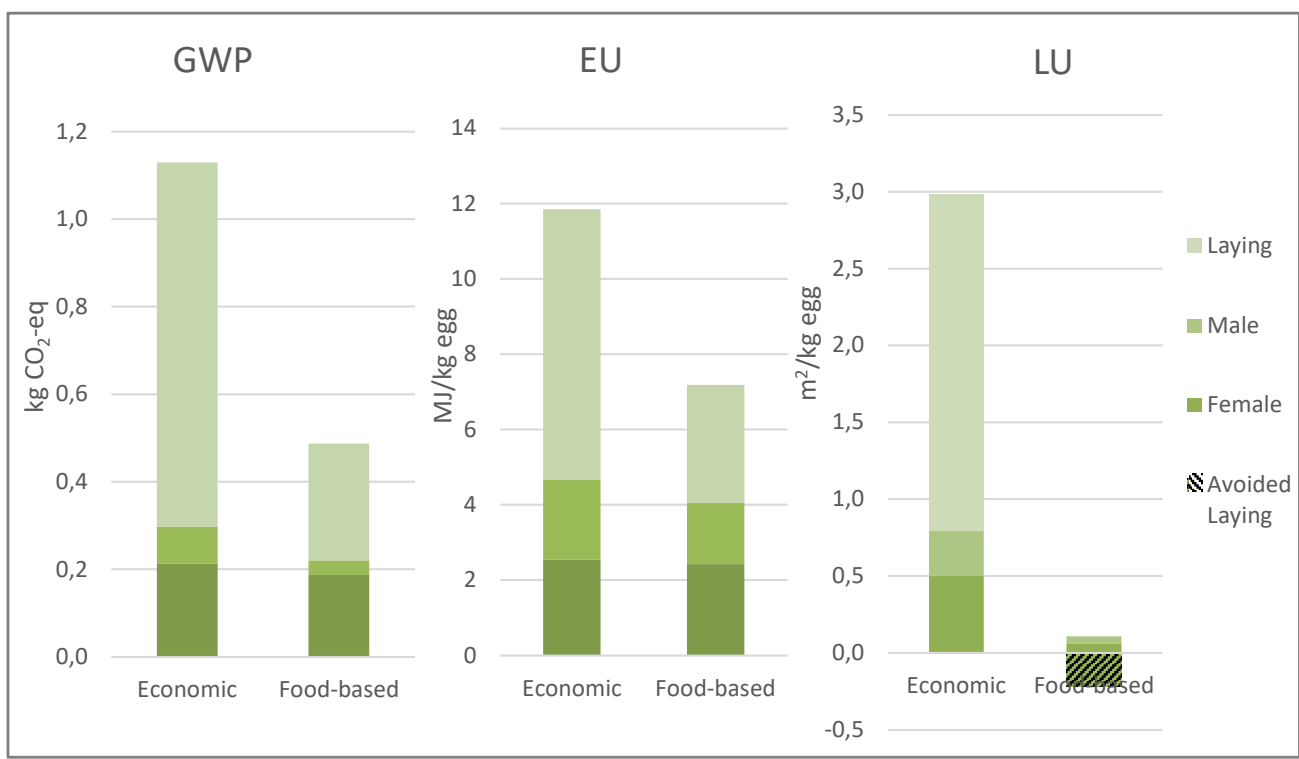

Figure 3. Global warming potential (GWP), energy use (EU), and land use (LU)/kg egg of Kipster as a whole using economic and food-based allocation, and the contribution of rearing of female and male chicks and egg production.

Using economic allocation, the majority of the GWP, EU, and LU per kg Kipster egg was related to feed production (Table 4). For GWP, a relatively large share (14.5\%) of the impact originated from manure management. For EU, the use and production of farm energy sources accounted for $22.5 \%$. While feed production remained the dominant impact source, food-based allocation reduced its contribution to all indicators (Table 4).

Table 4 Percentage of Kipster's global warming potential (GWP), energy use (EU) and land use (LU) resulting from energy use/production, feed production, bedding production, and manure management under economic and food-based allocation.

\begin{tabular}{|c|c|c|c|c|c|c|}
\hline & \multicolumn{3}{|c|}{ Economic } & \multicolumn{3}{|c|}{ Food-based } \\
\hline Input & GWP & $\mathrm{EU}$ & LU & GWP & EU & $\mathrm{LU}$ \\
\hline Energy & 5.8 & 22.5 & 0.0 & 9.9 & 32.4 & 0.0 \\
\hline Feed & 79.7 & $77 \cdot 5$ & 99.9 & $65 \cdot 3$ & 67.6 & 99.8 \\
\hline Bedding & & & & & & \\
\hline material & 0.0 & 0.0 & 0.0 & 0.0 & 0.0 & 0.0 \\
\hline Manure & 14.5 & 0.0 & 0.0 & 24.8 & 0.0 & 0.0 \\
\hline
\end{tabular}

\subsection{Diet scenarios}

With economic allocation, neither of the alternative diets (S2-S3) reduced the impact per kg egg for all indicators simultaneously, compared to the baseline diet (S1) (red dashed line, Figure 4). The insect meal diet ( $\left.\mathrm{S}_{3}\right)$ greatly reduces LU while slightly increasing EU and GWP. Food-based allocation results in a lower environmental impact on all indicators for all diets, most pronouncedly 
for LU. The difference between allocation methods is less pronounced for the insect meal diet $\left(\mathrm{S}_{3}\right)$ due to the high EU of insect rearing and the low economic value of the insect feed. With food-based allocation, the lowest impact on all indicators is achieved using the baseline diet (S1) (black dashed line, Figure 4).

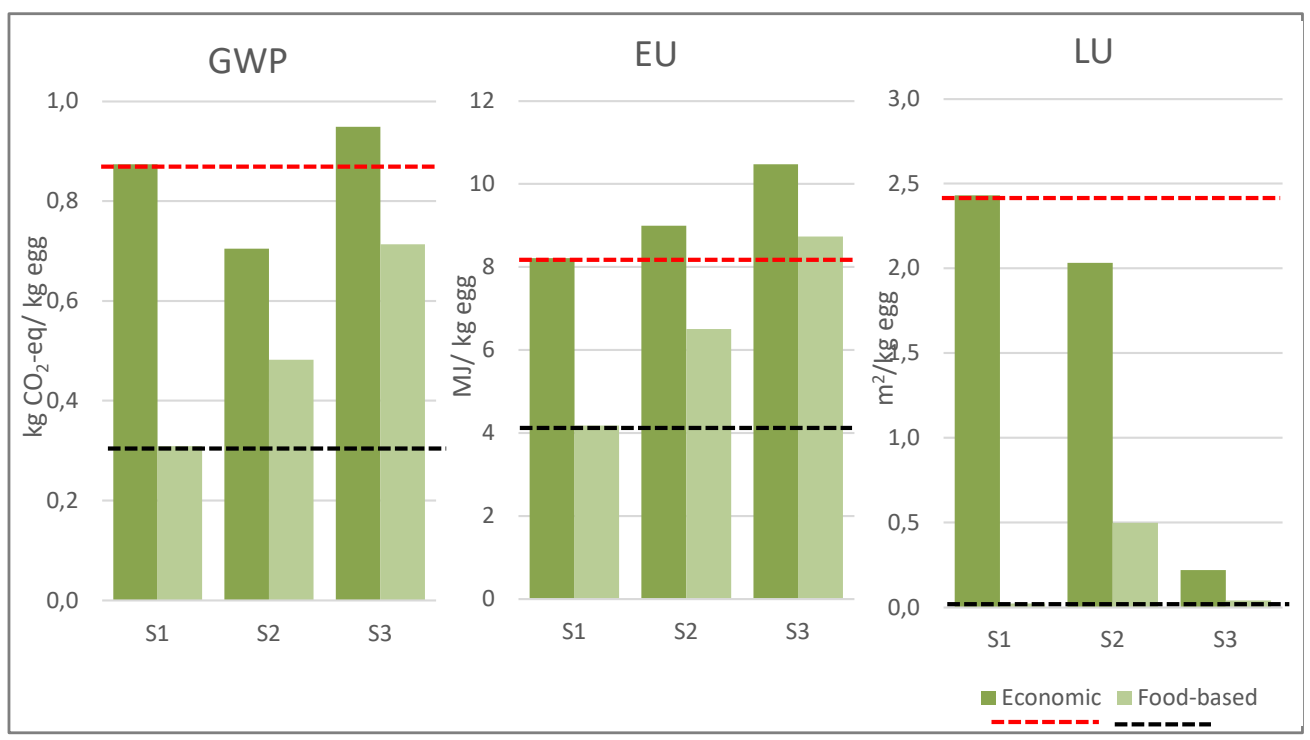

Figure 4 the environmental impact (GWP, EU, LU)/ kg egg from the Kipster system using alternative diets ( $\mathrm{S} 2$ soy bean meal, $\mathrm{S}_{3}$ insect meal), compared to the current diet (S1) using economic and food-based allocation.

\subsection{Land use ratio}

Using economic allocation, the LUR of the laying phase alone is $\geq 1$ for both S1 (1.14) and S2 (1.06). This implies that the land used to produce laying hen feed could yield more HDP if used to produce human food crops (Figure 5a). The LUR of S3 was o, implying an absence of competition for land between feed and food production. Adding the 0.57 LUR of the rearing phase to consider the entire Kipster system resulted in an LUR of 1.70 for $\mathrm{S} 1,1.63$ for $\mathrm{S} 2$, and 0.57 for $\mathrm{S} 3$ (Figure 5b). Using food-based allocation, the LUR of the laying phase is o for $\mathrm{S}_{1}$ and $\mathrm{S}_{3}$. The LUR of 0.36 for S2 implies that some feed-food competition occurs. Adding the 0.30 LUR of the rearing phase results in an LUR of 0.66 for S2 and 0.30 for S1 and S3 (Figure 5b). These <1 LUR's imply that Kipster produces protein more efficiently than achievable with food crops grown on the same land, thereby contributing to food system efficiency. 


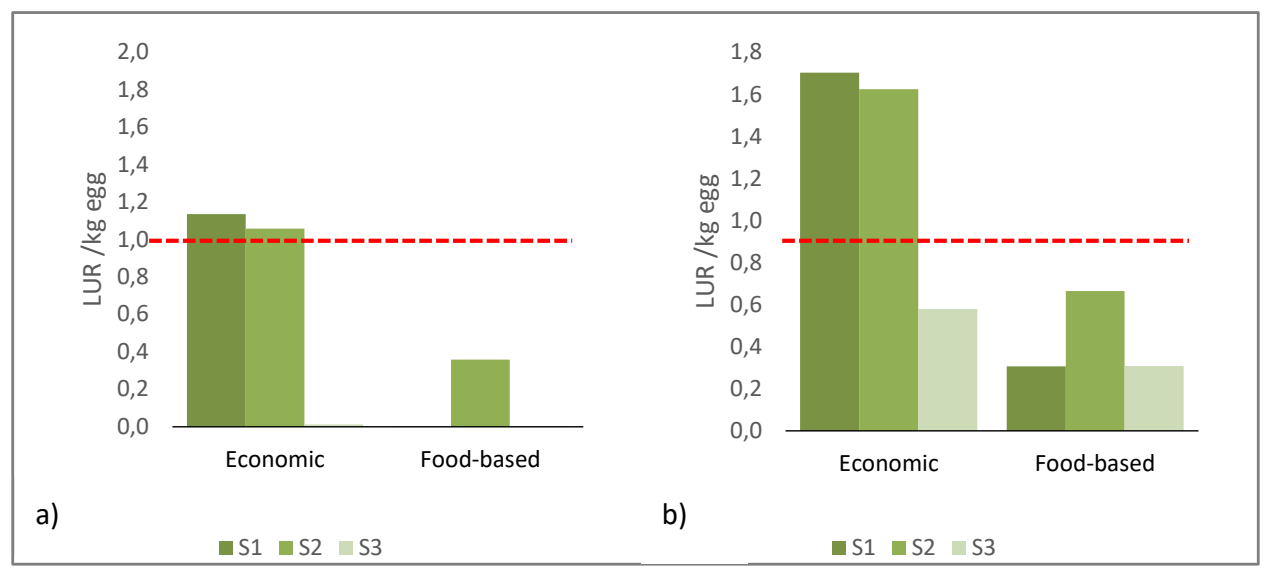

Figure 5 Land use ratio (LUR) of a) Kipster laying phase and b) Kipster as a whole under the current (S1) and alternative (S2-3) diets, using economic and food-based allocation.

\section{Discussion}

Before discussing the impact of allocation methods on LCA results, LCA results based on economic allocation are benchmarked against those found in literature. For this comparison, GWP results were recalculated using previously assumed equivalence weighing factors: 1 for $\mathrm{CO}_{2}, 25$ for $\mathrm{CH}_{4}$ and 298 for $\mathrm{N}_{2} \mathrm{O}$ (Forster P., 2007). The environmental impact per kg Kipster egg was lower than that of commercial free range or organic eggs (Table 4) due to avoided feed-food competition, onfarm solar energy use, supply of surplus solar energy to the grid, and rearing male chicks. While use and supply of solar energy reduced Kipster's environmental impacts, rearing male chicks resulted in a net impact increase; the impacts of growing male chicks were higher than impacts avoided by their meat output (Appendix D5; Table D6). This is a clear example of a sustainability trade-off, where addressing a social sustainability issue, namely culling of day-old chicks (Kipster, 2017), results in an environmental cost. Excluding the benefits of solar energy use and supply and the costs of rearing male chicks (Appendix D5, Tables D6 \& D11), resulted in a GWP of $1.43 \mathrm{~kg} \mathrm{CO}_{2^{-}}$ eq, EU of 14.77 MJ, and LU of $2.70 \mathrm{~m}^{2}$ per kg egg, and an LUR of 1.42. Compared to free range laying hens fed a conventional diet (Table 5), feeding only LCF to laying hens reduced GWP by 48$58 \%$, EU by $21-37 \%$, LU by $34-47 \%$, and LUR by $32 \%$. This was due to the small environmental impact allocated to LCF due to their relatively low economic value, and is in line with findings from studies assessing the impact of feeding specific LCF such as rape seed meal(van Zanten et al., 2015a), waste fed insects (van Zanten et al., 2015b), and food waste (zu Ermgassen et al., 2016). 
Table 5 Global warming potential (GWP), energy use (EU), and land use (LU) per kg egg from free range and organic systems found in literature and of Kipster found in this study.

\begin{tabular}{|c|c|c|c|c|c|c|c|}
\hline \multirow[b]{2}{*}{ Study } & \multicolumn{2}{|c|}{ GWP } & \multicolumn{2}{|c|}{ EU } & \multicolumn{2}{|c|}{ LU } & \multirow{2}{*}{$\begin{array}{c}\text { LUR } \\
\text { Free range }\end{array}$} \\
\hline & Free range & Organic & Free range & Organic & Free range & Organic & \\
\hline Dekker et al. (2011) & 2.75 & 2.54 & 23.45 & 20.55 & 4.08 & 6.76 & - \\
\hline Leinonen et al. (2012) & 3.38 & 3.42 & 18.78 & 26.41 & 5.10 & - & - \\
\hline Van Zanten et al. (2016) & - & - & - & - & - & - & 2.08 \\
\hline Kipster (current study) & 1.14 & - & 11.86 & - & 2.98 & - & 1.70 \\
\hline
\end{tabular}

Accounting for feed-food competition with food-based allocation further reduced the environmental impact per kg egg by 57\% for GWP, 40\% for EU, 96\% for LU (Figure 3), and 88\% for LUR (Figure 4). As to date, Kipster only avoids feed-food competition in the laying phase, the main impact reductions are achieved there. The reduction is most pronounced for LU, while the limited reduction in EU and GWP is due to the smaller contribution of feed production on these impacts (Table 4) and the energy needed to process LCF into compound feed, such as animal fat refinery, drying and additive production. GWP and EU can be further reduced by avoiding heavilyprocessed co-products, improving production processes, or using renewable energy sources. The second law of thermodynamics determines that recycling materials in a circular food system always requires energy which, by definition should be obtained from renewable sources (Korhonen et al., 2018).

A conventional LCA with economic allocation not only underestimates the mitigation potential of strategies directed at avoiding feed-food competition, it even promotes the use of food crops as livestock feed (van Zanten et al., 2018). This has been demonstrated in studies aiming to reduce the environmental impact of livestock production, as well as in studies aiming to reduce the impact of human diet. The latter typically recommend replacing grass-based beef with meat from fastgrowing livestock such as broilers (Hallström et al., 2015) which are fed high quality feed-like cereals.

Accounting for feed-food competition in LCA is essential to promoting the circular food system and economy strived for by the Dutch government (Rijksoverheid, 2016) and the European Union (European Commission, 2015). This study illustrates the potential of food-based allocation to account for feed-food competition. Food-based allocation is simplified and binary; a product is allocated all the impact of cultivation and processing when suitable for human consumption, and none when unsuitable. This simplistic allocation - assuming products are either food or not - is applicable in the case study, where only products unfit for human consumption are fed to livestock. When assessing conventional systems with a high-quality feed diet, the impact allocated to each product should reflect its value for human nutrition. Developing this type of allocation method is 
complex, as it requires implementing a measure expressing nutritional value including multiple nutritional aspects such as the nutrient density score (van Kernebeek et al., 2014). This score considers the nutrient content per $100 \mathrm{~g}$ of a product relative to the daily recommended nutrient intake, and averages the score per nutrient into one final score (Drewnowski \& Fulgoni III, 2014). Besides the complexity of implementing this score in an allocation method, it does not fully account for the nutritional benefits of ASF, for example, essential vitamin B12 is only available in animal products, and the amino acid composition matches daily requirements better than plant-source foods (Ertl et al., 2016).

Food system modelling (van Kernebeek et al., 2016) or scenario studies (Schader et al., 2015) are the most promising methods for capturing the complexity of the food system. Although these methods are unsuited to assessing or monitoring the impact of an individual product or production system, they provide valuable insights into how much ASF can be consumed when feeding only LCF. van Zanten et al. (2018) reviewed these food system studies and showed that feeding livestock LCF only, globally provides about 9-23 grams of animal protein per capita per day. Per capita availability of ASF when feeding only LCF can be further increased by optimally using LCF (van Hal et al., 2019) and exploring alternative LCF ingredients such as insect meal, as in S3 in this study. The insect meal diet $\left(\mathrm{S}_{3}\right)$ showed reductions of LU at the cost of an increase in EU and GWP. The high EU and GWP relate to the assumed high EU from larvae rearing and processing, based on an experimental trial of rearing larvae on food waste and manure conducted by a Dutch waste processor (van Zanten et al., 2015b). Both can be reduced by using renewable energy and developing industry-scale larvae rearing systems (van Zanten et al., 2015b), which can only occur when European legislation no longer prohibits the use of waste-fed insects in animal feed (van Zanten et al., 2015b).

Avoiding feed-food competition assumes that the ultimate goal of the food system is to feed humans efficiently, thereby neglecting other purposes served by agricultural production. In reality, the debate around competition for agricultural resources should not only consider the production of food and feed, but also the production of fibre (e.g. cotton), fuel (e.g. wood, biofuels), and the provision of other ecosystem services. This competition framework is complex and has not been comprehensively studied (Muscat et al., 2019). In the larger perspective of the battle for biomass, leftovers from the agricultural sector should be considered for other purposes than feeding livestock, keeping in mind that livestock feeding is seen as the most valuable use of food waste and by-products (Papargyropoulou et al., 2014). Including feed-food competition in the environmental impact assessment of food is an important first step towards a more efficient agricultural system. 


\section{Conclusion}

Compared to free range laying hens fed a conventional diet, feeding only low-opportunity-cost feeds (LCF) reduced GWP by $48-58 \%$, EU by $21-37 \%$, LU by $34-47 \%$ and LUR by $32 \%$ in case of economic allocation. This was caused by the small environmental impact allocated to LCF due to their relatively low economic value. Using food-based allocation, the impact per kg egg was further reduced by $54 \%$ for GWP, $38 \%$ for EU, $94 \%$ for LU, and $88 \%$ for LUR. An LCA with economic allocation underestimates the environmental benefits of avoiding feed-food competition. Although food-based allocation illustrates the inadequacy of LCA in accounting for the complexity of the food system, it is as yet simplistic, and should be further developed to reflect the nutritional value of coproducts for human nutrition. To promote mitigation measures that improve the resource use efficiency of the entire food system, improved LCAs that capture the complexity of the food system are needed.

\section{Acknowledgements}

This project received funding from the European Union's Horizon 2020 research and innovation program under grant agreement No 633692. The views expressed in this publication are the sole responsibility of the authors and do not necessarily reflect the views of the European Commission. 


\section{Chapter 6}

General discussion 


\section{Introduction}

The food system is faced with the challenge to feed a growing world population while limiting environmental impacts and resource use (Giampietro, 2019; Springmann et al., 2018; Willett et al., 2019). The EU aims to address this challenge by shifting to a more circular food system, as increasingly proposed by scientists (European Commission, 2015; Giampietro, 2019; Jurgilevich et al., 2016). A central principle of a circular food system is to prioritise the use of resources for direct food supply to avoid feed-food competition. This implies arable land should be used to cultivate food crops, and the edible yield of sustainably caught fish should be used for direct human consumption (de Boer \& van Ittersum, 2018; van Zanten et al., 2019). This food production and consumption, however, results in leftovers that are unsuitable or undesired for human consumption, such as food processing by-products and food waste (Caldeira et al., 2019). Farm animals can contribute to a circular food system by upcycling these food leftovers and grass resources, into valuable animal-source food (ASF) that contains essential nutrients (Garnett, 2009, 2011; van Zanten et al., 2018). As such low-opportunity-cost feeds (LCF) otherwise have a less valuable role in the food system, a diet containing a small amount of ASF from animals fed only LCF appears most resource efficient (van Zanten et al., 2018).

A review that explored the role of animals in a circular food system shows that animals, fed only LCF, can provide 7-30 g human digestible protein (HDP) per capita per day (cap/d) (van Zanten et al., 2018). While the reviewed studies illustrated that farm animals have a role in a circular food system, they gave limited insight into how different animals can contribute to the efficient use of LCF. This thesis, therefore, aims to evaluate the potential of various farmed animals in upcycling LCF in a circular food system, using the EU-28 as a case study, and addresses two main objectives. The first objective is to explore what combination of animals is needed to optimally use available $\mathrm{LCF}$, considering a variety of production animals and productivity levels. The second objective is to explore how to account for feed-food competition in chain level environmental impact assessment in practice. In Section 2, I will address the first objective by describing the unique role of different animal production systems (APS) to the optimal use of LCF. In Section 3, I will address the second objective by illustrating the relevance of accounting for feed-food competition in life cycle assessment (LCA) in order to derive mitigation strategies that stimulate a resource efficient food system (Section 3). Finally, I discuss how these findings contribute to the transition towards a circular food system, describe what further research and societal change is needed (Section 4), and provide the conclusions of this thesis (Section 5). 


\section{Animals in a circular food system}

To evaluate the value of different animals to a circular food system, I first explored under which two conditions these animals should function. The first condition relates to the availability and nutritional properties of the biomass expected to be available as LCF in a circular food system (Section 2.1), whereas the second condition relates to the nutrients humans want to derive from ASF (Section 2.2). To assess the potential of different animals given these conditions (Section 2.3), I developed an optimisation model that allocates available LCF to that combination of animals that contributes most to required nutrient supply (Chapter 2, 3 and 4). Finally, the answer to objective one is presented in section 2.4.

\subsection{Low-opportunity-cost feeds (LCF)}

There is much debate on what products should be considered LCF and differences in their assumed availability causes high variation between studies that predicted ASF supply when feeding only LCF (van Zanten et al., 2018). So far, most studies manually formulated LCF based rations and did not explore the potential applications of each LCF. van Zanten et al. (2016a) and Elferink et al. (2008), for example, assigned all food leftovers to pigs, while Röös et al. (2017b) assigned most of them to dairy cattle. The optimal allocation of LCF to different animals, so far was unknown. Below I explore the nutritional properties of the products expected to be available as LCF in a circular food system, and the potential role of different farm animals in upcycling them based on these properties. I considered both grass and a wide range of food leftovers (assumptions are illustrated in Figure 1).

\section{$\underline{\text { Grass }}$}

Grass resources consist of a variety of fibrous biomass obtained from managed grassland, natural grassland, or rangeland. Managed grassland is used to produce grass with use of management like fertiliser application, irrigation and/or harvesting, while natural grassland and rangeland are typically grazed extensively (Bruinenberg et al., 2002). Rangelands typically contain woody vegetation (Plutzar et al., 2016). My exploration of the nutritional quality of grass resources potentially available as LCF in an EU circular food system, illustrated that grass makes a major contribution to ASF supply due to its high availability throughout the EU and its provision of a balanced ration to ruminants. Below I discuss the value of grass and grazing to a circular food system and how limitations in data availability, and my assumptions, influenced my results. 


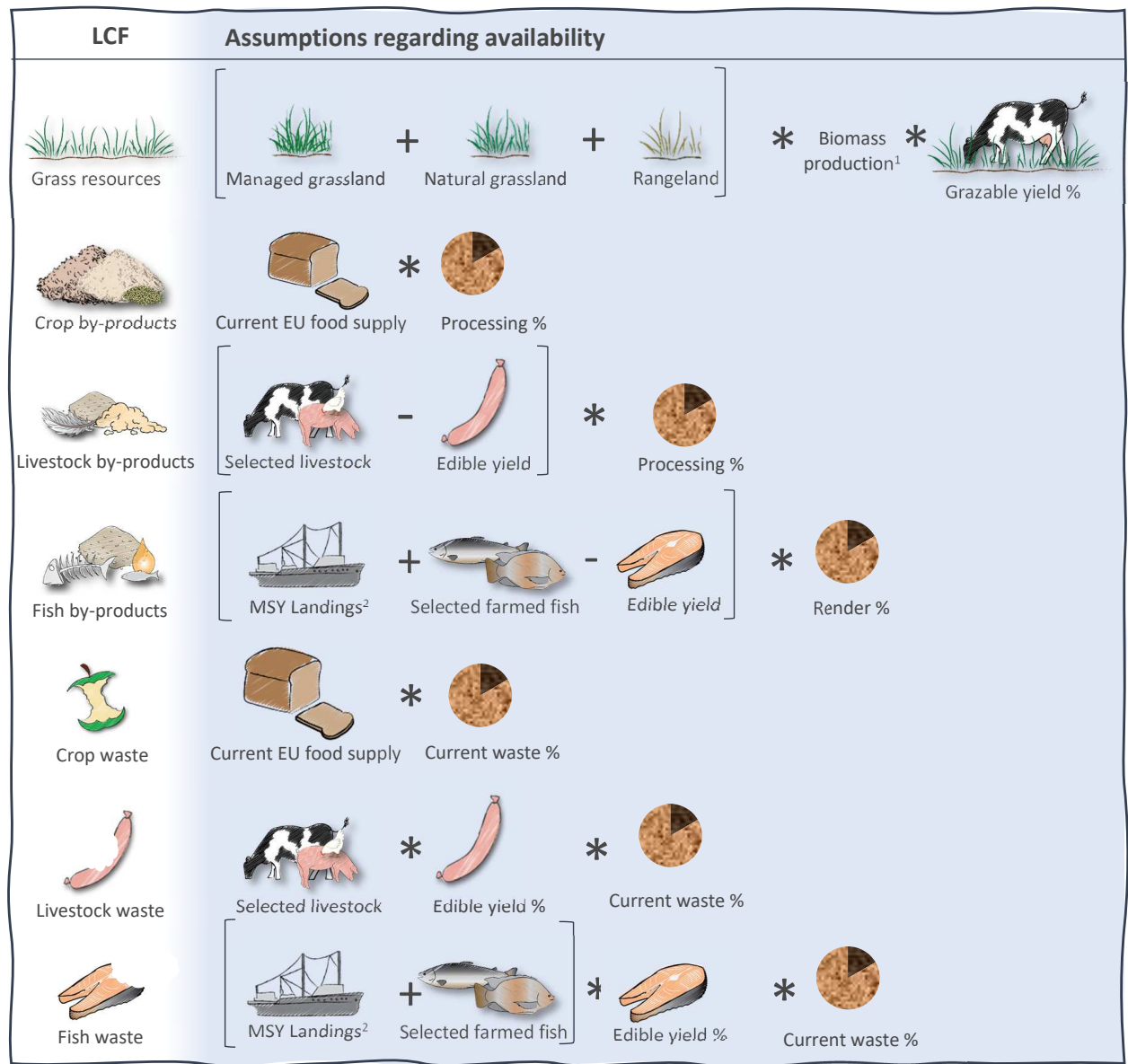

${ }^{1}$ Grass biomass production was based on net primary productivity (Chapter 2)

${ }^{2}$ MSY Maximum Sustainable Yields as defined in EU fisheries policy (EU, 2013b)

Figure 1 Included low-opportunity-cost feeds (LCF) and their assumed availability.

In my assessment I assumed all produced grass resources were available as LCF, and as long as it was used in the country of origin, grass could be combined with other LCF. Predicted dairy cattle rations typically combined low quality grass with high quality grass, and food leftovers (Chapter 2, 3 and 4). This ration reflects traditional European farming systems where, especially in mountainous areas, dairy livestock graze extensively in summer and are fed cultivated grass and cereals at the homestead in winter (Dodgshon \& Olsson, 2007). Prevalence of such transhumanist farming systems that use natural grassland and rangelands is, however, threatened for two reasons. First, they conflict with modern lifestyle standards as mountain pastures are often remote (from roads and farmstead), low productive and can only be used seasonally (Dodgshon \& Olsson, 2007; Fetzel et al., 2017a; Hinojosa et al., 2016). Second, the farmland at the homestead is increasingly 
intensified to produce crops with a higher value (Kristensen et al., 2004; Vicente-Serrano et al., 2004). When left unused, natural grasslands and rangelands are generally encroached by forest, which likely increases their carbon storage and is beneficial to mitigate climate change (Arora \& Montenegro, 2011). Proponents of preserving the use of natural grassland and rangeland, however, stress that they not only contribute to food supply, but also provide specific biodiversity, cultural values and a buffer against forest fires (Bengtsson et al., 2019; Caballero, 2007; Fetzel et al., 2017a; Krahulec et al., 2001).

For grass produced on managed grassland its availability as LCF is also under debate. To some extent this managed grassland is suitable for food crop cultivation, which would result in more efficient use of resources (Garnett, 2011; van Kernebeek et al., 2016). Conversion of grassland into cropland, however, is controversial as it results in release of stored carbon, loss of biodiversity and cultural value (Foley et al., 2005; Foley et al., 2011; Gerber et al., 2013). In Chapter 2, I illustrated that managed grassland is responsible for about $36 \%$ of animal protein supply in the simulated circular food system (van Hal et al., 2019a). The extent to which this land is used to cultivate grass, thus, has major impact on the extent of animal production in a circular food system. Achieving a consensus on the use of managed grassland requires better understanding of the above described controversy (Section 4.1). In conclusion, my approach illustrated the role of grass resources of different qualities in a circular food system. Future research that takes in account additional constraints to the use of this grass is, however, needed to better understand the role of ruminants in a circular food system.

\section{Food leftovers}

Food leftovers consist of biomass that enter the food supply chain but are not be consumed by humans, and include a variety of crop-residues, food processing by-products and food wastes. Crop residues are unharvested crop biomass, while by-products are unintended outputs of food processing, and food waste are products intended for human consumption but wasted along the supply chain (FAO, 2011). While, to some extent, crop residues are currently used as feed, a circular food system assumes most crop residues are left on the field to maintain soil fertility (de Boer \& van Ittersum, 2018). While there is debate on how much crop-residues a healthy soil requires, I excluded crop residues as feed since they are of limited feed value, and are more likely used as bedding material for animals (de Boer \& van Ittersum, 2018; Hijbeek et al., 2017). For all other food leftovers, I explored their availability and nutritional properties as LCF in chapters 2, 3 and 4. 


\section{Crop processing by-products}

In Chapter 2 I explored the nutritional properties of crop processing by-products available as LCF. Processing of harvested crop products (e.g. wheat grain or sunflower seeds) into food items (e.g. sunflower oil) or ingredients (e.g. wheat flour), results in by-products (e.g. wheat bran and sunflower meal) that humans cannot or do not want to eat. Currently, most of these crop processing by-products are collected separately and used as animal feed (Vernier et al., 2016). The different crop by-products available vary in their nutrient content and can be classified based on their nutritional properties (Chapter 2). Cereal by-products, such as wheat bran, contain both energy and protein but can be quite fibrous. Oilseed by-products, such as sunflower meal, are protein rich and are commonly used as protein source. Molasses, a by-product of sugar production, contains a high amount of glycogenic energy. By-products from vegetables and tubers, pulps from sugar and juice production and hulls of various crops are generally bulky, implying they have a low nutrient content as they contain much fibre or water.

\section{Animal processing by-products}

While I only considered plant-based food leftovers in Chapter 2, the animals selected to upcycle LCF also produce animal-based food leftovers that could also be used as LCF. I was the first to explore their role in a circular food system (see Chapter 3 and 4). Like crop processing, slaughter and processing of live animals into food items (meat) results in various by-products that, although humans cannot or do not want to eat them, are highly nutritious (USDA, 2018b, 2018c). Animal by-products are already collected and can be processed into meals that contain processed animal proteins (PAPs) and rendered animal fat. For livestock, residual meat, bones, feathers, blood and organs are collected separately resulting in meals that differ in quality, that of bone and feather meal being lowest. For fish, all slaughter by-products are collected together, and rendered into fish oil and a protein rich fish meal (Cashion et al., 2016). Livestock fat is generally highly saturated, while fish oil is not and contains valuable fatty acids.

\section{Food waste}

In what form food wastes can be collected and recycled depends on the stage of the supply chain they are generated in. At the manufacturing stage - where food ingredients are combined into food items - wasted ingredients and finished products are collected separately by the former foodstuffs (FFS) industry, which processes them into feed ingredients (EFFPA, 2019). The majority of FFS consist of cereal-based products, either enriched with fat (bread) or with sugar (pastry). As FFS were intended for human consumption they are generally highly nutritious. Retailing waste, if collected in separate streams, could produce similar feed ingredients, but provides relatively more 
wasted fresh foods, such as meat and vegetables (Cicatiello et al., 2017; Teller et al., 2018). Meat and vegetables could be processed into meat meal and a bulky wet feed, respectively. At home, households collect all inedible parts and food scraps together resulting in mixed food waste (Truong et al., 2019; zu Ermgassen et al., 2016). To ensure the safety of mixed household food waste as feed, biohazardous contaminants should be inactivated with heat treatment and/or fermentation resulting a wet feed (swill) that can be fed as is (with $20-30 \% \mathrm{DM}$ ) or dried to a concentrate feed (with >80\% DM) (Luyckx et al., 2019).

\section{Consumption patterns and LCF generation}

van Zanten et al. (2018) indicated that most variation between studies in the assumed generation food leftovers related to differences in assumed human consumption patterns. The healthy vegan diet assumed by van Zanten et al. (2016a) generated less LCF than currently available as used as a starting point by Elferink et al. (2008). To secure healthy diets in a circular food system, we must not only reduce ASF consumption, but also adapt our plant-based food consumption to compensate for this reduction and to avoid overconsumption (Jurgilevich et al., 2016). To use resources efficiently we should, furthermore, avoid generation of waste and by-products where possible (EU, 2008). As we must refrain from recycling as a justification to continue wasting, food wasted for commercial reasons should be avoided (Caldeira et al., 2019). Similarly, generation of some byproducts can be avoided and may even result in healthier diets when, for example, whole grains are consumed instead of white flour (Borneo \& León, 2012). These changes in consumption patterns affect the generation of food leftovers and, thus, how much ASF can be produced in a circular food system. In this thesis, I approximated the availability of plant-based LCF in a circular food system based on current plant-based food consumption in the EU, marked by overconsumption (FAO, 2017c) (Figure 1). While this slightly overestimated the availability of LCF, it suits my aim to evaluate the role of different animals in a circular food system. Availability of animal-based LCF was based on our model explorations and thus reflected ASF consumption tailored to a circular food system (Figure 1).

\section{Legislation and other barriers to the use of $L C F$}

The use of food leftovers as LCF is currently limited by legislation and other barriers. In Chapter 4 I explored what biomass lost along the food supply chain is currently used as LCF and which could potentially be used in the future. While plant and fish by-products are already fully used as feed (Vernier et al., 2016), use of livestock by-products is restricted by legislation implemented to avoid the spread of diseases like bovine spongiform encephalopathy BSE and foot and mouth disease (EU, 2009, 2013a). The legislation bans PAPs from bodily tissues, the main disease transmitter, 
but allows feeding animal fats, egg and dairy products under feed-safety regulations. While directed at animal by-products, feed legislation also applies to food wastes potentially contaminated with animal protein (EU, 2017, 2018). Thereby, it bans feeding of any household waste to food producing animals, which we found to have a high ASF supply potential, especially when provided in dried form. Safe feeding of such household swill, however, requires considerable effort, both in terms of legalisation and development of collection and treatment infrastructures (Luyckx et al., 2019). In contrast, most manufacturing and retail waste is allowed to be used as feed, but remains unused due to a lack of economic incentive (Truong et al., 2019). The animal protein supply potential of these wastes is limited due to their low quantities, but their high quality enables upcycling of low quality LCF.

Since a 2013 amendment to stimulate efficient resource use, farmed fish are allowed to feed on PAPs of non-ruminant origin (EU, 2013a). As this did not increase use of livestock by-products in fish feeds, also barriers other than legislation limit the use of food leftovers as LCF (BioMar, 2018; IUCN, 2017). Understanding and potentially overcoming these limitations is of high relevance, as we found livestock by-products are highly nutritious, and using them in fish feed has a high ASF supply potential (Chapter 4). Future research is, however, needed to consider the consequences of using currently unused food leftovers as LCF, as they are currently often used as compost, and may play a crucial role in maintaining soil health, the fundament of a circular food system (de Boer \& van Ittersum, 2018; Hijbeek et al., 2017).

\subsection{Desired outcomes of animal production}

While humans value ASF for various reasons, I focussed on their role in nutrient supply. Regarding macronutrients, ASF mainly provides proteins and fats that, historically, were highly relevant for nutrition security, but are currently overconsumed in the EU (FAO, 2017c). Animal proteins have a high bioavailability and their amino acid composition matches well with human requirements. While livestock fats are considered unhealthy, as they are saturated and rich in cholesterol, fish oil is generally unsaturated and considered essential to a healthy diet (Grundy, 1997; Willett et al., 2019). Fish are currently our main source of eicosapentaenoic (EPA) and docosahexaenoic (DHA) $\omega$-3 fatty acids, essential for brain development and functioning, and immune regulation (KrisEtherton et al., 2009; Racine \& Deckelbaum, 2007; Simopoulos, 2009). While humans can desaturate alpha-linolenic acid (ALA) into EPA/DHA, both ALA intake and desaturation potential are limited (Calder \& Yaqoob, 2009). It is therefore recommended that diets contain a significant share of fish to fulfil the daily recommended intake of $250 \mathrm{mg}$ EPA/DHA (EFSA, 2017). 
Regarding micronutrients, ASF is valued for its high bio-availability of iron and zinc, and supply of nutrients mainly obtained from ASF, such as selenium, or even only obtained from ASF such as vitamin B12 (Godfray et al., 2018; Smith et al., 2013; van Hal et al., 2019a; van Zanten et al., 2018). While the optimisations in chapter 2, 3 and 4 maximise HDP supply, I also illustrate the supply of all nutrients of which sufficient intake may be at risk when reducing ASF food supply: vitamins A, D and B12, calcium, iron, zinc, selenium and EPA+DHA (Macdiarmid et al., 2012; Mertens et al., 2017). As the ASF provided by livestock and fish vary in their content of these nutrients (Table 1), a combination of animal production systems is needed to derive balanced diets. In chapter 3 and 4 meeting human requirements of vitamin B12 and EPA/DHA was prioritised as they are currently only provided by ASF and under-consumed by a significant part of the EU-28 population (de Smet, 2012; Duru, 2019; Givens \& Gibbs, 2008; Oh \& Brown, 2003).

Table 1 Nutrient content per kg fresh matter of the included animal source food (USDA, 2019), for each nutrient the foods with the highest contents are marked dark green and with a high content light green.

\begin{tabular}{|c|c|c|c|c|c|c|c|c|c|c|c|}
\hline \multirow[b]{2}{*}{ Product } & \multirow[b]{2}{*}{$\begin{array}{l}\mathrm{DM}^{*} \\
\mathrm{~kg}\end{array}$} & \multirow[b]{2}{*}{$\begin{array}{l}\text { Protein } \\
\mathrm{g}\end{array}$} & \multicolumn{2}{|c|}{ PUFA } & \multicolumn{3}{|c|}{ Vitamins } & \multicolumn{4}{|c|}{ Minerals } \\
\hline & & & $\begin{array}{l}\text { EPA } \\
\mathrm{g}\end{array}$ & $\begin{array}{l}\text { DHA } \\
\mathrm{g}\end{array}$ & $\begin{array}{l}\text { A } \\
\mu g\end{array}$ & $\begin{array}{l}\mathrm{D} \\
\mathrm{Mg}\end{array}$ & $\begin{array}{l}\text { B12 } \\
\mu \mathrm{g}\end{array}$ & $\begin{array}{l}\text { Calcium } \\
\mathrm{mg}\end{array}$ & $\begin{array}{l}\text { Iron } \\
\text { mg }\end{array}$ & $\begin{array}{l}\text { Zinc } \\
\mathrm{mg}\end{array}$ & $\begin{array}{l}\text { Selenium } \\
\mu \mathrm{g}\end{array}$ \\
\hline Pig meat & 0.51 & 291 & 0.0 & 0.0 & 38 & 10 & 8 & 173 & 11 & 30 & 396 \\
\hline Pig offal & 0.33 & 198 & 0.6 & 0.2 & 163 & 8 & 91 & 155 & 68 & 34 & 367 \\
\hline Cattle meat & 0.41 & 293 & 0.0 & 0.0 & 20 & 1 & 31 & 129 & 28 & 69 & 307 \\
\hline Cattle offal & 0.34 & 231 & 0.5 & 0.1 & 584 & 5 & 313 & 383 & 45 & 46 & 191 \\
\hline Milk & 0.12 & 33 & 0.0 & 0.0 & 460 & 1 & 5 & 1130 & 0 & 4 & 37 \\
\hline Poultry meat & 0.38 & 260 & 0.1 & 0.4 & 46 & 0 & 3 & 140 & 12 & 19 & 210 \\
\hline Poultry offal & 0.32 & 272 & 0.1 & 0.3 & 18 & 0 & 94 & 140 & 70 & 42 & 596 \\
\hline Eggs & 0.26 & 123 & 0.0 & 0.1 & 175 & 20 & 15 & 540 & 16 & 12 & 301 \\
\hline Salmon & 0.35 & 254 & 6.9 & 14.6 & 690 & 140 & 40 & 150 & 3 & 4 & 414 \\
\hline Tilapia & 0.28 & 262 & 0.1 & 0.8 & 0 & 37 & 19 & 140 & 7 & 4 & 544 \\
\hline
\end{tabular}

*Dry matter content (DM): note that low dry matter content of milk and eggs causes relatively low protein contents

\subsection{Potential of various animals}

In circular food system, ASF can be obtained from harvested wild animals or from farm animals fed LCF, considering both terrestrial animals (livestock when farmed) and aquatic animals (fisheries and aquaculture). Sustainable harvest of wild animals should not exceed the restorative capacity of ecosystems (Froese et al., 2018). For fisheries - the harvest of wild fish that is a common source of food in the EU - historic over-exploitation has compromised the production potential of fish stocks in the EU (Hamilton et al., 2020). In Chapter 3, I proposed that fisheries tailored to a circular food system requires that harvest is limited to the maximum sustainable yield (MSY) implemented in EU legislation (EU, 2013b) and that all edible fish should be used for human consumption. I found that such fisheries provide $2 \mathrm{~g}$ HDP (cap/d) and fulfil $40 \%$ of EPA/DHA requirements. As terrestrial wild animals make a limited contribution to EU food supply, I did not 
explore their potential (FAO, 2017a). In chapter 2, 3 and 4 I assessed what characteristics of different livestock and farmed fish are of value in a circular food system and if reduced livestock productivity enables better use of available LCF. Below I discuss the value of the considered farm animals to the optimal use of LCF.

\section{Ruminant livestock}

Ruminants are terrestrial animals with a complex digestive system adapted to degrade fibrous feed through anaerobic digestion. While in the EU food producing ruminants include various types of cattle, sheep and goats, I used the most common species (dairy and beef cattle) as a representative (Chapter 2). During rumination, rumen microbiota digest mechanically degraded fibre into volatile fatty acids (energy) and microbial biomass (protein) used for animal metabolism and production (Baldwin, 1995). Research showed rumination is essential both for ruminant health (Webb et al., 2013) and welfare (Kok et al., 2017). Historically, humans used ruminants to graze fibrous vegetation and valued both the food and manure they provided (Dodgshon \& Olsson, 2007). Since the onset of the industrial revolution ruminant production has intensified and specialised, which increased productivity and replaced roughage with concentrate feeds (Hinojosa et al., 2016; Kristensen et al., 2004; Vicente-Serrano et al., 2004). Recent efforts to mitigate GHG emission enhance this trend, as the potent GHG methane is produced from volatile fatty acids produced specifically when degrading fibre (Baldwin, 1995; Garnett et al., 2017). With this transition, ruminant production became less directed at upcycling grass, which has reduced the resource use efficiency of our food system (Dumont et al., 2018; Wilkinson \& Lee, 2018).

My results show that in a circular food system, ruminants revert to their traditional role of valuing grass. As dairy cattle provide a daily product, they upcycle grass more efficiently than beef cattle (de Vries \& de Boer, 2010). Throughout this study the model selected dairy cattle to upcycle as much grass resources as possible. Regardless of the low productivity of the selected dairy cattle, their nutrient requirements could only be met by supplementing their diets with high quality LCF, such as oil seed meals and enriched cereals (bread meal). Furthermore, these cattle were unable to upcycle all grazing resources and left up to $62 \%$ of nature grass and $82 \%$ of rangeland unused. Increased availability of high quality LCF, however, enabled them to value more of the low quality grass (Chapter 4). Although the nutrient content of milk was relatively low due to its low DM content, its daily supply provided much HDP and vitamin B12, and is an excellent source of calcium. The meat and offal that accompany this milk production are rich in iron, zinc and especially vitamin B12. 
Dairy cattle were likely unable to value low quality grass due to their assumed nutrient requirements. The equations of the Dutch feed system underlying these requirements have been validated for Holstein Frisians, specifically bred for a high milk production and inefficient under low production (CVB, 2012). Future research should indicate how well marginal grass can be valued by traditional breeds, developed over centuries to thrive in these circumstances (Caballero, 2007). Considering the use of marginal grassland is often limited by remoteness as discussed in Section 2.1. Beef farming that requires less management, therefore, may be more realistic on these lands. We furthermore found beef cattle were better adapted to value low quality grass (Chapter 2). To stimulate use of marginal grasslands, small ruminants (i.e sheep and goats) may be of value as their small size and agility enables them to travel further and through rougher areas. As small ruminants browse rather than graze, they are well adapted to value rangeland biomass and grass left unharvested by cattle (Gordon et al., 1996). As the use of fibrous low quality grass may result in high methane emissions, GHG emissions should be considered when exploring the value of extending grazing of natural grassland and rangeland in a circular food system.

\section{Monogastric livestock}

Monogastric livestock are food producing, terrestrial animals with one stomach that in the EU include pigs and poultry (FAO, 2017d). Monogastric livestock convert feed into ASF more efficiently than ruminants, but their feeds typically contain more human edible products and high quality feed crops (de Vries \& de Boer, 2010; van Zanten et al., 2016b). Historically, humans kept pigs to convert food waste, often of the farm household, into ASF and manure (White, 2011). Pigs were especially suitable for this role due to their high feed intake capacity (FIC), as they eat almost everything (zu Ermgassen et al., 2016). Poultry, historically, were mainly farmed for egg production and kept in backyard systems, where they scavenged on insects, plants and harvest spills, but were also fed some cereals (Dixon, 1850). Both pigs and poultry thus helped get rid of a hazardous wastes, while providing food and manure. As no artificial fertiliser was available, manure was valuable for food crop cultivation (Woods, 2012). Currently, these animals are kept in highly specialised and intensified systems (Woods, 2012), where breeding and technological improvements increased productivity, but also require more and better quality feed (White, 2011).

My results show that in a circular food system, pigs revert to their role as "waste bin" while laying hens were mainly appreciated for the high efficiency at which they convert LCF into eggs. Throughout this study the model selected pigs to upcycle wet and fibrous food processing byproducts, and (when provided) treated wet household swill. When such household swill was dried, however, it became a high quality feed ingredient, which was more efficiently converted by laying 
hens (Chapter 4). While our model included broilers (chickens kept for meat production), these were never selected, indicating other animals provided the demanded nutrients more efficiently. Similarly, laying hens of low productivity were never selected, emphasising they were valued for the efficiency at which they convert high quality LCF. While both meat and eggs provided by monogastrics contributed to HDP and vitamin B12 supply, eggs may also contribute to the supply of vitamin A.

\section{Farmed fish}

Farmed fish consider finfish farmed in aquaculture systems, which are highly industrialised in Europe (European Commission, 2017). While the EU currently farms a variety of carnivorous and omnivorous fish species of different trophic levels, I used the high trophic, carnivorous and fatty Atlantic salmon and low trophic, omnivorous Nile tilapia as a representative species. Historically, fish farming traditions started in early Egyptian and Chinese civilisations (Malindine, 2019). In Europe they were introduced in their modern form- where eggs are fertilised and the hatched fish are fed and harvested - in the $18^{\text {th }}$ century (European Commission, 2019). Gradually, this system intensified from feeding fish to keeping fish in fully controlled environments (European Commission, 2019). Fish farming is increasingly implemented to meet the demand for fish as supply from fisheries is limited by nature's production potentials (Froehlich et al., 2018; HLPE, 2014).

My results show that in a circular food system, farmed fish have an important role in upcycling animal-based LCF. Under current legislation, only fish are allowed to feed on most livestock PAPs, and are, therefore, the only means to upcycle these valuable feeds (EU, 2013a). Also when this legislative restriction was released most livestock PAPS were fed to farmed fish, indicating these production systems are most efficient at upcycling animal by-products (Chapter 4). Farming of fatty fish like salmon that are rich in EPA/DHA is, furthermore, essential to meet human EPA/DHA requirements as, even under fish stock recovery as fisheries alone cannot meet this demand. In my optimisation, salmon production was, thus, driven by the demand for EPA/DHA, and supply of these nutrients is their main role in the proposed circular food system.

To supply EPA/DHA, and for their own health, these fatty fish require feed with a high EPA/DHA content, commonly achieved by including fish by-products (Hamilton et al., 2020; Sprague et al., 2016). As supply of EPA/DHA containing fish by-products from fisheries is limited, and current legislation bans feeding farmed fish with by-products of farmed fish of the same species (EU, 2013a), a circular food system requires a variety of fatty fish that can efficiently upcycle each other's 
by-products. Besides EPA/DHA rich ingredients, farmed fatty fish require high quality proteins to meet their protein requirement within their feed intake capacity. When limited to LCF, fish feeds can only reach such high protein content by including a large share of livestock by-products, which are currently avoided in aquafeeds as discussed in Section 2.1. I found the use of livestock byproducts enables salmon to value EPA/DHA containing LCF more efficiently, which is essential to meet EPA/DHA requirements. Like laying hens, farmed tilapia was mainly valued for its efficiency in upcycling high quality LCF. Whether laying hens or tilapia were selected depended on the types of available high quality LCF to feed them.

The farmed fish in our model required high quality feed because they were highly productive. Fish with lower productivity might be better able to value lower quality LCF, as illustrated for dairy cattle and pigs (van Hal et al., 2019a). Reduced productivity in fish, however, likely has limited potential as it increases excretion of non-digestible nutrients causing eutrophication and environmental degradation for cage farmed salmon (Nordvarg \& Johansson, 2002; Qi et al., 2019) and adverse health effects for tilapia farmed in tanks (Austin, 1998). Lower trophic fish, and species well adapted to synthesise EPA/DHA out of shorter chained fatty acids, such as rainbow trout (Mente et al., 2019) and various fresh water species (Rodrigues et al., 2017), are likely of more value and should be explored in future studies.

\subsection{Conclusions on the optimal use of LCF}

Results showed that optimal use of LCF can provide an HDP intake up to $39 \mathrm{~g}$ (cap/d), and fulfil the full requirements of EPA/DHA and vitamin B12. While this intake is significantly lower than current supply of animal protein ( $61 \mathrm{~g} / \mathrm{cap} / \mathrm{d})$, it fulfils up to $65 \%$ of total protein requirements (FAO, 2017c). Compared to current consumption, this protein is, furthermore, to a larger extent obtained from fish and dairy, and less from meat. A circular food system, thus, not only requires a reduction in ASF consumption, but also a change in the type of ASF we consume. As fish is the only source of EPA/DHA, increased fish consumption is needed to meet EPA/DHA requirements, while protein and vitamin B12 were mainly provided by milk and meat. While protein supply from animals fed only LCF is higher than in previous studies (7-30 g/cap/d; (van Zanten et al., 2018)), this increase is only partly due to the optimised use of LCF, as differences in study region and assumed availability of LCF confounds the comparison.

Optimal use of LCF requires a combination of animals tailored to the available LCF and the desired nutrient supply to the human population (van Hal et al., 2019a; van Hal et al., 2020). Human demand for EPA/DHA drives farming of fatty fish that require a feed comprised of fish and livestock 
by-products. To maximise the use of low quality LCF, they are fed to species that are best adapted to upcycle them and are typically combined with high quality LCF. While all ruminants are adapted to value low quality grass, dairy appears most efficient but may be unsuitable for valuing remote grasslands. In these areas low productive beef or sheep may be more realistic. The high feed intake capacity of pigs enables them to value wet by-products, such as pulp and (when available) wet household swill. Remaining high quality LCF, not needed to meet EPA/DHA requirement or facilitate upcycling of low quality LCF, were fed to animals with a high feed conversion efficiency. High quality animal-based LCF were typically fed to salmon, while those of plant origin were fed to laying hens or tilapia. If remaining plant-based LCF could not formulate a complete ration for hens or fish, they were used to increase dairy productivity (Chapter 2). Note that these principles are based solely on resource use efficiency and do not consider environmental impacts. When considering, for example, GHG emissions, the focus on dairy production and feeding more fibre may be less desirable. Future research is needed to illustrate synergies and trade-offs between environmental and circularity objectives and provide balanced solutions.

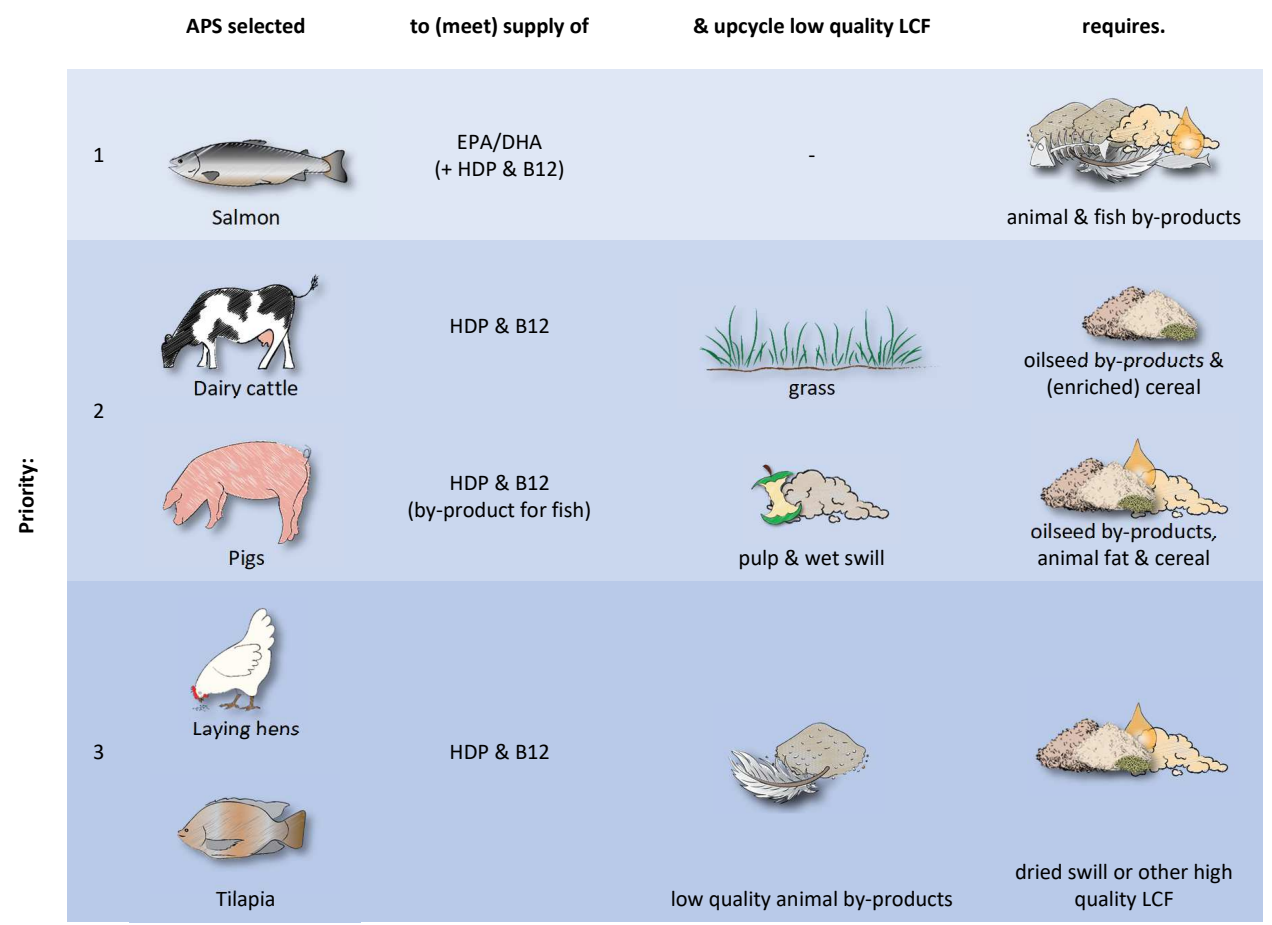

Figure 2 Principles to the selection of animal production systems (APS) for the optimal use of available lowopportunity-cost feeds to maximise human digestible protein (HDP) intake while meeting intake requirements of EPA/DHA fatty acids and vitamin B12 


\section{Supply chain environmental impact assessment for circularity}

Currently governments, farmers, and consumers base their sustainability strategies on LCAs which typically take a supply chain approach. This approach does not account for interlinkages between the numerous supply chains the food system entails, and thereby overlooks consequences of their recommended mitigation strategies on the food system as a whole. LCA studies directed at reducing the environmental impact of ASF or human diets, therefore, often propose mitigation strategies that counteract the resource use efficiency of the food system as a whole, effectively moving us away from circularity (Frehner et al., 2020; van Zanten et al., 2018). A prominent example of such mitigation strategies is reducing impacts per kg ASF by lowering the feed conversion ratio (FCR: $\mathrm{kg}$ feed needed per kg ASF) through, for example, breeding strategies (Herrero et al., 2016). A consumption oriented example is to replace products produced by animals with a high FCR (e.g. grass-fed beef) with those of animals with a low FCR (e.g. concentrate fed chicken) (Aleksandrowicz et al., 2016; Hallström et al., 2015). Generally, lowering the FCR increases the use of high quality ingredients, inherently moving the food system away from resource use efficiency.

The interlinkages overlooked in LCA studies relate to multifunctional processes for which environmental impacts must be divided over the resulting products. LCA on ASF typically allocate environmental impacts to multiple outputs (e.g. sunflower oil and meal) based on their relative economic value, which does not reflect their suitability for human consumption (de Vries \& de Boer, 2010). While the findings of LCA studies with such economic allocation remain valuable, as they illustrate the current impact of value chains, they will lead towards a circular food system (Frehner et al., 2020). In Chapter 5, I illustrate this controversy and initiate the development of a new supply chain environmental impact assessment that is suited to the circularity paradigm (van Hal et al., 2019b). To this end I compared a conventional LCA with economic allocation to an alternative LCA with so called feed-food allocation. This feed-food allocation relates the full impact of a multifunctional production process to the resulting human edible products, while products unsuitable for human consumption receive no impact. In case of soybean meal - accountable for most of the revenues of soybean cultivation - economic allocation allocates the majority of impact to soybean meal, while with feed-food allocation soybean oil carries the full burden under the assumption soybean cultivation is limited to the human demand for oil.

I applied both allocation methods to a novel egg production system that aims for circularity and feeds only LCF. Results show that, when using economic allocation, feeding only LCF reduces the impact per kg egg with 48-58\% for global warming potential (GWP) and $34-47 \%$ for (land use) LU, due to the low economic value of LCF. When using feed-food allocation, the environmental impact 
was reduced with $57 \%$ for global warming potential and $96 \%$ for land use, showing the larger mitigation potential of feeding LCF. While this case study illustrates the relevance and potential of accounting for feed-food competition in LCA, the used feed-food allocation has two main limitations. First, feed-food allocation is binary, implying that products are either suitable or unsuitable for human consumption and does, therefore, not yet consider the variation in nutritional value. Accounting for the nutritional value for human consumption is, however, complex due to the large variety of nutrients foods provide (van Kernebeek et al., 2014). Second, LCA, being a supply chain approach, is unable to account for the availability of LCF. While feed-food allocation accounts for the environmental benefits of feeding LCF, it gives no insights into the allocation question 'which animals should we fed what LCF' or about the total number animals we can keep, which requires a food systems approach applied in Chapter 2, 3 and 4 .

\section{Towards a resource efficient food system}

My thesis illustrated that animals play a valuable role in a circular food system and provided insights into what this role entails for various animals. In this section we address the advances in use of LCF (4.1) food systems modelling (4.2), societal change (4.1) needed to move towards a food system that can feed our growing population with respect for our planet.

\subsection{Improving the use of LCF}

My findings illustrate that feeding farm animals with LCF improves to the resource use efficiency of the food system and can reduce the environmental of ASF. In Chapter 4, I illustrated that food leftovers, that are currently not used as LCF due to legislation and other barriers, have a high ASF supply potential. To increase the resource use efficiency of animal production the barriers to feeding food leftovers should better understood and, where possible, overcome. Of the considered food leftover streams, livestock PAPs appeared most potent; they increased HDP supply by $18 \%$ and are essential to meet human EPA/DHA requirements. As legislation allows feeding of these PAPs to farmed fish (EU, 2013a), their limited use fish feed in the EU is caused by other barriers, of which improved understanding is needed. In contrast, the considerable effort required to safely feed household waste, the second most potent leftover stream, is well reported (Luyckx et al., 2019). While, when provided dry, this waste can increase HDP supply by $12 \%$, it requires legislative change and feed safety is difficult to guarantee. In contrast, most food wasted in manufacturing and retail are allowed to be used as feed, but remain unused due to a lack of economic incentive (Truong et al., 2019). The animal protein supply potential of these wastes $(+5 \%)$ is limited due to their low quantities, but their high quality they enables upcycling of low quality LCF. Improving the use of 
these food leftovers as LCF and understanding the barriers that limits such practice should be a priority of the industry to increase their resource use efficiency. This development may be stimulated by improving the transparency of resource use along the food supply chain(Jackson et al., 2020).

\subsection{Food systems modelling}

To evaluate the role of animals in a circular food system, I optimised the use of LCF by different farm animals given a predefined availability of plant-based LCF and focused on nutrients specifically provided by ASF (Section 2.4). While this approach served well to the aim of the study, in a circular food system not only animal production but also crop production should be optimised, which would affect the availability of plant-based LCF. We, therefore, need a full food systems modelling approach to further refine our understanding on the role of animals in a circular food system.

\section{$\underline{\text { An integrated model }}$}

Modelling the entire food system requires integration of soil, crop and animal components, to optimise use of available resources to meet all human nutritional requirements while minimising emissions to stay within our planetary boundaries. Besides various animal production systems, such a model should include various plant production systems, and their associated use of land, fertilisers and other inputs (van Kernebeek et al., 2018). To explore the full potential animals, a wide range of animal production systems should be included, such as traditional cattle breeds, goats and sheep, other fish species and insects (Section 2.3). Optimally, the model should use improved data on grass availability and quality, and account for restrictions to its use such as remoteness and seasonality (Section 2.1).

A full food systems model would provide valuable insights to or solve remaining dilemma's posed in this thesis. By minimising GHG emissions, for example, it could address land use change related issues, such as the conversion of arable grassland into cropland or marginal grasslands into forest. While in my thesis dairy cattle is prominent, minimising GHG may affect this conclusion as enteric methane emission and land use change emission are major contributors. Optimising the whole food system, furthermore, indicates the best use of resources in terms of food supply and gives valuable insights in which food leftovers should be used as fertiliser and which as feed. It effectively moves us from increasing yields per resource towards people fed per resource accounting both for direct (crop) and indirect (animal) food supply (Cassidy et al., 2013; van Zanten, 2016). Finally, this model 
can provide improved understanding of the value of animals in a circular food system based on all the nutrients they supply (van Zanten et al., 2019).

While in essence the described model would predict how to meet human dietary requirements with the lowest environmental burden, it could also estimate the environmental and resource costs of more extravagant diets to help policy makers and consumers make informed choices. If society wishes to consume more ASF than can be produced using only LCF, animal diets should be supplemented with high quality feeds that may increase their productivity or enable the production of more animals. To minimise the environmental costs of animal source food, the supplementation of high quality feed should be directed at increasing the efficiency with which LCF could be upcycled. Finally, to move towards circularity of agriculture at large, other agricultural functions such as energy and material production should be included as well (Muscat et al., 2019).

\subsection{Societal change}

A transition towards a circular food system, that stays within ecological boundaries, requires a paradigm shift in which all food system actors need to reconsider basic assumptions, norms and values nested deep within our societies (Clough, 2005; Jackson et al., 2020; van Zanten, 2016). Historically, humans have farmed animals and consumed their products since the onset of settlement, but production methods and consumption have changed drastically over time (Tauger, 2013). In the last century, ASF consumption increased with prosperity (Kearney, 2010; Speedy, 2003) and, in many high income countries, reached a level where it is no longer nutritionally beneficial and possibly even harmful (Willett et al., 2019). ASF are, however, not only consumed to provide nutrients, but for a variety of reasons including taste and habit (Clough, 2005; Dowsett et al., 2018). Negative impacts of ASF consumption that besides environmental impacts consider inequality issues and animal ethics, are increasingly acknowledged (Cassidy et al., 2013; Dowsett et al., 2018; Smil, 2014). While each person copes differently with the moral conflict between harming our planet and/or animals and the pleasure of consuming ASF (Piazza et al., 2015), small reductions in ASF consumptions have been observed in the EU (Vranken et al., 2014). While awareness increases due to political (LNV, 2019) and industry (Kipster, 2017) development, well guided collaboration across the food system is needed to take collective responsibility (Jackson et al., 2020)

A circular food system requires that society can make informed decisions regarding food consumption, based on not only economic but also social and environmental benefits and costs (de Boer \& van Ittersum, 2018). Such decisions require insights in the environmental cost of ASF 
production and what is possible within ecological boundaries which can be illustrated through integrated food system modelling (Section 4.1). Additionally, such research on the biophysical components of the food system, should be combined with social research to propose and stimulate a realistic food future.

While researchers gain knowledge on the principles of a circular food system, policy agendas are set, industries are developing and consumers become more aware, the state of the earth requires immediate action (Herrero et al., 2020). I, therefore, end my discussion with no regret solutions that can be implemented directly or with small adjustments to foster the transition towards a circular food system. Previous research indicates, we should target management (fertiliser/irrigation) at closing yield gaps; second, we should eat less, specifically ASF; and third, we should reduce food losses (de Boer \& van Ittersum, 2018; van Zanten et al., 2019). Based on this thesis I add we should consume all human edible fish obtained through fisheries, and animal production systems should efficient use available LCF in their rations.

\section{Conclusion}

This thesis illustrates that animals can contribute to the resource use efficiency of a circular food system by upcycling LCF: biomass unsuitable for human consumption. To make most of available LCF, their use should be optimised. I illustrated that by optimising the use of LCF, animals can provide up to $39 \mathrm{~g}$ HDP / cap/d, considerably more than previously illustrated in research (7-30 $\mathrm{g} / \mathrm{cap} / \mathrm{d}$ ). While this comparison is confounded by differences in the assumptions regarding the availability of LCF, this thesis illustrated that animals are crucial in a circular food systems and provided valuable principles about the role of animals in a circular food system.

Optimal use of LCF requires a combination of livestock and farmed fish. Animals in a circular food system should, thus, be tailored to available LCF and the nutrients we wish them to supply, where the role of each animal depends on their feeding characteristics and the nutrients in the ASF they provide. While some animals are well adapted to value specific low quality LCF, they must be combined with high quality LCF to formulate rations to derive an average nutrient content that can meet the nutritional need of each animal. Grass resources, for example, are used most efficiently by dairy cattle as ruminants are well adapted to value this feed and dairy cattle is especially efficient as it provides a daily product. Wet or fibrous food leftovers are used most efficiently by pigs that are known to have a high feed intake capacity. 
While ASF contain a variety of valuable nutrients, vitamin B12 and EPA/DHA are currently only obtained from ASF and should, therefore, be prioritised, next to our basal requirement of protein. While vitamin B12 is found in most ASF, fish is currently the only natural source of EPA/DHA in human diets. Fisheries (wild caught fish) supply is limited by production potentials in nature and cannot fully fulfil EPA/DHA requirements. A circular food system, therefore, also includes farmed fatty fish, that when feeding only LCF, can only be fed by using fish and livestock by-products.

A transition towards a circular food system requires a paradigm shift; consumers should change consumption pattern, industries should redesign production systems and policy makers should value social and economic aspects within the ecological boundaries of our planet. As environmental impact assessments that currently advise policymakers often counteract resource use efficiency, I made a first step to adapt these supply chain assessments to the circular paradigm. Understanding how many animals we can produce and which LCF we should feed them, however, requires food system modelling that can incorporate the partial food system model developed in thesis. Development of these scientific tools and the societal change needed to foster the transition towards a circular food system both take considerable time to realise, while we need to act know to preserve our planet for future generations. While conducting the needed bio-physical and social research we should, therefore, implement the no-regret solutions previously proposed for a circular food system, to which I add that animal production should efficiently use available LCF in their rations. Upcycling of animal-based LCF - that could be used in fish feeds tomorrow - has high potential to increase the resource use efficiency of our food system. 


\section{Appendix A}

A1 Animal protein supply estimates on low-opportunity-cost feeds

A2 Availability of low-opportunity-cost feeds

A3 Livestock herd composition

A4 Livestock nutrient requirements and product output

A5 Nutrient content of livestock food products

A6 Additional results of Chapter 2 
$\mathbf{1 1 6}$ | A p p endix A

\section{A1 - Animal protein supply estimates on low-opportunity-cost feeds}

Table A1 Estimates of per animal protein supply when limiting livestock production to low-opportunity-cost feed (LCF) availability, adapted from (van Zanten et al., 2018).

\begin{tabular}{|c|c|c|c|c|c|c|}
\hline \multirow[b]{2}{*}{ Article } & \multicolumn{4}{|c|}{ Input (LCF) } & \multicolumn{2}{|l|}{ Output } \\
\hline & $\begin{array}{l}\text { Food } \\
\text { waste }\end{array}$ & $\begin{array}{l}\text { By- } \\
\text { product }\end{array}$ & $\begin{array}{l}\text { Grass- } \\
\text { resources }\end{array}$ & $\begin{array}{l}\text { Crop- } \\
\text { residues }\end{array}$ & Products & $\begin{array}{l}\text { Protein } \\
g /\left(\text { cap*d) }^{*} \text { ) }\right.\end{array}$ \\
\hline Elferink et al. (2008) & & $x$ & & & meat & 27 \\
\hline Smil $(2014)^{c}$ & & $x$ & $x$ & $x$ & meat & 10 \\
\hline Schader et al. $(2015)^{c}$ & & $x$ & $x$ & & meat, milk, eggs & 9 \\
\hline van Kernebeek et al. $(2016)^{1 \mathrm{~A}}$ & $x$ & $x$ & $x$ & & meat, milk & 7 \\
\hline van Zanten et al. (2016a)) c & $x$ & $x$ & $x$ & & meat, milk & 21 \\
\hline Röös et al. $(2016)^{2 A}$ & & $x$ & $x$ & & meat, milk & 22 \\
\hline Röös et al. (2017a) $)^{2 B}$ & $x$ & $x$ & $x$ & & meat, milk & 23 \\
\hline Röös et al. (2017b) ${ }^{2 C}$ & $x$ & $x$ & $x$ & & meat, milk & 30 \\
\hline
\end{tabular}

1 included only $10 \%$ of produced waste, use of grass resources is very limited as land use is minimised

2 additional concentrates were fed to maintain high productivity

Scale: ${ }^{A}$ National, ${ }^{\mathrm{B}}$ Europe, ${ }^{\mathrm{C}}$ Global 


\section{A2- Availability of low-opportunity-cost feeds}

\section{Plant based food leftovers}

We related the annual availability of food leftovers (processing by-products and waste) to plantsource food supply in each EU country, between 2009-2013, according to FAO's food balance sheets (FBS) (FAO, 2017c). These FBS provide data on the amount of crop product available per country per year, and to what uses each product was allocated. Here, we consider only the amount of product allocated to food supply, generally expressed in primary product equivalents. The annual food supply of wheat, for example, was expressed in tonne of the primary product wheat grain (Figure A1) that are needed for the actual supply of processed products such as wheat flour (Becker et al., 2001). For some products (e.g. oil crops and beer), however, the FBS expressed supply in tonne of processed products (e.g. soybean oil (Figure A1) and beer) (Becker et al., 2001).

\section{Crop processing by-products}

The amount of by-products related to food supply in each EU country were calculated using technical conversion factors provided by FAO (1996), or Vellinga et al. (2013) for oilseeds and wheat. These factors represent the fraction of main product (e.g. wheat flour) and by-products (e.g. wheat bran, germ and feed [middling]) resulting from each process (e.g. wheat milling) relative to the input of one unit of primary product (e.g. wheat grain). The amount of wheat bran available in each country, for example, was calculated by multiplying the annual food supply of wheat grain equivalents, with the wheat bran fraction resulting from the wheat milling process, under the assumption that all wheat is consumed in the form of wheat flour (Figure A1). The annual supply in primary product equivalents of products that the FBS expresses in tonne of processed products (e.g. soybeans), were calculated by dividing the annual consumption in tonne of processed product by the main product fractions from the process that they already went through (e.g. soybean oil extraction) (Figure A1). The nutrient content of each by-product was based on the CVB system (CVB, 2016a). As the by-products were assumed to be tradable, the available by-products in all countries in the EU-28 were summed together. Their total supply is displayed in Figure A2 using a classification based on nutritional properties (Table A2). 
Figure A1 Example calculation of waste (wasted wheat flour/soybean oil) and by-product (produced wheat bran, germ and feed/ soybean meal and hulls) available based on food supply (tonnes wheat grain or soybean oil) according to food balance sheets (FBS) using wastage fractions (o.31 for cereals, 0.07 for oils; Gustavsson et al. (2011)) and technical conversion factors of (Vellinga et al., 2013)

Primary product
Main product

By-product

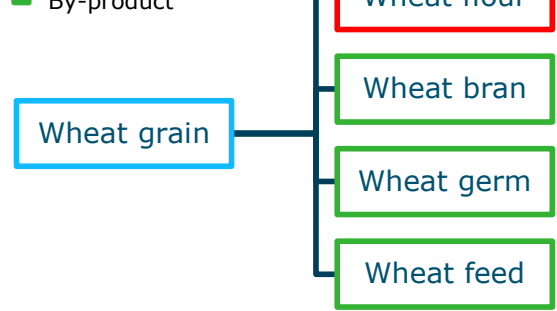

FBS:

Co-product:

Waste:

\section{Wgrain (ton)}

WBran $=$ WGrain $* 0.12$

WFlour $=$ WGrain $* 0.73 * 0.31$
$73 \%$

$12 \%$

$2 \%$

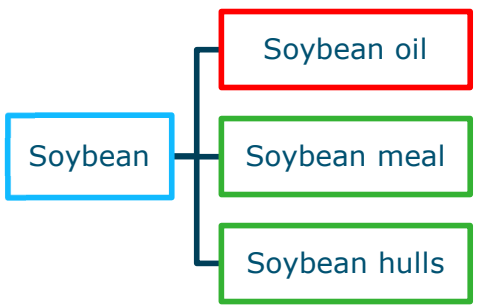

$19 \%$

$71 \%$

$8 \%$

$12.5 \%$

SBOil (ton)

SBMeal $=($ SBOil $/ 0.19) * 0.71$

SBOil $=$ SBOil $* 0.07$

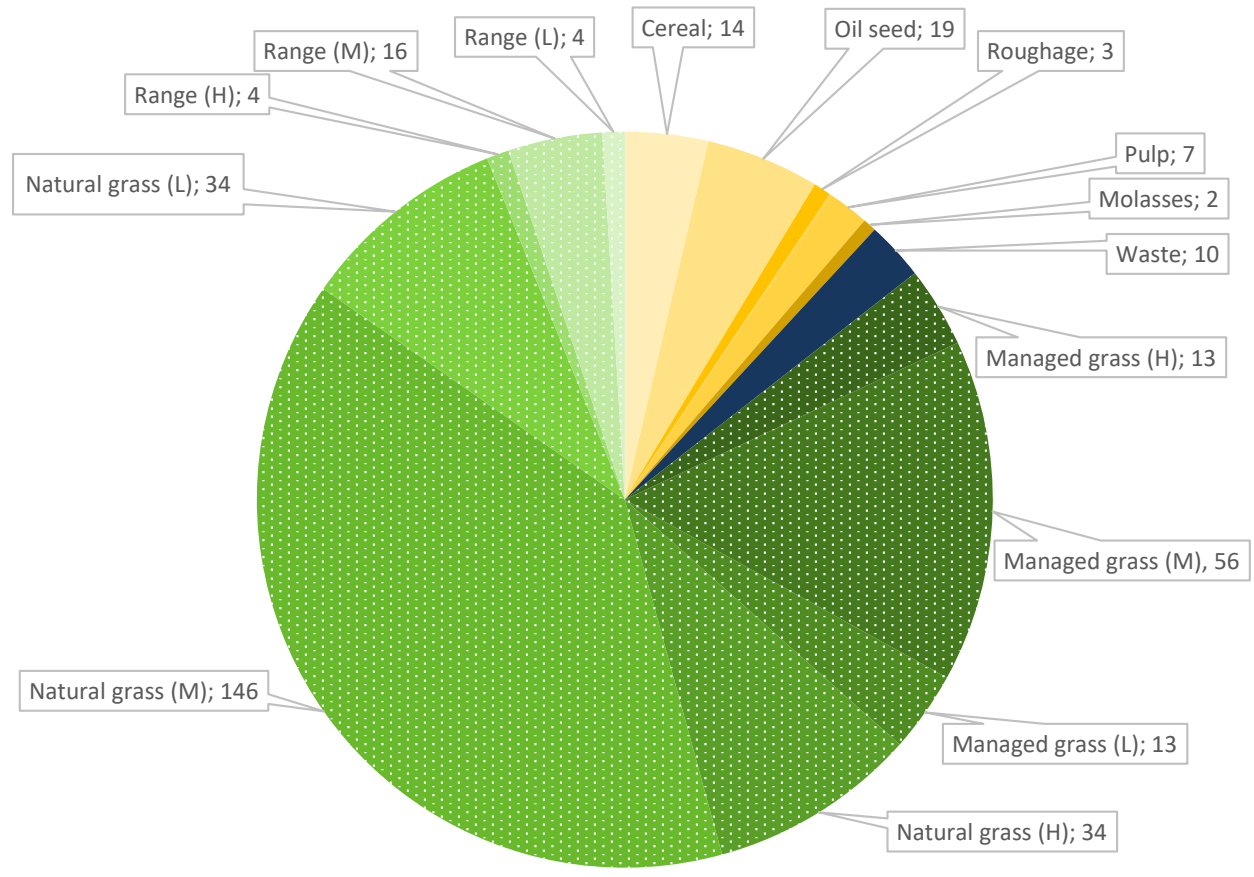

Figure A2 Total EU availability of low-opportunity-cost feeds (LCF), excluding feeding losses, in million tonne DM. LCF include food processing by-products (classified: cereals, oilseeds, roughages, pulps, molasses), food waste (waste) and grass resources of managed grassland, natural grassland and rangeland of high (H), mid (M), or low (L) quality. 
Table A2 Classification of food co-products based on their nutritional properties

\begin{tabular}{|c|c|c|}
\hline By-product & Type & Classification \\
\hline Wheat_bran & Cereal by-product & Cereal \\
\hline Wheat_germ & Cereal by-product & Cereal \\
\hline Wheat_feedmeal & Cereal by-product & Cereal \\
\hline Barley_byprod & Cereal by-product & Cereal \\
\hline Barley_rootlet & Cereal by-product & Cereal \\
\hline Brewers_grain_spend & Cereal by-product & Cereal \\
\hline Maize_bran & Cereal by-product & Cereal \\
\hline Maize_germ_meal & Oil by-product & Oilseed \\
\hline Rye_bran & Cereal by-product & Cereal \\
\hline Oat_offals & Cereal by-product & Cereal \\
\hline Oat_hulls & Shell, hull or straw & Roughage like by-products \\
\hline Rice_hulls & Shell, hull or straw & Roughage like by-products \\
\hline Potato_peel & Tuber by-product & Pulp \\
\hline Sweetpotato_peel & Tuber by-product & Pulp \\
\hline Sugarbeet_toptails & Shell, hull or straw & Roughage like by-products \\
\hline Sugarbeet_molasses & Molasses & Molasses \\
\hline Sugarbeet_pulp & Pulp & Pulp \\
\hline Soyabean_hulls & Shell, hull or straw & Roughage like by-products \\
\hline Soyabean_meal & Oil by-product & Oilseed \\
\hline Groundnut_shells & Shell, hull or straw & Roughage like by-products \\
\hline Groundnut_meal & Oil by-product & Oilseed \\
\hline Sunflowerseed_meal & Oil by-product & Oilseed \\
\hline Rapeseed_meal & Oil by-product & Oilseed \\
\hline Cottonseed_meal & Oil by-product & Oilseed \\
\hline Copra_meal & Oil by-product & Oilseed \\
\hline Sesameseed_meal & Oil by-product & Oilseed \\
\hline Palm_fiber & Shell, hull or straw & Roughage like by-products \\
\hline Palm_effluent & Oil by-product & Oilseed \\
\hline Palm_kernel_meal & Oil by-product & Oilseed \\
\hline Olive_residue & Oil by-product & Oilseed \\
\hline Citrus_pulp & Pulp & Pulp \\
\hline Grape_pomace & Pulp & Pulp \\
\hline Coffee_husk & Shell, hull or straw & Roughage like by-products \\
\hline Cocoa_husk & Shell, hull or straw & Roughage like by-products \\
\hline
\end{tabular}


Waste

Available waste products were calculated applying Europe specific consumption waste fractions of Gustavsson et al. (2011) to the available main products after processing, i.e. multiplying the tonnes of main product available for consumption with the product type specific consumption waste fraction (Figure A1). All waste products within each country were combined into one waste stream in this country, as waste was assumed not to be traded, of which the nutrient content equals the weighted average of the included products based on the CVB system (CVB, 2016a). The availability of food waste as feed (35\% of the produced food waste (zu Ermgassen et al., 2016)) and its nutritional value for pigs, laying hens, and broilers (to which the food waste can be fed) in each country is displayed in Table A3, total availability of food waste in the EU is displayed in Figure A2.

Table A3 Per country availability (tonne DM and FM) of the food waste stream as animal feed and the country specific nutrient content of this waste stream for pigs, laying hens, and broilers per kg DM.

\begin{tabular}{|c|c|c|c|c|c|c|c|c|c|c|c|}
\hline \multirow[b]{3}{*}{ Country } & \multicolumn{2}{|c|}{ Available waste } & \multicolumn{9}{|c|}{ Nutrients/ kg DM } \\
\hline & \multirow{2}{*}{$\begin{array}{r}\text { DM } \\
\text { Tonne } \\
\end{array}$} & \multirow{2}{*}{$\begin{array}{l}\text { DM } \\
\text { fract. }\end{array}$} & \multicolumn{3}{|c|}{ Pig } & \multicolumn{3}{|c|}{ Laying hen } & \multicolumn{3}{|c|}{ Broiler } \\
\hline & & & $\mathrm{NE}$ & Dlys & Dmeth & ME & Dlys & Dmeth & $\mathrm{ME}$ & Dlys & Dmeth \\
\hline Austria & 164176 & 0.41 & 10.9 & 2.39 & 0.68 & 12.6 & 2.08 & 0.60 & 12.2 & 2.08 & 0.60 \\
\hline Belgium & 232175 & 0.45 & 11.3 & 2.02 & 0.72 & 13.2 & 1.55 & 0.57 & 12.6 & 1.55 & 0.57 \\
\hline Bulgaria & 145770 & 0.55 & 12.1 & 3.15 & 1.06 & 14.2 & 2.68 & 0.90 & 13.5 & 2.68 & 0.90 \\
\hline Croatia & 78733 & 0.45 & 11.4 & 2.66 & 0.80 & 13.3 & 2.24 & 0.68 & 12.7 & 2.24 & 0.68 \\
\hline Cyprus & 14844 & 0.38 & 9.8 & 2.56 & 0.71 & 11.4 & 2.25 & 0.62 & 10.9 & 2.25 & 0.62 \\
\hline Czech R. & 190349 & 0.47 & 11.7 & 2.72 & 0.85 & 13.7 & 2.26 & 0.71 & 13.1 & 2.26 & 0.71 \\
\hline Denmark & 114791 & 0.44 & 10.6 & 2.49 & 0.77 & 12.4 & 2.10 & 0.66 & 11.9 & 2.10 & 0.66 \\
\hline Estonia & 26380 & 0.41 & 10.8 & 2.47 & 0.75 & 12.6 & 2.04 & 0.65 & 12.2 & 2.04 & 0.65 \\
\hline Finland & 88430 & 0.42 & 10.9 & 2.56 & 0.78 & 12.6 & 2.16 & 0.67 & 12.1 & 2.16 & 0.67 \\
\hline France & 1177293 & 0.43 & 10.7 & 2.50 & 0.78 & 12.5 & 2.11 & 0.66 & 11.9 & 2.11 & 0.66 \\
\hline Germany & 1487008 & 0.44 & 11.2 & 2.51 & 0.77 & 13.0 & 2.11 & 0.66 & 12.5 & 2.11 & 0.66 \\
\hline Greece & 229272 & 0.33 & 9.9 & 3.30 & 0.77 & 11.4 & 2.99 & 0.70 & 10.9 & 2.99 & 0.70 \\
\hline Hungary & 155231 & 0.42 & 11.1 & 2.82 & 0.84 & 12.9 & 2.38 & 0.71 & 12.2 & 2.38 & 0.71 \\
\hline Ireland & 86360 & 0.41 & 10.8 & 2.50 & 0.77 & 12.6 & 2.04 & 0.64 & 12.0 & 2.04 & 0.64 \\
\hline Italy & 1305040 & 0.41 & 10.3 & 2.93 & 0.83 & 12.0 & 2.59 & 0.71 & 11.3 & 2.59 & 0.71 \\
\hline Latvia & 36708 & 0.39 & 10.3 & 2.38 & 0.71 & 11.9 & 1.96 & 0.63 & 11.6 & 1.96 & 0.63 \\
\hline Lithuania & 68075 & 0.45 & 11.2 & 2.70 & 0.85 & 13.0 & 2.23 & 0.72 & 12.5 & 2.23 & 0.72 \\
\hline Luxembourg & 8111 & 0.36 & 9.9 & 2.40 & 0.74 & 11.5 & 2.05 & 0.63 & 10.9 & 2.05 & 0.63 \\
\hline Malta & 9820 & 0.40 & 9.7 & 2.65 & 0.75 & 11.3 & 2.30 & 0.64 & 10.8 & 2.30 & 0.64 \\
\hline Netherlands & 285071 & 0.38 & 10.6 & 2.12 & 0.61 & 12.4 & 1.73 & 0.52 & 12.0 & 1.73 & 0.52 \\
\hline Poland & 869757 & 0.43 & 11.2 & 2.72 & 0.81 & 13.0 & 2.27 & 0.70 & 12.5 & 2.27 & 0.70 \\
\hline Portugal & 204983 & 0.36 & 10.0 & 2.80 & 0.75 & 11.6 & 2.46 & 0.66 & 11.1 & 2.46 & 0.66 \\
\hline Romania & 515570 & 0.41 & 11.0 & 2.97 & 0.87 & 12.8 & 2.54 & 0.75 & 12.2 & 2.54 & 0.75 \\
\hline Slovakia & 101246 & 0.47 & 11.2 & 2.63 & 0.84 & 13.1 & 2.19 & 0.70 & 12.5 & 2.19 & 0.70 \\
\hline Slovenia & 37224 & 0.45 & 11.3 & 2.59 & 0.86 & 13.2 & 2.18 & 0.74 & 12.5 & 2.18 & 0.74 \\
\hline Spain & 733866 & 0.36 & 10.5 & 3.29 & 0.78 & 12.2 & 2.95 & 0.70 & 11.7 & 2.95 & 0.70 \\
\hline Sweden & 158035 & 0.41 & 10.5 & 2.46 & 0.71 & 12.2 & 2.10 & 0.62 & 11.7 & 2.10 & 0.62 \\
\hline UK & 1359989 & 0.43 & 12.4 & 2.44 & 0.70 & 14.3 & 2.01 & 0.59 & 13.7 & 2.01 & 0.59 \\
\hline
\end{tabular}




\section{Grass resources}

The amount of grass resources available in each EU country and their nutritional value, were based on spatially explicit data on the distribution and productivity of grazing land of several vegetation types, linked to a vegetation specific nutrient content. Grassland in each EU country was quantified from the land use maps of Plutzar et al. (2016). These spatially explicit ( $1 \mathrm{~km}$ scale) maps combine remote sensing land cover data (CORINE) and tier 2 census data on land use (CAPRI) to divide the available land in the EU over land use classes, one of them being grassland. Besides the land used for grass production according to the combined census and remote sensing data, this class includes all land not allocated a land used and deemed suitable for grazing.

The grassland class covers multiple of vegetation types (i.e. managed grassland, natural grassland, moors \& heathland, sclerophyllous and transitional, shrub and woodland) that vary in grazing suitability, due to differences in grazable fraction, nutrient content, and digestibility of the produced biomass. Plutzar et al. (2016) aggregated these vegetation types into managed grassland (meadows \& pastures) and other grassland. The natural grassland included in the "other grassland" is, however, more suitable for grazing than the included rangeland types (Astigarraga et al., 2009). We, therefore, reclassified the "other grassland" into natural grassland and rangeland using the country specific distribution of grassland over grazing suitability classes of Haberl et al. (2007). This earlier global study used methods similar to Plutzar et al. (2016) with a lower resolution yielding slightly less accurate results. They distributed grassland over four grazing classes based on vegetation type and productivity, where class 4 included all shrub land and woody vegetation we classified as rangeland (Figure A3). Our natural grassland, therefore, included grazing class 2 and 3 and the remainder of grazing class 1, after subtracting managed grassland quantified by Plutzar et al. (2016).

\begin{tabular}{|c|c|c|c|c|c|c|}
\hline Haberl et al. (2007) & \multicolumn{3}{|c|}{ Class: 1} & 2 & 3 & 4 \\
\hline Plutzar et al. (2016) & Managed & \multicolumn{5}{|c|}{ Other } \\
\hline Combined & Managed & \multicolumn{3}{|c|}{ Natural } & & Range \\
\hline
\end{tabular}

Figure A3 Distribution of available grass biomass over grazing classes (managed grassland, natural grassland, and rangeland) based on the classifications of Haberl et al. (2007) (quality class 1 to 4) and Plutzar et al. (2016) (managed grassland and other grassland) 
The amount of biomass available of each vegetation type (managed grassland, natural grassland, rangeland) in each EU country, was calculated using an additional layer of the Plutzar et al. (2016) maps considering the spatially explicit actual above ground net primary production (aNPPact). This aNPPact is an indicator of the actual annual amount of carbon $(\mathrm{kg})$ produced per hectare in above ground biomass. The amount of grazable aNPPact of each vegetation type (i) in each country (j) was calculated with the following equation:

aNPPact $_{i j}=\sum^{k}$ grassland $_{i j k} \times$ aNPPact $_{j k} \times$ grazable fraction $_{i}$

Where grassland is the amount of grassland (ha) of each vegetation type ( $i$ ) in each pixel $(k)$ of each country $(j)$ and $a N P P_{j k}$ was the above ground net primary production of carbon in each pixel $(k)$ of each country $(j)$. The grazable fraction of the aNPPact in each vegetation type ( $i)$ - the proportion of the annually produced above ground carbon available for grazing - was adapted from (Haberl et al., 2007) (Table A3) This grazable fraction was estimated based on the herbaceous fraction of the produced biomass (woody vegetation was assumed ungrazable), vegetation height, (biomass more than $1.2 \mathrm{~m}$ above the ground was assumed inaccessible) and seasonality. To convert the resulting grazable aNPPact (kg carbon/grazing class/country) into grazable biomass (kg DM/vegetation type/country) - displayed in Figure A4 - a factor 2 was used (IPPC). This availability of grazing resources was summed for the EU in Figure A2.

While the nutrient content and digestibility of grass resources of intensively managed grasslands is well studied, estimating the nutritional value of grass resources of natural grassland and rangeland is more difficult. Natural grasslands, for example, contain multiple species, that differ morphologically and in maturity stage at any given point (Bruinenberg et al., 2002). Generally, resources form natural grassland have a lower nutrient content than resources from intensively managed grasslands (Bruinenberg et al., 2003). Not only do many species in natural grassland, chemically have a lower protein and energy content also their digestibility is lower (Tallowin \& Jefferson, 1999), due to the different genetic make-up, and higher maturity which increases their content in lignified cell wall material (Bruinenberg et al., 2002). Higher maturity is caused by variation in maturity between species and a late harvest to maintain the nature value of the grassland (Korevaar, 1986). 
Table A4 The range nutritional value of the different vegetation types

\begin{tabular}{|c|c|c|c|c|c|c|c|}
\hline \multirow[b]{2}{*}{ Grazing class } & \multirow{2}{*}{$\begin{array}{l}\text { Grazable } \\
\text { \%aNPP1 }\end{array}$} & \multicolumn{6}{|c|}{ Nutrient content $/ \mathrm{kg} \mathrm{DM}{ }^{2}$} \\
\hline & & VEM & VEVI & DVE (g) & OEB & SV & SU \\
\hline Managed grassland & $75 \%$ & $830-1006$ & $880-1062$ & $60-95$ & $60-90$ & $1.5-2.2$ & $0.89-0.9$ \\
\hline Natural grassland & $60 \%$ & $550-750$ & $450-730$ & $30-40$ & $20-45$ & 2.3-3.5 & $1.25-1.45$ \\
\hline Shrub land & $40 \%$ & $490-735$ & $400-720$ & $15-30$ & $4-34$ & $3-3.4$ & $1.4-1.6$ \\
\hline
\end{tabular}

${ }^{1}$ based on Haberl et al. (2007).

2 based on literature (Astigarraga et al., 2009; Bruinenberg et al., 2002; Bruinenberg et al., 2003; Bruinenberg et al., 2004; Daccord et al., 2007; Deprez et al., 2007; Hayes et al., 2016; Korevaar, 1986; Mancilla-Leytón et al., 2012; Paton et al., 1999; Rogosic et al., 2006; Schippers, 2012; Schneider et al., 2009; Tallowin \& Jefferson, 1999).

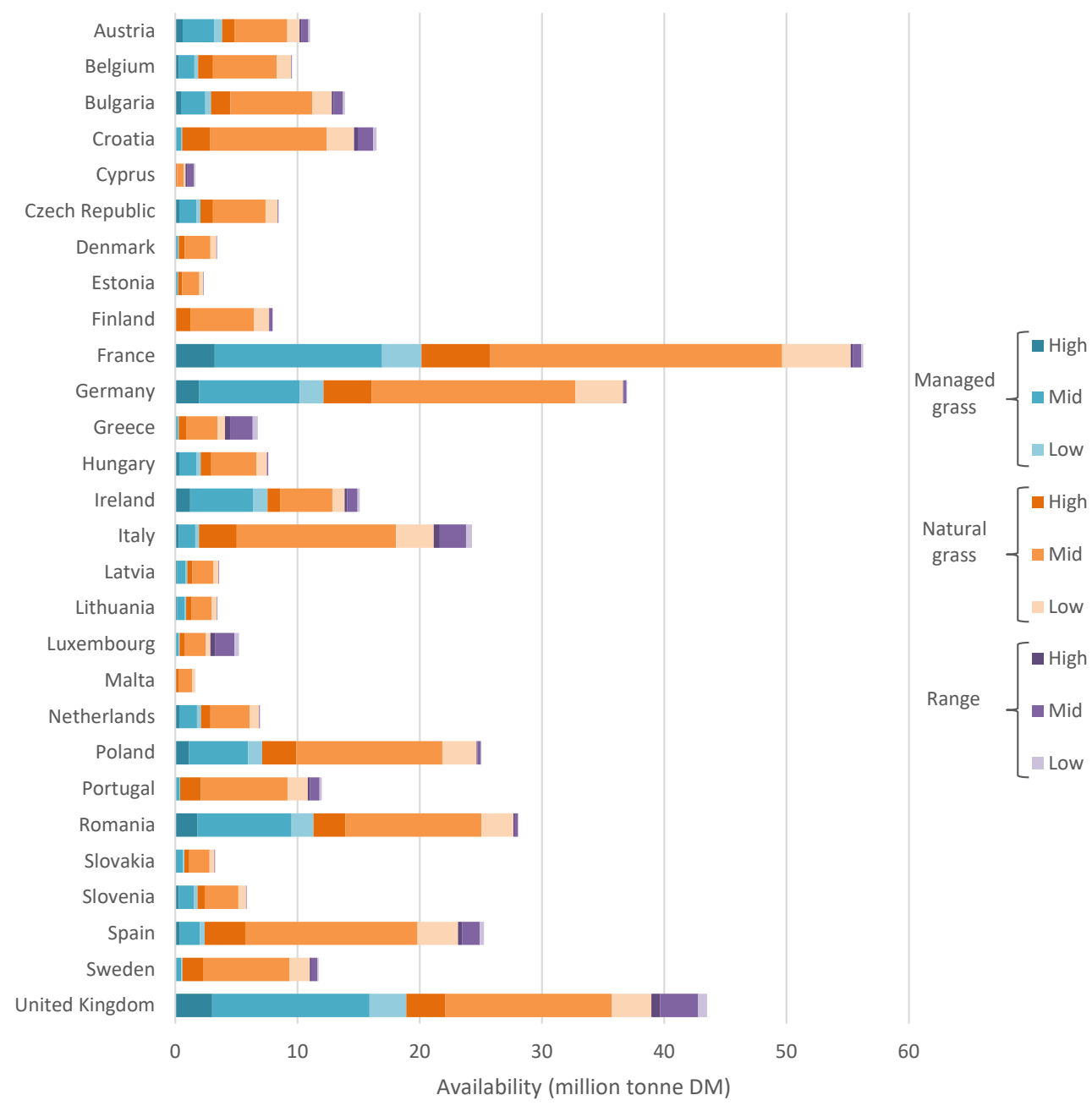

Figure A4 Available biomass (million tonne DM) in each grazing class (managed grassland, natural grassland, and rangeland) under each grazing quality (high, mid, low) in each EU 28 country, including feeding losses. 
Data on the nutrient content and digestibility of each vegetation type (managed grassland, natural grassland and rangeland) were collected from literature and converted to the units of the CVB system using the following formulas:

- Energy content in kJ metabolisable energy (ME) was converted into feed units milk (FUM) assuming: $\mathrm{FUM}=(0.0003392 \mathrm{xq}+0.0654656) \times \mathrm{ME}$. Where $\mathrm{q}$, the percentage of ME that is utilised as net energy (NE) ranging from 60 to 40 depending on the quality of the feed, 40 being poor rangelands (CVB, 2016a).

- Energy content in kJ ME was converted into feed units beef (FUB) assuming: $\mathrm{FUB}=\mathrm{ME} * 0.08054$ for low quality, and $\mathrm{ME} * 0.09728$ for high quality grazing (CVB, 2016a).

- Crude protein (CP) was first converted into digestible protein (DP) using the protein digestibility percentages provided in each study. This DP was, thereafter, converted into intestinal digestible protein (IDP), based on the IDP:DP ration (73:130) grass provided by (Tamminga, 2007).

- The rumen degraded protein balance (RDPB), structure value (SV) and satiety units (SU) were estimated from comparable products in CVB 2016. For managed grasslands this were various types of grass, for natural grassland this was late harvested grass, and fresh lucerne of various qualities, and for shrub land this was pea green, fresh lucerne, and pea straw (CVB, 2012).

Table A5 Nutritional values of each grass quality class (low, mid and high) for each vegetation type

\begin{tabular}{|c|c|c|c|c|c|c|c|}
\hline \multirow[b]{2}{*}{ Vegetation type } & \multirow{2}{*}{$\begin{array}{l}\text { Grass } \\
\text { Quality }\end{array}$} & \multicolumn{6}{|c|}{ Nutrient content /kg DM } \\
\hline & & FUM & FUB & $\operatorname{IDP}(\mathrm{g})$ & RDPB & SV & SU \\
\hline \multirow[t]{3}{*}{ Managed grassland } & Low & 830 & 880 & 60 & 60 & 2.2 & 0.9 \\
\hline & Mid & 918 & 971 & 77.5 & 75 & 1.85 & 0.895 \\
\hline & High & 1006 & 1062 & 95 & 90 & 1.5 & 0.89 \\
\hline \multirow[t]{3}{*}{ Natural grassland } & Low & 550 & 450 & 30 & 20 & 3.5 & 1.45 \\
\hline & Mid & 650 & 590 & 35 & 32.5 & 2.9 & 1.325 \\
\hline & High & 750 & 730 & 40 & 45 & 2.3 & 1.2 \\
\hline \multirow[t]{3}{*}{ Rangeland } & Low & 490 & 400 & 15 & 0 & 4.3 & 1.66 \\
\hline & Mid & 612.5 & 560 & 22.5 & 17 & 3.65 & 1.53 \\
\hline & High & 735 & 720 & 30 & 34 & 3 & 1.4 \\
\hline
\end{tabular}


For each vegetation type, these data resulted in a range nutrient content (Table A4), where a high nutritional value (high energy and protein content) was correlated to low structure value and saturation value. Based on this correlation, the range of nutritional values was converted into three grass quality classes for each vegetation type (high, mid, and low; Table A5). The biomass of each vegetation type was assumed the be normally distributed over the three grazing quality classes (16\% low, 36\% mid, and 16\% high quality; Figures A5 \& A2). For the sensitivity analysis, the biomass available of each vegetation type was alternatively assumed to be uniformly distributed over the grazing quality classes in each grazing class (33\% of each high, mid, and low grass quality, Figure A5).

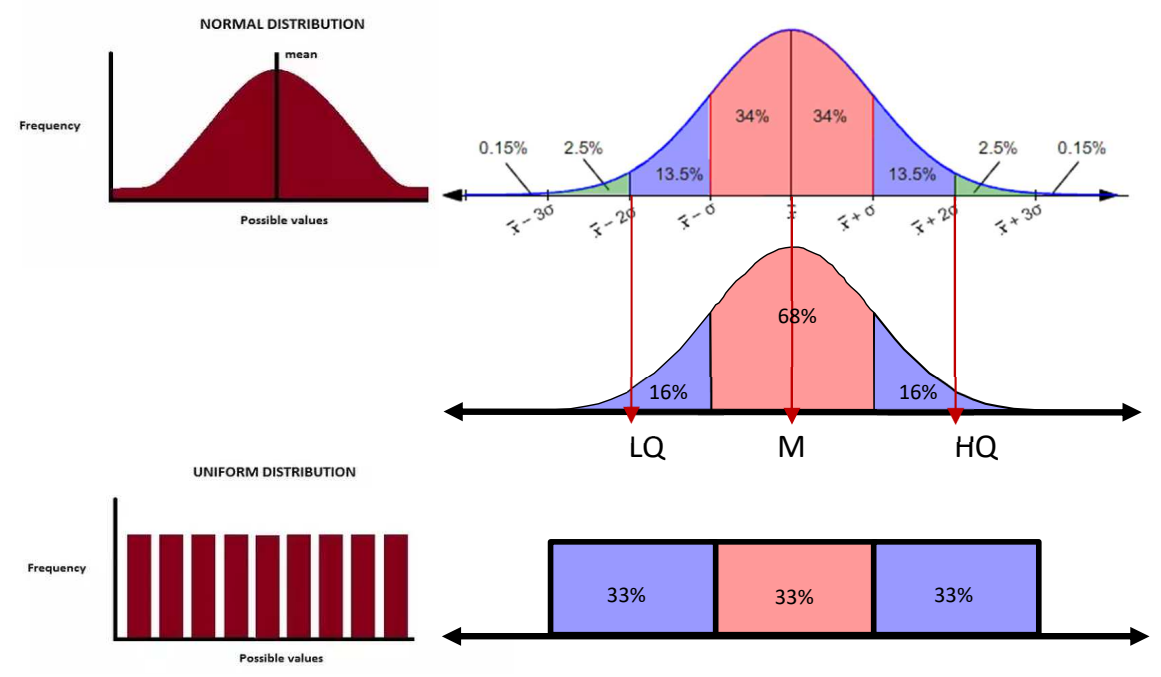

Figure A5 Normal distribution vs uniform distribution of nutrient content over the available biomass 


\section{A3 - Livestock herd composition}

The herd composition (i.e. the number of non-producing animals relative to a producing animal; Table A6) was calculated from the European herd composition (FAO, 2016a, 2016c); missing data on pig litter size and dairy calving interval were based on Dutch averages (AgroVision, 2016; CRV, 2017), serving as a proxy for conventional high productive livestock (Bos et al., 2013). Note that, due to death and selection, additional producing animals are needed to achieve the production of one producing animal.

Table A6 The number of non-producing animals relative to producer animals in each livestock system.

\begin{tabular}{|c|c|c|}
\hline Animal type & Herd component & Occurence \\
\hline \multirow[t]{5}{*}{ Pig } & Fattening pig & 1.04 \\
\hline & Sows & 0.04 \\
\hline & Boars & 0.00 \\
\hline & Piglets & 1.20 \\
\hline & Gilts & 0.02 \\
\hline \multirow[t]{6}{*}{ Laying hen } & Laying hen & 1.08 \\
\hline & Laying cock & 0.10 \\
\hline & Breeder hen & 0.01 \\
\hline & Breeder cock & 0.00 \\
\hline & Layer replacement chick & 1.03 \\
\hline & Breeder repl. chick & 0.01 \\
\hline \multirow[t]{4}{*}{ Broiler } & Broiler & 1.04 \\
\hline & Breeder hen & 0.03 \\
\hline & Breeder cock & 0.00 \\
\hline & Repl.chicks & 0.01 \\
\hline \multirow[t]{5}{*}{ Dairy } & Dairy cow & 1.45 \\
\hline & Dairy bull & 0.01 \\
\hline & Repl.calf & 0.51 \\
\hline & Repl. heifer & 0.47 \\
\hline & Veal calf & 0.57 \\
\hline \multirow[t]{5}{*}{ Beef } & Beef cow & 1.03 \\
\hline & Breeder cow & 1.28 \\
\hline & Breeder bull & 0.05 \\
\hline & Breeder repl. calf & 0.27 \\
\hline & Breeder repl. heifer & 0.25 \\
\hline
\end{tabular}




\section{A4 - Livestock nutrient requirements and product output}

Nutrient requirements for each livestock system were derived from the CVB system of the Dutch animal feed board (CVB, 2012; van Vliet et al., 1994). Below we describe in detail the product output and nutrient requirements of both non-producing animals (e.g. young stock and/or parent stock) and producing animals of the five considered livestock systems; pig, laying hen, broiler, dairy cattle, beef cattle. Energy requirements are expressed in MJ net energy (NE) for pigs, MJ apparent metabolisable energy (AME) for poultry, feed unit milk (FUM) for dairy cattle, and feed unit beef (FUB) for beef cattle. For monogastric, protein requirements were expressed in g digestible lysine (DLys) and methionine (DMet) for pigs based on ilieal digestibility and for poultry based on faecal digestibility. For ruminants protein requirements were expressed in intestinal digestible protein (IDP) and rumen degraded protein balance (RDPB) for cattle. The RDPB is a measure of digestible protein available in the intestine by estimating microbial protein production in the rumen, based on the energy to protein ratio of the ingredient. Additionally, rations of ruminants should meet a minimum structure value (SV), to ensure rumen functioning. Maximum feed intake capacity (FIC) was expressed in $\mathrm{kg}$ fresh matter for monogastrics and in satiety units (SU), which considers saturation effects of each ingredient, for ruminants (CVB, 2012).

\section{Non-producing animals}

For non-producing animals, both nutrient requirements and product output were based on conventional production systems (Dutch average used as proxy). Besides the CVB system, additional data was used for the nutritional requirements and feed intake capacity of all beef herd components (Hubrecht et al., 2013), veal calves (Vermeij, 2012), and young laying and breeder hens (NRC, 1984). Resulting nutrient requirements are displayed in Table A7. Animal source food output was estimated using meat fractions of sows and gilts (AgroVision, 2016), dairy cows and beef breeding cows (Nour et al., 1983a, 1983b), and breeding hens for broilers and laying hens (Loetscher et al., 2015; M. Haslinger, 2007).

\section{Producing animals}

For producing animals of each livestock system we included the productivity levels (high, mid, low). Below we describe, in detail, the assumed performance for each livestock system under each productivity level and the methods and assumptions used to determine their nutrient requirement. As proposed methods by the CVB system differ among livestock systems, each livestock system 
required a tailored approach. The nutrient requirement are expressed in the units of the CVB system, of which an overview is provided in Table 1 of the main article.

$\underline{\text { Pig }}$

Variation in pig productivity was achieved by assuming different growth curves for a growth from 25 to $115 \mathrm{~kg}$ live weight (LW) resulting in variation in average daily gain (ADG) and duration of the growth period. The input-output relation of the high productive pigs was based on the performance and related nutrient requirement of high performance fattening pigs in the Netherlands (CVB, 2012). A high-productive pig grows from 25 to $115 \mathrm{~kg} \mathrm{LW}$ in 118 days, resulting in 3.02 rounds of pigs per year and an ADG of $759 \mathrm{~g} /$ day (Table 1, main article). Achieving this growth required an average daily intake of $2.11 \mathrm{~kg}$ of a standard feed, containing 9.5 $\mathrm{MJ} \mathrm{NE}$ and $6.7 \mathrm{~g}$ Dlys and $4.1 \mathrm{~g}$ Dmeth per kg (CVB, 2012), resulting in the daily nutrient intake displayed in Table 1 of the main article. Over the entire growth period, a pig then consumes $2240 \mathrm{MJ}$ NE, $1705 \mathrm{~g}$ DLys and $1045 \mathrm{~g}$ DMeth.

Table A7 Period length, daily feed intake capacity (FIC), daily nutrient requirements, and required structure value of the diet of non-production animals of different animal types (a.-d.), expressed in the nutritional values of the CVB system

\begin{tabular}{|c|c|c|c|c|c|c|c|}
\hline \multirow[b]{3}{*}{ a. Pig } & \multirow{3}{*}{$\begin{array}{l}\text { Period } \\
\text { (d) }\end{array}$} & \multicolumn{5}{|c|}{ Average daily requirement/capacity } & \multirow[b]{2}{*}{ Structure } \\
\hline & & \multirow{2}{*}{$\frac{\mathrm{FIC}}{(\mathrm{kg})}$} & \multirow{2}{*}{$\begin{array}{l}\text { Energy } \\
\text { NE (MJ) }\end{array}$} & \multicolumn{2}{|c|}{ Protein } & \multirow[t]{2}{*}{ Milk } & \\
\hline & & & & Dlys (g) & Dmet $(\mathrm{g})$ & & \\
\hline Sow & 365 & 7.70 & 28.17 & 16.68 & 9.60 & & \\
\hline Boar & 365 & 8.00 & 28.16 & 14.72 & 9.27 & & \\
\hline Piglet & 70 & 0.57 & 4.08 & 4.22 & 2.53 & & \\
\hline Gilt & 133 & 3.52 & 14.87 & 13.35 & 6.67 & & \\
\hline b. Poultry & (d) & $(\mathrm{kg})$ & AME (MJ) & DLys (g) & DMet (g) & & \\
\hline Breeder & 365 & 0.15 & 1.37 & 0.70 & 0.35 & & \\
\hline Cock & 365 & 0.15 & 0.83 & 0.42 & 0.21 & & \\
\hline Juvenile & 119 & 0.06 & 0.53 & 0.34 & 0.17 & & \\
\hline c. Dairy cattle & (d) & (SU) & FUM & GDP $(\mathrm{g})$ & UPB & (g FM) & (SV/kg DM) \\
\hline Bull & 365 & 21.8 & 6300 & 225 & -65.00 & & 1.00 \\
\hline Veal calf & 178 & 4.1 & 3493 & 290 & -3.46 & 2.25 & 1.48 \\
\hline Repl. calf & 365 & 7.0 & 4094 & 244 & -3.37 & 0.56 & 1.48 \\
\hline Repl. heifer & 365 & 13.0 & 7094 & 380 & -47.51 & & 1.30 \\
\hline d. Beef cattle & (d) & $(\mathrm{SU})$ & FUM & GDP (g) & UPB & (g FM) & (SV/kg DM) \\
\hline Breeder cow & 365 & 13.4 & 8666 & 483 & -23 & & 0.65 \\
\hline Bull & 365 & 21.8 & 5850 & 150 & -100 & & 0.60 \\
\hline Repl. calf & 365 & 1.4 & 1235 & 94 & -6 & $x^{a}$ & 1.48 \\
\hline Repl. heifer & 365 & 7.6 & 7395 & 506 & -55 & & 1.30 \\
\hline
\end{tabular}


Growth curves of mid and low productive pigs were simulated using InraPorc (van Milgen et al., 2008), a pig growth simulation model representing the methods used by CVB (CVB, 2012). Reduced growth was simulated by maintaining (high productive) pig characteristics while reducing the feed energy content, assuming a maximum average feed intake of $3 \mathrm{~kg}$ Under this maximum feed intake, the nutrient requirements of the high productive pigs could be met when feeding a ration with an energy content down to $6.7 \mathrm{MJ} \mathrm{NE} / \mathrm{kg}$. Mid productive pigs were simulated providing a diet containing 6.16 MJ NE/ kg, which resulted in an ADG of 710 grams (6\% lower than the high productive pigs). This extended the growth period to 126 days resulting in 2.83 rounds of pigs grown per year. The low productive pigs were simulated providing a diet containing 5.72 MJ NE/kg, had an ADG of $690 \mathrm{~g}$ (12\% reduction), resulting in a 134 day growth period and 2.65 rounds of pigs per year. Performance as well as average daily nutrient requirements of all productivity levels are provided in Table 1 of the main article.

The average daily FIC of $3 \mathrm{~kg}$ (Lee et al., 2002; Quiniou \& Noblet, 2012) was assumed to remain equal for each productivity level as was the death rate of $3.9 \%$ (FAO, 2016c) during the entire growth period. This death rate implies a loss of 0.04 producing pig per slaughtered producing pig, assumed to occur evenly throughout the growth period. Carcass yield was based on InraPorc and varied between productivity levels (high: 77\%, mid: 76\%, low, 74\%).

\section{Laying hens}

Variation in laying hen productivity was achieved by assuming different laying percentages (\% of days eggs are laid) during the 56 week laying period. The egg weight was kept constant at 60 g per egg, being the average commercial egg weight over the laying period (Bozkurt et al., 2012). The laying percentage of the high-productive hen was set at $85 \%$, closest to the Dutch average laying percentage of $85.7 \%$ (LEI, 2017). Hens with this laying percentage require a total input of $541 \mathrm{MJ}$ NE, $294 \mathrm{~g}$ DLys and $143 \mathrm{~g}$ DMeth over the entire laying period (CVB, 2012). The laying percentage was reduced to $75 \%$ for mid-productive hens and $60 \%$ for low-productive hens as these were the levels provided by (CVB, 2012). Average daily nutrient requirements of all productivity levels are provided in Table 1 of the main article. The average daily FIC of $150 \mathrm{~g}$ (Forbes, 2007; Morris, 1968) was assumed to remain equal for each productivity level as was the death rate of $7 \%$ (FAO, 2016c), during the entire laying period. This death rate implies a loss of 0.08 laying hen per producing laying hen, assumed to occur evenly throughout the laying period. Considering this death rate and the 56 week laying period, implying 0.93 production rounds per year. 


\section{Broilers}

Variation in broiler productivity was based on the average performance of fast and slow growing broilers in the Netherlands, provided by (CVB, 2016b). The input-output relation of the high productive broilers was based on the performance and related nutrient requirement of fast growing broilers in the Netherlands. They grow to $2.26 \mathrm{~kg}$ LW in 40 days, resulting in 9.1 rounds of broilers per year and an ADG of $56 \mathrm{~g}$. To achieve this growth, a broiler needs 47.4 MJ NE, 36.7 g DLys and 14.3 g DMeth over the entire growth period. The low-productive broilers were based on slow growing broilers, which grow to $2.50 \mathrm{~kg} \mathrm{LW}$ in 56 days, resulting in 6.5 rounds per year and a ADG of $42 \mathrm{~g}$. They require an intake of 62.8 MJ NE, $48.7 \mathrm{~g}$ DLys and 19.0 $\mathrm{g}$ DMeth over the entire growth period. The mid-productive broiler was the average of these two, growing to $23.3 \mathrm{~kg} \mathrm{LW}$ in 49 days, resulting in 7.6 rounds per year and an $\mathrm{ADG}$ of $49 \mathrm{~g}$. They require an intake of $55.1 \mathrm{MJ} \mathrm{CE}, 42.7 \mathrm{~g}$ DLys and 16.6 g DMeth over the entire growth period. Average daily nutrient requirements of all productivity levels are provided in Table 1 of the main article. The average daily FIC of $114 \mathrm{~g}$ (Leeson et al., 1996) was assumed to remain equal for each productivity level as was the death rate of $4.3 \%$ (FAO, 2016c), during the entire growth period. This death rate implies a loss of 0.05 broilers per slaughtered broiler, assumed to occur evenly throughout the growth period.

\section{Dairy}

Variation in productivity of dairy cows was achieved by assuming different annual milk yields. For high productive cattle, the average Dutch milk production, between 2012 and 2016, amounting $8860 \mathrm{~kg}$ fat and protein corrected milk (FPCM) per cow per year (CRV, 2017) served as a proxy. For low productive dairy cattle the average milk yield of extensively farmed Irish dairy cattle of $4750 \mathrm{~kg}$ FPCM was assumed. Productivity of mid productive dairy cattle was assumed $6800 \mathrm{~kg}$, exactly between high and low productivity. Productivity related nutrient requirement were calculated using the following formulas (CVB, 2012):

$F U M=\left(42.4 \times B W^{0.75}+442 \times F P C M\right) \times(1+(F P C M-15) \times 0.00165)$

and

$I D P(g /$ day $)=\left(\left(2.75 * B W^{0.5}+0.2 \times B W^{0.6}\right) / 0.67\right)+\left(1.396 \times P+0.000195 \times P^{2}\right)$

where FUM = energy requirement in feed unit milk, BW = body weight (593 $\mathrm{kg}$ ), FPCM = fat and protein corrected milk, IDP = intestinal digestible protein requirement (g/day) and $\mathrm{P}=$ milk protein production (g/day). Resulting average daily nutrient requirements of all productivity levels are provided in Table 1 of the main article. 
For the milk output, the milk needed to feed the replacement and veal calves, $320 \mathrm{~kg}$, was subtracted from the average annual production resulting in an annual output of $8644 \mathrm{~kg}$ FPCM for high productive cows, $6589 \mathrm{~kg}$ FPCM for mid productive cows and $4534 \mathrm{~kg}$ FPCM for low productive cows. A SV of at least 0.99 should be achieved for high productive, 0.95 for mid productive, and 0.90 for low productive dairy cows (CVB, 2012). This required SV is calculated by deviating from 1 by subtracting 0.01 for every $\mathrm{kg}$ that the daily produced FPCM is below $25 \mathrm{~kg}$ and subtracting 0.05 for every percentage that the milk fat percentage is below $4.4 \%$ (CVB, 2012). The daily FIC of 14.5 saturation units (SU) (CVB, 2012) was assumed to remain equal for each productivity level as was the annual death rate of $4 \%$ and selection rate $31 \%$ (FAO, 2016c). This selection and death rate combined imply a loss of 0.45 dairy cows per milked dairy cow, assumed to occur evenly throughout the year.

\section{$\underline{\text { Beef }}$}

Variation in productivity of beef cattle was achieved by assuming different growth curves for a growth from 250 to $650 \mathrm{~kg} \mathrm{LW}$. The first 9 months the calf remains, suckling, with the dam to which the nutrient requirement during this period is assigned. Productivity of productive beef cattle was based on the optimal growth curve of late ripe beef cattle growing from 250 to $650 \mathrm{~kg}$ live weight in a period of 328 days resulting in 1.11 rounds of beef per year and an ADG of $1217 \mathrm{~g}$ (CVB, 2012; van Vliet et al., 1994). For low productive beef cattle the ADG of grass fed beef in the Charolaise region in France of $930 \mathrm{~g}$ was assumed, requiring a 431 day growth period resulting in 0.85 rounds per year. Productivity of the mid productive beef cattle was the average of high and low productivity (ADG 1070 g; 375 day growth period; 0.97 rounds per year). Productivity related nutrient requirement were calculated using the following formulas (CVB, 2012):

$F U B=\left(368.4 \times B W^{0.75}\right)+(22.94 \times \mathrm{PD}+39.31 \times \mathrm{FD})$

and

$I D P(g /$ day $)=\left(\left(2.75 * B W^{0.5}+0.2 \times B W^{0.6}\right) / 0.67\right)+(\mathrm{PD} / \mathrm{Ke})$

where FUB = energy requirement in feed unit beef, BW = body weight (varying through growth), PD and DF represent growth dependant protein/fat deposition, provided by (van Vliet et al., 1994), IDP = intestinal digestible protein requirement $(\mathrm{g} /$ day) and $\mathrm{Ke}=$ growth dependant protein efficiency provided by (van Vliet et al., 1994). As nutrient requirements vary throughout the growth period, they are calculated for each $50 \mathrm{~kg}$ growth stage. Resulting average daily nutrient 
requirements of all productivity levels are provided in Table 1 of the main article. The daily FIC of 10.7 SU (van Vliet et al., 1994), the minimum SV of the diet of 0.75 and the death rate during the growing period of $3 \%(\mathrm{FAO}, 2016 \mathrm{c})$ were assumed to remain equal for each productivity. This death rate implies a loss of 0.03 beef cows per slaughtered beef cow, assumed to occur evenly throughout the growth period.

\section{A5 - Nutrient content of livestock products}

The output of ASF available for human consumption, for each livestock system and productivity, is expressed in human digestible protein (HDP) and essential micronutrients (vitamin -D, -B12, calcium, iron, zinc, and selenium) per kg product (milk, meat, and eggs). Calculating the nutrient output requires data on the nutrient content per $\mathrm{kg}$ of the different animal products, which were collected the USDA database (USDA, 2018a). While for milk and eggs the available data could be used directly, for meat these nutrient contents are generally specified for the different cuts while we require an average of all cuts in the animal. Although previous studies have used estimations on the average protein content of the edible meat of various animal types, for other nutrients no data was available. Weighted average nutrient contents per $\mathrm{kg}$ of carcass weight, taking in account cutting (CBB \& NCBA, 2014) and cooking losses (USDA, 2012) (see Figure A7), were, therefore, calculated from the USDA database (USDA, 2018a). The weighted average protein content per $\mathrm{kg}$ of broiler carcass calculated from the USDA database as described above was adjusted to account for the different meat protein content found under the different productivity levels in (Fanatico et al., 2005). For the pig (van Milgen et al., 2008) and beef (van Vliet et al., 1994) carcass a similar correction was made, based on protein deposition related to the growth curve. The protein content of each animal product after corrections, as used in the model is displayed in Figure A6.

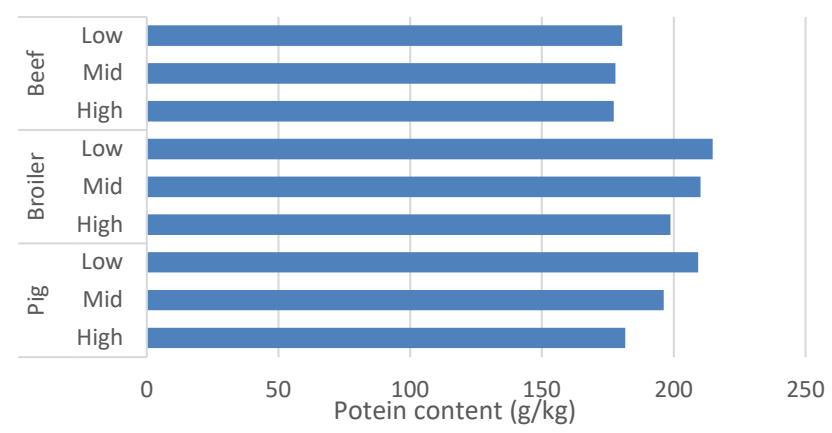

Figure A6 Human digestible protein content per kg of carcass weight for pigs, broilers, and beef cattle adjusted for predicted variation in protein deposition under varying productivity 


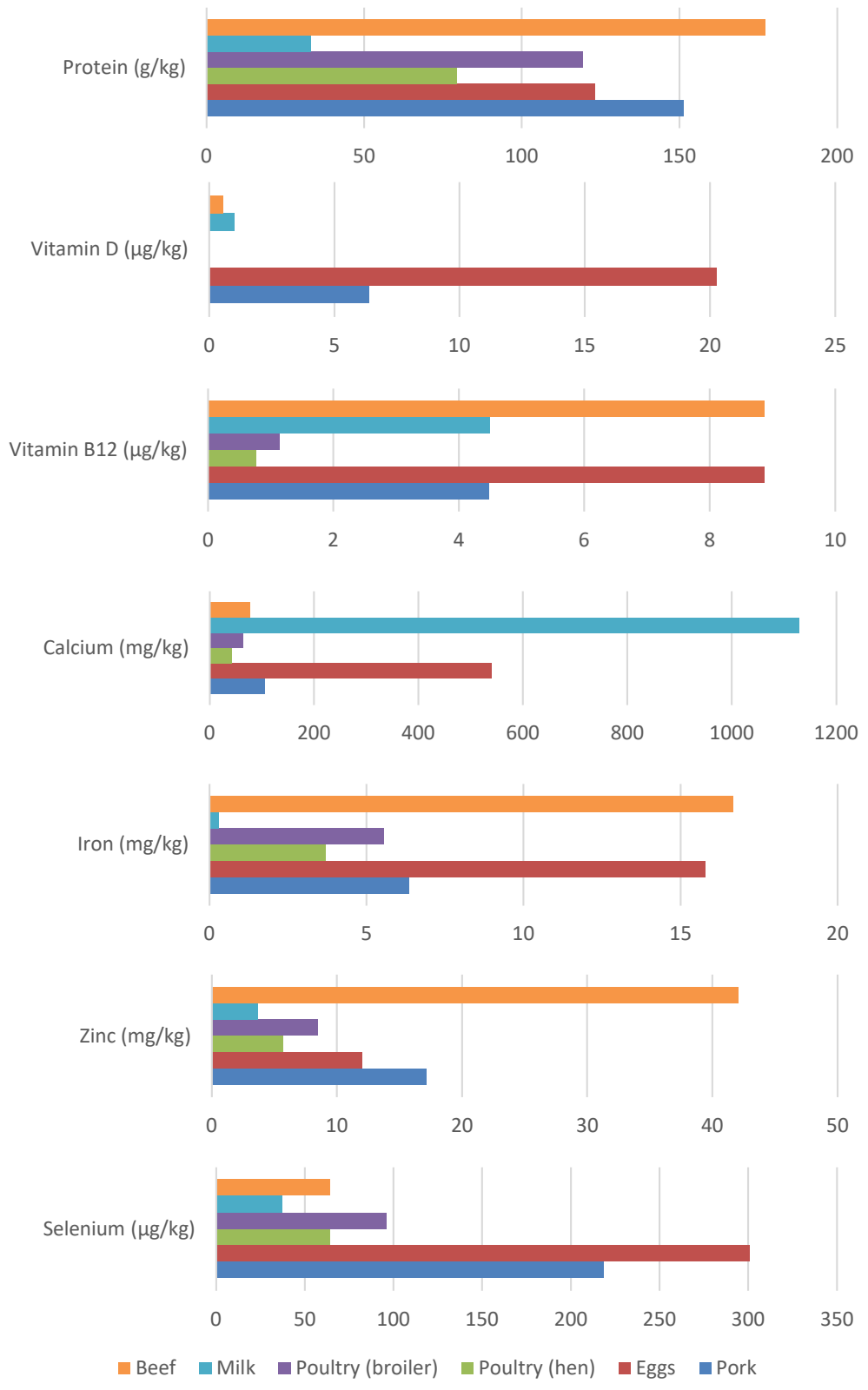

Figure A7 Human digestible nutrient content per $\mathrm{kg}$ of each animal product, for meat expressed per kg carcass weight accounting for cutting and cooking losses adapted from (USDA, 2012, 2018a). 
$\mathbf{1 3 4}$ | A p p endix A

\section{Appendix A6 - Additional results chapter 2}

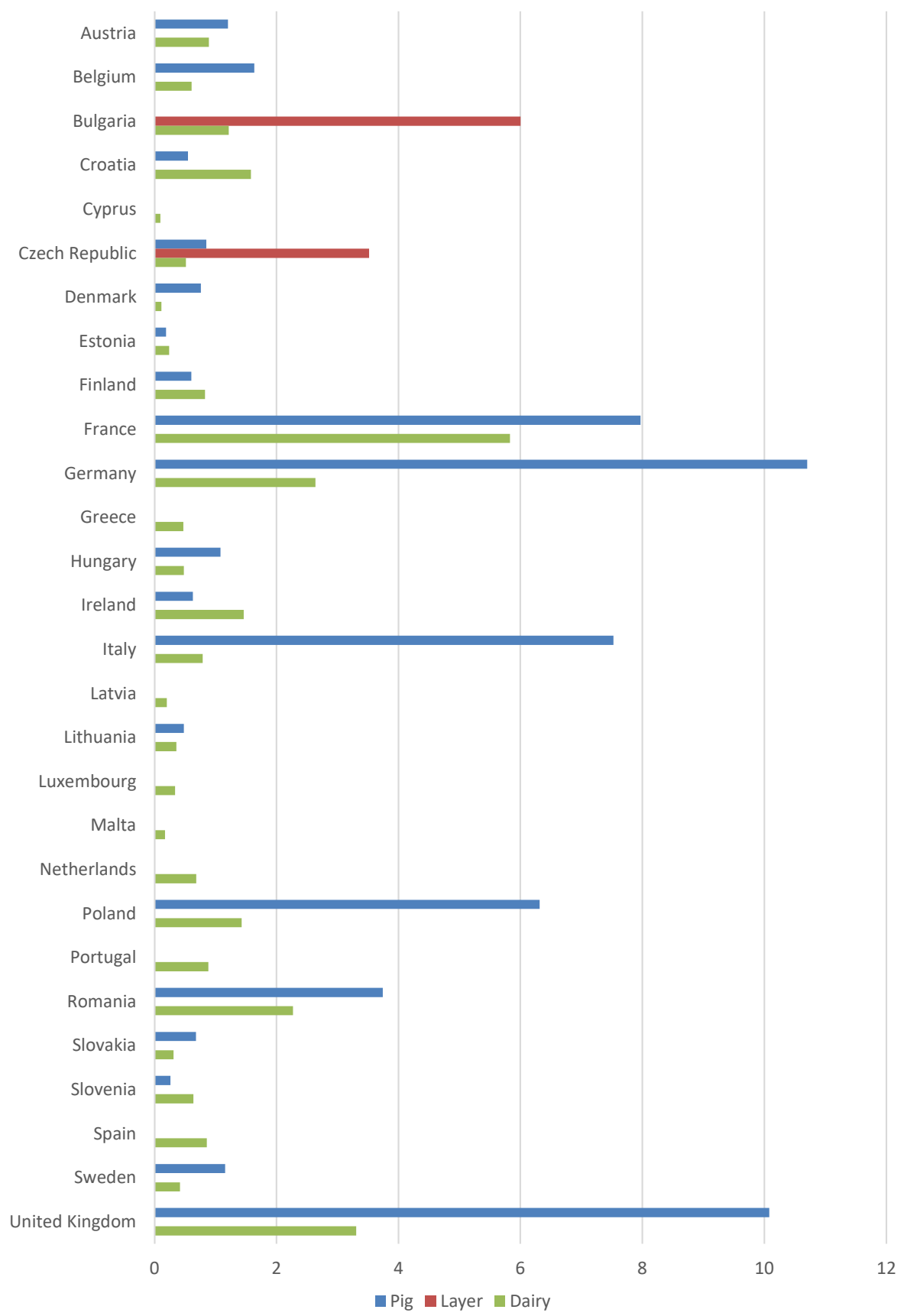

Figure A8 Number of producing animals of each livestock system $\times 10^{6}$ (pig, laying hen, dairy cattle) in each EU 28 country under optimal conversion of available low-opportunity-cost feed (LCF) 


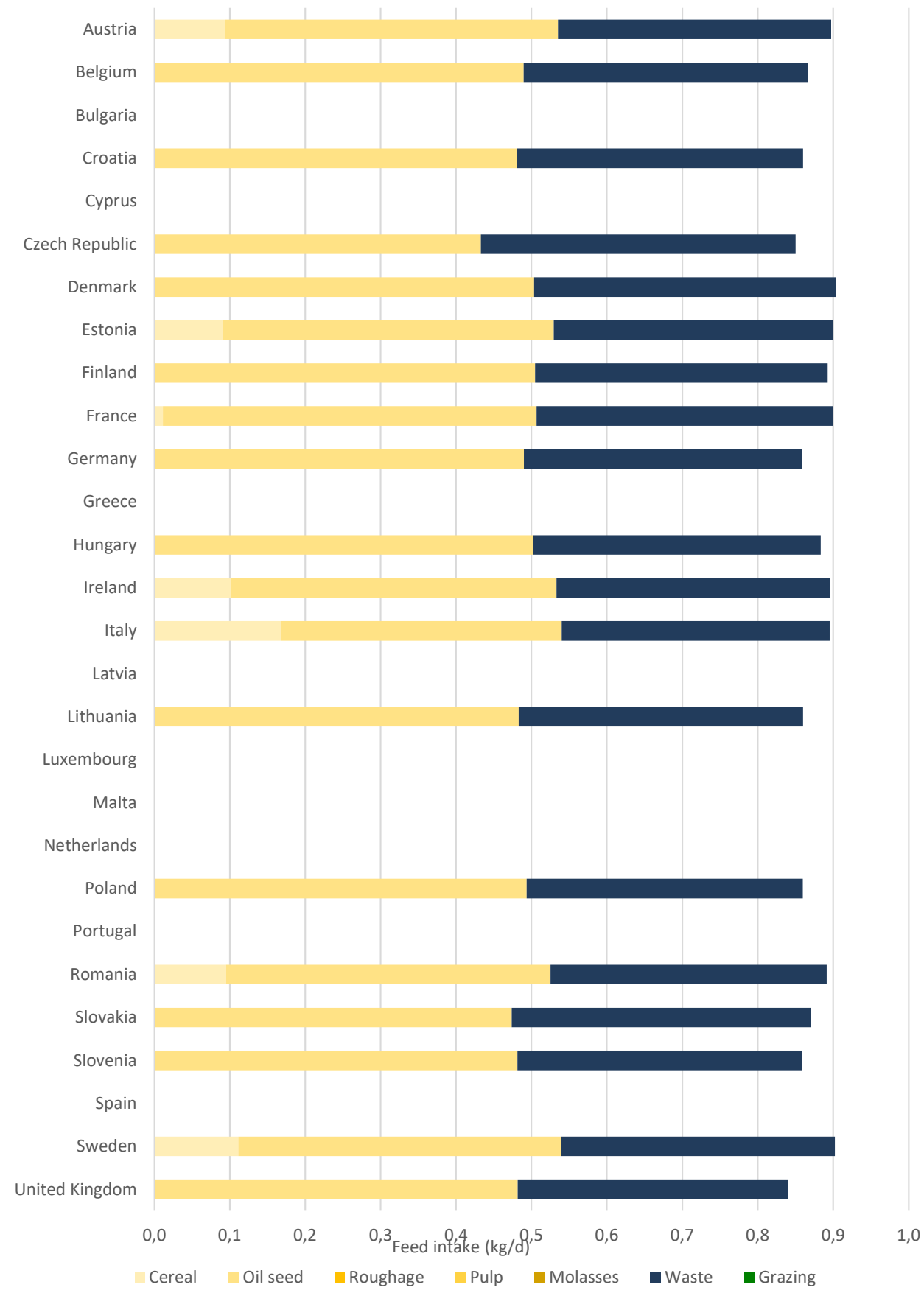

Figure A9 Proposed daily feed intake for pigs under the optimal use of low-opportunity-cost feed (LCF) for each country; expressed per production animal per day including related requirement of non-producing animals. 
$\mathbf{1 3 6}$ | A p p endix A

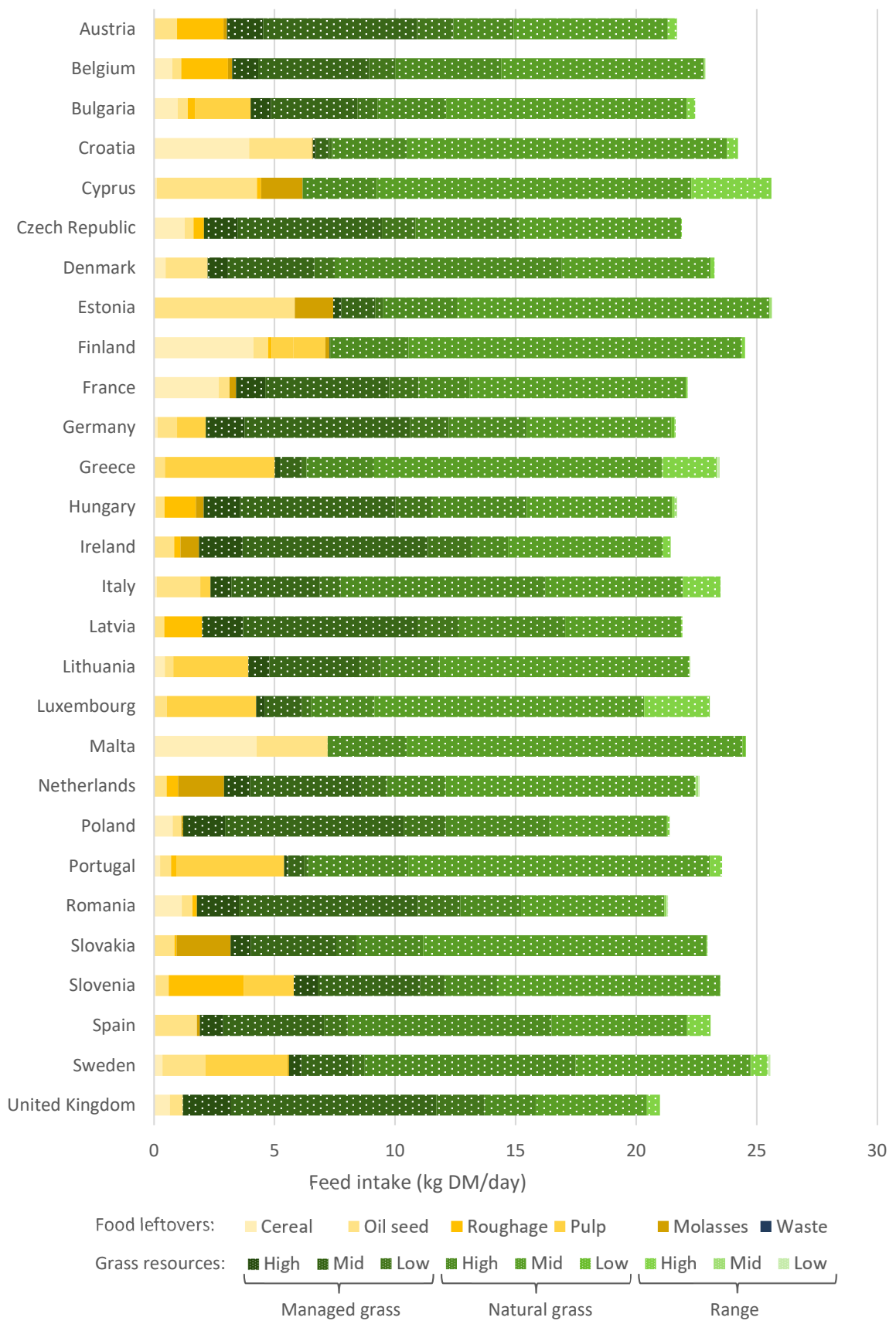

Figure A1o Proposed daily feed intake for dairy cattle under the optimal use of non-food-competing feed (LCF) for each country; expressed per production animal per day including related requirement of non-producing animals. 


\section{Appendix B}

B1 Fisheries assumptions

B2 Availability of low-opportunity-cost feeds

B3 Animal production systems

B4 Nutrient content of animal sourced food

B5 Additional results of Chapter 3 


\section{B1 - Fisheries assumptions}

For simplicity, we focused on the limited fisheries species that currently provide the majority of landed biomass. To this end, we collected landings data for the 122 stocks of 24 species (ICES, 2018) that provided $90 \%$ of the 2016 landings in the Northeast Atlantic (7.1 of 8.4 Mtonne). Five of these species (blue mussels, chub mackerel, scallop, edible crab, Greenland halibut; 4,7\% of total catches) were excluded because they did not have an ICES advice and could thus not be translated to MSY. Three additional species (beaked redfish, Atlantic redfishes and capelin; $2.5 \%$ of total catches) were excluded as their ICES advise did not match geographically with fishing quota distributions.

Table B1 Current and sustainable fisheries landings (tonne) in the north east Atlantic by EU-28 of the 16 selected species and their current and sustainable fractional allocation to human consumption (Fish use).

\begin{tabular}{|c|c|c|c|c|c|c|}
\hline \multirow[b]{3}{*}{ Fish species ${ }^{1}$} & & \multicolumn{3}{|c|}{ Fisheries landings } & \multicolumn{2}{|c|}{ Fish use } \\
\hline & & \multirow[b]{2}{*}{ Current } & \multicolumn{2}{|c|}{ Sustainable } & \multirow[b]{2}{*}{ Current $^{4}$} & \multirow[b]{2}{*}{ Sustainable ${ }^{5}$} \\
\hline & & & $\mathrm{MSY}^{2}$ & MSYO.8 & & \\
\hline Atlantic cod & Gadus morhua & 130089 & 119517 & 213083 & 1 & 1 \\
\hline Atlantic herring & Clupea harengus & 839837 & 487715 & 870792 & 0.74 & 1 \\
\hline Atlantic horse mackerel & Trachurus trachurus & 75103 & 187150 & 299184 & 0.86 & 1 \\
\hline Atlantic mackerel & Scomber scombrus & 456879 & 356308 & 323380 & 0.63 & 1 \\
\hline Blue whiting & Micromesistius poutassou & 222434 & 131935 & 236988 & 0 & 1 \\
\hline European hake & Merluccius merluccius & 108175 & 111181 & 95482 & 1 & 1 \\
\hline European plaice & Pleuronectes platessa & 98349 & 215121 & 201089 & 1 & 1 \\
\hline European pilchard & Sardina pilchardus & 73062 & 83721 & 155891 & 0.98 & 1 \\
\hline European sprat & Sprattus sprattus & 444022 & 320817 & 567749 & 0.35 & 1 \\
\hline Haddock & Melanogrammus aeglefinus & 85325 & 56115 & 110590 & 1 & 1 \\
\hline Ling & Molva molva & 10740 & 11261 & 15589 & 1 & 1 \\
\hline Norway pout & Trisopterus esmarkii & 23573 & 191812 & 96245 & 0 & 0 \\
\hline Norway lobster & Nephrops norvegicus & 49583 & 35642 & 66528 & 1 & 1 \\
\hline Northern prawn & Pandalus borealis & 13356 & 18163 & 13625 & 1 & 1 \\
\hline Pollock & Pollachius virens & 34379 & 43513 & 72732 & 1 & 1 \\
\hline Sandeels & Ammodytes sp. & 32463 & 106038 & 284911 & 0 & 0 \\
\hline \multicolumn{7}{|c|}{1 Considering the most exploited species in 2016 (ICES, 2018) } \\
\hline \multicolumn{7}{|c|}{2 MSY based on ICES advise (ICES, 2016) } \\
\hline \multicolumn{7}{|c|}{3 Long term (2030) MSY with reduced fishing mortality (0.8) (Froese et al., 2018) } \\
\hline \multirow{2}{*}{\multicolumn{7}{|c|}{$\begin{array}{l}4 \text { Fraction of landings of which edible yield is used for food; current post landing utilisation (EUROSTAT, 2016) } \\
5 \text { For all prime/food grade species (Cashion et al. 2017) the edible yield of full landings are allocated to food }\end{array}$}} \\
\hline & & & (1) 50 & & & \\
\hline
\end{tabular}

The 16 species with 100 stocks finally included represented 6,8 Mt (or 81\%) of catches Northeast Atlantic landings in 2016; 2.2 Mt of this volume were EU landings. These 2.2 Mt landed fish, here representing current EU landings, constitute $75 \%$ of total EU landings (EUROSTAT, 2019). Besides excluded species and stocks in the Northeast Atlantic, the other 25\% of EU landings originates from stocks in the Mediterranean and Black Seas, fished under third-country agreements. Inclusion of these stocks, especially under MSY, is less relevant as many of these stocks is severely impaired (Froese et al., 2018). While the current landings assumed here are based directly on above described data, maximum sustainable yield (MSY), for the same stocks and species were obtained from (ICES, 2016) for the short term MSY and (Froese et al., 2018) for the long term MSY. 


\section{B2 - Availability of low-opportunity-cost feeds}

The LCF that are input to the model consider human inedible products associated to primary use of spatial resources and include crop processing by-products, animal processing by-products, plant-based manufacturing wastes and grass resources. The availability of crop processing byproducts and grass resources was adopted from Hal et al. (2019) and are described in detail in Appendix A2. For grass resources, the availability of managed grass was corrected to a total of 89 Mt based as suggested by the authors of the underlying research Haberl et al. (2007) and Plutzar et al. (2016). The range of nutrient content of grass resources of each vegetation type, obtained from literature was assumed to be normally distributed over the available grass biomass. Below we describe the assumed availability of plant based manufacturing wastes and the data used to calculate available by-products related to processing yields of sustainable fisheries as well as animal by-products related to upcycling available LCF.

\section{Manufacturing waste: former food stuff}

To follow EU legislation (EU, 2017, 2018) only plant based former foodstuffs (FFS) -products intended for human consumption wasted during food manufacturing - were included as LCF. As studies on feeding food waste to animals focus on the potential of relegalising currently banned food waste (zu Ermgassen et al., 2016), no scientific data on the availability of FFS is available. EUROSTAT data on biomass lost during food processing and manufacturing, are unsuitable as it includes food co-products and their product composition in unknown (EUROSTAT, 2018). The European Former Foodstuff Processors Association (EFFPA), whose members process 3.5 million tonnes of FFS annually, estimates that in the EU a total of 5 million tonnes of FFS are processed into feed annually (EFFPA, 2019). While EFFPA indicates the majority of these FFS are cereal based (>70\%) the exact product composition of EU FFS remains unknown (EFFPA, 2019). We, therefore, assumed the product composition of FFS, excluding by-products, of the UK (UKFFPA, 2019), Netherlands (VIDO, 2019) and France (Vernier et al., 2016) combined (Figure B1) and applied this to the estimated 5 million tonnes of EU FFS. The resulting 4.2 million tonnes of cereal based FFS comes close Caldeira et al. (2019) estimation of 4.9 million ton cereal based products wasted during product manufacturing in the EU. Each of the former food products was assumed to be processed into common FFS based feed ingredients, resulting in the available feed ingredients displayed in Figure B2, classified based on their nutritional properties. 


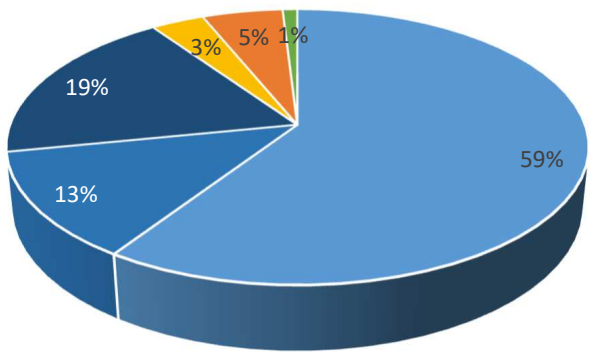

a. United Kingdom (0.6 Mt)

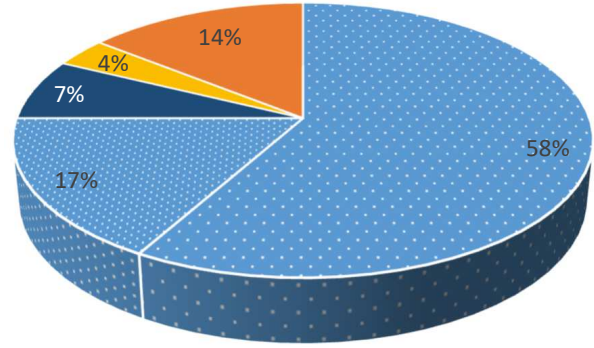

c. The Netherlands (0.3Mt)

Bread Biscuit Pasta

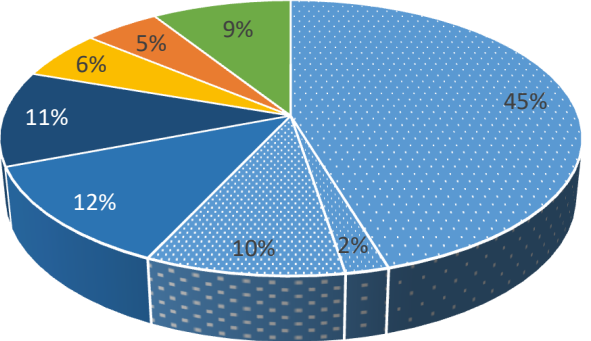

b. France $(1.1 \mathrm{Mt})$

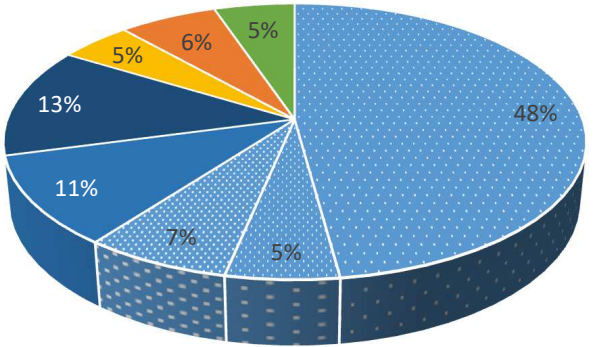

d. Combined (2.0 Mt)

- Savoury snacks

Figure B1 Combined (d) former foodstuff product composition based on that of the UK (UKFFPA, 2019), The Netherlands (VIDO, 2019) and France (Vernier et al., 2016) adapted to exclude animal based products and crop by-products.

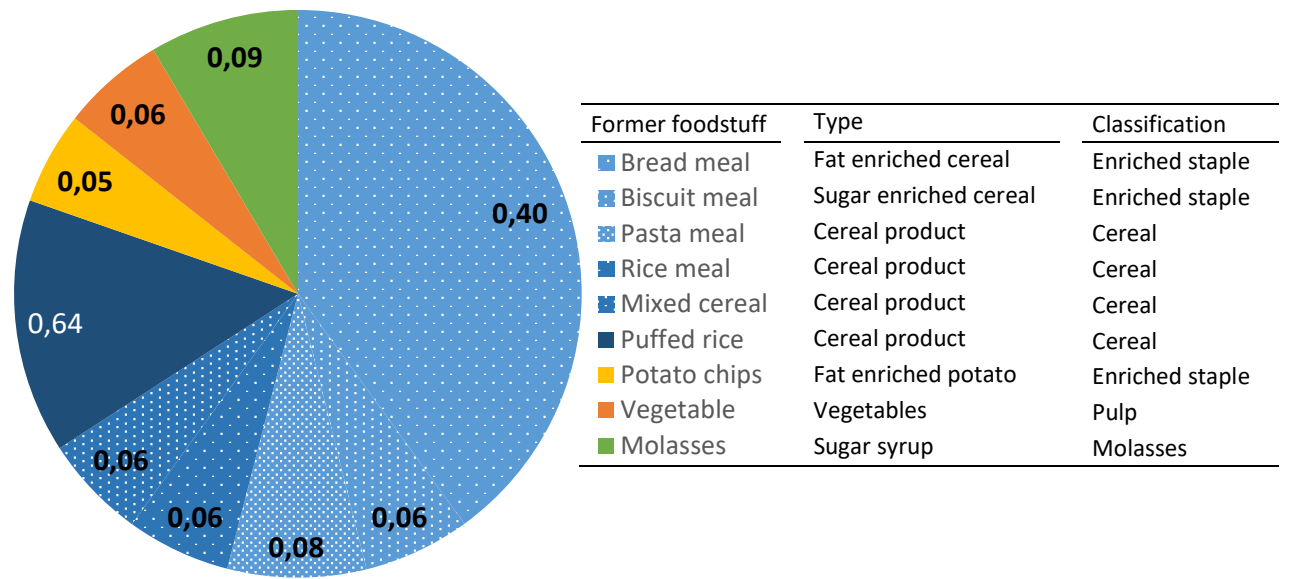

Figure B2 Available former food stuffs based ingredients (Mt) in the EU, assuming a total of 5 Mt (EFFPA, 2019) and the combined product composition in the UK, Netherlands and France (Figure B2) and their classification based on nutritional properties. 


\section{Animal by-products}

Table B2 Edible yield fraction of fresh whole fish obtained from DanishFoodlnstitute (2019), FAO (1989) and SwedishFoodAgency (2019); and oil and meal output from rendering fish and fish by-products in $\mathrm{kg}$ per kg input

\begin{tabular}{|c|c|c|c|c|}
\hline \multirow[b]{2}{*}{ Fish Species } & \multirow{2}{*}{$\begin{array}{l}\text { Slaughter yield } \\
\text { fraction }\end{array}$} & \multicolumn{2}{|c|}{ Render fraction } & \multirow[b]{2}{*}{ Reference } \\
\hline & & Meal & Oil & \\
\hline Atlantic herring & 0.52 & 0.20 & 0.04 & (Cashion et al., 2016) \\
\hline Atlantic Cod & 0.35 & 0.17 & 0.02 & (Cashion et al., 2016) \\
\hline Blue whiting & 0.46 & 0.20 & 0.02 & (Cashion et al., 2016) \\
\hline Atlantic mackerel & 0.38 & 0.19 & 0.19 & (Cashion et al., 2016) \\
\hline European sprat & 0.52 & 0.19 & 0.08 & (Cashion et al., 2016) \\
\hline Haddock & 0.33 & 0.17 & 0.02 & (Cashion et al., 2017) \\
\hline Pollock (=Saithe) & 0.39 & 0.17 & 0.02 & (Cashion et al., 2017) \\
\hline European plaice & 0.33 & 0.17 & 0.02 & (Cashion et al., 2017); Cod \\
\hline European hake & 0.42 & 0.17 & 0.02 & (Cashion et al., 2017); Cod \\
\hline Atlantic horse mackerel & 0.54 & 0.19 & 0.19 & (Cashion et al., 2017); Mackrel \\
\hline Sandeels & 0.00 & 0.20 & 0.04 & (Cashion et al., 2017) \\
\hline European pilchard & 0.62 & 0.23 & 0.18 & (Cashion et al., 2017) \\
\hline Norway pout & 0.00 & 0.20 & 0.12 & (Cashion et al., 2016) \\
\hline Norway lobster & 0.42 & 0.16 & 0.00 & (Cashion et al., 2016); Krill \\
\hline Northern prawn & 0.36 & 0.16 & 0.00 & (Cashion et al., 2016); Krill \\
\hline Ling & 0.46 & 0.17 & 0.02 & (Cashion et al., 2017); Cod \\
\hline Atlantic Salmon & 0.63 & 0.20 & 0.04 & (Cashion et al., 2016); Herring \\
\hline Nile Tilaptia & 0.42 & 0.17 & 0.02 & (Cashion et al., 2017); Cod \\
\hline
\end{tabular}

Table B3 Slaughter (and cutting) outputs for differnt livestock systems in $\mathrm{kg}$ per $\mathrm{kg} \mathrm{LW}$

\begin{tabular}{|c|c|c|c|c|c|}
\hline Slaughter output & $\mathrm{Pig}^{1}$ & Laying hen ${ }^{2}$ & Broiler $^{2}$ & Dairy ${ }^{1}$ & Beef $^{1}$ \\
\hline Carcass & $0.77^{3}$ & 0.61 & $0.72^{4}$ & 0.57 & 0.64 \\
\hline Meat, raw & 0.64 & $0.38^{5}$ & $0.47^{6}$ & 0.47 & 0.53 \\
\hline Bone meal & 0.12 & 0.22 & 0.23 & 0.09 & 0.10 \\
\hline Offals & 0.08 & 0.07 & 0.05 & 0.06 & 0.05 \\
\hline Animal fat & 0.04 & & & 0.13 & 0.11 \\
\hline Bloodmeal & 0.01 & & & 0.01 & 0.01 \\
\hline Meat and bone meal & 0.06 & 0.07 & 0.05 & 0.11 & 0.09 \\
\hline Feather meal & & 0.08 & 0.06 & & \\
\hline \multicolumn{6}{|c|}{1 Based on USDA slaughter reports (USDA, 2018b, 2018c) } \\
\hline \multicolumn{6}{|c|}{2 Based on Damme \& Ristic (2003), Haslinger et al. (2007) and Sams (2010; improved compared to van Hal et al. (2019) } \\
\hline \multicolumn{6}{|c|}{3 Carcass output varied per productivity level as reported in van Hal et al. (2019) } \\
\hline \multicolumn{6}{|c|}{ Outputs of broiler breeder stock based on laying hens } \\
\hline \multicolumn{6}{|c|}{ Meat yield/kg carcass based on: Damme \& Ristic (2003), Loetscher et al. (2015) and Zanders \& Claessens (2018) } \\
\hline \multicolumn{6}{|c|}{6 Meat yield/kg carcass based on: Denton \& Mellor, (1990), Sams (2010) and USDA, (2018a) } \\
\hline
\end{tabular}

\section{Legislation on feeding of animal by-products}

The strict EU regulations on feeding animal based products to food producing animals (Table B4) were implemented after the major BSE crisis to avoid transmission of diseases between animals, and specifically transmission of animal diseases to humans (EU, 2009). While, originally, these regulations banned feeding animal proteins to any food producing animals, a 2013 amendment has relegalised feeding these proteins (except from bovine origin) in aquaculture (EU, 2013a). With this relegalisation, aquaculture can upcycle human inedible outputs of fisheries, livestock production 
and even aquaculture itself, that livestock cannot consume. Proteins from bovine animals are, however, still banned as aquaculture feed. Additionally EU legislation forbids feeding farmed animals with proteins originating from farmed animals of the same species (EU, 2013a). Farmed salmon can, thus, not be fed with salmon meal originating from aquaculture. Salmon and tilapia in our model are, however, a proxy for multiple species with similar characteristics (e.g. rainbow trout, seabass and seabream for salmon) that are allowed to feed on each other's by-products. To reflect this we allow for intraspecies recycling of fish farming by-products, meaning we allow farmed salmon to eat salmon by-products, assuming salmon represents multiple species that could recycle each other's by-products.

Table B4 Allowance of animal by-products in feed of food producing animal species based on EU legislation (EU, 2009, 2013a).

\begin{tabular}{|c|c|c|c|c|}
\hline Animal by-product & Pig & Poultry & Cattle & Fish \\
\hline Meat\&Bone meal & NO & NO & NO & YES $^{1}$ \\
\hline Bone meal & NO & NO & NO & YES $^{1}$ \\
\hline Blood meal & YES $^{1}$ & YES $^{1}$ & NO & YES $^{1}$ \\
\hline Animal fat & YES & YES & YES & YES \\
\hline Feather meal & YES $^{2}$ & $\mathrm{YES}^{2}$ & NO & YES \\
\hline Poultry by-product meal & NO & NO & NO & YES \\
\hline Fish oil & YES & YES & YES & YES \\
\hline Fish meal & YES & YES & NO & YES \\
\hline
\end{tabular}

\section{B3 - Animal production systems}

The animal production systems considered to upcycle available LCF, include the entire lifecycle of 5 livestock and 2 aquaculture species composed of food producing animals and associated parent and young stock. The livestock systems considering pig, laying hen, broiler, dairy, and beef production under 3 productivity levels, were adopted from van Hal et al. (2019); underlying assumptions, data and calculations are provided in Appendix A3 and A4. In contrast, aquaculture production systems were simulated specifically for this study and all underlying data is provided below.

\section{Aquaculture production}

We included carnivorous Atlantic Salmon, the most farmed fish in the EU, and omnivorous Nile Tilapia, the most consumed omnivore, considering the entire lifecycle (EUROSTAT, 2019; FAO, 2018b) comprised of food producing animals and associated non-food producing animals such as parent and young stock. For both species status quo performance for the entire lifecycle was based on optimal growth and related feed intake simulated with Skretting's AquaSim model, validated and adjusted based on literature. 


\section{Herd composition}

The number of non-producing animals (e.g. alevin, fry, smolt and brood stock) needed to harvest one producing animal (e.g. Salmon grower) (Table B10) was based on species specific mortality and fertility data. Note that, due to death and selection, additional producing animals are needed to harvest of one producing animal. For Salmon, mortality in the early life phases was based on (McGeachy et al., 1995) and for growers on the average in Norway (EY, 2017). We assume salmon brood stock is selected from growers before slaughter, and to spawn only once (Sedgwick, 1982) after 32 days providing 9750 eggs (Eskelinen, 1989; FAO, 2018a), before being slaughtered at a slaughter weight of $6000 \mathrm{~g}$. A male salmon brood stock was assumed to fertilise the eggs of 100 female brood stock (Cryogenetics, 2014). For tilapia, mortality throughout the production cycle is based on (Bhujel, 2014). We assumed Tilapia brood stock is selected as juveniles of $125 \mathrm{~g}$ to ensure optimal fertility. A brood stock set consists of one male and two females, where each female spawns 5000 eggs over a period of 9 months, before being slaughtered at 400 gram BW (TIL-AQUA, 2016).

Table B5 Occurence of each herd component relative to one harvested adult fish.

\begin{tabular}{|c|c|c|}
\hline Animal type & Herd component & Occurrence \\
\hline \multirow[t]{6}{*}{ Salmon } & Grower & 1.19 \\
\hline & Male Brood stock & 0.00 \\
\hline & Female Brood stock & 0.00 \\
\hline & Alevin & 2.15 \\
\hline & Fry & 1.46 \\
\hline & Smolt & 1.28 \\
\hline \multirow[t]{7}{*}{ Tilapia } & Grower & 1.05 \\
\hline & Male Brood stock & 0.00 \\
\hline & Female Brood stock & 0.00 \\
\hline & Swim up fry & 5.78 \\
\hline & Fry & 1.73 \\
\hline & Fingerling & 1.30 \\
\hline & Juvenile & 1.17 \\
\hline
\end{tabular}

\section{Production performance}

\section{Atlantic Salmon}

Optimal growth and feed intake during the lifecycle of the poikilothermic Atlantic Salmon was simulated assuming the sea water temperature curve of atlantic ocean surrounding the UK (SeaTemperatures, 2019), where the majority of the EU's salmon production is situated (EUROSTAT, 2019). The simulated optimal growth is in line with studies that assessed growth performance over (specific parts) of the growth cycle (Figure B5). The simulated fish, housed in sea cages, grow from $77 \mathrm{~g}$ to a slaughter weight of $5500 \mathrm{~g}$ in 490 days after a yearlong freshwater phase. The cumulative feed conversion ratio (FCR: $\mathrm{kg}$ feed needed per kg growth) over the life cycle of this simulation (1.16) is low compared to those observed in practice (1.2-1.5; (Fry et al., 2018; Tacon \& 
Metian, 2008). This is likely due to simulation models such as AquaSim assuming a healthy population while continuous health cannot be assured in practice, especially under the extensive exposition to external influences in sea cages (Føre et al., 2016). The simulated FI and growth in the sea water phase - where most handling and treatment occurs - were therefore adapted (both growing period and FI extended with $5 \%$ ) to meet performance found in practice with a cumulative FCR of 1.22 and a 520 day long sea water phase (Main article; Table 2).

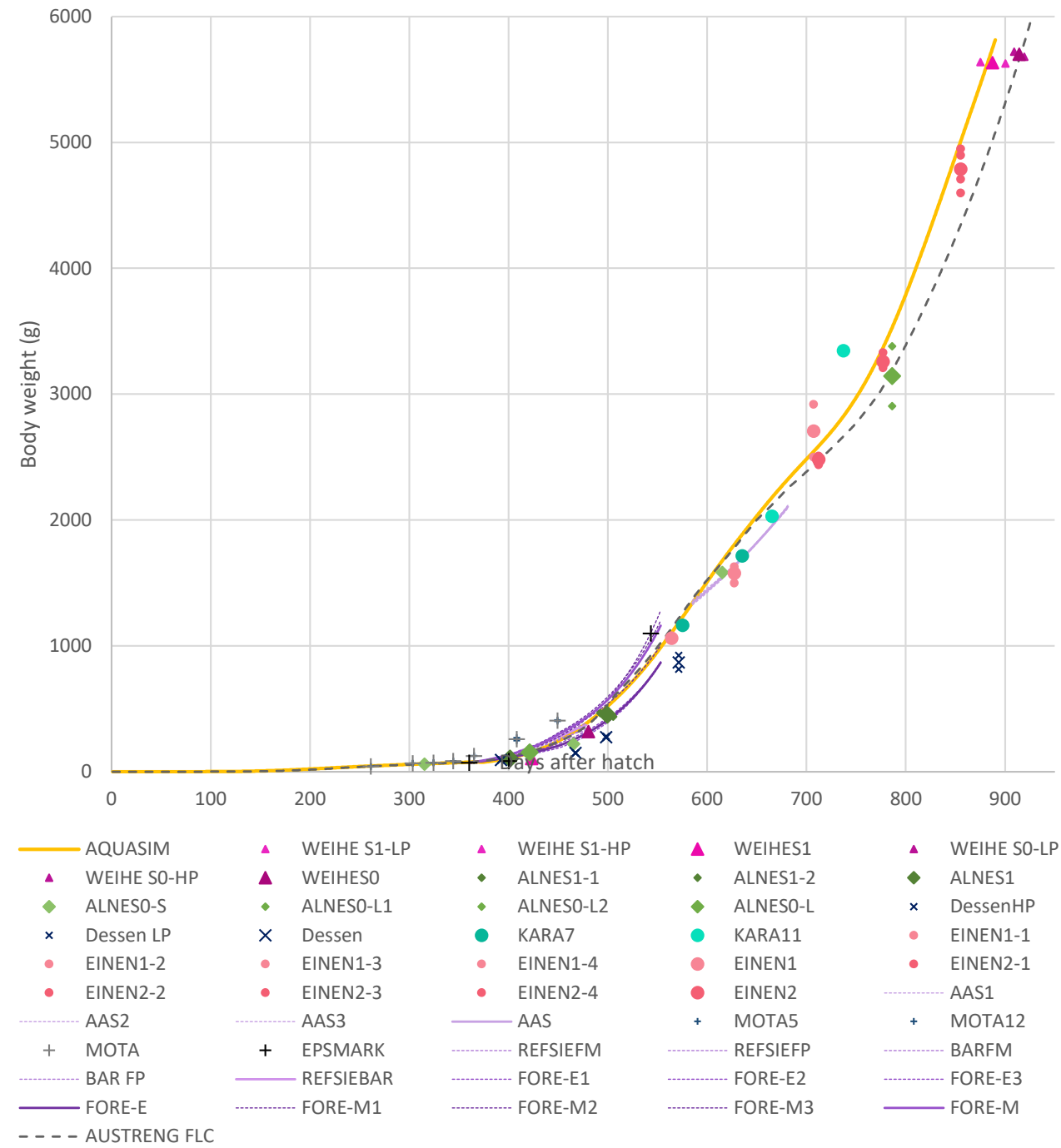

Figure B3 Optimal (temperature dependant) growth simulated with AquaSim compared to literature (Aas et al., 2015; Alne et al., 2011; Bar et al., 2007; Dessen et al., 2017; Einen \& Roem, 1997; Espmark et al., 2017; Føre et al., 2016; Karalazos et al., 2011; Karalazos et al., 2007; Mota et al., 2019; Refstie et al., 2004; Weihe et al., 2018). 


\section{Nile Tilapia}

For Nile Tilapia, optimal growth and feed intake during the entire lifecycle were simulated for a tank system with a constant water temperature of 28 degrees and controlled high oxygen levels and a slaughter weight of $750 \mathrm{~g}$ as is typical of the European market (TIL-AQUA, 2016). The cumulative FCR of this simulated performance of 1.45 (Main article; Table 2) falls low in the range observed in practice (1.4-2.4; (Fry et al., 2018), that includes less efficient systems without oxygen level management. This FCR is attained by growing to a slaughter weight of $750 \mathrm{~g}$ in 200 days.

\section{Nutrient requirements}

Digestible energy (DE) and protein (DP) requirementto achieve the growth described above (Main article; Table 1), were calculated by multiplying the required feed intake with the DE and DP content of Skrettings' commercial feeds, tailored for each species and life phase. The nutrient content of these phase specific feeds is provided in Table S3.5.

Table B6 digestible energy and digestible protein content of the assumed common phase specific Skretting feeds

\begin{tabular}{llr} 
& \multicolumn{2}{c}{ Nutrient content } \\
\cline { 2 - 2 } Salmon & & DP (\%) \\
Alevin $(\mathrm{MJ} / \mathrm{kg})$ & & \\
\cline { 2 - 2 } Fry & 18.50 & 49.88 \\
Fingerling & 19.30 & 48.16 \\
Parr & 19.10 & 48.16 \\
Smolt & 18.80 & 46.44 \\
Post-smolt & 18.40 & 41.28 \\
Grower & 20.50 & 36.55 \\
Brood & 21.30 & 32.68 \\
Tilapia & 17.60 & 41.28 \\
Swim up fry & & \\
Fry & 15.50 & 48.00 \\
Fingerling & 15.00 & 44.00 \\
Juvenile & 14.50 & 40.00 \\
Grower (60-200g) & 12.20 & 35.00 \\
Grower (200+g) & 12.00 & 32.00 \\
Broodstock & 11.60 & 30.00 \\
& 12.00 & 32.00 \\
\hline
\end{tabular}




\section{Protein digestibility (PD\%)}

Table B7 Protein digestibility of Tilapia and Salmon (and comparable carnivorous fish) obtained from literature used to overwrite IAFFD values where possible

\begin{tabular}{|c|c|c|c|c|c|c|c|c|c|c|c|}
\hline \multirow[b]{2}{*}{ Feed ingredient } & \multicolumn{11}{|c|}{ Tilapia } \\
\hline & 1 & 2 & 3 & 4 & 5 & 6 & 7 & 8 & 9 & 10 & used \\
\hline Spring wheat & & & & & & 0.96 & & & & & 0.96 \\
\hline Wheat flour & & & & & & & & & & & 0.96 \\
\hline Wheat middlings & & & 0.84 & & & 0.84 & & & & & 0.84 \\
\hline Wheat bran & & & & & & 0.85 & & & & & 0.85 \\
\hline Wheat germ & & & & & & 0.94 & & & & & 0.94 \\
\hline Corn & & & 0.93 & & & & 0.93 & & & & 0.93 \\
\hline Corn germ & & & & & & & 0.89 & & & & 0.89 \\
\hline Corn germ meal & 0.89 & 0.91 & & & & & 0.97 & & 0.83 & & 0.90 \\
\hline Broken rice & & & 0.83 & & & & & & & & 0.83 \\
\hline Rice bran & & & 0.87 & & & & & & & 0.84 & 0.86 \\
\hline Sorghum & & & 0.77 & & & & & & & & 0.77 \\
\hline Dried distillers grains & & & & & & & & & & 0.89 & 0.89 \\
\hline Pea & & & & 0.86 & 0.96 & & & & & & 0.91 \\
\hline Chickpea & & & & & 0.98 & & & & & & 0.98 \\
\hline Faba bean & & & & & 0.98 & & & & & & 0.98 \\
\hline Soybean meal & 0.87 & 0.92 & & 0.91 & & & & 0.97 & 0.87 & 0.92 & 0.91 \\
\hline Cottonseed meal & & 0.79 & & & & & & & & & 0.79 \\
\hline Canola meal & & & & 0.82 & & & & & & 0.88 & 0.85 \\
\hline \multicolumn{12}{|l|}{ Flaxseed meal } \\
\hline Dehulled flax & & & & 0.46 & & & & & & & 0.46 \\
\hline Sunflower meal & & & & & & & & & & 0.90 & 0.90 \\
\hline Meat and bone meal & & 0.78 & & & & & & & & & 0.78 \\
\hline Poultry by-product & & 0.90 & & & & & & & & & 0.90 \\
\hline Feather meal & & 0.79 & & & & & & & & 0.87 & 0.83 \\
\hline Poultry meat meal & & & & & & & & & 0.69 & & 0.69 \\
\hline Hemoglobin meal & & & & & & & & & 0.86 & & 0.86 \\
\hline Anchovy meal & 0.91 & & & & & & & & & & 0.91 \\
\hline \multicolumn{12}{|l|}{ Pilchard meal } \\
\hline \multicolumn{12}{|l|}{ menhaden meal } \\
\hline \multicolumn{12}{|l|}{ Herring meal } \\
\hline \multicolumn{12}{|l|}{ Capelin meal } \\
\hline \multicolumn{12}{|l|}{ Jack mackrel meal } \\
\hline \multicolumn{12}{|l|}{ Whitefish meal } \\
\hline Gammarid meal & 0.76 & & & & & & & & & & 0.76 \\
\hline \multicolumn{12}{|l|}{ Krill meal } \\
\hline Crayfish meal & 0.71 & & & & & & & & & & 0.71 \\
\hline
\end{tabular}

1 Köprücü and Özdemir (2005)

2 Guimarães et al. (2008a)

3 Guimarães et al. (2008b)

4 Borgeson et al. (2006)

5 Magalhães et al. (2018)

6 Vidal et al. (2017b)

7 Vidal et al. (2015)

8 Vidal et al. (2017a)

9 Davies et al. (2011)

10 Tran-Ngoc et al. (2019) 
Table B7 Protein digestibility of Tilapia and Salmon (and comparable carnivorous fish) obtained from literature used to overwrite IAFFD values where possible (Continued)

\begin{tabular}{|c|c|c|c|c|c|c|c|c|c|c|}
\hline \multirow[b]{2}{*}{ Feed ingredient } & \multicolumn{10}{|c|}{ Salmon } \\
\hline & 5 & 11 & 12 & 13 & 14 & 15 & 16 & 17 & 18 & used \\
\hline Spring wheat & & & & & & 0.87 & & & 0.85 & 0.86 \\
\hline Wheat flour & & & & & & & 0.91 & & 0.82 & 0.86 \\
\hline Wheat middlings & & & & & & 0.86 & & 0.92 & 0.69 & 0.82 \\
\hline \multicolumn{11}{|l|}{ Wheat bran } \\
\hline \multicolumn{11}{|l|}{ Wheat germ } \\
\hline Corn & & & & & & & & 0.95 & 0.68 & 0.82 \\
\hline Corn germ & & & & & & & & & & 0.91 \\
\hline Corn germ meal & & 0.95 & 0.87 & & 0.89 & & & 0.96 & 0.92 & 0.92 \\
\hline Broken rice & & & & & & & & & & 0.70 \\
\hline Rice bran & & & & & & & & & 0.72 & 0.72 \\
\hline Sorghum & & & & & & & & & & 0.70 \\
\hline Dried distillers grains & & & & & 0.87 & & & 0.85 & & 0.86 \\
\hline Pea & 0.98 & & & 0.87 & 0.90 & & 0.88 & & & 0.91 \\
\hline Chickpea & 0.92 & & & & & & & & & 0.92 \\
\hline Faba bean & 0.89 & & & & & & & 0.96 & & 0.93 \\
\hline Soybean meal & & 0.88 & 0.77 & & 0.83 & 0.77 & & 0.96 & 0.89 & 0.85 \\
\hline Cottonseed meal & & & & & & & & & 0.75 & 0.75 \\
\hline Canola meal & & 0.92 & & & 0.77 & 0.85 & & 0.77 & 0.75 & 0.81 \\
\hline Flaxseed meal & & & & & & & & & 0.7 & 0.70 \\
\hline \multicolumn{11}{|l|}{ Dehulled flax } \\
\hline \multicolumn{11}{|l|}{ Sunflower meal } \\
\hline Meat and bone meal & & & & & & & & 0.85 & & 0.85 \\
\hline Poultry by-product & & & & & 0.81 & 0.85 & & & 0.88 & 0.85 \\
\hline Feather meal & & & & & 0.72 & 0.70 & & & 0.87 & 0.76 \\
\hline Poultry meat meal & & & & & 0.85 & & & & & 0.85 \\
\hline Hemoglobin meal & & & & & 0.71 & & & 0.99 & 0.91 & 0.87 \\
\hline Anchovy meal & & & & & 0.94 & 0.92 & & & 0.97 & 0.94 \\
\hline Pilchard meal & & & & & & & 0.83 & & 0.89 & 0.86 \\
\hline menhaden meal & & 0.89 & & & & 0.83 & & 0.86 & 0.86 & 0.86 \\
\hline Herring meal & & 0.94 & & & & 0.91 & & 0.92 & & 0.92 \\
\hline Capelin meal & & & & & & 0.94 & & & & 0.94 \\
\hline Jack mackrel meal & & & & & & & 0.83 & & & 0.83 \\
\hline Whitefish meal & & & & & & & 0.73 & & & 0.73 \\
\hline \multicolumn{11}{|l|}{ Gammarid meal } \\
\hline Krill meal & & & & & & & 0.60 & & & 0.60 \\
\hline Crayfish meal & & & & & & & & & & \\
\hline
\end{tabular}

11 Anderson et al. (1992)

12 Opstvedt et al. (2003)

13 Zhang (2011)

14 FAO (2018a)

15 Hajen et al. (1993)

16 Bransden et al. (2001), Carter et al. (1999)

17 Cho (1990)

18 Gaylord et al. (2008) 


\section{B4 - Nutrient content of animal sourced food}

Table B8 Nutrient content of cooked ASF obtained from USDA (2019) and supplemented with (DanishFoodInstitute, 2019; FAO, 2016b; SwedishFoodAgency, 2019)

\begin{tabular}{|c|c|c|c|c|c|c|c|c|c|c|c|}
\hline \multirow[b]{2}{*}{ Product } & \multirow[b]{2}{*}{$\begin{array}{l}\text { DM } \\
\mathrm{kg}\end{array}$} & \multirow[b]{2}{*}{$\begin{array}{l}\text { Protein } \\
\mathrm{g}\end{array}$} & \multicolumn{2}{|c|}{ PUFA } & \multicolumn{3}{|c|}{ Vitamins } & \multicolumn{4}{|c|}{ Minerals } \\
\hline & & & $\begin{array}{l}\text { EPA } \\
\mathrm{g}\end{array}$ & $\begin{array}{l}\text { DHA } \\
\mathrm{g}\end{array}$ & $\begin{array}{l}\text { A } \\
\mu \mathrm{g}\end{array}$ & $\begin{array}{l}\mathrm{D} \\
\mu \mathrm{g}\end{array}$ & $\begin{array}{l}\mathrm{B} 12 \\
\mu \mathrm{g}\end{array}$ & $\begin{array}{l}\text { Calcium } \\
\mathrm{mg}\end{array}$ & $\begin{array}{l}\text { Iron } \\
\text { mg }\end{array}$ & $\begin{array}{l}\text { Zinc } \\
\mathrm{mg}\end{array}$ & $\begin{array}{l}\text { Selenium } \\
\mathrm{Mg}\end{array}$ \\
\hline Pig meat & 0.51 & 291 & 0.0 & 0.0 & 38 & 10 & 8 & 173 & 11 & 30 & 396 \\
\hline Pig offal & 0.33 & 198 & 0.6 & 0.2 & 163 & 8 & 91 & 155 & 68 & 34 & 367 \\
\hline Cattle meat & 0.41 & 293 & 0.0 & 0.0 & 20 & 1 & 31 & 129 & 28 & 69 & 307 \\
\hline Cattle offal & 0.34 & 231 & 0.5 & 0.1 & 584 & 5 & 313 & 383 & 45 & 46 & 191 \\
\hline Milk & 0.12 & 33 & 0.0 & 0.0 & 460 & 1 & 5 & 1130 & 0 & 4 & 37 \\
\hline Poultry meat & 0.38 & 260 & 0.1 & 0.4 & 46 & 0 & 3 & 140 & 12 & 19 & 210 \\
\hline Poultry offal & 0.32 & 272 & 0.1 & 0.3 & 18 & 0 & 94 & 140 & 70 & 42 & 596 \\
\hline Eggs & 0.26 & 123 & 0.0 & 0.1 & 175 & 20 & 15 & 540 & 16 & 12 & 301 \\
\hline Salmon & 0.35 & 254 & 6.9 & 14.6 & 690 & 140 & 40 & 150 & 3 & 4 & 414 \\
\hline Tilapia & 0.28 & 262 & 0.1 & 0.8 & 0 & 37 & 19 & 140 & 7 & 4 & 544 \\
\hline Atlantic herring & 0.36 & 203 & 12 & 15 & 54 & 54 & 141 & 740 & 14 & 13 & 468.0 \\
\hline Atlantic Cod & 0.24 & 105 & 1 & 2 & 12 & 12 & 15 & 140 & 5 & 6 & 376.0 \\
\hline Blue whiting & 0.25 & 116 & 3 & 5 & 18 & 18 & 26 & 620 & 4 & 5 & 411.0 \\
\hline Atlantic mackerel & 0.47 & 262 & 9 & 14 & 209 & 209 & 190 & 150 & 16 & 9 & 516.0 \\
\hline European sprat & 0.29 & 185 & 16 & 29 & 264 & 264 & 98 & 2028 & 15 & 13 & 208.7 \\
\hline Haddock & 0.20 & 90 & 1 & 4 & 6 & 6 & 24 & 140 & 2 & 4 & 317.0 \\
\hline Pollock & 0.28 & 118 & 2 & 5 & 13 & 13 & 37 & 770 & 6 & 6 & 468.0 \\
\hline European plaice & 0.27 & 108 & 2 & 2 & 15 & 15 & 42 & 263 & 1 & 6 & 368.4 \\
\hline European hake & 0.22 & 86 & 0 & 3 & 8 & 8 & 17 & 522 & 9 & 4 & 277.2 \\
\hline Atlantic $\mathrm{h}$ mackerel & 0.38 & 201 & 8 & 14 & 114 & 114 & 65 & 290 & 15 & 9 & 468.0 \\
\hline European pilchard & 0.34 & 172 & 9 & 18 & 55 & 55 & 86 & 649 & 20 & 9 & 653.9 \\
\hline Norway lobster & 0.29 & 116 & 16 & 6 & 6 & 6 & 9 & 591 & 14 & 36 & 441.7 \\
\hline Northern prawn & 0.26 & 99 & 2 & 2 & 6 & 6 & 167 & 700 & 5 & 16 & 193.5 \\
\hline Ling & 0.26 & 111 & 1 & 2 & 12 & 12 & 7 & 440 & 8 & 10 & 468.0 \\
\hline
\end{tabular}

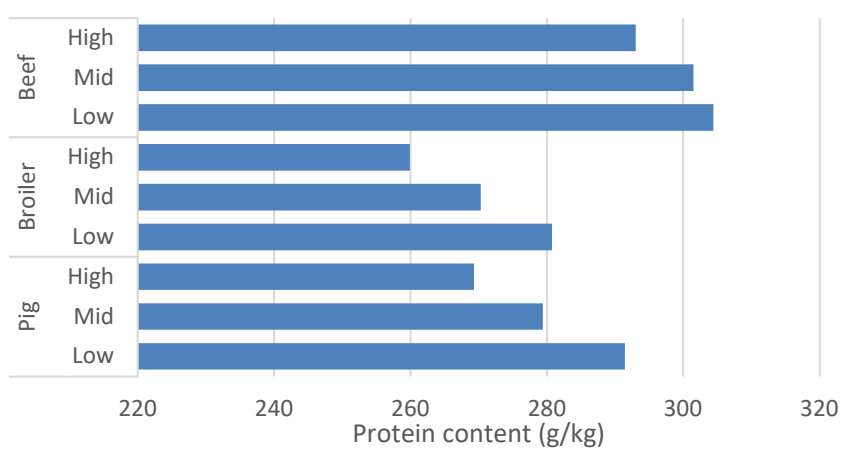

Figure B4 Human digestible protein content per kg cooked meat of pigs, broilers, and beef cattle adjusted for predicted variation in protein deposition under varying productivity 


\section{B5 - Additional results of Chapter 3}

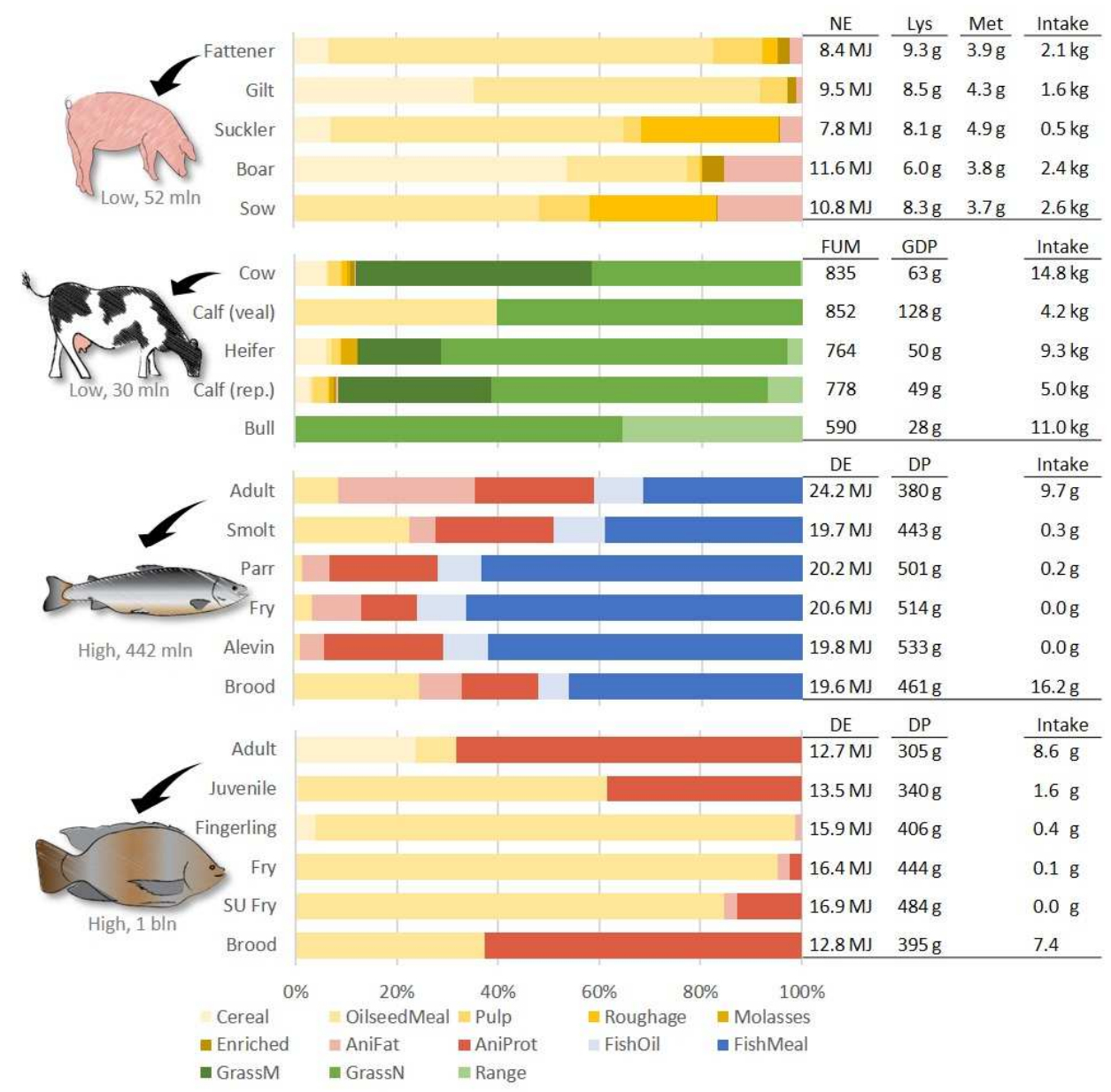

Figure B5 Required number of food producing animals, ration composition for each life phase of each animal production system and daily intake of this ration. 
150 | Appendix B

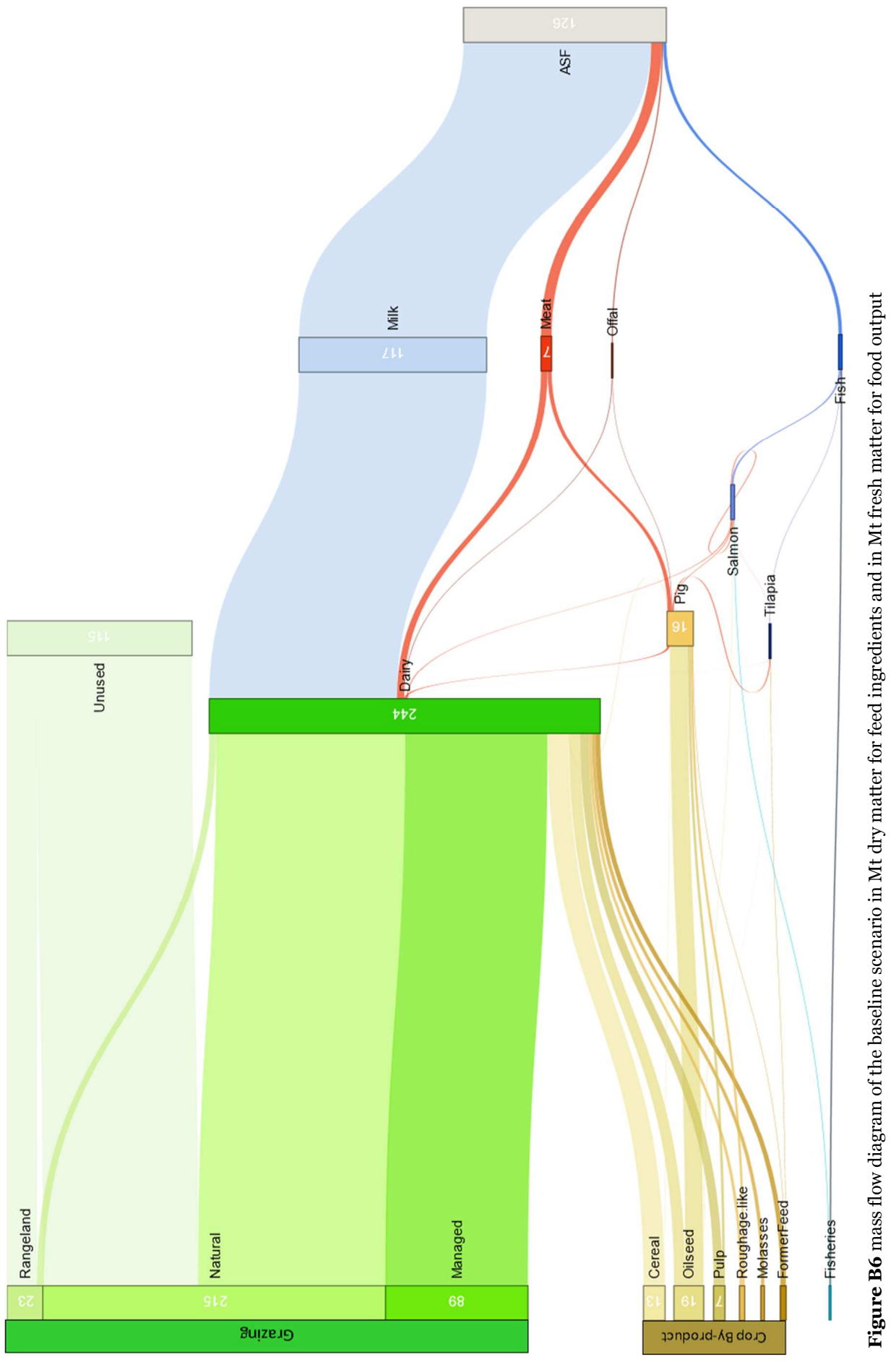




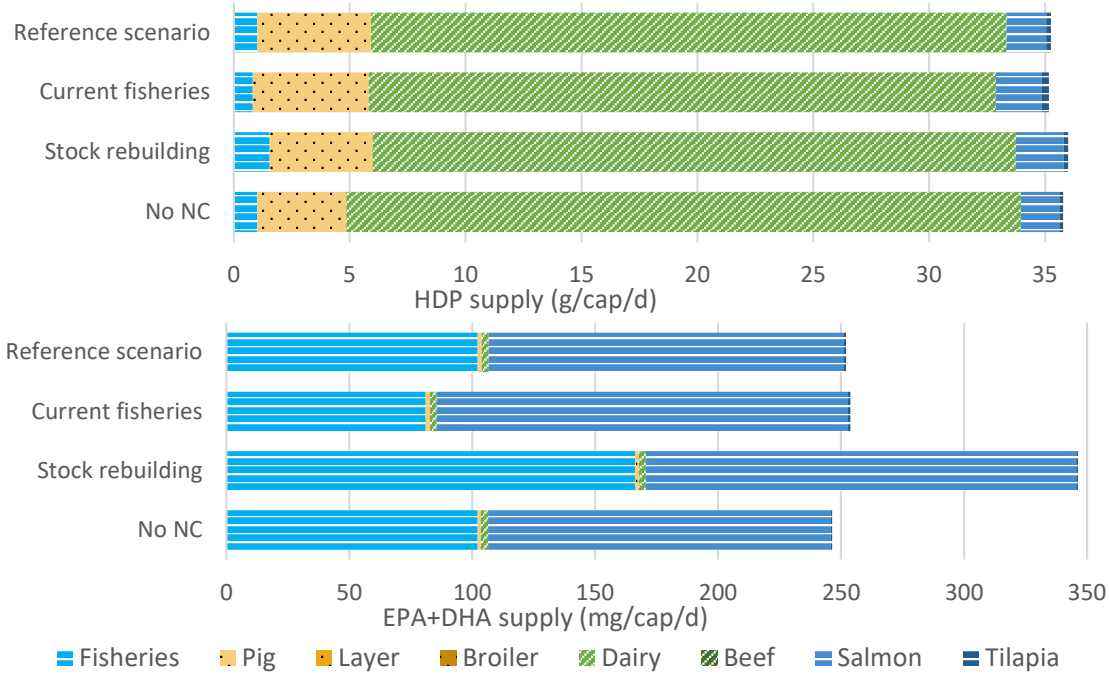

Figure B7 a. Human digestible protein (HDP) and b. essential $\omega_{3}$ fatty acid (EPA+DHA)) supply by fisheries and each animal production system in the reference scenario and under each scenario of the sensitivity analysis: Current fisheries, Stock rebuilding (fisheries) and No NC (excluding nutrient constraint regarding vitamin B12 and $\mathrm{EPA}+\mathrm{DHA})$

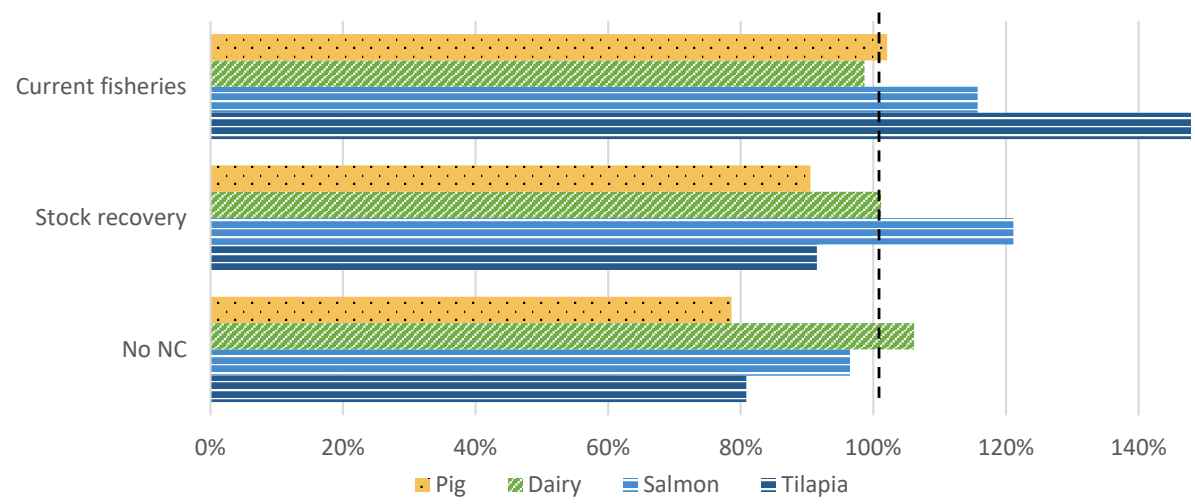

Figure B8 Number of animals of each production system under each scenario of the sensitivity analysis: Current fisheries, Stock rebuilding (fisheries) and No NC (excluding nutrient constraint regarding vitamin B12 and $\mathrm{EPA}+\mathrm{DHA}$ ), relative to animal numbers in the reference scenario. 
a. Current fisheries

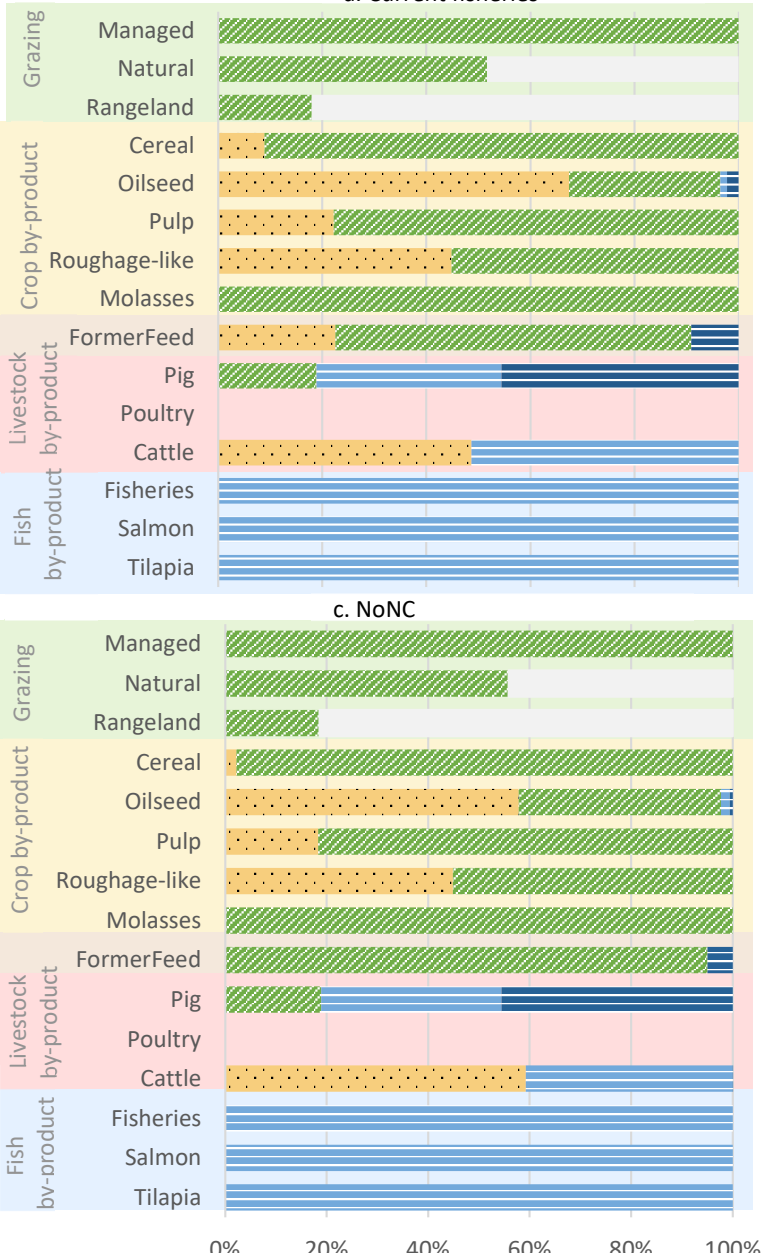

b. Stock rebuilding

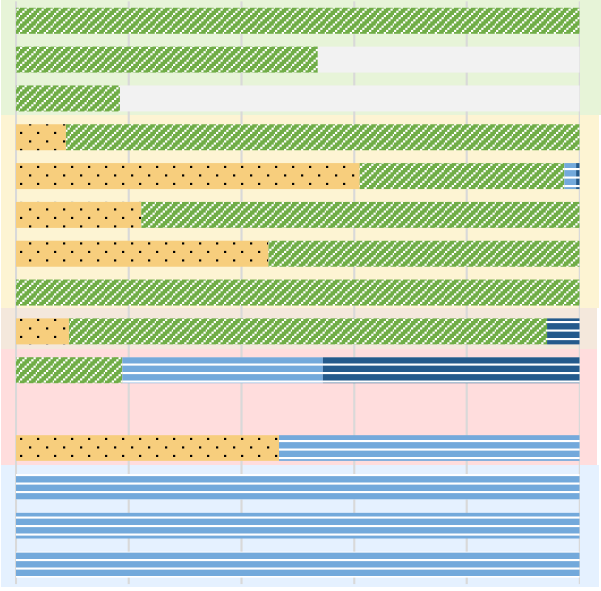

d. Reference scenario

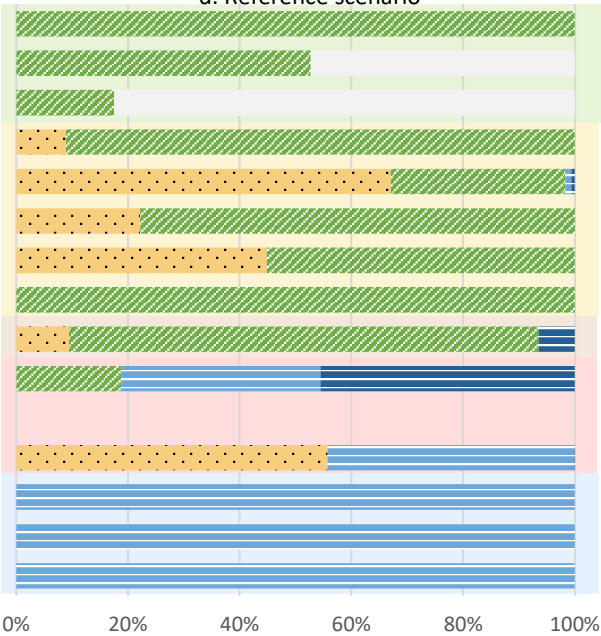

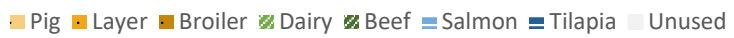

Figure B9 Feed allocation to the animal production systems (\% of available feed) under alternative optimisations: a. current fisheries, b. Stock rebuilding, c. Exclusion of nutrient constraint d. Reference scenario 


\section{Appendix C}

C1 Availability of low-opportunity-cost feeds

C2 Additional results of Chapter 4 


\section{C1 - Availability of low-opportunity-cost feeds}

The LCF that are input to the model consider human inedible products associated to primary use of spatial resources and include crop processing by-products, animal processing by-products, food wastes and grass resources. The availability of crop processing by-products and grass resources was adopted from Hal et al. (2019) and are described in detail in Appendix A2. For grass resources, the availability of managed grass was corrected to a total of $89 \mathrm{Mt}$ based as suggested by the authors of the underlying research Haberl et al. (2007) and Plutzar et al. (2016). The range of nutrient content of grass resources of each vegetation type, obtained from literature was assumed to be normally distributed over the available grass biomass. Below we first describe the data used to calculate the availability animal by-products related to processing sustainable fisheries yields and animals byproducts related to upcycling available LCF. Second we describe the assumed availability of food waste in each scenario.

\section{Animal by-products}

The strict EU regulations on feeding processed animal proteins (PAPs) to food producing animals were implemented after the major bovine spongiforme encepathology (BSE) and foot and mouth disease (FMD), to avoid future transmission of diseases between animals and to humans (EU, 2009). While, originally, this legislation banned feeding most livestock proteins to any food producing animals, a 2013 amendment has relegalised feeding these proteins (except from bovine origin) in aquaculture (EU, 2013a). Additionally EU legislation forbids feeding farmed animals with proteins originating from farmed animals of the same species (EU, 2013a). Farmed salmon can, thus, not be fed with salmon meal originating from aquaculture. Salmon and tilapia in our model are, however, a proxy for multiple species with similar characteristics (e.g. rainbow trout for salmon) that are allowed to feed on each other's by-products. To reflect this we allow for intraspecies recycling of fish farming by-products, meaning we allow farmed salmon to eat salmon by-products, assuming salmon represents multiple species that could recycle each other's byproducts.

With the 2013 amendment, the EU showed to a willingness explore legislative change to aid and stimulate efficient use of resources in the food system. With legalisation at processing scenario we assess the ASF supply potential of possible future amendments that pose least risk to public health. With these amendments the use of PAPs to monogastric livestock, including those of ruminants, would be legalised, excluding high risk organs of the nerve system (EU, 2009). Similarly, PAPs from ruminants would be legalised as feed for farmed fish. Allowance of different PAPs in the feed of the 
food producing animals included in the model, under current and our adapted legislation is illustrated in Table C1. The ban on cannibalism would be maintained.

Table C1 Allowance of animal by-products in feed of food producing animal species based on EU legislation (EU, 2009, 2013a).

\begin{tabular}{|c|c|c|c|c|c|c|c|c|}
\hline \multirow[b]{2}{*}{ Animal by-product } & \multicolumn{4}{|c|}{ Current legislation } & \multicolumn{4}{|c|}{ Adapted legislation } \\
\hline & Pig & Poultry & Cattle & Fish & Pig & Poultry & Cattle & Fish \\
\hline Meat\&Bone meal & NO & NO & NO & YES $^{1}$ & YES & YES & NO & YES \\
\hline Bone meal & NO & NO & NO & YES & YES & YES & NO & YES \\
\hline Blood meal & YES $^{1}$ & YES $^{1}$ & NO & YES $^{1}$ & YES & YES & NO & YES \\
\hline Feather meal & $\mathrm{YES}^{2}$ & $\mathrm{YES}^{2}$ & NO & YES & YES & YES & NO & YES \\
\hline Poultry by-product meal & NO & NO & NO & YES & YES & NO & NO & YES \\
\hline Fish meal & YES & YES & NO & YES & YES & YES & NO & YES \\
\hline
\end{tabular}

1: Allowed if not from bovine origin

2: Allowed in EU but prohibited in many of its member states

\section{Manufacturing wastes}

The European Former Foodstuff Processors Association (EFFPA), whose members process 3.5 million tonnes of FFS annually, estimates that in the EU a total of 5 million tonnes of FFS are processed into feed every year (EFFPA, 2019). While EFFPA indicates the majority of these FFS are cereal based (>70\%) the exact product composition of EU FFS remains unknown (EFFPA, 2019). We, therefore, assumed the product composition of FFS excluding by-products of the UK (UKFFPA, 2019), Netherlands (VIDO, 2019) and France (Vernier et al., 2016) and combined (Figure S3.3) and applied this to the estimated 5 million tonnes of EU FFS. The resulting 4.2 million tonnes of cereal based FFS comes close Caldeira et al. (2019) estimation of 4.9 million ton cereal based manufacturing waste currently used as feed. Each of the former food products was assumed to be processed into common FFS based feed ingredients, resulting in the available feed ingredients assumed in the reference scenario (Table C12).

Processors of FFS have joined forces in an association to improve the recovery of FFS as feed, and estimate an additional 2 Mt per year could be recovered (EFFPA, 2019) which we assume to have the same composition as currently fed FFS in the improved recovery scenario (Table C12). Legalisation at manufacturing includes plant based FFS that are possibly contaminated with PAPs available. We assume this would only make additional cereal based FFS available, of which in total 7.4 Mt fresh matter is wasted per year (Caldeira et al., 2019). We assume the additional cereal based FFS has the same composition as the cereal based FFS already included in previous scenarios (Table C12). Safe use of these possibly contaminated FFS as feed requires standardised treatment guidelines even if they are still of food quality. 


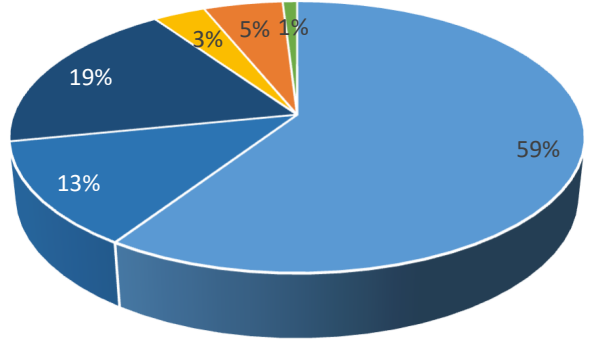

a. United Kingdom (0.6 Mt)

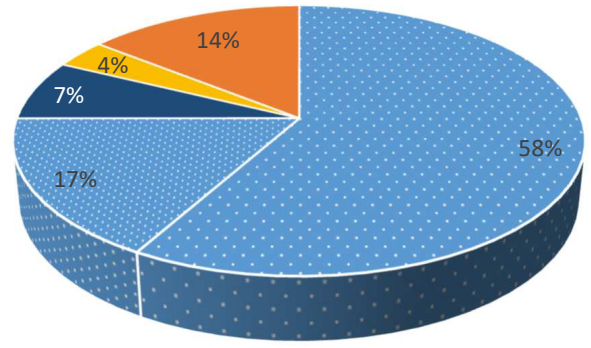

c. The Netherlands (0.3Mt)

- Bread Biscuit Basta

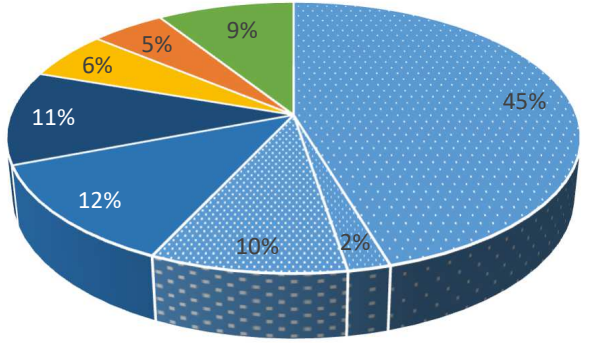

b. France (1.1 Mt)

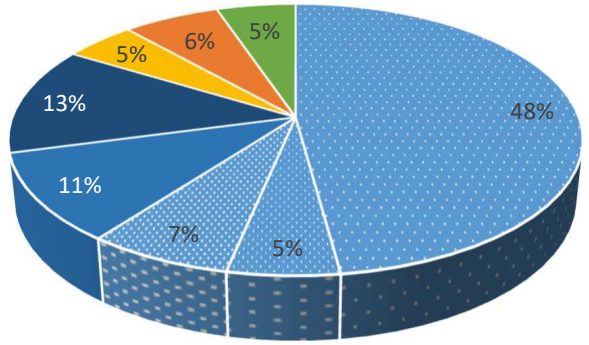

d. Combined (2.0 Mt)

Savoury snacks Confectionary Vegetable

Figure C1 Combined (d) former foodstuff product composition based on that of the UK (UKFFPA, 2019), The Netherlands (VIDO, 2019) and France (Vernier et al., 2016) adapted to exclude animal based products and crop byproducts.

Table C2 Available former food ingredients (Mt) in the EU, under current recovery ( $5 \mathrm{Mt}$ total) improved recovery (7 Mt total) and legalisation (7.4 Mt cereal based) assuming product composition in the UK, Netherlands and France (Figure $\mathrm{C}_{4}$ ).

\begin{tabular}{|c|c|c|c|}
\hline & Current & Improved recovery & Legalisation \\
\hline Bread meal & 1778981 & 2490573 & 4232027 \\
\hline Biscuit meal & 270843 & 379180 & 478863 \\
\hline Pasta meal & 351383 & 491936 & 621261 \\
\hline Puffed rice & 262944 & 368122 & 464898 \\
\hline Rice meal & 262944 & 368122 & 464898 \\
\hline Mixed cereal & 643679 & 901150 & 1138053 \\
\hline Potato chips & 234836 & 328771 & 415202 \\
\hline Fruit waste & 260933 & 365306 & 461342 \\
\hline Sugar syrup & 378544 & 529962 & 669283 \\
\hline
\end{tabular}

\section{Retail and consumption waste}

Table $\mathrm{C}_{13}$ shows the available plant based feed ingredients and available plant based household waste in the EU, both calculated from (Caldeira et al., 2019). Processing of of retailing waste considers drying of of bread and pastry into bread and biscuit meal. Processing of consumption waste considers the boiling and/or fermenting household food waste into swill. 
Table C3 Available plant based feed ingredients from retail and available household waste (Mt) in the EU.

\begin{tabular}{|c|c|c|}
\hline Waste product & Retail & Consumption \\
\hline Wheat flour & 43877 & 523893 \\
\hline Bread & 0 & 5021781 \\
\hline Pastry & 0 & 1083111 \\
\hline Bread meal & 1230084 & 0 \\
\hline Biscuit meal & 568534 & 201526 \\
\hline Pasta meal & 21620 & 335588 \\
\hline Beer & 180938 & 1980371 \\
\hline Mixed cereal & 129406 & 698011 \\
\hline Rice grain & 12616 & 327032 \\
\hline Fruit waste & 800000 & 10100000 \\
\hline Vegetable waste & 900000 & 14400000 \\
\hline Potato & 300000 & 5700000 \\
\hline Sugar syrup & 400000 & 1600000 \\
\hline Sunflowerseed oil & 100000 & 1700000 \\
\hline
\end{tabular}

\section{Classification of ingredients}

Table C14 shows the classification of LCF based on their origin and nutritional properties. 
Table C4 Classification LCF based on their origin and nutritional properties

\begin{tabular}{|c|c|c|}
\hline \multirow[b]{2}{*}{ Product } & \multicolumn{2}{|l|}{ Classification } \\
\hline & Allocation & Ration \\
\hline \multicolumn{3}{|l|}{ Crop by-products } \\
\hline Wheat bran & Cereal by-products & Cereal product \\
\hline Wheat germ & Cereal by-products & Cereal product \\
\hline Wheat feed meal & Cereal by-products & Cereal product \\
\hline Barley by-product & Cereal by-products & Cereal product \\
\hline Barley rootlet & Cereal by-products & Cereal product \\
\hline Spent brewers grain & Cereal by-products & Cereal product \\
\hline Maize bran & Cereal by-products & Cereal product \\
\hline Maize germ meal & Oilseed meals & Oilseed meals \\
\hline Rye bran & Cereal by-products & Cereal product \\
\hline Oat offal & Cereal by-products & Cereal product \\
\hline Oat hulls & Roughage like & Roughage like \\
\hline Rice hulls & Roughage like & Roughage like \\
\hline Potato peel (steam) & Pulp & Pulp \\
\hline Sweet potato peel (steam) & Pulp & Pulp \\
\hline Sugarbeet toptails & Roughage like & Roughage like \\
\hline Sugarbeet molasses & Molasses & Molasses \\
\hline Sugarbeet pulp & Pulp & Pulp \\
\hline Soybean hulls & Roughage like & Roughage like \\
\hline Soybean meal & Oilseed meals & Oilseed meals \\
\hline Groundnut shell & Roughage like & Roughage like \\
\hline Groundnut meal & Oilseed meals & Oilseed meals \\
\hline Sunflower seed meal & Oilseed meals & Oilseed meals \\
\hline Rapeseed meal & Oilseed meals & Oilseed meals \\
\hline Cottonseed meal & Oilseed meals & Oilseed meals \\
\hline Copra meal & Oilseed meals & Oilseed meals \\
\hline Sesameseed meal & Oilseed meals & Oilseed meals \\
\hline Palm fiber & Roughage like & Roughage like \\
\hline Palm effluent & Oilseed meals & Oilseed meals \\
\hline Palm kernel meal & Oilseed meals & Oilseed meals \\
\hline Olive residue & Oilseed meals & Oilseed meals \\
\hline Citrus pulp & Pulp & Pulp \\
\hline Grape pommace & Pulp & Pulp \\
\hline Coffee husk & Roughage like & Roughage like \\
\hline Cocoa husk & Roughage like & Roughage like \\
\hline \multicolumn{3}{|l|}{ Processsing by-products } \\
\hline Pig blood meal & Pig products & Livestock protein \\
\hline First choice grease & Pig products & Livestock fat \\
\hline Pig meat and bone meal & Pig products & Livestock protein \\
\hline Lard & Pig products & Livestock fat \\
\hline Pig plasma & Pig products & Livestock protein \\
\hline Beef blood meal & Cattle products & Livestock protein \\
\hline Tallow & Cattle products & Livestock fat \\
\hline Beef meat and bone meal & Cattle products & Livestock protein \\
\hline Poultry by-product & Poultry products & Livestock protein \\
\hline Feathermeal & Poultry products & Livestock protein \\
\hline Fisheries meal & Fisheries products & Fish meal \\
\hline Fisheries oil & Fisheries products & Fish oil \\
\hline Salmon meal & Salmon products & Fish meal \\
\hline Salmon oil & Salmon products & Fish oil \\
\hline Tilapia meal & Tilapia products & Fish meal \\
\hline Tilapia oil & Tilapia products & Fish oil \\
\hline
\end{tabular}


Table C4 Classification LCF based on their origin and nutritional properties (continued)

\begin{tabular}{|c|c|c|}
\hline \multirow[b]{2}{*}{ Product } & \multicolumn{2}{|l|}{ Classification } \\
\hline & Allocation & Ration \\
\hline \multicolumn{3}{|l|}{ Manufacturing waste } \\
\hline Bread meal & Processing waste & Enriched staple \\
\hline Biscuit meal & Processing waste & Enriched staple \\
\hline Pasta meal & Processing waste & Cereal product \\
\hline Puffed rice & Processing waste & Cereal product \\
\hline Rice meal & Processing waste & Cereal product \\
\hline Mixed cereal & Processing waste & Cereal product \\
\hline Potato chips & Processing waste & Enriched staple \\
\hline Fruit waste & Processing waste & Pulp \\
\hline Sugar syrup & Processing waste & Molasses \\
\hline \multicolumn{3}{|l|}{ Retail waste } \\
\hline Wheat flour & Retail waste & Cereal product \\
\hline Bread & Retail waste & Enriched staple \\
\hline Pastry & Retail waste & Enriched staple \\
\hline Bread meal & Retail waste & Enriched staple \\
\hline Biscuit meal & Retail waste & Enriched staple \\
\hline Pasta meal & Retail waste & Cereal product \\
\hline Beer & Retail waste & Cereal product \\
\hline Mixed cereal & Retail waste & Cereal product \\
\hline Rice grain & Retail waste & Cereal product \\
\hline Fruit waste & Retail waste & Pulp \\
\hline Vegetable waste & Retail waste & Pulp \\
\hline Potato & Retail waste & Pulp \\
\hline Sugar syrup & Retail waste & Molasses \\
\hline Sunflowerseed oil & Retail waste & Vegetable oil \\
\hline \multicolumn{3}{|l|}{ Consumption waste } \\
\hline Wheat flour & Consumption waste & Swill \\
\hline Bread & Consumption waste & Swill \\
\hline Pastry & Consumption waste & Swill \\
\hline Bread meal & Consumption waste & Swill \\
\hline Biscuit meal & Consumption waste & Swill \\
\hline Pasta meal & Consumption waste & Swill \\
\hline Beer & Consumption waste & Swill \\
\hline Mixed cereal & Consumption waste & Swill \\
\hline Rice grain & Consumption waste & Swill \\
\hline Fruit waste & Consumption waste & Swill \\
\hline Vegetable waste & Consumption waste & Swill \\
\hline Potato & Consumption waste & Swill \\
\hline Sugar syrup & Consumption waste & Swill \\
\hline Sunflowerseed oil & Consumption waste & Swill \\
\hline
\end{tabular}


160 | A p p e ndix C

\section{Appendix C4 - Additional results}

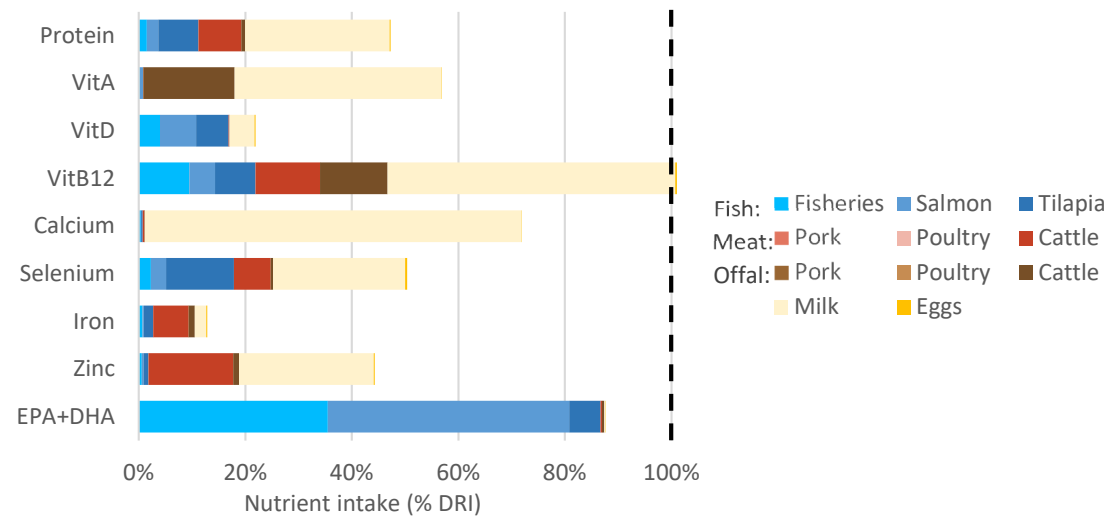

Figure C2 Nutrient intake from animal source food in the reference scenario expressed as \% of daily recommended intake (DRI) fulfilled

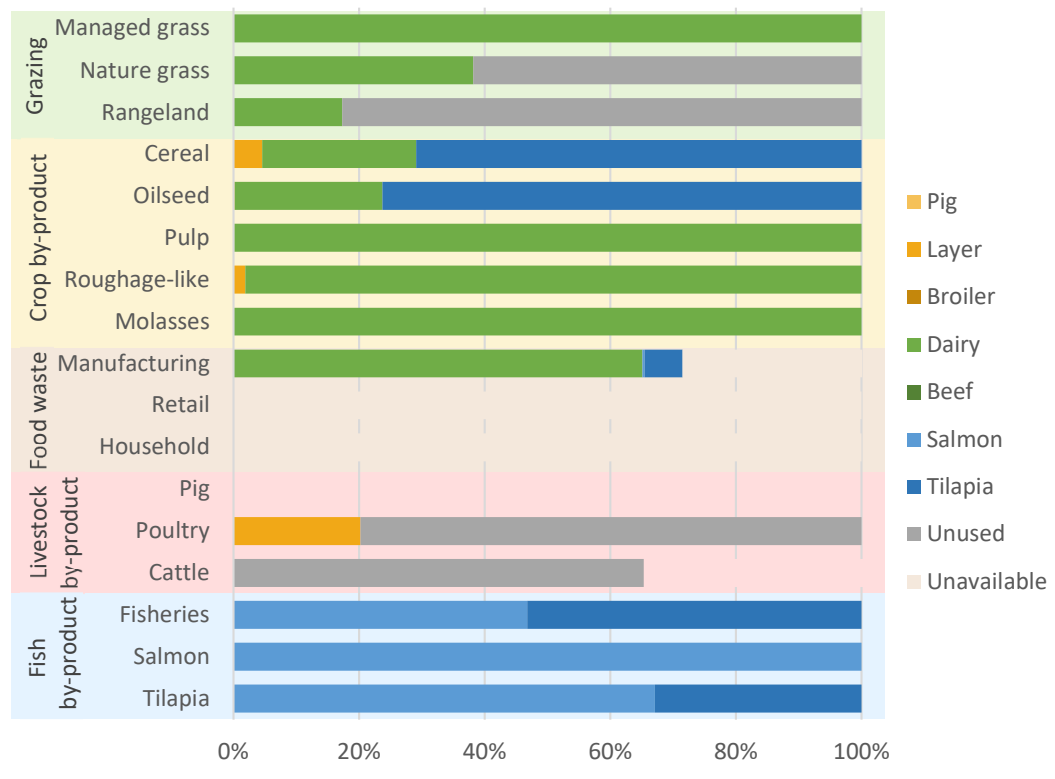

Figure C3 Feed allocation to each animal production system (\% of available feed) the reference scenario. 


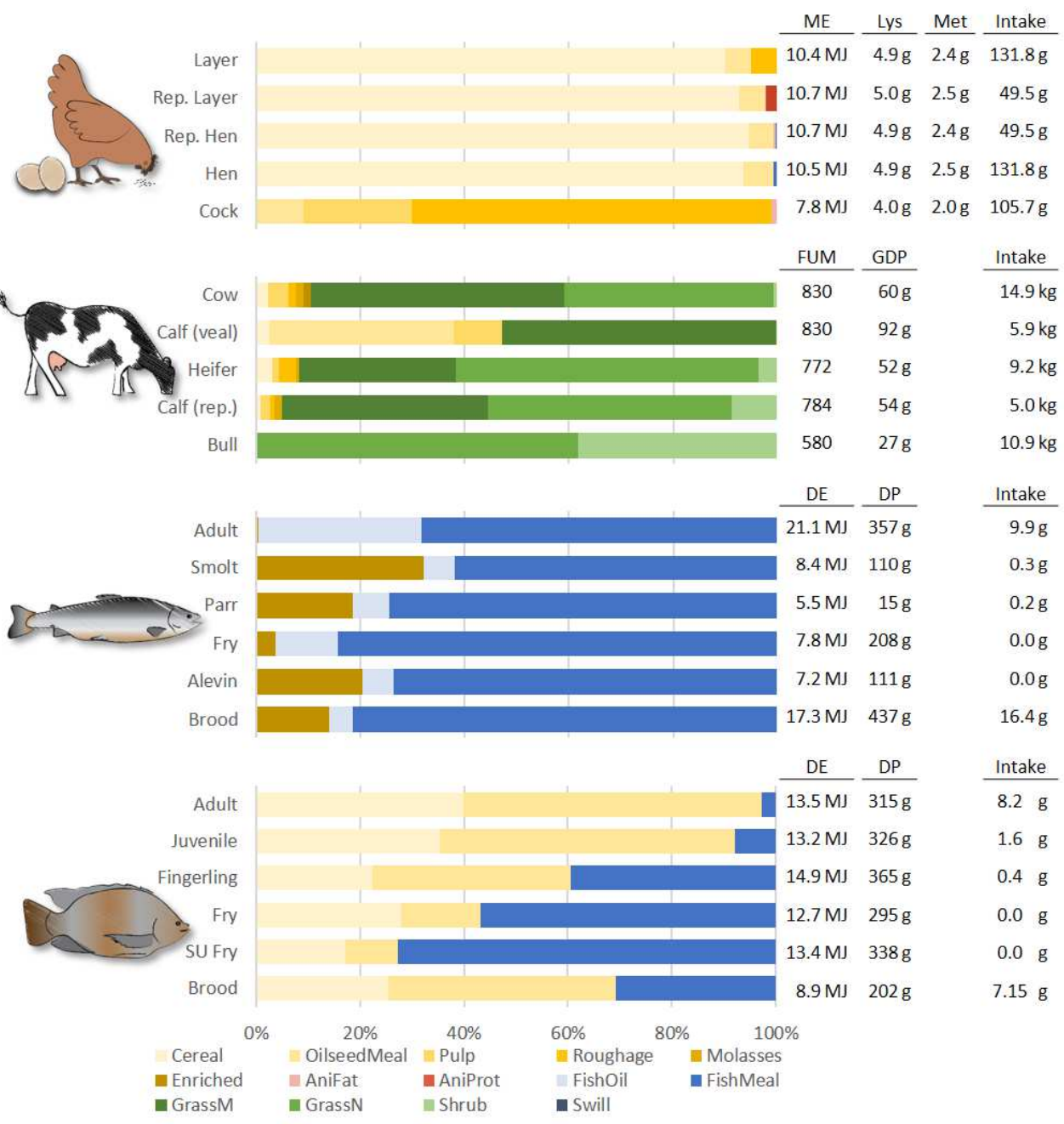

Figure C4 Ration composition for each life phase of each animal production system and daily intake of this ration in the reference scenario. 
162 | 


\section{Appendix D}

D1 The environmental impact of free range broiler production

D2 Feed composition and impact of ingredients

D3 Calculation of emissions related to manure management

D4 Calculation of the land use ratio

D5 Break-down of results of Chapter 5 


\section{D1 - The environmental impact of free range broiler production}

The environmental impact per kg free range broiler meat were calculated from literature (Table D1) Four studies have assessed the environmental impact of free range broiler production using life cycle assessment (LCA). Each of these studies expressed the environmental impact per kg carcass weight, except for (Da Silva et al., 2014) that expressed it per kg of live weight. These impacts were transformed with the assuming a carcass yield of $69 \%$ as introduced by (Da Silva et al., 2014) themselves. For all studies the environmental impacts where then transformed to per $\mathrm{kg}$ meat assuming a meat yield of 68\% (USDA, 2018a), after which the average impact per kg meat was calculated.

Table D1 Global warming potential (GWP), energy use (EU) and land use (LU) per kg of free range broiler production, expressed per kg carcass and per $\mathrm{kg}$ fresh meat, obtained from literature

\begin{tabular}{|c|c|c|c|}
\hline Study & GWP & EU & LU \\
\hline per kg carcass weight & $\mathrm{kg} \mathrm{CO}_{2}$-eq & MJ & $\mathrm{m}^{2}$ \\
\hline Williams et al. (2006) & 5.48 & 14.5 & 7.30 \\
\hline Leinonen et al. (2012) & 5.13 & 25.7 & 7.20 \\
\hline Leinonen et al. (2014) & 4.42 & 28.0 & \\
\hline Da Silva et al. (2014) & 4.02 & 44.0 & 5.83 \\
\hline Average & 4.76 & 28.0 & 6.78 \\
\hline \multicolumn{4}{|l|}{ per kg meat } \\
\hline Williams et al. (2006) & 8.06 & 21.3 & 10.74 \\
\hline Leinonen et al. (2012) & 7.54 & 37.7 & 10.59 \\
\hline Leinonen et al. (2014) & 6.50 & 41.2 & \\
\hline Da Silva et al. (2014) & 5.92 & 64.7 & 8.57 \\
\hline Average & 7.01 & 41.2 & 9.96 \\
\hline
\end{tabular}




\section{D2 - Feed composition and impact of ingredients}

Table D2 Feed compositions for each feed scenario (S1-S3) and rearing feed for female (f) and male (m) chicks, and GWP $\left(\mathrm{CO}_{2}\right.$-eq), EU (MJ) and $\mathrm{LU}\left(\mathrm{m}^{2}\right)$ per $\mathrm{kg}$ of each feed ingredient, under economic and food-based allocation.

\begin{tabular}{|c|c|c|c|c|c|c|c|c|c|c|c|}
\hline \multirow[b]{3}{*}{ Ingredient \% } & \multicolumn{5}{|c|}{ Feed composition } & \multicolumn{6}{|c|}{ Impact (/kg ingredient) } \\
\hline & \multicolumn{3}{|c|}{ Egg production } & \multicolumn{2}{|c|}{ Rearing } & \multicolumn{3}{|c|}{ Economic allocation } & \multicolumn{3}{|c|}{ Food-based allocation } \\
\hline & S1 & S2 & S3 & $f$ & $\mathrm{~m}$ & GWP & EU & LU & GWP & EU & LU \\
\hline Animal fat & - & 2.80 & - & - & 1.06 & 820 & 12.4 & 0.00 & 820 & 12.4 & 0.00 \\
\hline Biscuit sand & 6.95 & - & - & - & - & 12 & 0.2 & 0.00 & 12 & 0.2 & 0.00 \\
\hline Breadcrumbs & 4.85 & - & - & - & - & 12 & 0.2 & 0.00 & 12 & 0.2 & 0.00 \\
\hline Candy syrup & - & - & - & - & 0.5 & 12 & 0.2 & 0.00 & 12 & 0.2 & 0.00 \\
\hline Crispbread & - & 6.90 & 5.00 & - & - & 12 & 0.2 & 0.00 & 12 & 0.2 & 0.00 \\
\hline Dough melange & 3.00 & - & - & - & - & 12 & 0.2 & 0.00 & 12 & 0.2 & 0.00 \\
\hline Eggshells & 9.41 & 9.00 & 9.32 & - & - & 12 & 0.2 & 0.00 & 12 & 0.2 & 0.00 \\
\hline Insect meal & - & - & 21.53 & - & - & 770 & 9.3 & 0.03 & 420 & 6.6 & 0.01 \\
\hline Limestone & 1.50 & 1.50 & 1.50 & 1.04 & 1.18 & 19 & 0.2 & 0.00 & 19 & 0.2 & 0.00 \\
\hline Lysine $78 \%$ & 0.31 & 0.30 & 0.45 & 0.63 & 0.73 & 6030 & 119.2 & 2.37 & 6030 & 119.2 & 2.37 \\
\hline Maize & - & - & - & 33.71 & 30 & 604 & 5.2 & 1.29 & 604 & 5.2 & 1.29 \\
\hline Maize gluten & - & - & - & - & 5.1 & 997 & 1.3 & 11.41 & 37 & 0.5 & 0.00 \\
\hline MCP & 0.64 & 9.00 & 1.44 & 0.88 & 0.87 & 1170 & 17.7 & 0.31 & 1170 & 17.7 & 0.31 \\
\hline Methionine & 0.09 & 0.15 & 0.36 & 0.20 & 0.10 & 5490 & 90.9 & 0.01 & 5490 & 90.9 & 0.01 \\
\hline Natriumbicarb. & - & - & - & - & 0.31 & 1050 & 3.5 & 0.02 & 1050 & 3.5 & 0.02 \\
\hline Oat & - & - & - & 2 & - & 448 & 2.6 & 1.54 & 448 & 2.6 & 1.54 \\
\hline Oat hulls organic & - & 5.00 & 11.00 & - & - & 227 & 1.6 & 0.64 & 16 & 0.3 & 0.00 \\
\hline Premix & 0.50 & 0.40 & 0.40 & 1.15 & 0.88 & 2000 & 0.8 & 0.00 & 2000 & 0.8 & 0.00 \\
\hline Treonine 50\% & - & - & - & 0.31 & 0.2 & 8489 & 59.6 & 1.19 & 8489 & 59.6 & 1.19 \\
\hline Rapeseed meal & 12.00 & 5.00 & - & 3 & 10.7 & 456 & 3.4 & 1.25 & 16 & 0.2 & 0.00 \\
\hline Rice waffle & 8.40 & 8.00 & 8.00 & - & - & 12 & 0.2 & 0.00 & 12 & 0.2 & 0.00 \\
\hline Rusk & 25.00 & 41.90 & 41.00 & - & - & 12 & 0.2 & 0.00 & 12 & 0.2 & 0.00 \\
\hline Fish oil & - & - & - & 0.25 & - & 940 & 13.0 & 0.01 & 940 & 13.0 & 0.01 \\
\hline Salt & - & - & - & 0.18 & 0.17 & 180 & 3.5 & 0.02 & 180 & 3.5 & 0.02 \\
\hline Soya lecithin & 2.39 & - & - & - & - & 3190 & 20.9 & 4.37 & 3190 & 20.9 & 4.37 \\
\hline Soybean meal & - & 4.70 & - & 13.7 & - & 636 & 4.9 & 3.32 & 112 & 1.5 & 0.00 \\
\hline Soybean oil & - & - & - & 0.95 & - & 1830 & 12.0 & 3.90 & 4067 & 26.6 & 8.76 \\
\hline Sunflower oil & - & 0.85 & - & - & - & 2207 & 19.7 & 18.59 & 2759 & 24.7 & 23.24 \\
\hline Sunfl. meal HP* & 19.97 & - & - & - & - & 572 & 4.5 & 3.78 & 20 & 0.2 & 0.00 \\
\hline Sunfl. meal HP & - & - & - & 6 & 13 & 549 & 5.6 & 3.83 & 138 & 0.6 & 0.00 \\
\hline Sunfl. meal LP & - & 12.00 & - & 6 & 1.3 & 479 & 4.9 & 3.18 & 138 & 1.9 & 0.00 \\
\hline Waffle syrup & 5.00 & - & - & - & - & 12 & 0.2 & 0.00 & 12 & 0.2 & 0.00 \\
\hline Wheat & - & - & - & 30 & 33.9 & 329 & 2.9 & 1.14 & 329 & 2.9 & 1.14 \\
\hline
\end{tabular}




\section{D3 - Calculation of emissions related to manure management}

Table $\mathrm{D}_{3}$ shows the equations to calculate $\mathrm{CH}_{4}$ emissions, and direct and indirect $\mathrm{N}_{2} \mathrm{O}$ emissions with the related parameters calculated using the tier 2 approach (IPCC, 2006).

Table D3 Equations to calculate $\mathrm{CH}_{4}$, direct and indirect $\mathrm{N}_{2} \mathrm{O}$ emissions with the related parameters.

\begin{tabular}{|c|c|c|c|c|}
\hline \multicolumn{5}{|l|}{ General information } \\
\hline & & Egg production & Rearing female & Rearing male \\
\hline \multicolumn{2}{|l|}{ Approach } & Laying hen & Rearing hen & Rearing hen \\
\hline \multicolumn{2}{|l|}{ Avergage animal number $(\mathrm{N})$} & 23063 & 6175 & 6192 \\
\hline \multirow{2}{*}{$\begin{array}{l}\text { Round duration } \\
\text { feed intake }\end{array}$} & $\mathrm{d} /$ round & 469 & 119 & 119 \\
\hline & $\mathrm{g} / \mathrm{d}$ & 118 & & \\
\hline \multicolumn{5}{|l|}{ Equations } \\
\hline $\mathrm{CH}_{4}$ emission & \multicolumn{3}{|c|}{$=N *(V S * d) *\left(B 0 * 0,67 \mathrm{~kg} / \mathrm{m}^{3} *(\mathrm{MCF} / 100)\right)$} & \\
\hline Direct $\mathrm{N}_{2} \mathrm{O}$ Emission & \multicolumn{3}{|c|}{$N *(N E X / 365 * d) *$ EF3 $* 44 / 28$} & \\
\hline $\mathrm{N}_{2} \mathrm{O}$ leaching & \multicolumn{3}{|c|}{$N *($ NEX $/ 365 * d) *($ FracLeach / 100 $) *$ EF5 * $(44 / 28)$} & \\
\hline $\mathrm{N}_{2} \mathrm{O}$ volatilisation & \multicolumn{3}{|c|}{$N *($ NEX $/ 365 * d) *($ FracGas $/ 100) *$ EF4 $*(44 / 28)$} & \\
\hline \multicolumn{5}{|l|}{ CH4 emissions } \\
\hline & & Egg production & Rearing female & Rearing male \\
\hline Volatile solid excretion (VS) & kg/animal/day & 8.5 & 4 & 4 \\
\hline Potential $\mathrm{CH}_{4}$ Production (BO) & $\mathrm{m}^{3} \mathrm{CH}_{4} / \mathrm{kg}$ VS & 0.34 & 0.34 & 0.34 \\
\hline $\mathrm{CH}_{4}$ Conversion Factor (MCF) & kg CH4/animal/day & 0.015 & 0.015 & 0.015 \\
\hline CH4 emission & $\mathrm{kg} /$ round & 3141.58 & 395.86 & 396.90 \\
\hline \multicolumn{5}{|l|}{ N2O emissions } \\
\hline & & Egg production & Rearing female & Rearing male \\
\hline Nitrogen excreation & kg N/year & 0.75 & 0.35 & 0.35 \\
\hline Emission Factor 3 (EF3) & $\mathrm{kg} \mathrm{N} 2 \mathrm{O} / \mathrm{kg} \mathrm{N}$ & 0.001 & 0.001 & 0.001 \\
\hline Direct N2O emission & $\mathrm{kg} /$ round & 34.9 & 4.4 & 4.4 \\
\hline Leaching fraction (Fracleach) & kg N2O-N/kg N & & 0.13 & 0.13 \\
\hline Emission Factor 5 (EF5) & kg N2O/kg N & & 0.0075 & 0.0075 \\
\hline N2O leaching & $\mathrm{kg} /$ round & 0 & 0.04 & 0.04 \\
\hline FracGas & $\mathrm{kg} \mathrm{NH}+\mathrm{Nox}-\mathrm{N} / \mathrm{kg} \mathrm{N}$ & & 0.40 & 0.40 \\
\hline Emission Factor 4 (EF4) & kgN2O-N & & 0.010 & 0.010 \\
\hline N2O deposition & $\mathrm{kg} /$ round & 0 & 0.17 & 0.18 \\
\hline
\end{tabular}




\section{D4 - Calculation of the land use ratio}

The LUR was selected over the, more commonly used, protein conversion ratio as better accounts for the feed-food competition avoid by feeding only low-opportunity-cost feedstuffs. The protein conversion ratio compares the human digestible protein in a $\mathrm{kg}$ animal source food (ASF) with the human digestible protein (HDP) in the feed required to produce this kg of ASF. The LUR, alternatively compares it to the plant-based HDP that can be derived from the land used to cultivate feed required to produce this kg of ASF. Only the LUR, therefore, accounts for indirect feed-food competition by considering the amount of HDP that could be produced by a range of food crops on the land related to feed crop and energy rich food crop production.

Methods to calculate the LUR were based on van Zanten et al. (2016b) and consists of four steps. The first step quantified the country specific land occupation related the amount of each feed ingredient needed to produce one kg of ASF (eggs and meat), considering both the rearing and the laying phase. To do so feed intake (Main article; Table 1) and feed composition (Main article; Table 2) were linked to the land use (Vellinga et al., 2013) and country of origin and yields of each ingredient (Bongards, 2017; Heuvelmans, 2017; Lemmens, 2017; Vellinga et al., 2013). The second step assessed the suitability to produce the five major food crops (i.e. maize, wheat, potatoes (white and sweet), soybeans and rice) for each of these countries of origin based on the Global AgroEcological Zones (GAEZ) database (IIASA/FAO, 2012). This database classified land from 'not suitable' to 'very suitable' based on to what extend soil and climate conditions match requirements of each crop, under defined input and management circumstances. The crop suitability was assessed for current cultivated land in a situation of high input levels, optimal water supply and baseline climate conditions (1961-1990) (IIASA/FAO, 2012). Land was considered suitable for cultivation of a specific crop if the suitability was good, high, or very high (suitability index >55).

Table D4 Country average yields (kg/ha) of five major food crops for the year 2014 (FAO, 2017b). An empty cell implies a country was considered unsuitable to cultivate that crop (i.e. suitability index <55) (IIASA/FAO, 2012).

\begin{tabular}{|c|c|c|c|c|c|c|}
\hline Country & Maize & Wheat & $\begin{array}{l}\text { Sweet } \\
\text { potato }\end{array}$ & $\begin{array}{l}\text { White } \\
\text { potato }\end{array}$ & Soybeans & $\begin{array}{l}\text { Rice } \\
\text { (wet) }\end{array}$ \\
\hline Argentina & 6841 & 2667 & 14660 & 29411 & 2774 & 6504 \\
\hline Belgium & - & 9413 & - & 54000 & - & - \\
\hline Brazil & - & - & 13243 & - & 2866 & 5201 \\
\hline China & 5809 & - & - & 16924 & 1787 & 6812 \\
\hline France & 10050 & 7353 & - & 47978 & 2999 & - \\
\hline Germany & - & 8630 & - & 47415 & - & - \\
\hline The Netherlands & - & 9170 & - & 45660 & - & - \\
\hline Ukraine & 6159 & 4012 & - & - & - & - \\
\hline United Kingdom & - & 8578 & - & 41922 & - & - \\
\hline United States & 10733 & 2938 & - & 47151 & 3198 & 8492 \\
\hline
\end{tabular}


The third step calculates potential human-digestible protein production from the five food crops by multiplying their yields (Table D4) by their protein content and digestibility (Table D5). Countryaverage yields for crop production (FAO, 2017b) were used, as information about exact location and soil type were missing. Afterwards, the highest HDP for each area of land was chosen and summed across all land areas required to produce $1 \mathrm{~kg}$ of ASF, giving the numerator of the land use ratio. The last phase calculates the amount of HDP in $1 \mathrm{~kg}$ of ASF (i.e. eggs and meat) by multiplying with its protein content and its protein digestibility. The composition of one $\mathrm{kg}$ of ASF was based on Kipster's annual output of each product (i.e. eggs, laying hen meat and male laying hen chick meat) calculated from the outputs per round (Table 1) of the main paper.

Table D5 Dry matter (DM) and protein contents of products and protein digestibility (PD) by humans (van Zanten et al., 2016b).

\begin{tabular}{|c|c|c|c|c|}
\hline Product & Code $^{a}$ & $\begin{array}{l}\text { DM } \\
\% \\
\end{array}$ & $\begin{array}{l}\text { Protein } \\
\text { g/kg DM }\end{array}$ & $\begin{array}{l}D^{b} \\
\%\end{array}$ \\
\hline Eggs & 01123 & 24 & 527 & 97 \\
\hline Chicken meat & 05001 & 34 & 545 & 94 \\
\hline Maize & 20014 & 90 & 105 & 85 \\
\hline Wheat & 20074 & 90 & 125 & 87 \\
\hline Sweet potatoes & 11507 & 23 & 69 & 76 \\
\hline White potatoes & 11354 & 18 & 91 & 80 \\
\hline Soybeans & 16108 & 91 & 399 & 78 \\
\hline Rice & 20052 & 87 & 75 & 89 \\
\hline
\end{tabular}

a Product code in USDA database (USDA, 2018a) from which DM and protein content were derived

b Protein digestibility, source: (Gilani et al., 2005) except white potatoes (Eppendorfer et al., 1979; Khan et al., 1992; Kies \& Fox, 1972), and sweet potatoes (Ravindran et al., 1995). 


\section{D5 - Break-down of results}

In this appendix we provide a break-down of the results as presented in Figure 3 of the main paper.

Table D6 provides an overview of the made and avoided impacts in each phase, which together add up to the results presented in Figure 3 of the main paper. Tables D7-D9, give insights in how the made impacts in each phase, as presented in Table D6 were calculated, while Tables D1o \& D11 give insights in the avoided impacts due to the use and supply of solar energy.

Table D6 Made, avoided (-) and net global warming potential (GWP) energy use (EU) and land use (LU) per kg Kipster egg, in each phase

\begin{tabular}{|c|c|c|c|}
\hline & $\begin{array}{l}\text { GWP } \\
\text { (kg CO2-eq) }\end{array}$ & $\begin{array}{l}\text { EU } \\
(\mathrm{MJ})\end{array}$ & $\begin{array}{l}\text { LU } \\
(\mathrm{m} 2)\end{array}$ \\
\hline \multicolumn{4}{|l|}{ Rearing female } \\
\hline Rearing & 0.21 & 2.54 & 0.50 \\
\hline Total & 0.21 & 2.54 & 0.50 \\
\hline \multicolumn{4}{|l|}{ Rearing male } \\
\hline Rearing & 0.26 & 3.20 & 0.55 \\
\hline Meat output & -0.18 & -1.06 & -0.26 \\
\hline Total & 0.08 & 2.14 & 0.30 \\
\hline \multicolumn{4}{|l|}{ Egg production } \\
\hline Egg production & 1.10 & 9.59 & 2.44 \\
\hline Meat output & -0.17 & -0.99 & -0.24 \\
\hline Solar energy output & -0.09 & -1.42 & -0.002 \\
\hline Total & 0.83 & 7.18 & 2.19 \\
\hline Total & 1.13 & 11.86 & 2.99 \\
\hline
\end{tabular}

1: detailed calculations found in Tables D7-D9

2: avoided impact due to supply of solar energy as calculated in Table D11 
Table D7 Global warming potential (GWP; $\mathrm{kg} \mathrm{CO}_{2}$-eq) related to each process or input of each phase of Kipster egg production.

\begin{tabular}{|c|c|c|c|}
\hline \multicolumn{4}{|c|}{ Global warming potential (GWP; kg $\mathrm{CO}_{2}$-eq) } \\
\hline \multicolumn{2}{|c|}{ Rearing female } & (/round) & $(/ \mathrm{kg}$ egg $)$ \\
\hline \multirow[t]{4}{*}{ On-farm } & Manure management & 12298 & \\
\hline & Gas use & 7688 & \\
\hline & Electricity use & 6212 & \\
\hline & Total & 26198 & 0.05 \\
\hline \multirow[t]{4}{*}{ Off-farm } & Diesel use & 7 & \\
\hline & Litter & 25 & \\
\hline & Feed $^{1}$ & 88322 & \\
\hline & Total & 88420 & 0.17 \\
\hline \multicolumn{2}{|l|}{ Total } & & 0.21 \\
\hline
\end{tabular}

\begin{tabular}{|c|c|c|c|}
\hline \multicolumn{2}{|c|}{ Rearing male } & (/round) & (/kg egg) \\
\hline \multirow[t]{4}{*}{ On-farm } & Manure management & 12331 & \\
\hline & Gas use & 7688 & \\
\hline & Electricity use & 6196 & \\
\hline & Total & 26214 & 0.05 \\
\hline \multirow[t]{3}{*}{ Off-farm } & Litter & 25 & \\
\hline & Feed $^{1}$ & 115121 & \\
\hline & Total & 115212 & 0.22 \\
\hline \multicolumn{2}{|l|}{ Total } & & 0.26 \\
\hline \multicolumn{2}{|c|}{ Egg production } & (/round) & (/kg egg) \\
\hline \multirow[t]{3}{*}{ On-farm } & Manure management & 97220 & \\
\hline & Electricity use & 21302 & \\
\hline & Total & 118521 & 0.22 \\
\hline \multirow[t]{3}{*}{ Off-farm } & Litter & 143 & \\
\hline & Feed $^{1,2}$ & 467233 & \\
\hline & Total & 467315 & 0.87 \\
\hline \multirow{2}{*}{\multicolumn{3}{|c|}{$\begin{array}{l}\text { Total } \\
{ }^{1}: \text { Assuming solar energy; under average grid electricity } \\
\text { - Rearing female: } 11862 \mathrm{~kg} \mathrm{CO}_{2} \text {-eq } \\
\text { - Rearing male: } 85508 \mathrm{~kg} \mathrm{CO} 2 \text {-eq } \\
\text { - Rearing egg: } 22519 \mathrm{~kg} \mathrm{CO} \text {-eq } \\
\text { 2: impact of feed under economic allocation } \\
{ }^{3}: \text { impact of baseline (S1) feed }\end{array}$}} & 1.10 \\
\hline & & & cricity \\
\hline
\end{tabular}


Table D8 Energy use (EU, MJ) related to each process or input of each phase of Kipster egg production.

\begin{tabular}{|c|c|c|c|}
\hline \multicolumn{4}{|c|}{ Energy use (EU, MJ) } \\
\hline \multicolumn{2}{|c|}{ Rearing female } & (/round) & $(/ \mathrm{kg}$ egg $)$ \\
\hline \multirow[t]{3}{*}{ On-farm } & Gas use & 133238 & \\
\hline & Electricity use & 202339 & \\
\hline & Total & 335577 & 0.63 \\
\hline \multirow[t]{7}{*}{ Off-farm } & Diesel use & 7526 & \\
\hline & Diesel production & 102 & \\
\hline & Gas production & 142564 & \\
\hline & Electricity production & 73652 & \\
\hline & Litter & 278 & \\
\hline & Feed $^{1}$ & 798403 & \\
\hline & Total & 1023446 & 1.91 \\
\hline \multicolumn{2}{|l|}{ Total } & & 2.54 \\
\hline \multicolumn{2}{|c|}{ Rearing male } & $\underline{\text { (/round) }}$ & (/kg egg) \\
\hline \multirow[t]{3}{*}{ On-farm } & Gas use & 132888 & \\
\hline & Electricity use & 201809 & \\
\hline & Total & 334697 & 0.63 \\
\hline \multirow[t]{5}{*}{ Off-farm } & Gas production & 142190 & \\
\hline & Electricity production & 73458 & \\
\hline & Litter & 279 & \\
\hline & Feed $^{1}$ & 1159403 & \\
\hline & Total & 1376248 & 2.57 \\
\hline \multicolumn{2}{|l|}{ Total } & & 3.20 \\
\hline
\end{tabular}

\begin{tabular}{|c|c|c|c|}
\hline \multicolumn{2}{|c|}{ Egg production } & (/round) & $\underline{(/ \mathrm{kg} \text { egg })}$ \\
\hline \multirow[t]{2}{*}{ On-farm } & Electricity use & 540000 & \\
\hline & Total & 540000 & 1.01 \\
\hline \multirow[t]{4}{*}{ Off-farm } & Electricity production & 196560 & \\
\hline & Litter & 1609 & \\
\hline & Feed $^{1,2}$ & 4389897 & \\
\hline & Total & 4587524 & 8.58 \\
\hline \multicolumn{2}{|c|}{ Total } & & 9.59 \\
\hline \multicolumn{4}{|c|}{$\begin{array}{l}\text { : Assuming solar energy; under average grid electricity } \\
\qquad \quad \text { Rearing female: } 171593 \mathrm{MJ} \\
\bullet \quad \text { Rearing male: } 31530 \mathrm{MJ} \\
\bullet \quad \text { Egg production: } 298000 \mathrm{MJ} \\
2: \text { impact of feed under economic allocation } \\
\text { 3: impact of baseline (S1) feed }\end{array}$} \\
\hline
\end{tabular}


Table D9 Land use (LU, $\mathrm{m}^{2}$ ) related to each process or input of each phase of Kipster egg production.

\begin{tabular}{|c|c|c|c|}
\hline \multicolumn{4}{|c|}{ Land use $\left(\mathrm{LU}, \mathrm{m}^{2}\right)$} \\
\hline \multicolumn{2}{|c|}{ Rearing female } & \multicolumn{2}{|c|}{ (/round) (/kg egg) } \\
\hline \multirow[t]{5}{*}{ Off-farm } & Gas production & 8 & \\
\hline & Electricity production & 0 & \\
\hline & Litter & 2 & \\
\hline & Feed $^{1}$ & 268000 & \\
\hline & Total & 269446 & 0.50 \\
\hline \multicolumn{2}{|l|}{ Total } & & 0.50 \\
\hline \multicolumn{2}{|c|}{ Rearing male } & \multicolumn{2}{|c|}{$\underline{\text { (/round })}$ (/kg egg) } \\
\hline \multirow[t]{5}{*}{ Off-farm } & Gas production & 8 & \\
\hline & Electricity production & 541 & \\
\hline & Litter & 2 & \\
\hline & Feed $^{1}$ & 293058 & \\
\hline & Total & 295041 & 0.55 \\
\hline \multicolumn{2}{|l|}{ Total } & & 0.55 \\
\hline \multicolumn{2}{|c|}{ Egg production } & \multicolumn{2}{|c|}{ (/round) (/kg egg) } \\
\hline \multirow[t]{4}{*}{ Off-farm } & Electricity production & 1447 & \\
\hline & Litter & 10 & \\
\hline & Feed $^{1}$ & 1300195 & \\
\hline & Total & 1302920 & 2.44 \\
\hline \multicolumn{2}{|c|}{ Total } & & 2.43 \\
\hline \multicolumn{4}{|c|}{$\begin{array}{l}{ }^{1}: \text { Assuming solar energy; under average grid electricity } \\
-\quad \text { Rearing female: } 221 \mathrm{~m}^{2} \\
\text { - Rearing male: } 41 \mathrm{~m}^{2} \\
\text { 2: impact of feed under economic allocation } \\
{ }^{3}: \text { impact of baseline (S1) feed }\end{array}$} \\
\hline
\end{tabular}

Table D1o Production, use and supply (to the grid) of solar electricity by Kipster

\begin{tabular}{llll} 
& $\mathrm{kWh} /$ round & & $\mathrm{kWh} / \mathrm{egg}$ \\
\cline { 2 - 3 } Solar electricity produced & 385479 & & 0.72 \\
On farm electricity use & 305003 & & 0.57 \\
\hline Surplus of solar energy & 80476 & 0.15 \\
\hline
\end{tabular}


Table D11 Avoided global warming potential (GWP), energy use (EU) and land use (LU) by the use and supply of solar energy per kg Kipster egg

\begin{tabular}{|c|c|c|c|}
\hline & $\begin{array}{l}\text { GWP } \\
\text { (kg CO2-eq) }\end{array}$ & $\begin{array}{l}\mathrm{EU} \\
(\mathrm{MJ}) \\
\end{array}$ & $\begin{array}{l}\text { LU } \\
(\mathrm{m} 2)\end{array}$ \\
\hline Avoided by supply & 0.09 & 0.25 & 0.00 \\
\hline Avoided by use & 0.36 & 4.62 & 0.00 \\
\hline Rearing female & 0.07 & 0.99 & 0.00 \\
\hline Rearing male & 0.07 & 0.99 & 0.00 \\
\hline Egg production & 0.23 & 2.64 & 0.00 \\
\hline Avoided total & 0.45 & 4.87 & 0.00 \\
\hline
\end{tabular}

1: Calculated by multiplying the difference in impact between production of solar electricity and Dutch average grid electricity (Appendix D1) with the supply of (surplus) solar electricity by Kipster (Table D10)

2: Calculated as the difference in impact of each phase when assuming solar electricity use (Tables D7D9) and when assuming average grid electricity (see note 1 of Tables D7-D9) 


\section{References}

Aas, T.S., H.J., S., Hillestad, M., Ytrestoyl, T., Sveier, H., \& Asgard, T. (2015). Feed intake and nutrient digestibility and retention in Atlantic Salmon fed diets with different physical pellet quality. Nofima, Tromso, Norway. http://hdl.handle.net/11250/298423

AgriBalyse. (2017). AgriBalyse life cycle inventory (LCI) database of the main French agricultural products. ADEME, France. Retrieved January 16th 2018.

AgroVision. (2016). Kengetallenspiegel varkenshouderij 2015-2016. AgroVision, Deventer, The Netherlands.

Alcott, B. (2008). The sufficiency strategy: Would rich-world frugality lower environmental impact? Ecological Economics, 64(4), 770-786. https://doi.org/10.1016/j.ecolecon.2007.04.015

Aleksandrowicz, L., Green, R., Joy, E. J., Smith, P., \& Haines, A. (2016). The impacts of dietary change on greenhouse gas emissions, land use, water use, and health: a systematic review. PloS one, 11(11), e0165797. https://doi.org/10.1371/journal.pone.0165797

Alne, H., Oehme, M., Thomassen, M., Terjesen, B., \& Rørvik, K. A. (2011). Reduced growth, condition factor and body energy levels in Atlantic salmon Salmo salar L. during their first spring in the sea. Aquaculture Research, 42(2), 248-259. https://doi.org/10.1111/j.1365-2109.2010.02618.x

Anderson, J. S., Lall, S. P., Anderson, D. M., \& Chandrasoma, J. (1992). Apparent and true availability of amino acids from common feed ingredients for Atlantic salmon (Salmo salar) reared in sea water. Aquaculture, 108(1-2), 111-124. https://doi.org/10.1016/0044-8486(92)90322-C

Arora, V. K., \& Montenegro, A. (2011). Small temperature benefits provided by realistic afforestation efforts. Nature Geoscience, 4(8), 514-518. https://doi.org/10.1038/ngeo1182

Astigarraga, N. M., Roteta, A. A., \& Oregui, L. M. (2009). Atlantic mountain grassland-heathlands: structure and feeding value. Spanish Journal of Agricultural Research, $\chi(1), \quad 129-136$. https://doi.org/10.5424/sjar/2009071-405

Austin, B. (1998). The effects of pollution on fish health. Journal of applied microbiology, 85(S1), 234S-242S. https://doi.org/10.1111/j.1365-2672.1998.tb05303.x

Bajželj, B., Richards, K. S., Allwood, J. M., Smith, P., Dennis, J. S., Curmi, E., \& Gilligan, C. A. (2014). Importance of food-demand management for climate mitigation. Nature Climate Change, 4(10), 924929. https://doi.org/10.1038/nclimate2353

Bar, N. S., Sigholt, T., Shearer, K. D., \& Krogdahl, Å. (2007). A dynamic model of nutrient pathways, growth, and body composition in fish. Canadian Journal of Fisheries and Aquatic Sciences, 64(12), 1669-1682. https://doi.org/10.1139/fo7-127

Becker, K. H., Gillin, E., \& Kabat, L. (2001). Food Balance Sheets, a handbook. Rome: FAO.

Baldwin, R. L. (1995). Modeling ruminant digestion and metabolism. Chapman and Hall, New York, USA.

Balmford, A., Amano, T., Bartlett, H., Chadwick, D., Collins, A., Edwards, D., . . . Smith, P. (2018). The environmental costs and benefits of high-yield farming. Nature Sustainability, 1(9), 477. https://doi.org/10.1038/s41893-018-0138-5

Baumann, H., \& Tillman, A. (2004). The Hitchhiker's Guide to LCA. Lund, Sweden: Studentlitteratur.

Bell, J. G., \& Koppe, W. (2010). Lipids in aquafeeds. In G. M. Turchini, W.-K. Ng, \& D. R. Tocher (Eds.), Fish oil replacement and alternative lipid sources in aquaculture feeds (Vol. 1, pp. 21-59). CBC Press, UK.

Bell, J. G., Tocher, D. R., Henderson, R. J., Dick, J. R., \& Crampton, V. O. (2003). Altered fatty acid compositions in Atlantic salmon (Salmo salar) fed diets containing linseed and rapeseed oils can be 
partially restored by a subsequent fish oil finishing diet. The Journal of nutrition, 133(9), 2793-2801. https://doi.org/10.1093/jn/133.9.2793

Béné, C., Barange, M., Subasinghe, R., Pinstrup-Andersen, P., Merino, G., Hemre, G.-I., \& Williams, M. (2015). Feeding 9 billion by 2050-Putting fish back on the menu. Food Security, ‘(2), 261-274. https://doi.org/10.1007/s12571-015-0427-Z

Bengtsson, J., Bullock, J., Egoh, B., Everson, C., Everson, T., O'Connor, T., . . L Lindborg, R. (2019). Grasslands-more important for ecosystem services than you might think. Ecosphere, 1O(2), e02582. https://doi.org/10.1002/ecs2.2582

Bhujel, R. C. (2014). A manual for tilapia business management. CABI, UK.

Biesalski, H.-K. (2005). Meat as a component of a healthy diet-are there any risks or benefits if meat is avoided in the diet? Meat science, $70(3), 509-524$. https://doi.org/10.1016/j.meatsci.2004.07.017

BioMar. (2018). Sustainability report 2018 Biomar. BioMar, Denmark. https://www.biomar.com/globalassets/.global/pdf-files/biomar-group-sustainability-report-2018.pdf

Bokma, M., \& Leenstra, F. (2010). The market for culled one-day-old chicks. Wageningen Livestock Research, Lelystad, The Netherlands. http://n2gf.com/dossier-day-old-chickens-the-market-for-culled-one-dayold-chikcs/

Bongards, M. (2017). Interview: [Diet compostitions and the origin of feedstuffs].

Borgeson, T., Racz, V., Wilkie, D., White, L., \& Drew, M. (2006). Effect of replacing fishmeal and oil with simple or complex mixtures of vegetable ingredients in diets fed to Nile tilapia (Oreochromis niloticus). Aquaculture Nutrition, 12(2), 141-149. https://doi.org/10.1111/j.1365-2095.2006.00394.x

Borneo, R., \& León, A. E. (2012). Whole grain cereals: functional components and health benefits. Food \& function, 3(2), 110-119. https://doi.org/10.1039/C1FO10165J

Bos, J. F., Smit, A. B. L., \& Schröder, J. J. (2013). Is agricultural intensification in The Netherlands running up to its limits? NJAS-Wageningen Journal of Life Sciences, 66, 65-73. https://doi.org/10.1016/j.njas.2013.06.001

Bou, M., Berge, G. M., Baeverfjord, G., Sigholt, T., Østbye, T.-K., Romarheim, O. H., . . Ruyter, B. (2017). Requirements of n-3 very long-chain PUFA in Atlantic salmon (Salmo salar L): effects of different dietary levels of EPA and DHA on fish performance and tissue composition and integrity. British Journal of nutrition, 11入(1), 30-47. https://doi.org/10.1017/Sooo7114516004396

Bowles, N., Alexander, S., \& Hadjikakou, M. (2019). The livestock sector and planetary boundaries: A 'limits to growth' perspective with dietary implications. Ecological Economics, 160, 128-136. https://doi.org/10.1016/j.ecolecon.2019.01.033

Bozkurt, M., Küçükyılmaz, K., Çabuk, M., \& Çatll, A. U. (2012). Performance, egg quality, and immune response of laying hens fed diets supplemented with mannan-oligosaccharide or an essential oil mixture under moderate and hot environmental conditions. Asian Australas. J. Anim. Sci, 25(4), 524-530. https://www.ncbi.nlm.nih.gov/pmc/articles/PMC4092905/

Bransden, M., Carter, C., \& Nowak, B. (2001). Alternative methods for nutrition research on the southern bluefin tuna, Thunnus maccoyii (Castelnau): evaluation of Atlantic salmon, Salmo salar L., to screen experimental feeds. Aquaculture Research, 32, 174-181. https://doi.org/10.1046/j.1355557x.2001.00014.x

Bruinenberg, M., Valk, H., Korevaar, H., \& Struik, P. (2002). Factors affecting digestibility of temperate forages from seminatural grasslands: a review. Grass and Forage Science, 57(3), 292-301. https://doi.org/10.1046/j.1365-2494.2002.00327.x 
Bruinenberg, M., Valk, H., \& Struik, P. (2003). Voluntary intake and in vivo digestibility of forages from seminatural grasslands in dairy cows. NJAS wageningen journal of life sciences, 51(3), 219-235. https://doi.org/10.1016/S1573-5214(03)80017-9

Bruinenberg, M., Van Gelder, A., Perez, P. G., Hindle, V., \& Cone, J. (2004). Estimating rumen degradability of forages from semi-natural grasslands using nylon bag and gas production techniques. NJAS wageningen journal of life sciences, 51(4), 351-368. https://doi.org/10.1016/S1573-5214(04)80002-2

Caballero, R. (2007). High Nature Value (HNV) grazing systems in Europe: a link between biodiversity and farm economics. The Open Agriculture Journal, 11-19. https://doi.org/10.2174/1874331500701010011

Caldeira, C., De Laurentiis, V., Corrado, S., van Holsteijn, F., \& Sala, S. (2019). Quantification of food waste per product group along the food supply chain in the European Union: a mass flow analysis. Resources, Conservation and Recycling, 149, 479-488. https://doi.org/10.1016/j.resconrec.2019.06.011

Calder, P. C., \& Yaqoob, P. (2009). Understanding omega-3 polyunsaturated fatty acids. Postgraduate medicine, 121(6), 148-157. https://doi.org/10.3810/pgm.2009.11.2083

Carter, C., Bransden, M., Van Barneveld, R., \& Clarke, S. (1999). Alternative methods for nutrition research on the southern bluefin tuna, Thunnus maccoyii: in vitro digestibility. Aquaculture, 179(1-4), 57-70. https://doi.org/10.1016/So044-8486(99)00152-O

Cashion, T., Hornborg, S., Ziegler, F., Hognes, E. S., \& Tyedmers, P. (2016). Review and advancement of the marine biotic resource use metric in seafood LCAs: a case study of Norwegian salmon feed. The International Journal of Life Cycle Assessment, 21(8), 1106-1120. https://doi.org/10.1007/s11367-0161092-y

Cashion, T., Le Manach, F., Zeller, D., \& Pauly, D. (2017). Most fish destined for fishmeal production are foodgrade fish. Fish and Fisheries, 18(5), 837-844. https://doi.org/10.1111/faf.12209

Cassidy, E. S., West, P. C., Gerber, J. S., \& Foley, J. A. (2013). Redefining agricultural yields: from tonnes to people nourished per hectare. Environmental Research Letters, 8(3), 034015. https://doi.org/10.1088/1748-9326/8/3/034015

CBB, \& NCBA. (2014). Beef Cuts, Primal and Subprimal Weights and Yields. USDA, USA.

Cho, C. (1990). Fish nutrition, feeds, and feeding: with special emphasis on salmonid aquaculture. Food Reviews International, 6(3), 333-357. https://doi.org/10.1080/87559129009540876

Cicatiello, C., Franco, S., Pancino, B., Blasi, E., \& Falasconi, L. (2017). The dark side of retail food waste: Evidences from in-store data. Resources, Conservation and Recycling, 125, 273-281. https://doi.org/10.1016/j.resconrec.2017.06.010

Clough, D. (2005). Why do some people eat meat? Epworth Review, 32-40. https://chesterrep.openrepository.com/handle/10034/135489

Codabaccus, M. B., Ng, W.-K., Nichols, P. D., \& Carter, C. G. (2013). Restoration of EPA and DHA in rainbow trout (Oncorhynchus mykiss) using a finishing fish oil diet at two different water temperatures. Food chemistry, 141(1), 236-244. https://doi.org/10.1016/j.foodchem.2013.02.032

Cordell, D., \& White, S. (2015). Tracking phosphorus security: indicators of phosphorus vulnerability in the global food system. Food Security, 丸(2), 337-350. https://doi.org/10.1007/s12571-015-0442-0

Costello, C., Ovando, D., Clavelle, T., Strauss, C. K., Hilborn, R., Melnychuk, M. C., . . Cabral, R. B. (2016). Global fishery prospects under contrasting management regimes. Proceedings of the National Academy of Sciences, 113(18), 5125-5129. https://doi.org/10.1073/pnas.1520420113 
Craig, W. J., \& Mangels, A. R. (2009). Position of the American Dietetic Association: vegetarian diets. Journal of the American dietetic association, $109(7)$, 1266-1282. https://doi.org/10.1016/j.jada.2009.05.027

Crone, P. (2015). Pre-industrial societies: Anatomy of the pre-modern world. London: Oneworld Publications.

Cryogenetics. (2014). Milt from one salmon male has the capacity to fertilize up to 1 million eggs. Aquaculture news. https://www.cryogenetics.com/blog/2014/og/milt-from-one-salmon-male-has-the-capacity-tofertilize-up-to-1-million-eggs/

CRV. (2017). CRV jaarstatistieken 2016, Annual Statistics of Milk Production Registration (MPR). Arnhem, The Netherlands.

CVB. (2012). Tabellenboek Veevoeding 2012 (PDV Ed. 50 ed.) PDV, The Netherlands.

CVB. (2016). CVB Feed Table 2016; Chemical composition and nutritional values of feedstufs. PDV, The Netherlands.

CVB. (2016a). CVB Feed Table 2016; Chemical composition and nutritional values of feedstufs. PDV, The Netherlands.

CVB. (2016b). Voedernormen Pluimvee. PDV, The Netherlands.

Daccord, R., Wyss, U., Jeangros, B., \& Meisser, M. (2007). Bewertung von Wiesen futter. In AGFF (Ed.), (Vol. Merkblatt 3). Zurich, Switzerland.

Da Silva, V. P., van der Werf, H. M., Soares, S. R., \& Corson, M. S. (2014). Environmental impacts of French and Brazilian broiler chicken production scenarios: An LCA approach. Journal of environmental management, 133, 222-231. https://doi.org/10.1016/j.jenvman.2013.12.011

Damme, K., \& Ristic, M. (2003). Fattening performance, meat yield and economic aspects of meat and layer type hybrids. World's Poultry Science Journal, 59(1), 50-53. https://doi.org/10.1079/WPS20030002

DanishFoodInstitute. (2019). Nutrient composition database of National Food Institute of Denmark. Retrieved 10-09-2019 http://frida.fooddata.dk.

Davies, S. J., Abdel-Warith, A. A., \& Gouveia, A. (2011). Digestibility characteristics of selected feed ingredients for developing bespoke diets for Nile tilapia culture in Europe and North America. Journal of the World Aquaculture Society, 42(3), 388-398. https://doi.org/10.1111/j.1749-7345.2011.00478.x

de Bakker, E., \& Dagevos, H. (2012). Reducing meat consumption in today's consumer society: questioning the citizen-consumer gap. Journal of Agricultural and Environmental Ethics, 25(6), 877-894. https://doi.org/10.1007/s10806-011-9345-Z

de Boer, I. J., \& van Ittersum, M. K. (2018). Circularity in agricultural production. Wageningen University, Wageningen, The Netherlands. https://www.nutrientplatform.org/wpcontent/uploads/2019/06/3939 Circularity-in-agricultural-production-012019final.pdf

Denton, J. H., \& Mellor, D. B. (1990). Cost and Yield Comparisions of Ready-To-Cook Chicken Products. Texas Agricutural Extension Service, L-229o.

de Smet, S. (2012). Meat, poultry, and fish composition: Strategies for optimizing human intake of essential nutrients. Animal Frontiers, 2(4), 10-16. https://doi.org/10.2527/af.2012-0057

de Vries, M., \& de Boer, I. J. M. (2010). Comparing environmental impacts for livestock products: A review of life cycle assessments. Livestock science, 128(1), 1-11. https://doi.org/10.1016/j.livsci.2009.11.007

de Vries, M., van Middelaar, C., \& de Boer, I. (2015). Comparing environmental impacts of beef production systems: A review of life cycle assessments. Livestock science, 178, 279-288. https://doi.org/10.1016/j.livsci.2015.06.020

Deprez, B., Parmentier, R., Lambert, R., \& Peeters, A. (2007). Les prairies temporaires: une culture durable pour les exploitations mixtes de la Moyenne-Belgique. Les Dossiers de la Recherche agricole, 2. 
Dessen, J.-E., Weihe, R., Hatlen, B., Thomassen, M. S., \& Rørvik, K.-A. (2017). Different growth performance, lipid deposition, and nutrient utilization in in-season (S1) Atlantic salmon post-smolt fed isoenergetic diets differing in protein-to-lipid ratio. Aquaculture, 473, 345-354. https://doi.org/10.1016/j.aquaculture.2017.02.006

Dixon, E. S. (1850). Ornamental and domestic poultry: Their history and management: Gardeners' Chronicle. Dodgshon, R. A., \& Olsson, E. G. A. (2007). Seasonality in European mountain areas: a study in human ecology. In Seasonal landscapes (pp. 85-101): Springer.

Dowsett, E., Semmler, C., Bray, H., Ankeny, R. A., \& Chur-Hansen, A. (2018). Neutralising the meat paradox: Cognitive dissonance, gender, and eating animals. Appetite, 123, 280-288. https://doi.org/10.1016/j.appet.2018.01.005

Drewnowski, A., \& Fulgoni III, V. L. (2014). Nutrient density: principles and evaluation tools. The American Journal of clinical nutrition, 99(5), 1223S-1228S. https://doi.org/10.3945/ajen.113.073395

Duarte, C. M., Holmer, M., Olsen, Y., Soto, D., Marbà, N., Guiu, J., . . Karakassis, I. (2009). Will the Oceans Help Feed Humanity? BioScience, 59(11), 967-976. https://doi.org/10.1525/bio.2009.59.11.8

Dumont, B., Groot, J., \& Tichit, M. (2018). Make ruminants green again-how can sustainable intensification and agroecology converge for a better future? Animal, 12(s2), s210-s219. https://doi.org/10.1017/S1751731118001350

Duru, M. (2019). Trends in agri-food choices for health since the 1960s: the case of fatty acids. OCL, 26,44 . https://doi.org/10.1051/ocl/2019038

EC 1069/2009 health rules as regards animal by-products and derived products not intended for human consumption, (2009).

EC 1380/2013; Common Fisheries Policy, EC2371/2002; EC639/2004; EC585/2004 C.F.R. (2013b).

EC 2017/1017; Catalogue of feed materials 2017/1017 C.F.R. (2017).

EC 56/2013; Amendments to EC999/2001: rules for the prevention, control and eradication of certain transmissible spongiform encephalopathies (2013a).

EC Directive 2008/98 Waste Framework Directive, (2008).

EC/2018/2035; Guidelines for the feed use of food no longer intended for human consumption, (2018).

Ecoinvent. (2013). Life cycle inventory (LCI) database 3.0. Retrieved January 16th 2018.

EFFPA. (2019). EUFFPA Figures and Network. Keeping food losses in the food chain. https://www.effpa.eu/figures-network/

EFPRA. (2016). The facts about aquafeed. EFPRA, 2016/11.. https://efpra.eu/wpcontent/uploads/2016/11/The-facts-about-aguafeed.pdf

EFSA. (2017). Reference values for nutrients; summary report. EFSA Journal, $13(3), 84$. https://doi.org/10.2903/j.efsa.2015.4028

Einen, O., \& Roem, A. (1997). Dietary protein/energy ratios for Atlantic salmon in relation to fish size: growth, feed utilization and slaughter quality. Aquaculture Nutrition, 3(2), 115-126. https://doi.org/10.1046/j.1365-2095.1997.00084.x

Elferink, E., Nonhebel, S., \& Moll, H. (2008). Feeding livestock food residue and the consequences for the environmental impact of meat. Journal of Cleaner Production, 16(12), 1227-1233. https://doi.org/10.1016/j.jclepro.2007.06.008

El-Sayed, A.-F. M. (2019). Tilapia culture(P. Osborne Ed. 2 ed. Vol. 2). London Academic Press. 
Eppendorfer, W. H., Eggum, B. O., \& Bille, S. W. (1979). Nutritive value of potato crude protein as influenced by manuring and amino acid composition. Journal of the Science of Food and Agriculture, 3o(4), 361368. https://doi.org/10.1002/jsfa.2740300404

Erb, K.-H., Fetzel, T., Kastner, T., Kroisleitner, C., Lauk, C., Mayer, A., \& Niedertscheider, M. (2016). Livestock grazing, the neglected land use. In Social ecology (pp. 295-313): Springer.

Ertl, P., Knaus, W., \& Zollitsch, W. (2016). An approach to including protein quality when assessing the net contribution of livestock to human food supply. Animal, 1O(11), 1883-1889. https://doi.org/10.1017/S1751731116000902

Eskelinen, P. (1989). Effects of different diets on egg production and egg quality of Atlantic salmon (Salmo salar L.). Aquaculture, $79(1-4), 275-281$. https://doi.org/10.1016/0044-8486(89)90468-7

Espmark, Å. M., Kolarevic, J., Åsgård, T., \& Terjesen, B. F. (2017). Tank size and fish management history matters in experimental design. Aquaculture Research, 48(6), 2876-2894. https://doi.org/10.1111/are.13121

EuropeanCommission. (2015). Closing the loop - An EU action plan for the Circular Economy. Brussels, December 2015: http://eur-lex.europa.eu/legal-content/EN/TXT/?uri=CELEX:52015DCo614

EuropeanCommission. (2017). The fish market, 2017 edition. Brussels. http://www.eumofa.eu/documents/20178/108446/The+EU+fish+market+2017.pdf/80acad95-907f4 b9o-b2a7-1086964df3d9

EuropeanCommission. (2019). A short history of aquaculture. Brussels. https://ec.europa.eu/fisheries/cfp/aquaculture/aquaculture methods/history en

EUROSTAT. (2016). Post landing utilisation of fish species.

EUROSTAT. (2018). Generation of waste by waste category, hazardousness and NACE Rev. 2 activity [env_wasgen]. Retrieved 5-7-2019

EUROSTAT. (2019). Aquaculture statistics.

EY. (2017). The Norwegian aquaculture analysis 2017, EY's annual review. Ernst \& Young, Norway. https://www.ey.com/Publication/vwLUAssets/EY -

The Norwegian Aquaculture Analysis 2017/\$FILE/EY-Norwegian-Aquaculture-Analysis-2017.pdf

Fairlie, S. (2010). Meat: a benign extravagance: Chelsea green publishing.

Fanatico, A., Cavitt, L., Pillai, P., Emmert, J., \& Owens, C. (2005). Evaluation of slower-growing broiler genotypes grown with and without outdoor access: meat quality. Poultry Science, 84(11), 1785-1790. https://doi.org/10.1093/ps/84.11.1785

FAO. (1988). Definition of aquaculture, Seventh Session of the IPFC Working Party of Expects on Aquaculture. Food and Agriculture Organisation of the United Nations (FAO), Bangkok, Thailand

FAO. (1996). Technical Conversion Factorsfor Agricultural Commodities; Commodity trees. Food and Agriculture Organisation of the United Nations (FAO), Rome, Italy.

FAO. (2009). Proceedings of the expert meeting on how to feed the world in 2050 Paper presented at the How to feed the world in 2050. Food and Agriculture Organisation of the United Nations (FAO), Rome, Italy.

FAO. (2011). Global food losses and food waste - Extent, causes and prevention. Food and Agriculture Organisation of the United Nations (FAO), Rome, Italy. http://www.fao.org/3/a-i2697e.pdf

FAO. (2016a). GLEAM-i V2. Food and Agriculture Organisation of the United Nations (FAO), Rome, Italy.

FAO. (2016b). Global food composition database for fish and shellfish (978-92-5-109570-6 ). Food and Agriculture Organisation of the United Nations (FAO), Rome, Italy. Retrieved March 142019 
FAO. (2016c). Global Livestock Environmental Assesment Model (GLEAM) Model Description Version 2.o.

Food and Agriculture Organisation of the United Nations (FAO), Rome, Italy.

FAO. (2017a). FAOSTAT: Commodity Balances - Livestock and Fish Primary Equivalent. Food and Agriculture Organisation of the United Nations (FAO), Rome, Italy. Retrieved February 10th 2018.

FAO. (2017b). FAOSTAT: Crop yields. Food and Agriculture Organisation of the United Nations (FAO), Rome, Italy. Retrieved February 1oth 2018.

FAO. (2017c). FAOSTAT: Food Balance Sheets. Food and Agriculture Organisation of the United Nations (FAO), Rome, Italy. Retrieved February 10th 2018.

FAO. (2017d). FAOSTAT: Livestock Primary Production. Food and Agriculture Organisation of the United Nations (FAO), Rome, Italy. Retrieved February 10th 2018.

FAO. (2017e). FAOSTAT: Population Statistics. Food and Agriculture Organisation of the United Nations (FAO), Rome, Italy. Retrieved February 10th 2018.

FAO. (2018a). Atlantic salmon - Feed Production. Food and Agriculture Organisation of the United Nations

(FAO), Rome, Italy. http://www.fao.org/fishery/affris/species-profiles/atlantic-salmon/feedproduction/en/

FAO. (2018b). The State of World Fisheries and Aquaculture 2018 - Meeting the sustainable development goals. Food and Agriculture Organisation of the United Nations (FAO), Rome, Italy.

FEFAC. (2018). PEFCR feed for food producing animals. Brussels, Belgium.

Fetzel, T., Havlik, P., Herrero, M., \& Erb, K. H. (2017a). Seasonality constraints to livestock grazing intensity. Global Change Biology, 23(4), 1636-1647. https://doi.org/10.1111/gcb.13591

Fetzel, T., Havlik, P., Herrero, M., Kaplan, J., Kastner, T., Kroisleitner, C., . . . Wirsenius, S. (2017b). Quantification of uncertainties in global grazing systems assessments. Global Biogeochemical Cycles, 31(7), 1089-1102. https://doi.org/10.1002/2016GB005601

Foley, J. A., DeFries, R., Asner, G. P., Barford, C., Bonan, G., Carpenter, S. R., . . Gibbs, H. K. (2005). Global consequences of land use. science, 309(5734), 570-574. https://doi.org/10.1126/science.1111772

Foley, J. A., Ramankutty, N., Brauman, K. A., Cassidy, E. S., Gerber, J. S., Johnston, M., . . West, P. C. (2011). Solutions for a cultivated planet. Nature, 478(7369), 337-342. https://doi.org/10.1038/nature10452

Forbes, J. M. (2007). Voluntary food intake and diet selection in farm animals: CABI, UK.

Forster P., R. V., Artaxo P., Berntsen T., Betts R., Fahey D.W., Haywood J., Lean J., Lowe D.C., Myhre G., Nganga J., Prinn R., Raga G., Schulz M., Van Dorland R. (2007). Climate Change 2007: The Physical Science Basis. Contribution of Working Group I to the Fourth Assessment Report of the Intergovernmental Panel on Climate Change (S. Solomon, Qin D., Manning M., Chen Z., Marquis M., Averyt K.B., Tignor M., Miller H.L. Ed. Vol. 4). Cambridge, UK.

Frehner, A., Muller, A., Schader, C., De Boer, I., \& Van Zanten, H. H. (2020). Methodological choices drive differences in environmentally-friendly dietary solutions. Global Food Security, 24, 100333. https://doi.org/10.1016/j.gfs.2019.100333

Froehlich, H. E., Runge, C. A., Gentry, R. R., Gaines, S. D., \& Halpern, B. S. (2018). Comparative terrestrial feed and land use of an aquaculture-dominant world. Proceedings of the National Academy of Sciences, 115(20), 5295-5300. https://doi.org/10.1073/pnas.1801692115

Froese, R., Winker, H., Coro, G., Demirel, N., Tsikliras, A., Dimarchopoulou, D., . . Matz-Lück, N. (2018). Status and rebuilding of European fisheries. Marine Policy, 93, 159-170. https://doi.org/10.1016/j.marpol.2018.04.018 
Fry, J. P., Love, D. C., MacDonald, G. K., West, P. C., Engstrom, P. M., Nachman, K. E., \& Lawrence, R. S. (2016). Environmental health impacts of feeding crops to farmed fish. Environment international, 91, 201-214. https://doi.org/10.1016/j.envint.2016.02.022

Fry, J. P., Mailloux, N. A., Love, D. C., Milli, M. C., \& Cao, L. (2018). Feed conversion efficiency in aquaculture: do we measure it correctly? Environmental Research Letters, 13(2), 024017. https://doi.org/10.1088/1748-9326/aaa273

Fuhlendorf, S. D., Harrell, W. C., Engle, D. M., Hamilton, R. G., Davis, C. A., \& Leslie, D. M. (2006). Should heterogeneity be the basis for conservation? Grassland bird response to fire and grazing. Ecological Applications, 16(5), 1706-1716. https://doi.org/10.1890/1051-0761(2006)016[1706:SHBTBF]2.0.CO;2

Føre, M., Alver, M., Alfredsen, J. A., Marafioti, G., Senneset, G., Birkevold, J., . . Terjesen, B. F. (2016). Modelling growth performance and feeding behaviour of Atlantic salmon (Salmo salar L.) in commercialsize aquaculture net pens: Model details and validation through full-scale experiments. Aquaculture, 464, 268-278. https://doi.org/10.1016/j.aquaculture.2016.06.045

Gamboa, G., Kovacic, Z., Di Masso, M., Mingorría, S., Gomiero, T., Rivera-Ferré, M., \& Giampietro, M. (2016). The complexity of food systems: Defining relevant attributes and indicators for the evaluation of food supply chains in Spain. Sustainability, 8(6), 515. https://doi.org/10.3390/su8060515

Ganias, K. (2014). -Role of Anchovies and Sardines as Reduction Fisheries in the World Fish Meal Production: Overview of the Interaction between the Resource and Environmental and Socioeconomic Drivers. In Biology and Ecology of Sardines and Anchovies (pp. 298-320): CRC Press.

Garcia-Launay, F., Van der Werf, H., Nguyen, T. T. H., Le Tutour, L., \& Dourmad, J.-Y. (2014). Evaluation of the environmental implications of the incorporation of feed-use amino acids in pig production using Life Cycle Assessment. Livestock science, 161, 158-175. https://doi.org/10.1016/j.livsci.2013.11.027

Garnett, T. (2009). Livestock-related greenhouse gas emissions: impacts and options for policy makers. environmental science \& policy, 12(4), 491-503. https://doi.org/10.1016/j.envsci.2009.01.006

Garnett, T. (2011). Where are the best opportunities for reducing greenhouse gas emissions in the food system (including the food chain)? Food policy, 36, S23-S32. https://doi.org/10.1016/j.foodpol.2010.10.010

Garnett, T., Godde, C., Muller, A., Röös, E., Smith, P., de Boer, I. J. M., . . van Zanten, H. H. E. (2017). Grazed and confused? Ruminating on cattle, grazing systems, methane, nitrous oxide, the soil carbon sequestration question - and what it all means for greenhouse gas emissions FCRN, Oxford, UK. https://www.fcrn.org.uk/sites/default/files/project-files/fcrn gnc report.pdf

Garnett, T., Röös, E., \& Little, D. C. (2015). Lean, green, mean, obscene...? What is efficiency? And is it sustainable? Animal production and consumption reconsidered. FCRN Oxford, UK. https://fcrn.org.uk/sites/default/files/fcrn_lmgo.pdf

Gaylord, T. G., Barrows, F. T., \& Rawles, S. D. (2008). Apparent digestibility of gross nutrients from feedstuffs in extruded feeds for rainbow trout, Oncorhynchus mykiss. Journal of the World Aquaculture Society, 39(6), 827-834. https://doi.org/10.1111/j.1749-7345.2008.00220.x

Giampietro, M. (2019). On the circular bioeconomy and decoupling: implications for sustainable growth. Ecological Economics, 162, 143-156. https://doi.org/10.1016/j.ecolecon.2019.05.001

Gilani, G. S., Cockell, K. A., \& Sepehr, E. (2005). Effects of antinutritional factors on protein digestibility and amino acid availability in foods. Journal of AOAC International, 88(3), 967-987. https://doi.org/10.1093/jaoac/88.3.967

Gerber, P. J., Steinfeld, H., Henderson, B., Mottet, A., Opio, C., Dijkman, J., . . Tempio, G. (2013). Tackling climate change through livestock: a global assessment of emissions and mitigation opportunities (978- 
92-5-107920-1). Food and Agriculture Organisation of the United Nations (FAO), Rome, Italy. http://www.fao.org/docrep/o18/i3437e/i3437e.pdf

Ghisellini, P., Cialani, C., \& Ulgiati, S. (2016). A review on circular economy: the expected transition to a balanced interplay of environmental and economic systems. Journal of Cleaner Production, 114, 11-32. https://doi.org/10.1016/j.jclepro.2015.09.007

Givens, D. I., \& Gibbs, R. A. (2008). Current intakes of EPA and DHA in European populations and the potential of animal-derived foods to increase them: Symposium on 'How can the n- 3 content of the diet be improved?'. Proceedings of the nutrition society, 67(3), 273-280. https://doi.org/10.1017/So029665108007167

Godfray, H. C. J., Aveyard, P., Garnett, T., Hall, J. W., Key, T. J., Lorimer, J., . . Jebb, S. A. (2018). Meat consumption, health, and the environment. science, 361(6399), eaam5324. https://doi.org/10.1126/science.aam5324

Godfray, H. C. J., Beddington, J. R., Crute, I. R., Haddad, L., Lawrence, D., Muir, J. F., . . Toulmin, C. (2010). Food security: the challenge of feeding 9 billion people. science, $327(5967)$, 812-818. https://doi.org/10.1126/science.1185383

Goodland, R. (1997). Environmental sustainability in agriculture: diet matters. Ecological Economics, 23(3), 189-200. https://doi.org/10.1016/So921-8009(97)00579-X

Gordon, I., Illius, A., \& Milne, J. (1996). Sources of variation in the foraging efficiency of grazing ruminants. Functional Ecology, 219-226. https://doi.org/10.2307/2389846

Grundy, S. M. (1997). What is the desirable ratio of saturated, polyunsaturated, and monounsaturated fatty acids in the diet? The American journal of clinical nutrition, 66(4), 988S-990S. https://doi.org/10.1093/ajcn/66.4.988S

Guimarães, I., Pezzato, L. E., \& Barros, M. M. (2008a). Amino acid availability and protein digestibility of several protein sources for Nile tilapia, Oreochromis niloticus. Aquaculture Nutrition, 14(5), 396-404. https://doi.org/10.1111/j.1365-2095.2007.00540.x

Guimarães, I. G., Pezzato, L. E., Barros, M. M., \& Tachibana, L. (2008b). Nutrient digestibility of cereal grain products and by-products in extruded diets for Nile tilapia. Journal of the World Aquaculture Society, 39(6), 781-789. https://doi.org/10.1111/j.1749-7345.2008.00214.x

Guinée, J. B. (2002). Handbook on life cycle assessment operational guide to the ISO standards, Vol. 7. Kluwer Academic Publishers, Dordrecht, The Netherlands.

Gustavsson, J., Cederberg, C., Sonesson, U., Van Otterdijk, R., \& Meybeck, A. (2011). Global food losses and food waste. Food and Agriculture Organisation of the United Nations (FAO), Rome, Italy.

Haberl, H., Erb, K. H., Krausmann, F., Gaube, V., Bondeau, A., Plutzar, C., . . Fischer-Kowalski, M. (2007). Quantifying and mapping the human appropriation of net primary production in earth's terrestrial ecosystems. Proceedings of the National Academy of Sciences, 104(31), 12942-12947. https://doi.org/10.1073/pnas.0704243104

Haberl, H., Fischer-Kowalski, M., Krausmann, F., Martinez-Alier, J., \& Winiwarter, V. (2011). A sociometabolic transition towards sustainability? Challenges for another Great Transformation. Sustainable development, 19(1), 1-14. https://doi.org/10.1002/sd.410

Hajen, W., Higgs, D., Beames, R., \& Dosanjh, B. (1993). Digestibility of various feedstuffs by post-juvenile chinook salmon (Oncorhynchus tshawytscha) in sea water. 2. Measurement of digestibility. Aquaculture, 112(4), 333-348. https://doi.org/10.1016/0044-8486(93)90394-E 
Hamilton, H. A., Newton, R., Auchterlonie, N. A., \& Müller, D. B. (2020). Systems approach to quantify the global omega-3 fatty acid cycle. Nature Food, 1(1), 59-62. https://doi.org/10.1038/s43016-019-0006-0

Hallström, E., Carlsson-Kanyama, A., \& Börjesson, P. (2015). Environmental impact of dietary change: a $\begin{array}{llllll}\text { systematic } & \text { review. Journal } & \text { 1-11. }\end{array}$ https://doi.org/10.1016/j.jclepro.2014.12.008

Haslinger, M., Leitgeb, R., Bauer, F., Ettle, T., \& Windisch, W. (2007). Slaughter yield and meat quality of chicken at different length of preslaughter feed withdrawal. Die Bodenkultur, 6入(58), 1-4. https://diebodenkultur.boku.ac.at/volltexte/band-58/heft-1-4/haslinger.pdf

Hayes, F., Mills, G., Jones, L., Abbott, J., Ashmore, M., Barnes, J., . . Rintoul, N. (2016). Consistent ozoneinduced decreases in pasture forage quality across several grassland types and consequences for UK lamb production. Science of the Total Environment, 543, 336-346. https://doi.org/10.1016/j.scitotenv.2015.10.128

Herrero, M., Henderson, B., Havlík, P., Thornton, P. K., Conant, R. T., Smith, P., . . . Gill, M. (2016). Greenhouse gas mitigation potentials in the livestock sector. Nature Climate Change, 6(5), 452-461. https://doi.org/10.1038/nclimate2925

Heuvelmans, A. (2017). Interview: [Diet composition and feed origin Nijssen Granico].

Hijbeek, R., van Ittersum, M. K., ten Berge, H. F., Gort, G., Spiegel, H., \& Whitmore, A. P. (2017). Do organic inputs matter-a meta-analysis of additional yield effects for arable crops in Europe. Plant and Soil, 411(12), 293-303. https://doi.org/10.1007/s11104-016-3031-X

Hinojosa, L., Napoléone, C., Moulery, M., \& Lambin, E. F. (2016). The "mountain effect" in the abandonment of grasslands: Insights from the French Southern Alps. Agriculture, Ecosystems \& Environment, 221, 115-124. https://doi.org/10.1016/j.agee.2016.01.032

HLPE. (2014). Sustainable fisheries and aquaculture for food security and nutrition. A report by the High Level Panel of Experts on Food Security and Nutrition of the Committee on World Food Security. Food and Agriculture Organisation of the United Nations (FAO), Rome, Italy. http://www.fao.org/3/ai3844e.pdf

Hubrecht, L., Willems, W., \& Fiems, L. (2013). Voeding van runderen van het Belgisch witblauwe ras (D/2013/3241/264). Vlaamse overheid, Brussles, Belgium. https://www.vlaanderen.be/publicaties/voeding-van-runderen-van-het-belgische-witblauwe-ras

IAFFD. (2018). International Aquaculture Feed Formulation Database. USAID. http://www.iaffd.com/.

ICES. (2016). ICES advice for Maximum Sustainable Yield. ICES, Copenhagen, Denmark. https://doi.org/10.17895/ices.pub.4503

ICES. (2018). Official Nominal Catches. ICES, Copenhagen, Denmark. Retrieved August 2019. http://ices.dk/marine-data/dataset-collections/Pages/Fish-catch-and-stock-assessment.aspx.

IDELE. (2014). Conjoncture économique des systèmes Bovins Charolais.

IIASA/FAO. (2012). Global Agro-ecological Zones (GAEZ v3.o). Food and Agriculture Organisation of the United Nations (FAO), Rome, Italy.

IPCC. (2006). 2006 IPCC Guidelines for National Greenhouse Gas Inventories, prepared by the National Greenhouse Gas Inventories Programme. Volume 4: Agriculture, forestry and other land use. IPCC, Kanagawa, Japan: https://www.ipcc-nggip.iges.or.jp/public/2006gl/

IUCN. (2017). Sustainability of Fish Feed in Aquaculture: Reflections and Recommendations. Paris, France. 
Jackson, A., \& Newton, R. W. (2016). Project to model the use of fisheries by-products in the production of marine ingredients with special reference to omegaz fatty acids EPA and DHA. Retrieved from United Kingdom: https://www.iffo.net/system/files/Report\%20IoA\%20IFFO\%2oproject\%20Final o.pdf

Jurgilevich, A., Birge, T., Kentala-Lehtonen, J., Korhonen-Kurki, K., Pietikäinen, J., Saikku, L., \& Schösler, H. (2016). Transition towards circular economy in the food system. Sustainability, 8(1), 69. https://doi.org/10.3390/su8010069

Kabir, K., Verdegem, M., Verreth, J., Phillips, M., \& Schrama, J. (2019). Effect of dietary protein to energy ratio, stocking density and feeding level on performance of Nile tilapia in pond aquaculture. Aquaculture, 511, 634200. https://doi.org/10.1016/j.aquaculture.2019.06.014

Karalazos, V., Bendiksen, E., \& Bell, J. G. (2011). Interactive effects of dietary protein/lipid level and oil source on growth, feed utilisation and nutrient and fatty acid digestibility of Atlantic salmon. Aquaculture, 311(14), 193-200. https://doi.org/10.1016/j.aquaculture.2010.11.022

Karalazos, V., Bendiksen, E., Dick, J. R., \& Bell, J. G. (2007). Effects of dietary protein, and fat level and rapeseed oil on growth and tissue fatty acid composition and metabolism in Atlantic salmon (Salmo salar L.) reared at low water temperatures. Aquaculture Nutrition, 13(4), 256-265. https://doi.org/10.1111/j.1365-2095.2007.00471.x

Karlsson, J. O., \& Röös, E. (2019). Resource-efficient use of land and animals-Environmental impacts of food systems based on organic cropping and avoided food-feed competition. Land Use Policy, 85, 63-72. https://doi.org/10.1016/j.landusepol.2019.03.035

Kearney, J. (2010). Food consumption trends and drivers. Philosophical Transactions of the Royal Society B: Biological Sciences, 365(1554), 2793-2807. https://doi.org/10.1098/rstb.2010.0149

Khan, M., Saeeda, J., Rana, I., \& Ihsan, U. (1992). Improvement of wheat protein by supplementation with potato flour. Pakistan Journal of Agricultural Research, 13(2), 101-106.

Kies, C., \& Fox, H. M. (1972). Effect of amino acid supplementation of dehydrated potato flakes on protein nutritive value for human adults. Journal of Food Science, 3خ(3), 378-380. https://doi.org/10.1111/j.1365-2621.1972.tbo2642.x

Kipster. (2017, April 26th 2018). Kipster, Oirlo, The Netherlands. www.kipster.nl

Kok, A., van Hoeij, R. J., Tolkamp, B. J., Haskell, M. J., van Knegsel, A. T., de Boer, I. J., \& Bokkers, E. A. (2017). Behavioural adaptation to a short or no dry period with associated management in dairy cows. Applied animal behaviour science, 186, 7-15. https://doi.org/10.1016/j.applanim.2016.10.017

Köprücü, K., \& Özdemir, Y. (2005). Apparent digestibility of selected feed ingredients for Nile tilapia (Oreochromis niloticus).

Aquaculture,

$250(1-2)$ 308-316. https://doi.org/10.1016/j.aquaculture.2004.12.003

Korevaar, H. (1986). Produktie en voederwaarde van gras bij gebruiks-en bemestingsbeperkingen voor natuurbeheer. Korevaar,

Korhonen, J., Honkasalo, A., \& Seppälä, J. (2018). Circular economy: the concept and its limitations. Ecological Economics, 143, 37-46. https://doi.org/10.1016/j.ecolecon.2017.06.041

Krahulec, F., Skálová, H., Herben, T., Hadincová, V., Wildová, R., \& Pecháčková, S. (2001). Vegetation changes following sheep grazing in abandoned mountain meadows. Applied Vegetation Science, 4(1), 97102. https://doi.org/10.1111/j.1654-109X.2001.tboo239.x

Kris-Etherton, P. M., Grieger, J. A., \& Etherton, T. D. (2009). Dietary reference intakes for DHA and EPA. Prostaglandins, Leukotrienes and Essential Fatty Acids, 81(2-3), 99-104. https://doi.org/10.1016/j.plefa.2009.05.011 
Kristensen, L. S., Thenail, C., \& Kristensen, S. P. (2004). Landscape changes in agrarian landscapes in the 1990s: the interaction between farmers and the farmed landscape. A case study from Jutland, Denmark. Journal of environmental management, https://doi.org/10.1016/j.jenvman.2004.03.003

Krogdahl, Å. (2016, 10-19-2016) A look at sustainable fishmeal alternatives/Interviewer: Feedinfo. World Nutrition Forum, Feedinfo, Vancouver, Canada.

Lambin, E. F., \& Meyfroidt, P. (2011). Global land use change, economic globalization, and the looming land scarcity. Proceedings of the National Academy of Sciences, 108(9), 3465-3472. https://doi.org/10.1073/pnas.1100480108

Läpple, D., Hennessy, T., \& O’Donovan, M. (2012). Extended grazing: a detailed analysis of Irish dairy farms. Journal of Dairy Science, 95(1), 188-195. https://doi.org/10.3168/jds.2011-4512

Lee, C., Lee, H., Jeong, J., Baik, K., Jin, S., Lee, J., \& Sohnt, S. (2002). Effects of restricted feeding, low-energy diet, and implantation of trenbolone acetate plus estradiol on growth, carcass traits, and circulating concentrations of insulin-like growth factor (IGF)-I and IGF-binding protein-3 in finishing barrows. Journal of Animal Science, 8o(1), 84-93. https://doi.org/10.2527/2002.80184x

Leeson, S., Caston, L., \& Summers, J. (1996). Broiler response to diet energy. Poultry Science, 75(4), 529-535. LEI. (2017). Agrimatie. from Wageningen University and Research

Leinonen, I., Williams, A., \& Kyriazakis, I. (2014). The effects of welfare-enhancing system changes on the environmental impacts of broiler and egg production. Poultry Science, 93(2), 256-266. https://doi.org/10.3382/ps.2013-03252

Leinonen, I., Williams, A., Wiseman, J., Guy, J., \& Kyriazakis, I. (2012). Predicting the environmental impacts of chicken systems in the United Kingdom through a life cycle assessment: Broiler production systems. Poultry Science, 91(1), 8-25. https://doi.org/10.3382/ps.2011-01634

Lemmens, T. (2017). [Diet compostition and origin of feedstuffs Vitelia].

Levis, J. W., Barlaz, M. A., Themelis, N. J., \& Ulloa, P. (2010). Assessment of the state of food waste treatment in the United States and Canada. Waste management, 3o(8-9), 1486-1494. https://doi.org/10.1016/j.wasman.2010.01.031

LNV. (2019). Realisatieplan Visie LNV: op weg met een nieuw perspectief. Ministerie van Landbouw, Natuur en Voedselveiligheid, Den Haag, The Netherlands. https://www.rijksoverheid.nl/documenten/publicaties/2019/06/17/realisatieplan-visie-lnv-op-wegmet-nieuw-perspectief

Loetscher, Y., Albiker, D., Stephan, R., Kreuzer, M., \& Messikommer, R. (2015). Differences between spent hens of different genotype in performance, meat yield and suitability of the meat for sausage production. Animal, 9 (02), 347-355. https://doi.org/10.1017/S1751731114002468

Loizia, P., Neofytou, N., \& Zorpas, A. A. (2019). The concept of circular economy strategy in food waste management for the optimization of energy production through anaerobic digestion. Environmental Science and Pollution Research, 26(15), 14766-14773. https://doi.org/10.1007/s11356-018-3519-4

Luyckx, K., Bowman, M., Woroniecka, K., Taillard, D., \& Broeze, J. (2019). Technical Guidelines Animal Feed: The safety, environmental and economic aspects of feeding surplus food to omnivorous livestock. Brussels, Belgium. https://eu-refresh.org/technical-guidelines-animal-feed

Macdiarmid, J. I., Kyle, J., Horgan, G. W., Loe, J., Fyfe, C., Johnstone, A., \& McNeill, G. (2012). Sustainable diets for the future: can we contribute to reducing greenhouse gas emissions by eating a healthy diet? The American journal of clinical nutrition, 96(3), 632-639. https://doi.org/10.3945/ajcn.112.038729 
Magalhães, S., Cabrita, A., Valentão, P., Andrade, P., Rema, P., Maia, M., . . Fonseca, A. (2018). Apparent digestibility coefficients of European grain legumes in rainbow trout (Oncorhynchus mykiss) and Nile tilapia (Oreochromis niloticus). Aquaculture Nutrition, 24(1), 332-340. https://doi.org/10.1111/anu.12564

Malindine, J. (2019). Prehistoric Aquaculture: Origins, Implications, and an Argument for Inclusion. Culture, Agriculture, Food and Environment, 41(1), 66-70. https://doi.org/10.1111/cuag.12226

Mancilla-Leytón, J., Farnés, C. P., \& Vicente, A. M. (2012). Selection of browse species and energy balance of goats grazing on forest understory vegetation in Doñana Natural Park (SW Spain). Livestock science, 148(3), 237-242. https://doi.org/10.1016/j.livsci.2012.06.012

McGeachy, S. A., Benfey, T., \& Friars, G. (1995). Freshwater performance of triploid Atlantic salmon (Salmo salar) in New Brunswick aquaculture. Aquaculture, 137(1-4), 333-341. https://doi.org/10.1016/0044$\underline{8486(95) 01100-5}$

M. Haslinger, R. L., F. Bauer, T. Ettle and W. M. Windisch. (2007). Slaughter yield and meat quality of chicken at different length of preslaughter feed withdrawa. Die Bodenkultur, 58, 1-4.

Mente, E., Jokumsen, A., Carter, C. G., Antonopoulou, E., \& Tacon, A. G. (2019). Nutrition in relation to organic aquaculture: Sources and strategies. In Organic Aquaculture (pp. 141-188): Springer.

Mertens, E., van't Veer, P., Hiddink, G. J., Steijns, J. M., \& Kuijsten, A. (2017). Operationalising the health aspects of sustainable diets: a review. Public health nutrition, 20(4), 739-757. https://doi.org/10.1017/S1368980016002664

Morris, T. (1968). The effect of dietary energy level on the voluntary calorie intake of laying birds. British Poultry Science, 9(3), 285-295. https://doi.org/10.1080/00071666808415720

Mota, V. C., Nilsen, T. O., Gerwins, J., Gallo, M., Ytteborg, E., Baeverfjord, G., . . Terjesen, B. F. (2019). The effects of carbon dioxide on growth performance, welfare, and health of Atlantic salmon post-smolt (Salmo salar) in recirculating aquaculture systems. Aquaculture, 498, 578-586. https://doi.org/10.1016/j.aquaculture.2018.08.075

Mottet, A., de Haan, C., Falcucci, A., Tempio, G., Opio, C., \& Gerber, P. J. (2017). Livestock: On our plates or eating at our table? A new analysis of the feed/food debate. Global Food Security, 14, 1-8. https://doi.org/10.1016/j.gfs.2017.01.001

Mourad, M. (2016). Recycling, recovering and preventing "food waste": competing solutions for food systems sustainability in the United States and France. Journal of Cleaner Production, 126, 461-477. https://doi.org/10.1016/j.jclepro.2016.03.084

Muscat, A., de Olde, E. M., De Boer, I. J. M., \& Ripoll-Bosch, R. (2019). The battle for biomass: a systematic review of food-feed-fuel competition. Journal of Cleaner Production, 100330. https://doi.org/10.1016/j.gfs.2019.100330

Newbold, T., Hudson, L. N., Arnell, A. P., Contu, S., De Palma, A., Ferrier, S., . . Phillips, H. R. (2016). Has land use pushed terrestrial biodiversity beyond the planetary boundary? A global assessment. science, 353(6296), 288-291. doi:10.1126/science.aaf2201

Nordvarg, L., \& Johansson, T. (2002). The effects of fish farm effluents on the water quality in the Åland archipelago, Baltic Sea. Aquacultural Engineering, 25(4), 253-279. https://doi.org/10.1016/So1448609(01)00088-7

Nour, A., Thonney, M., Stouffer, J., \& White, W. (1983a). Changes in carcass weight and characteristics with increasing weight of large and small cattle. Journal of Animal Science, 5ך(5), 1154-1165. https://doi.org/10.2527/jas1983.5751154x 
Nour, A., Thonney, M., Stouffer, J., \& White, W. (1983b). Changes in primal cut yield with increasing weight of large and small cattle. Journal of Animal Science, 5ך(5), 1166-1172. https://doi.org/10.2527/jas1983.5751166x

NRC. (1984). Nutrient requirements of poultry (8th revised edition ed.). Waschington D.C. : National Academies.

Oh, R., \& Brown, D. L. (2003). Vitamin B12 deficiency. American family physician, 67(5), 979-986.

O’Neill, D. W., Fanning, A. L., Lamb, W. F., \& Steinberger, J. K. (2018). A good life for all within planetary boundaries. Nature Sustainability, 1(2), 88-95. https://doi.org/10.1038/s41893-018-0021-4

Oenema, O., van Liere, L., \& Schoumans, O. (2005). Effects of lowering nitrogen and phosphorus surpluses in agriculture on the quality of groundwater and surface water in the Netherlands. Journal of Hydrology, 304(1-4), 289-301. https://doi.org/10.1016/j.jhydrol.2004.07.044

Opstvedt, J., Aksnes, A., Hope, B., \& Pike, I. H. (2003). Efficiency of feed utilization in Atlantic salmon (Salmo salar L.) fed diets with increasing substitution of fish meal with vegetable proteins. Aquaculture, 221(14), 365-379. https://doi.org/10.1016/So044-8486(03)00026-7

Palmer, S., \& Raftery, J. (1999). Opportunity cost. Bmj, 318(7197), 1551-1552.

Papargyropoulou, E., Lozano, R., Steinberger, J. K., Wright, N., \& bin Ujang, Z. (2014). The food waste hierarchy as a framework for the management of food surplus and food waste. Journal of Cleaner Production, 76, 106-115. https://doi.org/10.1016/j.jclepro.2014.04.020

Parodi, A., Leip, A., De Boer, I. J. M., Herrero, M., Ziegler, F., . . HHE, V. Z. (2018). The potential of future food for sustainable and healthy diets. Nature Sustainability. https://doi.org/10.1038/s41893-0180189-7

Patnaik, U. (1996). Export-oriented agriculture and food security in developing countries and India. Economic and Political Weekly, 2429-2449. https://www.jstor.org/stable/4404563

Paton, D., Nunez-Trujillo, J., Díaz, M. A., \& Muñoz, A. (1999). Assessment of browsing biomass, nutritive value and carrying capacity of shrublands for red deer (Cervus elaphus L.) management in Monfragüe Natural Park (SW Spain). Journal of Arid Environments, 42(2), 137-147. https://doi.org/10.1006/jare.1999.0501

Peltomaa, E., Johnson, M. D., \& Taipale, S. J. (2018). Marine cryptophytes are great sources of EPA and DHA. Marine drugs, 16(1), 3. https://doi.org/10.3390/md16010003

Piazza, J., Ruby, M. B., Loughnan, S., Luong, M., Kulik, J., Watkins, H. M., \& Seigerman, M. (2015). Rationalizing meat consumption. The 4Ns. Appetite, 91, 114-128. https://doi.org/10.1016/j.appet.2015.04.011

Plutzar, C., Kroisleitner, C., Haberl, H., Fetzel, T., Bulgheroni, C., Beringer, T., . . Lauk, C. (2016). Changes in the spatial patterns of human appropriation of net primary production (HANPP) in Europe 19902006. Regional Environmental Change, 16(5), 1225-1238. https://doi.org/10.1007/s10113-015-0820-3

Poore, J., \& Nemecek, T. (2018). Reducing food's environmental impacts through producers and consumers. science, 36o(6392), 987-992. https://doi.org/10.1126/science.aaq0216

Preston, T. (1986). Better utilization of crop residues and by-products in animal feeding: research guidelines. 2. A practical manual for research workers. Rome, Italy. http://www.fao.org/3/X6554E/X6554Eoo.htm

Priefer, C., Jörissen, J., \& Bräutigam, K.-R. (2016). Food waste prevention in Europe-A cause-driven approach to identify the most relevant leverage points for action. Resources, Conservation and Recycling, 109, 155-165. https://doi.org/10.1016/j.resconrec.2016.03.004 
Qi, Z., Shi, R., Yu, Z., Han, T., Li, C., Xu, S., . . Lin, H. (2019). Nutrient release from fish cage aquaculture and mitigation strategies in Daya Bay, southern China. Marine pollution bulletin, 146, 399-407. https://doi.org/10.1016/j.marpolbul.2019.06.079

Quiniou, N., \& Noblet, J. (2012). Effect of the dietary net energy concentration on feed intake and performance of growing-finishing pigs housed individually. Journal of Animal Science, 9o(12), 4362-4372. https://doi.org/10.2527/jas.2011-4004

Racine, R. A., \& Deckelbaum, R. J. (2007). Sources of the very-long-chain unsaturated omega-3 fatty acids: eicosapentaenoic acid and docosahexaenoic acid. Current Opinion in Clinical Nutrition \& Metabolic Care, 1O(2), 123-128. https://doi.org/10.1097/MCO.obo13e3280129652

Ravindran, V., Ravindran, G., Sivakanesan, R., \& Rajaguru, S. B. (1995). Biochemical and nutritional assessment of tubers from 16 cultivars of sweet potato (Ipomoea batatas L.). Journal of agricultural and food chemistry, 43(10), 2646-2651. https://pubs.acs.org/doi/pdf/10.1021/jfoo058a017?casa token=S7j3GoosAjwAAAAA:1qGltU9ioH2U B2uJcsko9B7g EBr6nAdZQkrOh8YKlohIQ6c8hRo4ZrU819i8 arW3Tj8sAyHHske22U

Reckmann, K., Traulsen, I., \& Krieter, J. (2012). Environmental Impact Assessment-methodology with special emphasis on European pork production. Journal of environmental management, 107, 102-109. https://doi.org/10.1016/j.jenvman.2012.04.015

Refstie, S., Olli, J. J., \& Standal, H. (2004). Feed intake, growth, and protein utilisation by post-smolt Atlantic salmon (Salmo salar) in response to graded levels of fish protein hydrolysate in the diet. Aquaculture, 239(1-4), 331-349. https://doi.org/10.1016/j.aquaculture.2004.06.015

Reicosky, D., \& Wilts, A. (2005). Crop residue management. Encyclopedia of Soils in the Environment, 1, 334338. https://doi.org/10.1016/Bo-12-348530-4/00254-X

Rindorf, A., Dichmont, C. M., Levin, P. S., Mace, P., Pascoe, S., Prellezo, R., . . Ulrich, C. (2017). Food for thought: pretty good multispecies yield. ICES Journal of Marine Science, 74(2), 475-486. https://doi.org/10.1093/icesjms/fsw071

Rijksoverheid. (2016). Rijksbreed programma Circulaire Economie. Den Haag, The Netherlands. https://www.rijksoverheid.nl/onderwerpen/circulaireeconomie/documenten/rapporten/2016/09/14/bijlage-1-nederland-circulair-in-2050

Rodrigues, B. L., da Cruz Silva, A. C. V., Canto, M. P. d. C., da Silva, F. A., Marsico, E. T., \& Conte-Junior, C. A. (2017). Fatty acid profiles of five farmed Brazilian freshwater fish species from different families. PloS one, 12(6). https://doi.org/10.1371/journal.pone.0178898

Rogosic, J., Pfister, J. A., Provenza, F. D., \& Grbesa, D. (2006). Sheep and goat preference for and nutritional value of Mediterranean maquis shrubs. Small Ruminant Research, 64(1-2), 169-179. https://doi.org/10.1016/j.smallrumres.2005.04.017

Röös, E., Bajželj, B., Smith, P., Patel, M., Little, D., \& Garnett, T. (2017a). Greedy or needy? Land use and climate impacts of food in 2050 under different livestock futures. Global Environmental Change, 47, 112. https://doi.org/10.1016/j.gloenvcha.2017.09.001

Röös, E., Bajželj, B., Smith, P., Patel, M., Little, D., \& Garnett, T. (2017b). Protein futures for Western Europe: potential land use and climate impacts in 2050. Regional Environmental Change, 17(2), 367-377. https://doi.org/10.1007/s10113-016-1013-4

Röös, E., Patel, M., Spångberg, J., Carlsson, G., \& Rydhmer, L. (2016). Limiting livestock production to pasture and by-products in a search for sustainable diets. Food policy, 58, 1-13. https://doi.org/10.1016/j.foodpol.2015.10.008 
Ruttanavut, J., Yamauchi, K., \& Thongwittaya, N. (2011). Utilization of eco-feed containing Mugwort microorganism compounds as a feed ingredient source for layer hens. American Journal of Animal and Veterinary Sciences. https://doi.org/10.3844/ajavsp.2011.35.39

Rutten, M. J., Bovenhuis, H., \& Komen, H. (2004). Modeling fillet traits based on body measurements in three Nile tilapia strains (Oreochromis niloticus L.). Aquaculture, 231(1-4), 113-122. https://doi.org/10.1016/j.aquaculture.2003.11.002

Salemdeeb, R., zu Ermgassen, E. K., Kim, M. H., Balmford, A., \& Al-Tabbaa, A. (2017). Environmental and health impacts of using food waste as animal feed: a comparative analysis of food waste management options. Journal of Cleaner Production, 140, 871-880. https://doi.org/10.1016/j.jclepro.2016.05.049

Sams, A. R. (2010). Poultry Meat Processing (2 ed.). Boca Raton, Florida: CRC Press.

Sánchez-Muros, M.-J., Barroso, F. G., \& Manzano-Agugliaro, F. (2014). Insect meal as renewable source of food for animal feeding: a review. Journal of Cleaner Production, 65, 16-27. https://doi.org/10.1016/j.jclepro.2013.11.068

SAPEA. (2017). Food from the oceans: how can more food and biomass be obtained from the oceans in a way that does not deprive future generations of their benefits?. Berlin

Saravanan, S., Geurden, I., Figueiredo-Silva, A. C., Kaushik, S., Verreth, J., \& Schrama, J. W. (2013). Voluntary Feed Intake in Rainbow Trout Is Regulated by Diet-Induced Differences in Oxygen Use. The Journal of nutrition, 143(6), 781-787. https://doi.org/10.3945/jn.112.173062

Saravanan, S., Geurden, I., Figueiredo-Silva, A. C., Kaushik, S. J., Haidar, M. N., Verreth, J. A., \& Schrama, J. W. (2012). Control of voluntary feed intake in fish: a role for dietary oxygen demand in Nile tilapia (Oreochromis niloticus) fed diets with different macronutrient profiles. British Journal of nutrition, 1O8(8), 1519-1529. https://doi.org/10.1017/Sooo7114511006842

Schader, C., Muller, A., Scialabba, N. E.-H., Hecht, J., Isensee, A., Erb, K.-H., . . Leiber, F. (2015). Impacts of feeding less food-competing feedstuffs to livestock on global food system sustainability. Journal of The Royal Society Interface, 12(113), 20150891. http://dx.doi.org/10.1098/rsif.2015.0891

Schippers, W. (2012). Ontwikkelen van kruidenrijk grasland: Aardewerk Advies.

Schneider, M., Elmer, R., \& Staheli, B. (2009). Abgestufte Bewirtschaftungsintensitat im Naturfutterbau. In AGFF (Ed.), (Vol. Merkblatt 3). Zurich, Switzerland.

SeaTemperatures. (2019). Atlantic Ocean temperature. Retrieved July 25th 2019 https://www.seatemperature.org/atlantic-ocean.

Sedgwick, S. D. (1982). The salmon handbook, the life and cultivation of fishes of the salmon family. London. Sharma, B., Vaish, B., Singh, U. K., Singh, P., \& Singh, R. P. (2019). Recycling of organic wastes in agriculture: an environmental perspective. International Journal of Environmental Research, 13(2), 409-429. https://doi.org/10.1007/s41742-019-00175-y

Shepon, A., Eshel, G., Noor, E., \& Milo, R. (2018). The opportunity cost of animal based diets exceeds all food losses. Proceedings of the National Academy of Sciences, 115(15), 3804-3809. https://doi.org/10.1073/pnas.1713820115

Simopoulos, A. P. (2009). Omega-6/omega-3 essential fatty acids: biological effects. World Rev Nutr Diet, g9(1), 1-16. https://doi.org/10.1159/000192755

Sims, J., Bergström, L., Bowman, B., \& Oenema, O. (2005). Nutrient management for intensive animal agriculture: policies and practices for sustainability. Soil Use and Management, 21(1), 141-151. https://doi.org/10.1111/j.1475-2743.2005.tbo0118.x 
Smil, V. (2014). Eating meat: Constants and changes. Global Food Security, 3(2), 67-71. https://doi.org/10.1016/j.gfs.2014.06.001

Smith, J., Sones, K., Grace, D., MacMillan, S., Tarawali, S., \& Herrero, M. (2013). Beyond milk, meat, and eggs: Role of livestock in food and nutrition security. Animal Frontiers, 3(1), 6-13. https://doi.org/10.2527/af.2013-0002

Speedy, A. W. (2003). Global production and consumption of animal source foods. The Journal of nutrition, 133(11), 4048S-4053S. doi:https://doi.org/10.1093/jn/133.11.4048S

Sprague, M., Dick, J. R., \& Tocher, D. R. (2016). Impact of sustainable feeds on omega-3 long-chain fatty acid levels in farmed Atlantic salmon, 2006-2015. Scientific reports, 6(1), 1-9. https://doi.org/10.1038/srep21892

Springmann, M., Clark, M., Mason-D’Croz, D., Wiebe, K., Bodirsky, B. L., Lassaletta, L., . . Carlson, K. M. (2018). Options for keeping the food system within environmental limits. Nature, 562(7728), 519. https://doi.org/10.1038/s41586-018-0594-0

Steffen, W., Richardson, K., Rockström, J., Cornell, S. E., Fetzer, I., Bennett, E. M., .. . de Wit, C. A. (2015). Planetary boundaries: Guiding human development on a changing planet. science, 34 (6223), 1259855. https://doi.org/10.1126/science.1259855

Steinfeld, H., Gerber, P., Wassenaar, T., Castel, V., \& de Haan, C. (2006). Livestock's long shadow: environmental issues and options. Rome: Food and Agriculture Organization of the United Nations (FAO).

SwedishFoodAgency. (2019). Swedish Food Composition Database. Retrieved August 27th 2019. http://www7.slv.se/SokNaringsinnehall/

Tacon, A. G. (1997). Review of the State of World Aquaculture: Aquafeeds and feeding strategies. Food and Agriculture Organisation of the United Nations (FAO), Rome, Italy. http://www.fao.org/3/W7499E/w7499e16.htm

Tacon, A. G., \& Metian, M. (2008). Global overview on the use of fish meal and fish oil in industrially compounded aquafeeds: Trends and future prospects. Aquaculture, 285(1-4), 146-158. https://doi.org/10.1016/j.aquaculture.2008.08.015

Tacon, A. G., \& Metian, M. (2015). Feed matters: satisfying the feed demand of aquaculture. Reviews in Fisheries Science \& Aquaculture, 23(1), 1-10. https://doi.org/10.1080/23308249.2014.987209

Tacon, A. G. J. (2012). The role of rendered products in aquaculture feeds (0928-124X). https://www.allaboutfeed.net/Process-Management/Aquafeed/2012/4/The-role-of-renderedproducts-in-aquaculture-feeds-AAF013134W/

Tallowin, J., \& Jefferson, R. (1999). Hay production from lowland semi-natural grasslands: a review of implications for ruminant livestock systems. Grass and forage science: the journal of the British Grassland Society. https://doi.org/10.1046/j.1365-2494.1999.00171.x

Tamminga, S., Brandsma, G. G., van Duinkerken, G., van Vuuren, A. M., \& Blok, M. C. (2007). Protein valuation by ruminants; the new gut digestible proein system (in Dutch: Eiwitwaardering voor herkauwers; het DVE-OEB 2007 systeem. Wageningen Livestock Research, Wageningen, The Netherlands. https://edepot.wur.nl/336207

Tauger, M. B. (2013). Agriculture in world history: Routledge.

Teller, C., Holweg, C., Reiner, G., \& Kotzab, H. (2018). Retail store operations and food waste. Journal of Cleaner Production, 185, 981-997. https://doi.org/10.1016/j.jclepro.2018.02.280 
Thorpe, R. B., Jennings, S., \& Dolder, P. J. (2017). Risks and benefits of catching pretty good yield in multispecies mixed fisheries. ICES Journal of Marine Science, 74(8), 2097-2106. https://doi.org/10.1093/icesjms/fsxo62

TIL-AQUA. (2016). Tilapia hatchery management system. TilAqua, The Netherlands: https://www.tilaqua.com/app/uploads/2019/02/Til-Aquas-Hatchery-Nursery-Concept.pdf

Tilman, D., Balzer, C., Hill, J., \& Befort, B. L. (2011). Global food demand and the sustainable intensification of agriculture. Proceedings of the National Academy of Sciences, 108(50), 20260-20264. https://doi.org/10.1073/pnas.1116437108

Tocher, D. R. (2015). Omega-3 long-chain polyunsaturated fatty acids and aquaculture in perspective. Aquaculture, 449, 94-107. https://doi.org/10.1016/j.aquaculture.2015.01.010

Tran-Ngoc, K. T., Haidar, M. N., Roem, A. J., Sendão, J., Verreth, J. A., \& Schrama, J. W. (2016). Effects of feed ingredients on nutrient digestibility, nitrogen/energy balance and morphology changes in the intestine of Nile tilapia (Oreochromis niloticus). Aquaculture Research. https://doi.org/10.1111/are.14214

Truong, L., Morash, D., Liu, Y., \& King, A. (2019). Food waste in animal feed with a focus on use for broilers. International Journal of Recycling of Organic Waste in Agriculture, 1-13. https://doi.org/10.1007/s40093-019-0276-4

UKFFPA. (2019). Former foods to animal feed - the facts. UKFFPA, AIC. Peterborough, England.

UnitedNations. (2015). World population prospects: The 2015 revision. United Nations Econ Soc Aff, 33(2), 1-66.

USDA. (2012). USDA Table of Cooking Yields for Meat and Poultry. USDA, Beltsville, Maryland, USA. https://data.nal.usda.gov/dataset/usda-table-cooking-yields-meat-and-poultry/resource/9961ab5ae8a4-4676-88de-1919eec438ed\#\{\}

USDA. (2018a). USDA Food Composition Databases 3.8.5. United States Department of Agriculture (USDA), Wachington D.C., USA. $\quad$ Retrieved June 2017. https://ndb.nal.usda.gov/ndb/foods/show/05009?n1=\%7BQv\%3D1\%7D\&fgcd=\&man=\&lfacet=\&coun

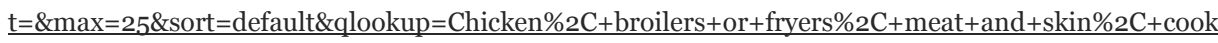
ed\&offset $=\&$ format $=$ Full \&new $=\& m e a s u r e b y=\& Q v=1 \& d s=\& \mathrm{qt}=\& \mathrm{qp}=\& \mathrm{qa}=\& \mathrm{qn}=\& \mathrm{q}=\&$ ing $=$

USDA. (2018b). USDA BY-PRODUCT DROP VALUE (STEER) FOB CENTRAL U.S. Des Moines, Ioha, USA. USDA. (2018c). WEEKLY USDA BY-PRODUCT DROP VALUE (HOG). Des Moines, Ioha, USA.

USDA. (2019). FoodData Central. United States Department of Agriculture (USDA), Wachington D.C., USA. Retrieved December 2019. https://fdc.nal.usda.gov/index.html

van Bruggen, C., Bannink, A., Groenestein, C. M., De Haan, B., Huijsmans, J. F. M., Luesink, H., . . Vonk, J. (2014). Emissies naar lucht uit de landbouw in 2012: berekeningen van ammoniak, stikstofoxide, lachgas, methaan en fijn stof met het model NEMA (2352-2747). Wageningen Economic Research, Wageningen, The Netherlands. https://www.wur.nl/nl/Publicatiedetails.htm?publicationId=publication-way-34.35.32393134

van den Bos Verma, M., de Vreede, L., Achterbosch, T., \& Rutten, M. M. (2020). Consumers discard a lot more food than widely believed: Estimates of global food waste using an energy gap approach and affluence elasticity of food waste. PloS one, 15(2), e0228369. https://doi.org/10.1371/journal.pone.0228369 
van den Pol- van Dasselaar, A., Corré, W. J., Hopster, H., Van Laarhoven, G. C. P. M., \& Rougoor, C. W. (2002). Belang van weidegang (the value of grazing). Wageningen Livestock Research, Wageningen, the Netherlands. https://edepot.wur.nl/34279

van der Werf, H. M., Petit, J., \& Sanders, J. (2005). The environmental impacts of the production of concentrated feed: the case of pig feed in Bretagne. Agricultural systems, 83(2), 153-177. https://doi.org/10.1016/j.agsy.2004.03.005

van Hal, O., de Boer, I. J. M., Muller, A., de Vries, S., Erb, K.-H., Schader, C., Gerrits, W.W.J. \& van Zanten, H. H. E. (2019). Upcycling food leftovers and grass resources through livestock: Impact of livestock system and productivity. Journal of Cleaner Production, 219, 485-496. https://doi.org/10.1016/j.jclepro.2019.01.329

van Hal, O., De Boer, I. J. M., Ziegler, F., Schrama, J. W., Kuipers, K., \& van Zanten, H.H.E. (2020). The role of fisheries and farmed fish in a circular food system. Fish and Fisheries. (submitted)

van Hal, O., Weijenberg, A. A. A., de Boer, I. J. M., \& van Zanten, H. H. E. (2019b). Accounting for feed-food competition in environmental impact assessment: Towards a resource efficient food-system. Journal of Cleaner Production, 24O, 118241. https://doi.org/10.1016/j.jclepro.2019.118241

van Kernebeek, H., Oosting, S., van Ittersum, M., Ripoll-Bosch, R., \& de Boer, I. (2018). Closing the phosphorus cycle in a food system: insights from a modelling exercise. Animal, 12(8), 1755-1765. https://doi.org/10.1017/S1751731118001039

van Kernebeek, H. R. J., Oosting, S. J., Feskens, E. J. M., Gerber, P. J., \& de Boer, I. J. M. (2014). The effect of nutritional quality on comparing environmental impacts of human diets. Journal of Cleaner Production, 73, 88-99. https://doi.org/10.1016/j.jclepro.2013.11.028

van Kernebeek, H. R. J., Oosting, S. J., Van Ittersum, M. K., Bikker, P., \& de Boer, I. J. M. (2016). Saving land to feed a growing population: consequences for consumption of crop and livestock products. International Journal of Life Cycle Assesment, 21(5), 677-687. https://doi.org/10.1007/s11367-0150923-6

van Milgen, J., Valancogne, A., Dubois, S., Dourmad, J.-Y., Sève, B., \& Noblet, J. (2008). InraPorc: a model and decision support tool for the nutrition of growing pigs. Animal Feed Science and Technology, 143(1), 387-405. https://doi.org/10.1016/j.anifeedsci.2007.05.020

van Vliet, J., Heeres- van de Tol, J. J., \& Blok, M. C. (1994). Herziening van de energie en eiwitnorment voor vleesvee (11). Wageningen Livestock Research, Lelystad, The Netherlands. https://edepot.wur.nl/346919

van Woensel Kooy, P. (2020). Kipster-kippen voortaan gevoerd met broodresten van Lidl. MarketingTribune. van Zanten, H. H. E. (2016). Feed Sources for Livestock: Recycling Towards a Green Planet. (Doctorate). Wageningen University, Wageningen, The Netherlands. http://edepot.wur.nl/380267

van Zanten, H. H. E., Bikker, P., Mollenhorst, H., Meerburg, B. G., \& de Boer, I. J. M. (2015a). Environmental impact of replacing soybean meal with rapeseed meal in diets of finishing pigs. Animal, $9(11), 1866-1874$. https://doi.org/10.1017/S1751731115001469

van Zanten, H. H. E., Herrero, M., van Hal, O., Röös, E., Muller, A., Garnett, T., . . de Boer, I. J. M. (2018). Defining a land boundary for sustainable livestock consumption. Global Change Biology, 24(9), 41854194. https://doi.org/10.1111/gcb.14321

van Zanten, H. H. E., Meerburg, B. G., Bikker, P., Herrero, M., \& de Boer, I. J. M. (2016a). Opinion paper: The role of livestock in a sustainable diet: a land-use perspective. Animal, 10, 547-549. https://doi.org/10.1017/S1751731115002694 
van Zanten, H. H. E., Mollenhorst, H., Klootwijk, C. W., van Middelaar, C. E., \& de Boer, I. J. M. (2016b). Global food supply: land use efficiency of livestock systems. The International Journal of Life Cycle Assessment, 21(5), 747-758. https://doi.org/10.1007/s11367-015-0944-1

van Zanten, H. H. E., Mollenhorst, H., Oonincx, D. G. A. B., Bikker, P., Meerburg, B. G., \& de Boer, I. J. M. (2015b). From environmental nuisance to environmental opportunity: housefly larvae convert waste to livestock feed. Journal of Cleaner Production, 102: 362-369. https://doi.org/10.1016/j.jclepro.2015.04.106

van Zanten, H. H. E., van Ittersum, M. K., \& de Boer, I. J. M. (2019). The role of farm animals in a circular food system. Global Food Security, 21, 18-22. https://doi.org/10.1016/j.gfs.2019.06.003

Veldkamp, T., van Duinkerken, G., van Huis, A., Lakemond, C., Ottevanger, E., Bosch, G., \& van Boekel, T. (2012). Insects as a Sustainable Feed Ingredient in Pig and Poultry Diets: a Feasibility Study (Dutch: Insecten als duurzame diervoedergrondstof in varkens-en pluimveevoeders: een haalbaarheidsstudie) (638). Wageningen University, Wageningen, The Netherlands. https://www.wur.nl/upload mm/2/8/o/f26765b9-98b2-49a7-ae43-5251c5b694f6_234247\%5B1\%5D

Vellinga, T. V., Blonk, H., Marinussen, M., Van Zeist, W., \& Starmans, D. (2013). Methodology used in feedprint: a tool quantifying greenhouse gas emissions of feed production and utilization (674). Wageningen Livestock Research, Wageningen, The Netherlands. https://edepot.wur.nl/254098

Vermeij, I. (2017). KWIN Kwantitatieve Informatie Veehouderij 2016-2017. Wageningen Livestock Research, Wageningen, The Netherlands.

Vermeulen, S. J., Campbell, B. M., \& Ingram, J. S. (2012). Climate change and food systems. Annual review of environment and resources, 37, 195-222. https://doi.org/10.1146/annurev-environ-020411-130608

Vernier, A., Redlingshoefer, B., Debarge, S., Galio, P., Martin, S., Colomb, V., . . Gaborel, H. (2016). Pertes et gaspillages alimentaires : l'état des lieux et leur gestion par étapes de la chaîne alimentaire

Vidal, L., Xavier, T., de Moura, L., Graciano, T., Martins, E., \& Furuya, W. (2017a). Apparent digestibility of soybean coproducts in extruded diets for Nile Tilapia, Oreochromis niloticus. Aquaculture Nutrition, 23(2), 228-235. https://doi.org/10.1111/anu.12383

Vidal, L. V. O., Xavier, T. O., Michelato, M., Martins, E. N., Pezzato, L. E., \& Furuya, W. M. (2015). Apparent Protein and Energy Digestibility and Amino Acid Availability of Corn and Co-products in Extruded Diets for Nile Tilapia, Oreochromis niloticus. Journal of the World Aquaculture Society, 46(2), 183-190. https://doi.org/10.1111/jwas.12184

Vidal, L. V. O., Xavier, T. O., Moura, L. B. d., Michelato, M., Martins, E. N., \& Furuya, W. M. (2017b). Apparent digestibility of wheat and coproducts in extruded diets for the Nile tilapia, Oreochromis niloticus. Revista Brasileira de Saúde e Produção Animal, 18(3), 479-491. https://doi.org/10.1590/s151999402017000300008

VIDO. (2019). Former foodstuffs processed in the Netherlands 2018.

Vigani, M., Parisi, C., Rodríguez-Cerezo, E., Barbosa, M. J., Sijtsma, L., Ploeg, M., \& Enzing, C. (2015). Food and feed products from micro-algae: Market opportunities and challenges for the EU. Trends in Food Science \& Technology, 42(1), 81-92. https://doi.org/10.1016/j.tifs.2014.12.004

Vicente-Serrano, S. M., Lasanta, T., \& Romo, A. (2004). Analysis of spatial and temporal evolution of vegetation cover in the Spanish Central Pyrenees: role of human management. Environmental management, 34(6), 802-818. https://doi.org/10.1007/s00267-003-0022-5

Vivien, F.-D., Nieddu, M., Befort, N., Debref, R., \& Giampietro, M. (2019). The hijacking of the bioeconomy. Ecological Economics, 159, 189-197. https://doi.org/10.1016/j.ecolecon.2019.01.027 
Vranken, L., Avermaete, T., Petalios, D., \& Mathijs, E. (2014). Curbing global meat consumption: Emerging evidence of a second nutrition transition. environmental science \& policy, 39, 95-106. https://doi.org/10.1016/j.envsci.2014.02.009

Warde, P. (2009). The environmental history of pre-industrial agriculture in Europe. In Nature's End (pp. 7092): Springer.

Webb, L., Bokkers, E., Heutinck, L., Engel, B., Buist, W., Rodenburg, T., .. . Van Reenen, C. (2013). Effects of roughage source, amount, and particle size on behavior and gastrointestinal health of veal calves. Journal of Dairy Science, 96(12), 7765-7776. https://doi.org/10.3168/jds.2012-6135

Weihe, R., Dessen, J. E., Arge, R., Thomassen, M. S., Hatlen, B., \& Rørvik, K. A. (2018). Improving production efficiency of farmed Atlantic salmon (Salmo salar L.) by isoenergetic diets with increased dietary proteinto-lipid ratio. Aquaculture Research, 49(4), 1441-1453. https://doi.org/10.1111/are.13598

West, P. C., Gerber, J. S., Engstrom, P. M., Mueller, N. D., Brauman, K. A., Carlson, K. M., . . Ray, D. K. (2014). Leverage points for improving global food security and the environment. science, 345(6194), 325-328. https://doi.org/10.1126/science.1246067

White, S. (2011). From globalized pig breeds to capitalist pigs: a study in animal cultures and evolutionary history. Environmental History, 16(1), 94-120. https://doi.org/10.1093/envhis/emq143

Williams, A., Audsley, E., \& Sandars, D. (2006). Determining the environmental burdens and resource use in the production of agricultural and horticultural commodities: Defra project report. Cranfield, UK.

Wilkinson, J., \& Lee, M. (2018). Use of human-edible animal feeds by ruminant livestock. Animal, 12(8), 17351743. https://doi.org/10.1017/S175173111700218X

Willett, W., Rockström, J., Loken, B., Springmann, M., Lang, T., Vermeulen, S., . . Wood, A. (2019). Food in the Anthropocene: the EAT-Lancet Commission on healthy diets from sustainable food systems. The Lancet, 393(10170), 447-492. https://doi.org/10.1016/So140-6736(18)31788-4

WRAP. (2016). Household food waste collections guide. Banbury, UK. https://wrap.org.uk/content/household-food-waste-collections-guide

Woods, A. (2012). Rethinking the history of modern agriculture: British pig production, c. 1910-65. Twentieth Century British History, 23(2), 165-191. https://doi.org/10.1093/tcbh/hwro10

Zanders, R., \& Claessens, S. (2018) Kipsters first year performance/Interviewer: A. Weijenberg. Kipster, Oirlo.

Zehetmeier, M., Gandorfer, M., Hoffmann, H., Müller, U., de Boer, I. J., \& Heißenhuber, A. (2014). The impact of uncertainties on predicted greenhouse gas emissions of dairy cow production systems. Journal of Cleaner Production, 73, 116-124. https://doi.org/10.1016/j.jclepro.2013.09.054

Zijlstra, R., \& Beltranena, E. (2013). Swine convert co-products from food and biofuel industries into animal protein for food. Animal Frontiers, 3(2), 48-53. https://doi.org/10.2527/af.2013-0014

Zhang, Y. (2011). Optimal use of plant protein concentrates in extruded feeds for carnivorous fish. (PhD). Norwegian University of Life Sciences, As, Norway. (2011:53)

Zhou, S., Kolding, J., Garcia, S. M., Plank, M. J., Bundy, A., Charles, A., . . van Zwieten, P. A. M. (2019). Balanced harvest: concept, policies, evidence, and management implications. Reviews in Fish Biology and Fisheries, 29(3), 711-733. https://doi.org/10.1007/s11160-019-09568-w

zu Ermgassen, E. K., Phalan, B., Green, R. E., \& Balmford, A. (2016). Reducing the land use of EU pork production: where there's swill, there'sa way. Food policy, 58, 35-48. https://doi.org/10.1016/j.foodpol.2015.11.001 


\section{Summary}

The food system faces the challenge of feeding a growing world population while limiting environmental impacts and resource use. The European Union (EU) aims to address this challenge by shifting to a more circular food system, as increasingly proposed by scientists. A central principle of a circular food system is to prioritise the use of resources for direct food supply to avoid feedfood competition. This implies arable land should be used to cultivate food crops, and the edible yield of sustainably caught fish should be used for direct human consumption. This food production and consumption, however, results in food leftovers that are unsuitable or undesired for human consumption, such as food processing by-products and food waste. Farm animals can contribute to a circular food system by upcycling these food leftovers and grass resources (so-called such lowopportunity-cost feeds; LCF) into valuable animal-source food (ASF) that contains essential nutrients for humans. A diet containing a small amount of ASF from animals fed only LCF appears most resource efficient, because if everyone would become vegan these LCF are no longer upcycled in the food system. Previous studies show that animals fed only LCF can provide 7-30 g human digestible protein (HDP) per capita per day. While these studies illustrate that farm animals can have a role in a circular food system, they give limited insight in how different animals can contribute to the efficient use of LCF. This thesis, therefore, aims to evaluate the potential of various farmed animals in upcycling LCF in a circular food system, using the EU-28 as a case study.

In Chapter 2 we explored what combination of livestock systems (pigs, laying hens, broilers, dairy cattle and beef cattle), differing in productivity level (low, mid and high), optimally convert the LCF available in the EU-28 into HDP. To this aim, we developed an optimisation model that allocates available plant-based LCF to that combination of animals that maximises HDP supply. We found that optimal conversion requires a variety of both livestock systems and productivity levels. Dominant livestock systems were those that have a high conversion efficiency (laying hens, dairy cattle), were best able to valorise specific LCF (dairy cattle for grass; pigs for food waste), and could valorise low quality LCF because of their low productivity. We conclude that under the assumed availability of LCF, livestock could supply $31 \mathrm{~g}$ HDP per EU capita per day, but that this result was sensitive to assumptions regarding the availability and quality of LCF, especially grass.

While Chapter 2 focussed on livestock, aquatic animals also can make a valuable contribution to food supply. Fish are, for example, currently our only natural source of the essential eicosapentaenoic (EPA) and docosahexaenoic (DHA) $\omega$-3 fatty acids. In Chapter 3 we explored the contribution of capture fisheries and fish farming (salmon and tilapia), to a circular food system 
in an EU-28 case study. Similar to Chapter 2, we maximised HDP supply but in addition demanded that human requirements of nutrients currently only obtained from ASF are met (i.e. vitamin B12 and EPA/DHA). We demonstrated that, under the circular paradigm, fish provide nutritious food via both capture fisheries and fish farming. Capture fisheries should increase their food supply by rebuilding fish stocks and prioritising edible fish for human consumption. Sustainable fisheries, however, can fulfil only about $40 \%$ of the EPA/DHA requirement and, therefore, additional farmed fatty fish, such as salmon, are needed. These fatty fish, however, depend on fisheries by-products to meet their EPA/DHA requirements and on livestock slaughter by-products to meet their high requirements of other nutrients, such as energy and protein. Optimal use of LCF requires a combination of livestock and farmed fish and - given the assumed availability of LCF -can supply 35 g HDP per capita per day. A circular food system, therefore, requires a combination of codependent animal production systems (e.g. fish farming requires capture fisheries and livestock byproducts) to achieve balanced healthy diets with respect for our planet.

While Chapters 2 and 3 illustrate how different animals can contribute to a circular food system, literature shows large variations in the estimated amount of ASF that can be produced when feeding only LCF. To a large extent, this variations is caused by differences in the assumed availability and quality of LCF. The availability of food leftovers as LCF is currently restricted by legislation and other barriers. To address the ongoing debate on what products can be considered LCF, we explored the potential of food leftovers currently not used as LCF due to legislation and other barriers (Chapter 4). To this aim, we compared the optimal use of currently used LCF with various scenarios that add food leftovers currently banned or not fully recovered as feed. Our results showed that of the considered food leftovers, household waste and livestock by-products had most potential to increase animal protein supply. Optimal use of currently used LCF (given their assumed availability) provides an intake of $27 \mathrm{~g}$ HDP per capita per day. Reintroducing household swill can increase this intake with $12 \%$, while using livestock by-products in fish feeds increased protein intake with $18 \%$, and is essential to meet human requirements of EPA/DHA $\omega-3$ fatty acids. Feeding swill, however, requires legislative change while feed quality and safety remain difficult to safeguard even with the development of a collection and processing system. In contrast, livestock by-products are allowed in fish feed, but not used currently, indicating other barriers to the transition towards a circular food system. We concluded that improved use and legalisation of inevitable food leftovers can improve the resource use efficiency of both current and future circular food systems.

While the food systems approach, used in Chapters 2-4, provides valuable insights into the role of different animals in a circular food system, it provides little direction to farmers in achieving 
sustainability and circularity objectives. At present, food system actors base their sustainability strategies on farm or product-level life cycle assessments (LCA), which do not consider interlinkages in the food system. To divide the environmental impact between multiple outputs (e.g. flour and middlings) of a process (e.g. wheat milling), an LCA commonly uses economic allocation. As economic allocation does not consider whether the outputs are suitable for human consumption, it does not account for feed-food competition. In Chapter 5, we proposed that a "food-based" allocation - assigning no environmental impact to feed products unfit for human consumption may better account for food-feed competition. To evaluate the impact of accounting for feed-food competition on LCA results, economic and food-based allocation were compared in an LCA of a novel egg production system that feeds only products unsuitable or undesired for human consumption. Using economic allocation, the global warming potential (GWP) of $1.13 \mathrm{~kg} \mathrm{CO}_{2}$-eq, energy use of $11.86 \mathrm{MJ}$, land use (LU) of $2.99 \mathrm{~m}^{2}$, and land use ratio (LUR) of 1.70 per $\mathrm{kg}$ egg of the case study farm, were all lower than that of free range or organic eggs. Avoiding feed-food competition on this farm halved GHG emission, and reduced energy use, LU and the LUR with about one third compared to free range laying hens fed a conventional diet. With our food-based allocation methods impacts per kg egg further reduced with $57 \%$ for GWP to $0.49 \mathrm{~kg} \mathrm{CO}_{2}$-eq, $40 \%$ for energy use to $7.19 \mathrm{MJ}, 96 \%$ for LU to $0.11 \mathrm{~m}^{2}$, and $88 \%$ for LUR to 0.30 . This illustrates that our improved LCA better captures the complexity of the food system.

To conclude (Chapter 6), optimal use of LCF requires a combination of livestock and farmed fish. Animals in a circular food system should be tailored to available LCF and the nutrients we wish them to supply, and the unique role of each animal depends on its feeding characteristics and the nutrients in the ASF it provides. In the simulated circular food system, where all LCF were allowed, livestock and fish provide an HDP intake up to $39 \mathrm{~g}$ per capita per day, and fulfil the full requirements of EPA/DHA and vitamin B12. While this HDP intake is significantly lower than the current supply of animal protein (61 g per capita per day), it fulfils up to $65 \%$ of total protein requirements. A circular food system, thus, requires a reduction in ASF consumption, and a change in the type of ASF we consume, where fish and milk become more prominent. Besides the discussed changes in farming systems and consumption patterns, the paradigm shift needed for the transition towards a circular food system requires that industries redesign their production systems and policy makers value social and economic aspects within the ecological boundaries of our planet. This way, farm animals can contribute to the resource use efficiency of the entire food system. 


\section{Samenvatting}

In de toekomst moet ons voedselsysteem meer mensen voeden terwijl milieu-impact en gebruik van schaarse grondstoffen moeten worden beperkt. De Europese Unie (EU) wil daarom een meer circulair voedselsysteem, zoals in toenemende mate voorgesteld door wetenschappers. Een kernprincipe van een circulair voedselsysteem is dat agrarische grondstoffen, waar mogelijk, gebruikt worden voor directe voedselvoorziening om zogenaamde voer-voedselcompetitie te vermijden. Akkerland wordt dan gebruikt voor teelt van voedselgewassen en ook eetbare, duurzaam gevangen vis wordt gebruikt voor menselijke consumptie. Deze voedselproductie en -consumptie resulteren echter in voedselresten (d.w.z. bijproducten en afval) die mensen niet kunnen of willen eten. Productiedieren kunnen bijdragen aan een circulair voedselsysteem door deze voedselresten en gras (zogenaamde low-opportunity-cost feeds; LCF) om te zetten in dierlijk voedsel dat essentiële nutriënten voor mensen bevat. Een dieet met een klein aandeel dierlijk product, geproduceerd met enkel LCF, lijkt grondstoffen het meest efficiënt te gebruiken. Indien iedereen veganistisch wordt, worden LCF namelijk niet langer gewaardeerd in het voedselsystem. Voorgaande studies laten zien dat dieren enkel gevoerd met LCF 7-30 g humaan verteerbaar eiwit (HVE) per capita per dag kunnen leveren. Hoewel deze studies illustreren dat productiedieren wel degelijk een rol spelen in een circulair voedselsysteem, geven ze beperkt inzicht in de bijdrage van verschillende dieren in het efficiënt gebruik van LCF. Het doel van dit proefschrift is daarom om de potentie van verschillende productiedieren in het verwaarden van LCF in een circulair voedsel systeem te evalueren in een EU-28 casestudy.

In hoofdstuk 2 verkenden we welke combinatie van veehouderijsystemen (varkens, leghennen, vleeskuikens, melkkoeien en vleeskoeien), verschillend in productieniveau (laag, midden, hoog), beschikbare LCF optimaal omzetten in HVE. Daarvoor hebben we een optimalisatiemodel ontwikkeld dat beschikbare plantaardige LCF toewijst aan de combinatie van dieren die het meeste HVE levert. We demonstreerden dat de optimale omzetting van plantaardige LCF een combinatie van veehouderijsystemen en productiviteitniveaus behoeft. Prominente veehouderijsystemen hebben een hoge voerefficiëntie (leghennen en melkkoeien), zijn in staat specifieke LCF te verwaarden (gras door melkkoeien, voedselafval door varkens) en kunnen laagwaardige LCF verwaarden door hun lage productiviteit. We concludeerden dat, onder de aangenomen beschikbaarheid van LCF, vee $31 \mathrm{~g}$ HVE per capita per dag kan leveren. Dit resultaat is echter gevoelig voor aannames betreffende de beschikbaarheid en kwaliteit van LCF, in het speciaal gras. 
Hoewel we ons in Hoofdstuk 2 richtten op vee, kunnen ook waterdieren een waardevolle bijdrage leveren aan voedselvoorziening. Vis is, bijvoorbeeld, momenteel onze enige natuurlijke bron van de essentiële $\omega$-3-vetzuren eicosapentaeen (EPA) en docosahexaeen (DHA). In hoofdstuk 3 verkenden we daarom de bijdrage van visserij en kweekvis (zalm en tilapia) aan een circulair voedselsysteem. Net als in hoofdstuk 2 maximaliseerden we HVE, maar vereisten daarbij dat de behoefte aan nutriënten die mensen momenteel enkel uit dierlijk product opnemen (d.w.z. vitamine B12 en EPA/DHA) moet worden vervuld. We demonstreerden dat in een circulair voedselsysteem zowel visserij als viskweek voedzame vis leveren voor menselijke consumptie. Visserij dient de voedselopbrengst te verhogen door het visbestand te herstellen en menselijke consumptie van eetbare vis te prioriteren. Duurzame visserij kan echter maar aan $40 \%$ van de EPA/DHA-behoefte voldoen waardoor aanvullende kweek van vette vis nodig is. Deze vette vis is echter afhankelijk van visserij bijproducten om te voldoen aan hun eigen EPA/DHA-behoefte en veehouderij bijproducten voor hun hoge behoefte aan vet en eiwit. Optimaal gebruik van LCF behoeft een combinatie van vee en kweekvis die - gegeven de aangenomen beschikbaarheid van LCF - 35 g HVE per capita per dag kan leveren. Een circulair voedselsysteem behoeft daarom een combinatie van, van elkaar afhankelijke, dierlijke productiesystemen (b.v. kweekvis is afhankelijk van visserij en veehouderij) om te komen tot evenwichtige gezonde diëten met respect voor onze planeet.

Terwijl hoofdstukken 2 en 3 demonstreerden hoe verschillende dieren kunnen bijdragen aan een circulair voedselsysteem, variëren schattingen van de hoeveelheid HVE dieren enkel gevoerd met LCF kunnen produceren sterk in de literatuur. Veel van deze variatie is veroorzaakt door verschillen in de aangenomen beschikbaarheid en kwaliteit van LCF. Momenteel wordt de beschikbaarheid van voedselresten als LCF beperkt door wetgeving en andere barrières. In het licht van het aanhoudende debat over de geschiktheid van voedselresten als LCF, verkenden we in hoofdstuk 4 het potentieel van voedselresten die momenteel niet als LCF gebruikt worden. We vergeleken daartoe het optimale gebruik van momenteel gebruikte LCF met scenario's die voedselresten toevoegen die momenteel verboden of niet (volledig) herwonnen worden als LCF. Van de overwogen voedselresten hebben huishoudelijk voedselafval en dierlijke bijproducten de meeste potentie om de toevoer van dierlijk voedsel te verhogen. Optimaal gebruik van momenteel gebruikte LCF (gegeven hun aangenomen beschikbaarheid) levert een inname van $27 \mathrm{~g}$ HVE per capita per dag. Herintroductie van huishoudelijk voedselafval kan deze inname met $12 \%$ verhogen, terwijl het gebruik van bijproducten van veehouderij in visvoer HVE inname met $18 \%$ verhoogde en essentieel is om de menselijke behoefte aan EPA/DHA te voldoen. Het voeren van huishoudelijk 
voedselafval behoeft echter wetswijziging terwijl voerkwaliteit en veiligheid moeilijk te waarborgen zijn, zelfs met de ontwikkeling van een verzamel- en verwekingsinfrastructuur. Bijproducten van veehouderij zijn daarentegen al toegestaan in visvoer, maar worden momenteel niet gebruikt; een indicatie van andere beperkingen in de transitie naar een circulair voedsel systeem. We concludeerden dat verbeterd gebruik en legalisering van onvermijdbaar voedselafval als LCF, zowel in ons huidige als in een circulair voedselsysteem, de efficiëntie waarmee grondstoffen worden gebruik kan verbeteren.

Hoewel de voedselsysteembenadering, gebruikt in hoofdstukken $2-4$, waardevolle inzichten biedt over de rol van verschillende dieren in een circulair voedselsysteem, geeft het boeren weinig richting in het behalen van hun duurzaamheids- en circulariteitsdoelstellingen. Momenteel baseren actoren in het voedselsysteem hun duurzaamheidsstrategieën op levenscyclusanalyses (LCA's) op voedselketenniveau. Deze LCA's houden geen rekening met onderlinge verbanden tussen de verschillende ketens waaruit het voedselsysteem is opgebouwd door gebruik te maken van economische allocatie. Economische allocatie verdeelt de milieu-impact van processen die resulteren in verschillende producten (bijvoorbeeld: het malen van tarwe resulteert in meel en zemelen) namelijk op basis van hun relatieve economische waarde. Deze allocatie houdt geen rekening met de geschiktheid van producten voor humane consumptie en negeert daarmee voervoedselcompetitie. In hoofdstuk 5 stelden we voor dat voer-voedselcompetitie beter wordt gevangen door een "voedselallocatie", waarbij geen milieu-impact wordt toegekend aan voer ongeschikt voor humane consumptie. Om het effect van rekening houden met voervoedselcompetitie in LCA te evalueren, hebben we economische- en voedselallocatie vergeleken in een LCA van een nieuw eierproductiesysteem dat enkel LCF voert. Onder economische allocatie was het aardopwarmingsvermogen (GWP) van $1.13 \mathrm{~kg} \mathrm{CO}$-eq, energieverbruik van $11.86 \mathrm{MJ}$, landgebruik (LU) van $2.99 \mathrm{~m}^{2}$, en landgebruikratio (LUR) van 1.70 per kg ei van de casestudy, allemaal lager dan dat van vrije uitloop en biologische eieren. Het vermijden van voervoedselcompetitie op deze boerderij halveerde broeikasgasemissies en verminderde energie en landgebruik met een derde in vergelijking met vrijeuitloophennen gevoerd met een conventioneel dieet. Met onze voerallocatie verminderde de impact per ei verder met $57 \%$ voor GWP tot $0.49 \mathrm{~kg}$ $\mathrm{CO}_{2}$-eq, $40 \%$ voor energie gebruik tot 7.19 MJ, 96\% voor $\mathrm{LU}$ tot $0.11 \mathrm{~m}^{2}$, en $88 \%$ voor LUR tot 0.30. Dit illustreert dat onze verbeterde LCA de complexiteit van het voedselsysteem beter vangt.

In conclusie (hoofdstuk 6): optimaal gebruik van LCF behoeft een combinatie van vee- en kweekvissystemen. De dieren in een circulair voedselsysteem moeten worden afgestemd op de beschikbare LCF en gewenste nutriëntvoorziening; en de unieke rol van elk dier is afhankelijk van 
de voergewoonte en nutriënten die ze leveren. In het gesimuleerde circulaire voedselsysteem, waar alle LCF zijn toegestaan, leveren vee en vis samen $39 \mathrm{~g}$ HVE per capita per dag en vervullen ze de behoefte aan EPA/DHA en vitamine B12. Hoewel deze HVE inname significant lager is dan de huidige toevoer aan dierlijk eiwit (61 g per capita per dag) vervult het $65 \%$ van de totale eiwitbehoefte. Een circulair voedselsysteem behoeft niet enkel een afname in de consumptie van dierlijkvoedsel, maar ook verandering in welke dierlijk voedsel we eten, waarbij vis en melk prominenter worden. Naast de bediscussieerde veranderingen in boerderijsystemen en consumptiepatronen, behoeft de paradigmaverschuiving voor een circulair voedselsysteem herinrichting van de verwerkingsindustrie en dat beleidsmakers sociale en economische aspecten waarderen binnen de ecologische grenzen van onze planeet. Op deze manier kunnen dieren bijdragen aan de efficiëntie waarmee grondstoffen worden gebruikt in het voedselsysteem. 


\section{Acknowledgements / Dankwoord}

Bij het maken van dit proefschrift heb ik onnoemelijk veel baat gehad van de inhoudelijke bijdrage, inspiratie, relativering en steun van anderen waarvoor ik graag mijn dank wil uitspreken.

In de kern is dit proefschrift een product van een klein team van drie koppige vrouwen. Ik wil daarom allereerst mijn begeleiders, Imke en Hannah, bedanken voor hun inspiratie, stimulatie en vertrouwen. Hannah, het is inspirerend hoe je bij je waarden blijft in je streven om zowel voedselproductie als de wetenschap te verbeteren. Je creativiteit en overzicht zijn van onschatbare waarde geweest in de studieopzet en de duidelijke bewoording in deze thesis. Bedankt voor de mogelijkheden die je hebt geboden om te doen waar ik goed in ben en blij van wordt en de hulp bij het overzien van mijn project. Imke, jouw betrokkenheid en empathie zijn de basis voor de productieve werkomgeving waarvan ik heb mogen genieten. Bedankt voor je visie, eindeloze vertrouwen en uitingen hiervan, uitvoerige feedback en je inzet om elk inhoudelijke, fysieke of emotionele uitdaging te verlichten. Beiden bedankt voor de fijne, leerzame jaren.

Besides my supervisors also my co-authors contributed significantly to the quality of my research. I feel honoured to be part of this new but flourishing field or research where passionate scientists are open for any form of collaboration that may lead to a better world. Adrian Müller and Christian Schader, thank you for all your help in setting up the initial model, central to this thesis. Our collaboration provided a solid base for my research and you made it a fun and exciting journey. Walter Gerrits, Sonja Vermeulen en Johan Schrama, dank voor jullie vele inzichten over het voeren en produceren van vis en vee die de basis van mijn model hebben verstevigd. Karl-Heinz Erb, thank you for your valuable insights in socio-ecology and landcover. Friederike, thank you for all the valuable insights and debates regarding resource efficient fisheries and fish farming, it was a pleasure to collaborate so closely. Adinda, bedankt voor de doorlopende samenwerking om circulariteit in de praktijk te brengen.

My work was largely facilitated by the great atmosphere at the Animal Production Systems group and the support of my colleagues. Thank you all for the interesting, oftentimes slightly derailed, discussions during our breaks, the walks, dancing and other active breaks. You have added much fun and "gezelligheid" to my job and made me feel appreciated as a person and as a scientist. Fokje, Theo en Lia, bedankt voor alle technische steun. To my colleagues in our shared office, thank you for the great working environment that made me happy to go to work every day even, for looking out for me and for enduring the disturbance of my constant movement. 
A special thanks to Akke, Abigail and Anita for not only being colleagues but also amazing friends. Akke, bedankt dat je van begin tot eind voor me klaar stond met een luisterend oor en een knuffel. Abi, thank you for improving my understanding of the world while keeping it light with your amusing sarcasm; I had so much fun but might be scarred for life. Anita, thank you for your support, kindness, insights, you make me feel valued. I'm happy to have experienced this special Finish summer and have shared some very relaxing (h)olidays.

I was lucky to not only find a warm and supporting atmosphere at work but also with my friends and in the homes I found in Wageningen and Oslo. Linda, Ajla, Pien, Jacky, Matty, Mier en Selma, bedankt voor al zo veel jaren vriendschap en gekkigheid. Current and previous inhabitants of Witte Wilma, thank you for always welcoming me with open arms and a warm hart and for letting me empty my head in your garden. Kjære beboere av Granåsen, takk at dere har tatt meg opp i familien og for alle beroligende ferier. Annika en Monique, bedankt dat jullie samen met Pien ons idyllische huisje zo'n warm thuis maakte en het zijn van mijn ietwat ongewone gezin. Dit stabiele thuis heeft mij in vele uitdagingen gesterkt. Annika, bedankt voor de dagelijks heerlijke maaltijden en voor de toevoer van zelfbakken koekjes die even oneindig blijkt als jouw energie. Monique, bedankt voor je aanmoediging, openheid en oprechte knuffels. Jullie maken het leven elke dag een feestje, en ik zal het missen jullie altijd om mij heen te hebben. Na alles wat we gedeeld hebben, vooral in de door COVID-19 beïnvloedde laatste maanden van mijn $\mathrm{PhD}$ voel ik me zeker met jullie als paranimfen aan mijn zijde.

Ten slotte wil ik mijn familie bedanken. Mama, niemand snapt mijn hersenkronkels zoals jij, bedankt voor je liefde en begrip. Papa, mijn held, bedankt dat je altijd alles in perspectief weet te plaatsen om mij te doen inzien wat belangrijk is. Beer bedankt voor je onvoorwaardelijke liefde en vertrouwen, ik ben trots jouw zusje te zijn. Ook bedankt voor alle belangstelling van jou en Bart in mijn onderzoek, het was fijn dit met jullie te kunnen delen. Suze, niets is zo relativerend en aanstekelijk als jouw gelukzaligheid. Kjære Aleid, ikke mange har noen på sin side som forstår så godt hva de jobber med; jeg føler meg velsignet. Takk for alle dyptgående diskusjoner, din tillit i meg og dit støtte med denne oppgaven. Du får frem det beste i meg og utfordrer meg og gjør meg veldig lykkelig. Jeg gleder meg til vår felles fremtid, selv om vi skal ikke bare drømme, dyrke poteter og leve i fred. 


\section{About the author}

Ollie van Hal was born in IJsselstein in 1989. In 2013 she obtained a BSc in Animal Husbandry from Hogeschool HAS Den Bosch (cum laude), where her graduation project, commissioned by AgentschapNL, addressed the environmental implications of welfare enhancing measures in pig production. In 2015 she obtained her MSc in Animal Sciences at Wageningen University (cum laude, 2015). In her thesis at the Adaptation Physiology group she assessed environmental influences on eliminatory behaviour of piglets with the ultimate aim to direct this behaviour to improve housing and reduce environmental impacts. In her second thesis at the

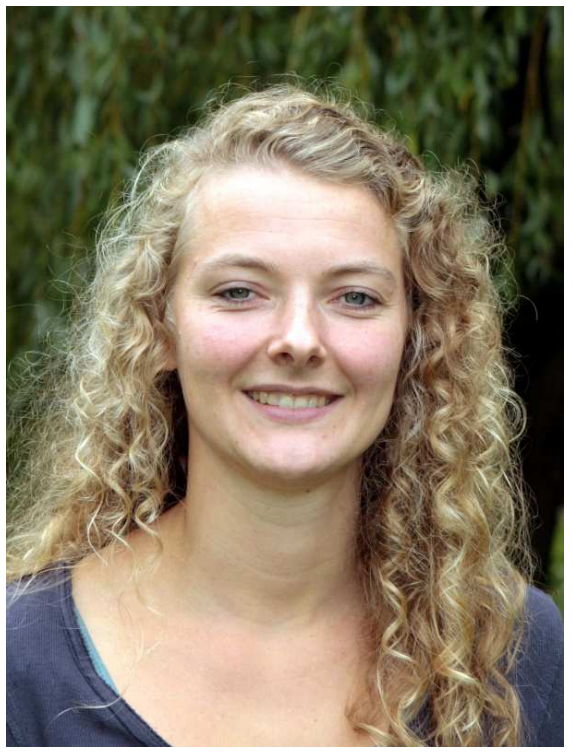
Animal Production Systems group, she explored the potential of livestock on leftovers in the Spanish province Aragon. From September 2015 onwards, Ollie continued in this research domain with her PhD at the Animal Production Systems group, that explored the role of animals in upcycling biomass, such as food leftovers and grass, in a circular food system. This $\mathrm{PhD}$ was part of the "sustainable food and nutrition security (SUSFANS)" project and funded with a Horizon 2020 grant. For this $\mathrm{PhD}$, Ollie developed an optimisation model to explore the role of different production animals (livestock and fish) in the efficient use of biomass unsuitable for human consumption. Findings of this thesis were presented at international conferences and published in peer-reviewed scientific journals. Since completing her $\mathrm{PhD}$ thesis in 2020, she has been working as Researcher Sustainable animal husbandry \& agrobiodiversity at the Louis Bolk Institute. As a nature enthusiast, Ollie spends most of her free time outside gardening and exploring the countryside. 


\section{Publications}

\section{Refereed scientific journals}

van Hal, O., de Boer, I. J. M., Muller, A., de Vries, S., Erb, K.-H., Schader, C., Gerrits, W.J.J. and van Zanten, H. H. E. (2019). Upcycling food leftovers and grass resources through livestock: Impact of livestock system and productivity. Journal of Cleaner Production, 219, 485-496. https://doi.org/10.1016/j.jclepro.2019.01.329

van Hal, O., de Boer, I. J. M., Ziegler, F., Schrama, J. W., Kuipers, K., \& van Zanten, H.H.E. (2020). The role of fisheries and farmed fish in a circular food system (submitted).

van Hal, O., de Boer, I. J. M. and van Zanten, H.H.E. (2020). Feeding food leftovers to farm animals: the potential of improved use and legalisation (submitted).

van Hal, O., Weijenberg, A. A. A., de Boer, I. J. M., \& van Zanten, H. H. E. (2019b). Accounting for feed-food competition in environmental impact assessment: Towards a resource efficient food$\begin{array}{lllll}\text { system. Journal of Cleaner Production, } & 240, & 118241 .\end{array}$ https://doi.org/10.1016/j.jclepro.2019.118241

van Zanten, H. H. E., Herrero, M., van Hal, O., Röös, E., Muller, A., Garnett, T., . . . de Boer, I. J. M. (2018). Defining a land boundary for sustainable livestock consumption. Global Change Biology, 24(9), 4185-4194. https://doi.org/10.1111/gcb.14321

\section{Refereed conference papers}

van Hal, O., de Boer, I.J.M. \& van Zanten, H.H.E. (2016). How much animal-source food can we produce while avoiding feed-food competition? Proceedings of the 1oth International Life Cycle Assessment of Foods Conference (LCA Food 2016, Dublin, Ireland) p. 1053 -1058

van Hal, O., van Zanten, H.H.E., Schader, C. Muller, A., Gerrits, W.J.J., de Vries, S. \& de Boer, I.J.M. \&. (2018). Valuing leftover streams through livestock; the impact of livestock system and productivity level. Proceedings of the 11th International Life Cycle Assessment of Foods Conference (LCA Food 2018, Bangkok, Thailand) p. 129

\section{Abstracts in conference proceedings}

van Hal, O., de Boer, I.J.M., Muller, A., de Vries, S., Erb, K.-H., Schader, C., Gerrits, W.J.J. and van Zanten, H.H.E. (2019). Upcycling food leftovers and grass resources through farm animals. Book of Abstracts of the 7oth Annual Meeting of the European Federation of Animal Science, Ghent, Belgium. Wageningen Academic Publishers, EAAP vol. 25, p. 316. 
van Hal, O., de Boer, I.J.M., Muller, A., de Vries, S., Erb, K.-H., Schader, C., Gerrits, W.J.J. and van Zanten, H.H.E. (2019). Efficiently upcycling food leftovers and grass resources through livestock. Selected Abstracts of Aligning the Food System for Improved Nutrition in Animal Source Foods. Davis, California, USA. https://nasfc.ucdavis.edu/abstracts

van Hal, O., de Boer, I.J. M., Ziegler, F., Schrama, J.W., Kuipers, K., \& van Zanten, H.H.E. (2020). The role of fisheries and aquaculture in a circular food system. Abstracts of the WIAS Annual Conference 2020: Frontiers in Animal Sciences p. 46. https://edepot.wur.nl/517927

van Hal, O., van Zanten, H.H.E., Schader, C., Muller, A., Gerrits, W.J.J. and de Boer, I.J.M. (2017). Valuing leftover streams through livestock: impact of livestock system and productivity level. Digital book of abstracts of the $3^{\text {rd }}$ International Conference on Global Food Security Conference - Cape Town, South Africa. https://edepot.wur.nl/431970

van Hal, O., van Zanten, H.H.E., Schader, C., Muller, A., Gerrits, W.J.J., de Vries, S. and de Boer, I.J.M. (2018). Valuing leftover streams through livestock: impact of livestock system and productivity level. Abstracts of the WIAS Science Day 2018: Impact in Science and Society. p. 35. https://edepot.wur.nl/445870

van Hal, O., Weijenberg, A. A. A., de Boer, I. J. M., \& van Zanten, H. H. E. (2019). Avoiding feedfood competition in practice; Environmental impact assessment of a novel egg production system. Abstracts of the WIAS Science day 2019, Keeping the balance p. 42-43

van Zanten, H.H.E., van Hal, O. \& de Boer, I.J.M. (2016). How much animal-source food can we produce while avoiding feed-food competition? Book of Abstracts of the 67st Annual Meeting of the European Federation of Animal Science, Belfast, Ireland. Wageningen Academic Publishers, EAAP vol. 22, p. 102.

\section{Scientific reports}

van Zanten, H. H. E., van Hal, O. \& de Boer, I. J. M. (2016). Report on T4.1: Deliverable No. 4.1: The drivers of livestock production in the EU. SUSFANS Deliverable No. D4.1, 66p. http://susfans.eu/system/files/public files/Publications/Reports/SUSFANS\%20D4.1 V1.pd f? ga $=1.220584016 .995999759 .1483713582$

van Zanten, H. H. E., van Hal, O., Ziegler, F., Hornborg, S., Latka, C., Parodi, A., Achterbosch, T. J., Bianchi, M., de Boer, I. J. M., Borthwick, L., Burgstaller, E., Heckelei, T., Leip, A. \& Valin, H. (2019). Report on T5.4: Sustainability impacts of potential innovations in the supply chain of livestock and fish, and fruit and vegetables, and sustainable future diets. SUSFANS Deliverable No. D5.4, 84p. https://edepot.wur.nl/476875 


\section{Education certificate}

Completed training and supervision plan ${ }^{1}$

Basic package

3 ECTS

WIAS introduction day

2015

Essential skills

2015

Philosophy of science and ethics

2016

Disciplinary competences

15.2 ECTS

Quantative analysis of land use systems

2016

Writing research proposal

2016

Rundveevoeding

2016

Environmental impact assessment of livestock systems

2017

Workshop food safety \& food waste (UC Davis)

2019

Professional competences

1.8 ECTS

Project and Time management (PTM)

2018

Brain friendly working and writing

2020

Presentation skills

4 ECTS $^{2}$

Poster, WIAS science day, Wageningen, The Netherlands

2016-2019

Theater, LCA Food, Dublin, Ireland

2016

Theater, SUSFANS stakeholder meeting, Vienna, Austria

2017

Poster, Global Food Security, Cape Town, South Africa

2017

Theater, LCA Food, Bangkok, Thailand

2018

Poster, Aligning the food system, Davis, California, USA

2019

Theater, WIAS annual conference, Lunteren, The Netherlands

2020

Teaching competences

Thesis supervisor, 3 BSc theses

Thesis supervisor, 4 MSc theses 2018-2019

Project supervisor, Introduction animal sciences

Lecturer, Future food systems

Practical supervisor, Global sustainable animal production

Practical supervisor, Sustainability assessment of animal systems

2016-2019

Education and training total

30 ECTS

1 With the listed activities, the $\mathrm{PhD}$ candidate complied with the educational requirements of Wageningen Institute of Animal Sciences (WIAS) a Wageningen University \& Research graduate school. One ECTS equals a study load of 28 hours.

2 Listed activities provided more ECTS than granted by WIAS regulations 


\section{Colophon}

The research described in this thesis was financially supported by the European Union's Horizon 2020 research and innovation project SUSFANS under grant agreement No 633692. The views expressed in this publication are the sole responsibility of the authors and do not necessarily reflect the views of the European Commission.

Cover:

- concept by Ollie van Hal

- design by Iliana Boshoven-Gkini, Agile Colour, graphic design and training

Illustrations:

- drawn components by Birgit Boogaard, Kuwona, advise, training and illustrations

- designed by Ollie van Hal

- compiled by Fokje Steenstra (pages 7 and 39)

Photo page 204 by Fokje Steenstra

Printed by GVO drukkers \& vormgevers B.V., Ede

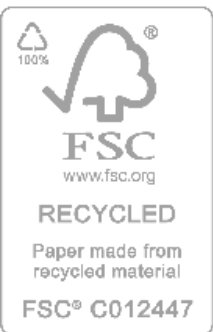

